3 Regards croisés Afrique-Europe Cahiers supplementaires

Abraham Tamukum Tangwe

\title{
Violence and Educational Quality
}

Effects of Violence on the Learning Outcomes of Students in Cameroon 
3 Regards croisés Afrique-Europe.

Cahiers supplementaires

Regards croisés Afrika-Europa. Beihefte

Regards croisés Africa-Europe. Supplements 
Regards croisés Afrique-Europe.

Cahiers supplementaires

Regards croisés Afrika-Europa. Beihefte Regards croisés Africa-Europe. Supplements

pour le comité éditorial de la revue für das Herausgebergremium der Zeitschrift for the board of editors of the journal éd. par / hrsg. v. / ed. by Klaus van Eickels

volume 3

Band 3

volume 3

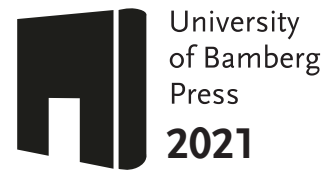




\section{Violence and Educational Quality}

Effects of Violence on the Learning Outcomes

of Students in Cameroon

Abraham Tamukum Tangwe 
Bibliographische Information der Deutschen Nationalbibliothek Die Deutsche Nationalbibliothek verzeichnet diese Publikation in der Deutschen Nationalbibliographie; detaillierte bibliographische Informationen sind im Internet über http://dnb.d-nb.de abrufbar.

Cet œuvre a été présenté comme thèse doctorale à la faculté des Sciences de l'homme et de l'éducation de l'Université de Bamberg (Allemagne):

rapporteur: Prof. Dr. Annette Scheunpflug rapporteur: Prof. Dr. Maximilian Pfost

Date de la soutenance: 14/07/2021

Diese Arbeit hat der Fakultät Geistes- und Kulturwissenschaften der Otto-Friedrich-Universität Bamberg als Dissertation vorgelegen.

Gutachterin: Prof. Dr. Annette Scheunpflug

Gutachter: Prof. Dr. Maximilian Pfost

Tag der mündlichen Prüfung: 14.07.2021

This study has been submitted as a doctoral thesis to the Faculty of Human Sciences and Education of the University of Bamberg (Germany): examiner: Prof. Dr. Annette Scheunpflug examiner: Prof. Dr. Maximilian Pfost

Date of viva: $14 / 07 / 2021$

Dieses Werk ist als freie Onlineversion über den Publikationsserver (FIS; https://fis.uni-bamberg.de) der Universität Bamberg erreichbar. Das Werk ausgenommen Cover, Zitate und Abbildungen - steht unter der CC-Lizenz CC-BY.

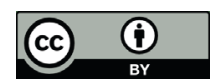

Herstellung und Druck: docupoint, Magdeburg Umschlaggestaltung: University of Bamberg Press Umschlagfoto: (C) Colourbox

(C) University of Bamberg Press, Bamberg 2021

http://www.uni-bamberg.de/ubp

ISSN: 2749-8743 (Print)

eISSN: 2749-8751 (Online)

ISBN: 978-3-86309-823-0 (Druckausgabe)

eISBN: 978-3-86309-824-7 (Online-Ausgabe)

URN: urn:nbn:de:bvb:473-irb-516050

DOI: https://doi.org/10.20378/irb-51605 


\section{Dedication}

This dissertation is dedicated to my late mother, Isabella Atundoh, who, all her life, elevated me to the rank of "Dr." by referring to me as 'Dr. Lincoln' before her passing into eternity. Such words put me on course, and unfortunately, she is not there anymore to bask in the joy of my becoming a 'Dr.' as she wanted! Keep resting in the bosom of the Lord. 



\section{Acknowledgment}

I pay glowing tribute to my supervisors Prof. Dr. Annette Scheunpflug and Prof. Dr. Maximillian Pfost. I owe an incalculable debt for their unquantifiable, selfless, unwavering, untiring, and steady support and encouragement in all spheres to mold my modest personality into the scientific realm. They availed themselves and accorded me all the necessary approval.

I express immense thanks and appreciation to the Church Development Service of the Protestant Churches in Germany (Brot für die Welt) for their generous funding of my bursary for four years. In addition, I remain most grateful to the team, particularly to Nadine Ebinghaus and Fanny Kamptz, for their empathetic support, concern, and follow-up, especially during COVID19.

The Presbyterian Church in Cameroon, through the Pedagogic InService Training Program (ISTP), was my anchor organization and provided the moral and legal backup on which I wrested to sail through with my study. This was awesome and remains emblematic.

I would want to extend my profound thanks and appreciation to the University of Bamberg for all the human, financial and infrastructural resources put at my disposal to ensure my studies. Mention must be made of the International Welcome Center of the University, particularly Alexandra Wolf and Dr. Sandra Niemeier, for championing the 'Welcome Center' into a hub of hospitality and prominence for international students. Special thanks go to the Chair of the Foundations of Education (Allgemeine Pädagogik) for laying the foundation of my scientific journey. I hail the moral and robust support from the members of the chair of the foundations of education, particularly to Dr. Susanne Timm, for perfecting the final details for submission, Evi Plötz, Dr. Mark Wenz, and Emmer Demorel. With them, I shared stress-relieving moments and conversations that strengthened me to be upbeat. I give special appreciation to the Bamberg Graduate School of Social Sciences (BAGSS) for the weekly scientific exchanges and to the IT center of the University of Bamberg, especially the technical inputs of Günther Fößel. All these, remains invaluable and outstanding: thank you. 
I owe Dr. Matthias Borgstede a deep thank that cannot be measured on scales for teaching my statistics skills and guiding me through the work. This made it easily accessible and allowing me to share office space with him during my entire stay at the University of Bamberg. Thanks to him, I was introduced to Dr. Franziska Meincke of the University of Oxford, whose indispensable and incisive comments on my methodology and additional inputs on my data collection tools remain invaluable. Above all, a big thank you to my friend and my second statistics proofreader, Kilian Schmidt.

I want to thank my colleagues of the Ph.D. Learning Community for their constructive feedback and moral support during all our brainstorming and interactions. I am most grateful and appreciative to Frederick Njobati for the unique and invaluable role he has played during this journey and for being my counselor throughout my study.

My heartfelt thanks and appreciation goes to Emmanuel Wepngong, Banboye Frederick, and Claude Ernest Njoya for the high level of collaboration accorded to me in the field of data collection.

I pay homage to my mates and friends, Prof. Ndille Roland, Dr. George Njung, Dr. Augustine Che Mofor, and Hans B. Schmidt and wife Angela for their constant encouragement. Family Fößel provided me with a very supportive environment, I am very thankful for.

A special big thank is dedicated to my family, especially my loving wife Rita Fekamia, for her unwavering, patient, and sustained push in all aspects to enable me to cross this intellectual winning lane. Indeed, your unfailing love and all your sacrifices got me here!

In all, I give all praises and glory to God as I have realized that a PhD is not only an educational journey but also a profound and unexplained spiritual journey. My spiritual life was rebranded through it all, for God kept me, and I remain forever thankful for His grace, mercy, favor, love, and blessings.

Bamberg, June 2021

Abraham T. Tangwe 


\section{Content}

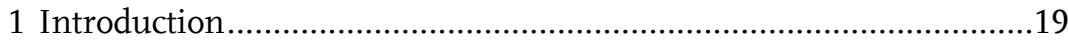

1.1 Context of the Study: Violence against Students in Schools .......20

1.2 Schooling in Cameroon ...........................................................22

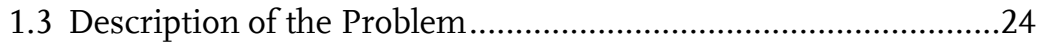

1.4 Research Questions and Objectives .......................................25

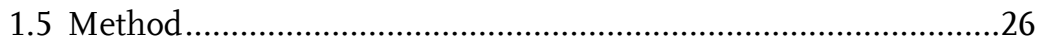

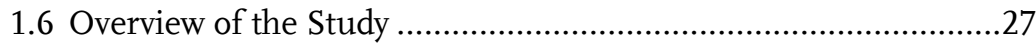

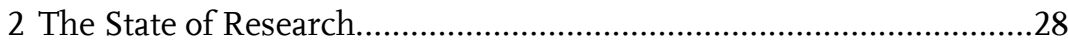

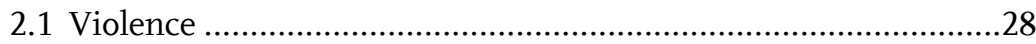

2.1.1 The concept of Violence ......................................................28

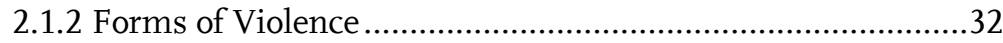

2.2 The Objectives of Schools: Developing the Person and Learning 43

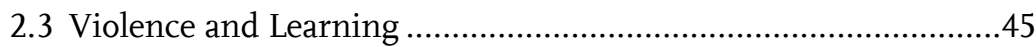

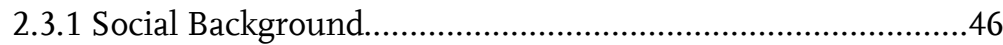

2.3.2 Direct Influence of Violence to Learning ...............................48

2.3.3 Indirect Relations Between Violence and Learning ...............50

2.4 The Conceptual Framework for this Study ................................52

3 Methodological Approach and Methods ...........................................54

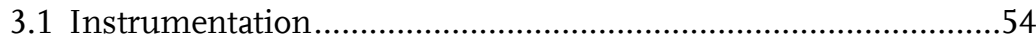

3.1.1 Conceptualization of the Questionnaires ..............................55

3.1.2 The Selected Scales ............................................................57

3.1.2.1 Experienced Forms of Violence (Independent Variables) ...57

3.1.2.2 Aspects of Learning (Mediating Variables)...........................64

3.1.2.3 Outcome/Output (Dependent Variables) .............................68 
3.1.2.4 Social Background (Control Variables) ................................69

3.1.3 Summary of Instrumentation ............................................... 71

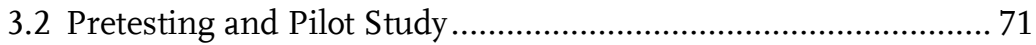

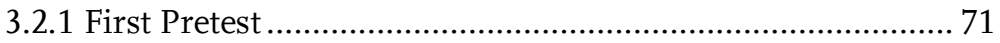

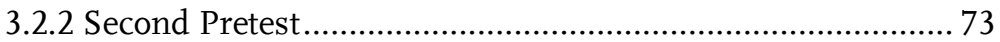

3.3 The Sample of the Main Study ................................................... 75

3.4 Data Collection for the Main Study ............................................ 79

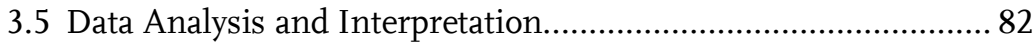

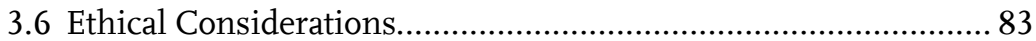

4 Description of the Findings and Analysis ........................................... 83

4.1 Descriptive Statistics: Social Background of Students, Experiences of Violence, Learning Mediators and Learning Output ...................... 84

4.1.1 Demographic Description of the Sample ............................. 84

4.1.2 Independent Variables: Experiences of Violence................... 91

4.1.3 Mediating Variables: Aspects of Learning ............................. 94

4.1.4 Dependent Variables: Learning Outcomes............................ 95

4.1.5 Summary: Descriptive Findings......................................... 100

4.2 Analysis: The Influence of Violence in Learning ....................... 101

4.2.1 Social Background and Learning Outcomes ...................... 102

4.2.2 Social Background and Experiences of Violence ................. 106

4.2.3 Social Background, Experiences of Violence and Mediators of

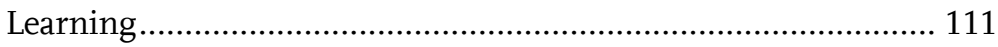

4.2.4 Social Background, Experiences of Violence, Mediators of

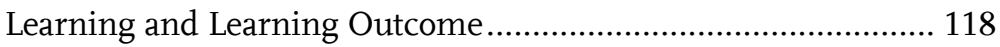

4.2.5 Summary of the Analysis of Data....................................... 128

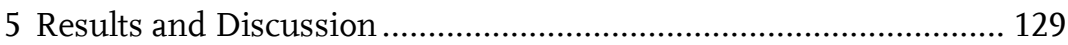




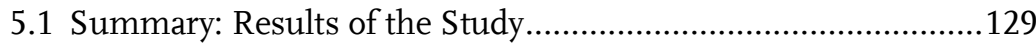

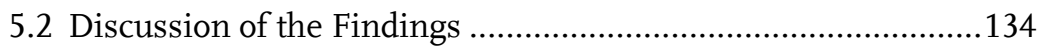

5.2.1 Schooling in the Light of Experiences of Violence ...............134

5.2.2 Repetition as a Challenge to the Educational Quality Discourse

5.2.3 Schooling in a Violent Environment: Towards a Systemic understanding .....

5.2.4 The Autonomy of Sexuality.

5.2.5 Violence as a Hindrance to the Fundamental Rights of Students

5.3 A Plea for a View on Latent Violence in Education 147

6 Implications of the Study

6.1 Implications for Further Research 149

6.1.1 Research on Parents' Involvement. 149

6.1.2 Research on Teacher Training about Violence and Violence Management. 150

6.1.3.The Perception of Churches and Pastors Concerning Violence 150

6.1.4 Research on Sexual Violence and Human Rights. 151

6.1.5 Class Repetition as a Challenge to Educational Discourse...152

6.1.6 The Development of a Contextual Scale of Violence..... 152

6.2 Limitations of the Study 152

6.3 Implication for Practice. 154

6.3.1 Development of Schools to Open Spaces without Violence.154

6.3.2 Education of Students in a Holistic Landscape 155

6.3.3 Human Capital Development through Teacher Training....155

6.3.4 Sensitization of the Society 156 


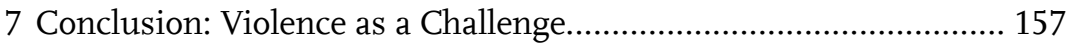

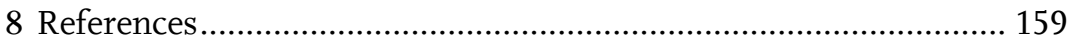

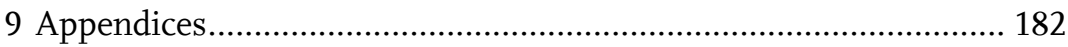

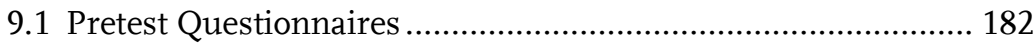

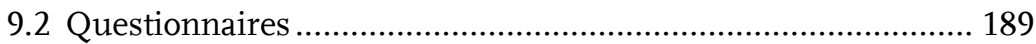

9.3 Questionnaire Data Set ........................................................... 210

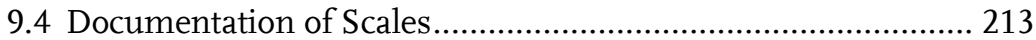




\section{List of Tables}

Table 1: Neglectful and Deliberate Acts of Psychological Violence .........34

Table 2: Direct and Structural Typology of Violence .................................38

Table 3: Characteristics of Schools in the Sample..................................77

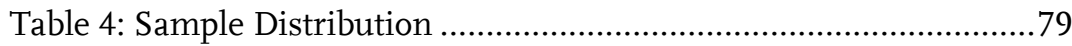

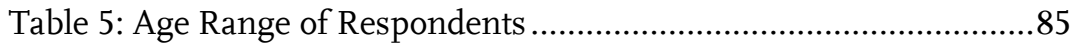

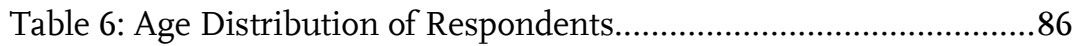

Table 7: Class Distribution of Respondents ...........................................86

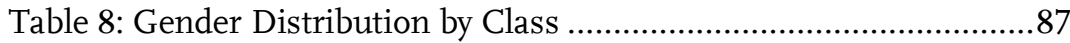

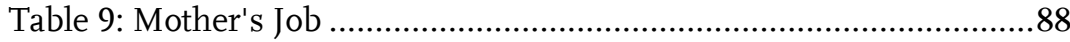

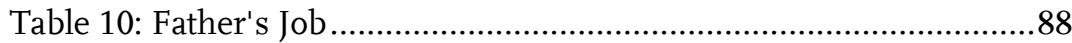

Table 11: Mother's Level of Education....................................................89

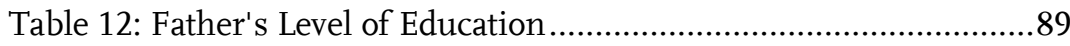

Table 13: Orphans and Refugees....................................................... 90

Table 14: Books at Home .......................................................................91

Table 15: Levels of Experienced Violence …............................................92

Table 16: Experienced Sexual Violence ………......................................93

Table 17: Summary of Experienced Violence ..........................................93

Table 18: Summary of Learning Mediators ...........................................95

Table 19: Grading Level of Subjects .....................................................96

Table 20: Grades in English and French Language.............................97

Table 21: Grades in Mathematics.........................................................97

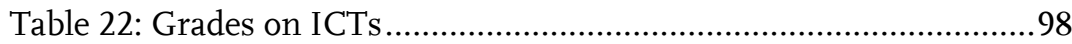

Table 23: Class Repetition ....................................................................99

Table 24: Extra Reading Enjoyment .................................................. 100 
Table 25: Effects of the Social Background on the Learning Outcome of

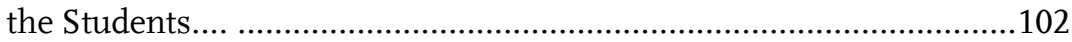

Table 26: Social Background on the Class Repitition ...........................103

Table 27: Social Background on Rading Enjoyment............................104

Table 28: Social Background Explaining English Grades .....................104

Table 29: Social Background Explaining French Grades .......................105

Table 30: Social Background Explaining Mathematics........................105

Table 31: Social Background Explaining Science Grades .....................106 Table 32: Effects of the Social Background on Different Types of Violence 107

Table 33: Social Background on Physical Violence at Home.................108

Table 34: Social Background on Physical Violence at school.................108

Table 35: Social Background on Psychlogical Violence ........................109

Table 36: Social Background on Hostile Environment in School.........109

Table 37: Social Background on Worries about Family Background....110 Table 38: Social Background on Perceived Social Learning Support....110 Table 39: Social Background on Sexual Violence .................................111 Table 40: Different Forms of Violence on the Students' Self-Esteem and Motivation

Table 41: Social Background and Violence predicting Academic SelfEsteem

Table 42: Social Background and Violence Predicting Body Self-Esteem .114

Table 43: Social Background and Violence predicting General Self-Esteem 
Table 44: Social Background and Violence Predicting Learning

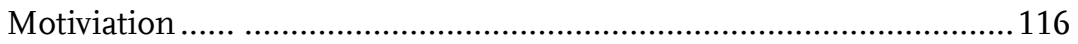

Table 45: Social Background and Violence Predicting School Motivation 117

Table 46: Social Background and Violence Predicting Health Impairment 118

Table 47: Effects of Violence, Self-Esteem and Motivation on School Grades (Estimates from full Models, Control Variables not displayed) 120 Table 48: Summary of Combined Predictors on Class Repetition ........ 121 Table 49: Summary of Combined Predictors on Extra Reading ........... 123 Table 50: Summary of Combined Predictors on English Grades......... 124

Table 51: Summary of Combined Predictors on French Grades.......... 124 Table 52: Summary of Combined Predictors on Grades in Mathematics 126

Table 53: Summary of Combined Predictors on Science Grades.... 127 


\section{List of Figures}

Figure 1: Magnitude of the Problem of Sexual Violence ....................... 42

Figure 2: WHO: Types of Violence....................................................... 43

Figure 3: Conceptual Model of this Study: Forms of Violence and their

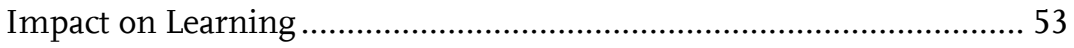

Figure 4: Framework with Instrumentation.......................................... 71 


\section{Abbreviations}

AIDS Acquired Immune Deficiency Syndrome

ANOVA Analysis of Variance

CRC Convention on the Rights of the Child

ECCE Early Childhood Care Education

EDA Exploratory Data Analysis

EFA Education for All

FGM Female Genital Mutilation

HIV Human Immunodeficiency Virus

ICAST-CH International Child Abuse Screening Tools Home Version

ICT Information and Communication Technology

ICTs Information and Communication Technology

MOS Medical Outcome Study

MRQ Main Research Question

NGO Non-Governmental Organization

OECD Organization for Economic Cooperation and Development

PISA Program for International Student Assessment

SACMEQ Southern African Consortium for Monitoring Educational Quality

SAQ Self-Administered Questionnaire

SDGs Sustainable Development Goals

SMMV Student Measurement Model of Violence 
SPSS Statistical Package of Social Science

SQ Sub-Question

UDHR Universal Declaration of Human Rights

UNDP United Nation Development Program

UNESCO United Nations Educational, Scientific and Cultural Organization

UNICEF United Nations International Children Emergency Fund

WHO World Health Organization 


\section{Introduction}

This study examines violence and educational quality in Cameroon colleges, emphasizing the effects of violence on students' learning outcomes in Cameroon. Many students in Cameroon face experiences of different forms of violence at home and at school. Even if violence towards children and young persons is banned in Cameroon, it is still an ongoing practice. This study aims at exploring the experiences of violence of young persons and research its consequences for the learning process.

The essence of quality education (UNESCO, 2005; UNESCO, 2000) underscores the child's rights to education through accessibility by eliminating gender disparity, instilling a favorable climate, self-esteem, tolerance, and responsible behavior. Education translates to "how much and how well children learn and the extent to which their education leads to personal, social, and developmental benefits" (Grima, 2008, p. 1). Quality education subscribes to peaceful social interaction (Bowling \& Hershcovis, 2017). This position is supported by (UNICEF, 2000, p. 4) by arguing that "educational quality helps the learners be healthy, well-nourished and ready to participate and learn, and supported in learning by their families and communities in environments that are also healthy, safe and protective." However, the wide spread of violence in education remains a universal challenge.

Throughout the study, I attempt to diagnose the spread of violence, the various forms, and how it manifests itself. Above all, it is important to understand the outcome of violence on school leavers' educational achievement. As such, the present introductory chapter lays the foundation of the study. It starts by examining the context of the study (chapter 1.1). It proceeds with a description of the situation of the educational system in Cameroon in regard to the ongoing civil war (chapter 1.2) and gives a description of the problem (1.3). Research questions and objectives of the study are identified (chapter 1.4), followed by a brief presentation of the methods (chapter 1.5), and a general overview of the research and structuration of the dissertation (chapter 1.6). 


\subsection{Context of the Study: Violence against Students in Schools}

The study is embedded in a policy context, in which violence against children and young persons is banned on an international as well a national level.

On an international level, the protection and enhancement of the child's rights (UDHR 1948; EFA 2005; Mumthass, Munavirr, Gafoor, 2014) is seen as a standard. Such an ideal strengthen the rights of the child to quality education by accessibility and eliminating gender disparity, instilling a positive school climate, self-esteem, responsible behavior, freethinking for life, tolerance, and democratic actions (EFA, 2005; Dakar Framework for Action UNESCO, 2000). Human rights give individuals the right to conduct their lives, even when their choices challenge societal or community norms in regard to political, sexual or religious orientations. Violent and peaceful social interaction need sensitive and detailed explication of the values and meanings that shape behavior in various social settings (Bowling \& Hershcovis, 2017).

On the national level, Cameroon authorities strive to improve education policies, ensuring the quality of service provision, more equitable distribution of learning opportunities, and more substantial incentives for greater schooling efficiency (OECD, 2010). The quest to achieve quality education fundamentally assures that children, youth, and adults gain the knowledge and skills they need to better their lives and play a role in building more peaceful and equitable societies (EFA, 2005). Over the years, Cameroon educational stakeholders have undertaken to protect all aspects of education with legislation and instill quality output utterly devoid of violence. Article 35 of the Law of Cameroon National Educational Guidelines No: 98/004 1998 explicitly shows this position in the following statement,

"The physical and moral integrity of the student is guaranteed in the educational system. It is evident in that corporal punishment, and all other forms of violence, discrimination of any kind, and the sale, distribution, and consumption of alcoholic beverages, tobacco, and drugs are prohibited."

In principle, Cameroon does not subscribe to any form of violence. Still, this view may be problematic because a recently updated country report 
of Cameroon (UNICEF, 2016, p. 4) presented statistics collected from an earlier UNICEF study in 2005-2006, which found that $87 \%$ of children between the age range of 2-14 experience physical aggression and other forms of violence. The violence includes shouted at, yelled at, screamed at, insulted, or the use of violent language. Violence is therefore still an issue in school and learning contexts. Children and youth studying in the Cameroon context are usually subjected to a high degree of physical and other forms of violence by their families, relatives, teachers, and communities that exert violence on them as a form of punishment (Ghorab \& AlKhaldi, 2014).

All international academic institutions and organizations entirely prohibit violence as an educational instrument. According to O'Neal, "the use of corporal punishment within African states' public educational system is unlawful, detrimental to the children's health, welfare, constitute an unnecessary impediment to educational excellence in the region. Public school corporal punishment violates several international and regional human rights treaties, customary international law" (2008, p. 60).

For professionals and parents, the practice and use of corporal punishment is seen as a normality (see i.e. for the Afro-American context Straus \& Paschall, 2009). In their perceptions, this ensures the discipline and proper behavior of children. They are surprised to learn that the consequences of child neglect are as severe as those associated with physical abuse, sexual abuse, and witnessing domestic violence (Hildyard \& Wolfe, 2002). Neglected children face risk factors impairing normal development, including chronic poverty, severe caregiving deficits, substance abuse, homelessness, family breakup, and inadequate prenatal and postnatal care (Hildyard \& Wolfe, 2002). Often violence becomes structural, ensuring that the teaching-learning process is related to the expectations of teachers, following a very strict code of conduct and giving no room for the self-expression and learning of the learners. Hence, many students lack social-emotional competencies and become less connected to the school as they progress from elementary to high school. This "lack of connection negatively affects their academic performance, behavior, and 
health" (Durlak et al., 2011, p. 405). Such a situation has dramatically affected Cameroon schools and depleted the outcome of students and their study environment. Different kinds of violence have aggravated the case in any school, whether public or private, in Cameroon, thereby making the global initiative to end all corporal punishment relevant in Cameroons' context. Due to the lack of any rights-oriented regime, which leads to civil society's development, a fundamental respect for human dignity that ensures the securement of fundamental rights, liberty and the rule of law (Dicklitch, 2002), violence in educational processes is widely accepted and tolerated.

Instead of serving as a violence reduction agent, Cameroon's education has been misused through action indoctrination rather than teaching. The perceived lack of closeness with parents deprives early adolescents of a vital source of affective support. The indoctrination has decreased self-esteem and later affiliation with delinquent friends (Tchombe, 2006). Through education, Cameroon has been rooted in colonial mentalities, negating the humanist and liberating praxis of education (Freire, 2005). The Cameroon context ascertains how violence is present. Therefore it is crucial to investigate, how this affects the learners' cognitive outputs, self-concepts, and achievements. Besides this implications to the learning process, the ban of violence is key to social justice, empowerment, and democratic participation (Agbenyenga, 2006). The concept of quality education will be only achieved without violence.

\subsection{Schooling in Cameroon}

Cameroon is a multilingual country with two different mode of administration, coming from a British and a French colonial heritage (Ndille, 2018; Karugu, 2020). Generally speaking, Cameroon operates two systems of education, which converge at the post-secondary level-professional schools, and university education (Tosam, 1988). The diverse educational traditions reflect different value systems and perspectives on academic development (Tosam, 1988).

Christian missionaries who came to Cameroon through the Littoral and South Western parts in 1844 introduced Christian Education in 
schools (Ndame, 2019) and managed the historical development of the education system in Southern Cameroon. The British orientation of education during the mandate period was founded in the British policy of Indirect Rule. The value system was embedded in community management that emphasizing literacy and numeracy skills (UNESCO 2005). Each school was empowered to manage their resources. With the Indirect Rule, indigenous Southern Cameroonians operated education with native authorities and by missionaries (Tosam, 1988; Ndille, 2019; Karugu, 2020), using the language of the people with a decentralized system.

The French system was following the concept of an assimilationist education. The French adopted a centralized orientation with assimilation policy where public and mission schools were centrally controlled by the French colonisers (Tosam, 1988; Ndame 2019). The reunification of British and French Cameroon through the controversial processes of institutional re-configuration from the Foumban Conference in July 1961 led to harmonizing a bi-cultural education system that did not function.

Harmonization became the effective term adopted to reunify the inherited colonial educational systems getting into the union. The specific purpose is to establish a synchronized approach to strengthen educational institutions' capacity to meet emergent needs (Ndille, 2019).

Certain aspects of the curricula or syllabi of the two systems at the primary and secondary levels should have the same contents. The assumption that underlies harmonization is that the contents taught in the two systems are universal. Scholars, observers, and stakeholders agree that harmonization has sparingly succeeded and accounts for the current socio-political, economic and cultural impasse that the country is currently undergoing. Despite the harmonization guidelines, the structures of education remain opposed to each other. Curricula have been designed over the years, but due to political bottlenecks, technical and financial setbacks, there have never been implemented (Tosam, 1988; Ngalim, 2014; Ndille, 2019). Ngalim (2014) observes that Cameroon's bicultural setting, and the weak political will, hinders educational reforms. Harmonization has simply been an untenable concept, impractical and restoring the maintenance of the pre-1961 status quo. 
Bilingualism has been used as the modus-operandi of the educational system based on the colonial hangovers regarding English for Southern Cameroons and French for French Cameroon. At the Foumban Conference of July 1961, the two languages were maintained as the federated states' languages (Tangwe \& Kiawi, 2014). However, as the nation is mainly operating in French, as all circulars and decisions are in French, even in administration, English remains inexistent in official circles, and this led to a feeling of being excluded in the English region. The President has never addressed Cameroon in the English Language for more than 38 years. This led to a civil war situation, in which the English-speaking region was taken into a struggle on identity and representation in the state of Cameroon, which led to an increase of violence throughout the regions and the country as a whole. Schools in the Anglophone region had been exposed to violence and became a war target as representing and not a welcomed identity in the country. By this, experiences of violence increased in the last years and did not at all reduce.

\subsection{Description of the Problem}

It is common in Cameroonian schools to see parents and teachers belittle, humiliate, denigrate, scapegoat, threaten, scare or ridicule the child and the young person. It is viewed as a palpable method of child upbringing (see for a similar debate in the USA Straus \& Paschall, 2009; Ellison \& Sherkat 1993). Education in Cameroon is not seen as a violent reduction agent but has instead been used as a toxic, unaccommodating concept that rather unteaches the learner in school (Tchombe, 2006). This usually manifests itself in screaming and bullying at the kids, insulting and abusing students living with broken homes' relics and sexual harassment by their teachers for marks (Arnstein, 2009). Schools that have witnessed violence, especially in Cameroon, have indicated that violence is a great contributor to distress, reduces self-esteem and risk of depression. It contributes to "psychological imbalance, reduces school attendance, impaired concentration, fear, and a diminished ability to learn" (Mncube \& Harber, 2013, p. 1). This has a severe influence on how the learners study and even 
complicates how the victims see this even as a problem. Such action influences the behavior, especially the learners' learning and social abilities even if the extent or degree of such influences is not readily measured or seen (see for similar debates in Rwanda Krogull, Scheunpflug \& Rwambonera, 2014).

For this study, various forms of violence that are interlocking are of relevance, like structurally oriented violence that would include sexism, class-based structures, and hierarchical power influence (Ho, 2007) or corporal punishment (Ember \& Ember, 2005; Tangwe, 2015). The manifestations of violence can be physical or verbal and at different levels of the society, especially at home, or in schools, with adverse outcomes that are psychosocial, economic, physical, and moral (Tchombe, 2006). Learners are subjected to different types of violence from teachers, classmates, and their environments, and this inhibits their conceptualization of concepts related to their learning. Students are mocked, teased, given funny names by teachers, and while in class, they are mimicked, threatened, verbally assaulted, and treated with scorn in some cases by classmates. This situation is worsened by gender-based violence that limits girls' education benefits and causes poor health and trauma. These actions affect the learners in Cameroon schools.

The plethora of literature on violence in Cameroon in particular and Sub-Saharan Africa, links to gender violence and negates the effect of violence on the learning outcome of students (Muluneh, 2020; Teke \& Johnson, 2019; Decker et al., 2016; McCloskey et al., 2016; UNICEF; 2007; Bamiwuye, \& Odimegwu, 2014). There is no research or scientific literature that assesses the impact of violence and how it perturbs children's learning in school. The absence explains the lack of awareness and absence of sensitization of its catastrophic demerits. This project attempts to fill this gap of the absence of scientific literature against violence and its effects on learning in Cameroon and Sub-Saharan Africa in general.

\subsection{Research Questions and Objectives}

Given the preceding context problem, the present research sets out to explore the extend of experiences of violence of students in Cameroonian 
schools and to understand how violence hinder students' learning outcome. To ease understanding of the phenomenon, the following question serves as the primary research question: Which experiences do student in Cameroonian schools have with violence and how does violence affect the learning of students in Cameroon?

This leads to the following sub-questions:

(i) What experiences of violence do students in colleges in Cameroon report?

(ii) In what ways does violence affect the learning of students in colleges in Cameroon?

(iii) What are the effects of violence on student learning outcomes in colleges in Cameroon?

The study aims to investigate and enhance the understanding of the concept of violence, the prevalent type's standard in schools in Cameroon. It seeks to identify the effects of violence on students' learning and learning outcomes in Cameroon's colleges. It investigates the problem of experiences of violence and use the findings to create awareness that can be used later for further investigations and the conceptualization of pedagogical prevention programs.

The study will support to visualize a latent problem that hinders education in Cameroon and undertake a comparative analysis of its effects on Sub-Saharan Africa and its impact on global learning values.

\subsection{Method}

This study has been conceived using a quantitative approach with questionnaires to students. It is, therefore, "a recording of observations, quantitative [...] made by defined and recorded operations and in defined conditions, followed by an examination of the data by appropriate statistical and mathematical rules for the existence of significant relations" (Cash et al., 2016, p. 5). Thus, the research questions are therefore answered in this 
study with a quantitative data collection approach, giving the students anonymity and allowing them to express themselves by their own will. The methodological approach and the used methods will be further examined in chapter 3.

\subsection{Overview of the Study}

The present study is organized into seven chapters.

The following chapter 2 pays close attention to the literature review by an examination of the concept of violence (chapter 2.1), and a reflection about the objectives of schools in regard to the development of the person and learning (chapter 2.2). The relation between violence and learning are discussed (chapter 2.3). The chapter ends with a theoretical framework (chapter 2.4) giving the conceptual design of the study.

Chapter 3 describes the methodology and methods used by this study. It begins with the instrumentations used to collect data (chapter 3.1), and the pretests of the study (chapter 3.2). The sampling process of the main study is outlined (chapter 3.3) as well as the data collection (chapter 3.4) and the data analysis and interpretation (3.5.). Ethical considerations are mentioned (chapter 3.6).

Chapter 4 presents the results. It starts by reporting the findings of descriptive statistics (chapter 4.1), followed by the analysis of the influence of experiences of violence in learning (chapter 4.2).

Chapter 5 gives a comprehensive summary of the study results (chapter 5.1) and proceeds with an interpretation of the findings (chapter 5.2). The chapter finishes with a plea for a view on latent violence in education (chapter 5.3)

Chapter 6 deals with the study's implications concerning further research (chapter 6.1), the limitations of the study (chapter 6.2) and implications for practice (chapter 6.3).

Chapter 7 concludes the entire study with a brief reflection on the impact of teachers.

Chapter 8 gives the references and in chapter 9 all the technical appendices (questionnaires, scales etc.) are summarized. 


\section{The State of Research}

This chapter deals with the literature that has handled different forms, manifestations and aspects of violence, educational outcomes, and educational quality. The chapter will therefore explain the various concepts and give an overview about the state of research. Chapter 2.1 delves on the various aspects of violence. In chapter 2.2, the concept of educational outcome is explained in relation to the objectives of schools. Chapter 2.3 explores the relations between the both. Chapter 2.4 presents the theoretical framework of the study. This chapter connects this study to the scientific discourse, shows the research gap in relation to research carried out in Africa and explains the relevance and reasons why this study's attempt remains imperative.

\subsection{Violence}

\subsubsection{The concept of Violence}

Bufacchi (2005) sees violence "where everyone endeavors to destroy or subdue one another, making life solitary, nasty and short" (p. 193). Violence means "the intentional use of physical force or power, threatened or actual, against oneself, another person, or against a group or community that either result in or has a high likelihood of resulting in injury, death, psychological harm, maldevelopment or deprivation" (Krug et al., 2014, p. 1084). This particular definition encompasses all types of violence and covers the wide range of acts of commission and omission that constitute violence and outcomes beyond deaths and injuries (Krug et al., 2014). Violence is "present when human beings are being influenced so that their actual somatic and mental realizations are below their potential realizations" (Scriver, 2005). McGuigan \& Pratt (2001) further elaborate this position by indicating that psychological child abuse encompasses mental injury, ridiculing, the threat of harm, emotional abuse, and emotional and mental neglect. These acts may not cause immediate physical harm but may cause long-term mental health problems that are just as damaging as physical abuse or neglect. Worthy of note is the cultural violence which Galtung (1990, p. 295) elaborated on. To him, "cultural violence preaches, 
teaches, admonishes, eggs on, and dulls us into exploitation and repression as normal and natural or into not seeing them mainly as the aspect of exploitation."

Again, violence can also be an avoidable impairment of fundamental human needs. Apparently, in the sub-Saharan African context, the respect for human rights, which shows an inclusive environment void of violence, is more often the exception than the rule. Becoming a victim or perpetrator of violent relationships such as those with family, friends, and the community context, may occur at any places, including schools, workplaces, and neighborhoods (Krug, James, Dahlberg \& Kwi, 2014). Violence is initiated by those who oppress, exploit, and fail to recognize others as persons - not by those oppressed, used, and unrecognized in the process (Freire, 2005).

In regard to overcome violence, education plays a double role. Schools should be safe places, empower students to overcome violence and to learn a life without violence. Secondly, schools should teach to overcome violence. This can be handled in a process wherein liberation is not a selfachievement attempt but a mutual process revolving around all the stakeholders of education (Freire, 2005). It is there that quality education plays a role by cultivating the learner's cognitive adaptability to new knowledge (Straus \& Paschall, 2009) and enhancing the essence of education for life. Consequently, this notwithstanding and cognizance of protecting and enhancing the child's rights (UDHR 1948; EFA 2005; Mumthass, Munavirr, Gafoor, 2014), leads to expectations in holistic child upbringing and to an enhancement of the quality of education. Such a concept helps to strengthen the rights of the child by, a sense of belonging through accessibility and eliminating gender disparity, positive school climate, self-esteem, responsible behavior, free-thinking for life, tolerance, and democratic actions (EFA, 2005; Dakar Framework for Action UNESCO, 2000).

Human rights give individuals the right to conduct their lives as they see fit, even when their choices challenge societal or community norms (International Covenant of Economic, Social and Cultural Rights, 1976). It has given a lucid, explicit explanation of the structural nuances related to violence which remains anathema to education in the Cameroonian 
society but hardly respected and upheld. This again presents complete disproportionate practicality of the concept of violence, especially in Cameroon's educational milieu from the home to the school, with seemingly significant consequences. Such violence has imparted the students' learning outcomes in Cameroon, especially in Cameroon's West region. They have not been allowed to study by no fault of theirs, primarily emanating from a bilingual and multicultural Cameroon's political differences. This completely negates the home and school violent inclined processes whose normative bearing on the students' learning ability in the West Region of Cameroon leaves a lot to be desire.

Furthermore, violence is aggression that has extreme harm as its goal (e.g., death). All violence is aggression, but many instances of aggression are not violence. For example, "one child pushing another off a tricycle is an act of aggression but is not an act of violence" (Anderson \& Bushman, 2002, p. 29). Hence, Alrawwad \& Atif (2014) argue that it is spreading in developed and developing countries. Students typically do not learn alone but rather in collaboration with their teachers, in the company of their peers, and with their families' encouragement. Emotions can facilitate or impede children's academic engagement, work ethic, commitment, and ultimate school success (Durlak et al., 2011). Because relationships and emotional processes affect how and what we learn, schools and families must effectively address these aspects of the educational process for all students' benefit (Durlak et al., 2011).

Violence has become a severe problem affecting students, families, and educational construction and affects the overall society (Alrawwad \& Atif, 2014). The relevant variables to ascertain the learners' learning and social abilities in improving social competencies are tightly link to better educational quality. This can be achieve by "raising knowledge, supporting resilience, and promoting self-regulation and self-efficacy" (Krogull, Scheunpflug \& Rwambonera, 2014, p. 43). Hence, this explains why social and affective processes connected to children's relationships inside and outside the school setting are essential factors in children's successful adaptation to school (Lynch \& Cicchetti, 1997) and how experiences of violence do influence the learning process. Cameroon's study environment 
is incidentally and visibly pro-violence and acting contrary to law No: 98/004 of 1998.

Teachers maximal inability to create instructions in a conducive school climate and produce students who are culturally literate, intellectually reflective, and committed to lifelong learning as high-quality education are therefore unable to teach young people to interact in socially skilled and respectful ways (Greenberg et al. 2003). They are thereby creating leverage at home and in school environments where child abuse and neglect (McGuigan \& Pratt, 2001) remains primordial. Through developmentally and culturally appropriate classroom instruction and application to everyday situations, programming it builds children's skills to recognize and manage their emotions. It helps them "appreciate others' perspectives, establish positive goals, make responsible decisions, and handle interpersonal situations effectively" (Greenberg et al. 2003, p. 469) in a school setting. The Cameroon dispensation invariably remains a truly problematic area that requires an exacting and concise examination of what could be more acceptable and responsible.

Bockler, Seeger \& Sitzer (2013) argue that violence can be viewed as a specific, problematic pattern of dealing with states of the individual or social disintegration of that individual. Such breakdown marks social institutions and communities' failure to deliver basic material needs, social recognition, and personal integrity for such an individual. It plunges the mind of such an individual to disorientation. Such disorientation of an individual mindset can be prevented if they can indulge in activities that could engender change (Romano, 2015), thereby enhancing their wellbeing and preventing the development of violence of any kind. In a context in which life itself, the life of human beings has become cheap, undervalued, what may appear to some to be inexcusable acts of violence represents to others a way of life-or death-in-life (Jolly, 2010). This in the Cameroon context remains a causal dynamic of the phenomenon. It does not include "a rights protective regime" (Dicklitch, 2002, p. 155) and hence may therefore not be adequately ready to assuage any violent inclination. The situation is further complicated by the desire for violence to be readily 
registered and understood and our simultaneous desire for acts of violence.

\subsubsection{Forms of Violence}

Violence, especially in school, manifests itself in different forms. These forms are described in the following subchapters.

Physical violence

Physical violence is refer to as violence that denotes "the hitting, striking, wounding, slapping or bruising a dependent child to punish, discipline, or showing disapproval (Ember \& Ember, 2005; Schlack et al. 2013). This is the form of violence which is mostly visible in schools, when teachers beat students or students are beaten by classmates. The American Humane fact sheet (2003) sees it as physical injury caused by punching, beating, kicking, biting, burning, or otherwise harming a child. Such physical abuse is the most visible form of child maltreatment. Many times, physical abuse results from inappropriate or excessive physical discipline. A parent or caretaker in anger may be unaware of the magnitude of force with which he or she strikes the child. Other factors that can contribute to child abuse include parents' immaturity, lack of parenting skills, poor childhood experiences, and social isolation, as well as situations of frequent crises, drug or alcohol problems, and domestic violence (The American Human Fact Sheet, 2003). This view is upheld by Khewu (2012) when she states that "such punishment is a kind of punishment that entails direct infliction of pain on the physical body" (p. 1). However, it can also take beyond the physical to emotional and psychological domains. As such, Laye \& Mykota (2014) further factor in and argue that "many children exposed to domestic violence are also very intrinsically linked to physical punishment" (p. 22). Physical violence exposure has been link with numerous adverse effects and its impact on the development of the victim. 


\section{Psychological violence}

There is no simple definition of the concept of psychological violence. Doherty (2008) sees it as "the systemic destruction of a person's self-esteem and sense of safety, often occurring in relationships where there are differences in power and control. It includes threats of harm or abandonment, humiliation, deprivation of contact, isolation and other psychologically abusive tactics and behaviors" (p. 1). Varieties of terms are used "interchangeably with psychological abuse, including emotional abuse, verbal abuse, mental cruelty, intimate terrorism, and psychological aggression. Also, when the abuse occurs in a residential care setting, it is often called systemic or institutional abuse" (Doherty, 2008). Moreover, psychological violence is regarded as an indirect form of violence to damage social relationships such as "physical and mental injury, withdrawal and isolation, depression, anxiety disorders, social impairments in the victims, but also with delinquency and personality disorders" (Schlack et al., 2013, p. 1).

According to the arguments of Doherty (2008, p. 2), such violence can be measured in "two categories: neglectful and deliberate acts." Neglectful tactics involve the withholding of regular human interaction or refusing to validate the victim's feelings and that may be hard to detect. This is because the person using them may have normalized the behaviors and may not regard them as abusive. In contrast, deliberate tactics, on the other hand, are more aggressive forms of control. Nevertheless, both forms involve the willful infliction of mental or emotional harm (Doherty, 2008). It is depicted in table 1 below.

In the case of Cameroon, the lack of a rights-respective society and a protective rights regime not only undermines the prospects for democratic consolidation but also heightens the potential for violence and chaos (Dicklitch, 2011). Given this, it has resulted in students' inability to attend school for several months in the Anglophone region of Cameroon from 2016 up until now and on the same time being exposed to a high level of violence in society. This situation contributed significantly to psychological violence, including lies, brainwashing, indoctrination of various kinds and threats. It has serve to "decrease mental potentialities" (Dicklitch, 


\section{1) and does not prioritize the impact of one form over the other} (Scriver). This has gradually institutionalized its functionality and inadvertently makes it structural, as expatiated in the subchapter below.

Table 1: Neglectful and Deliberate Acts of Psychological Violence

\begin{tabular}{l} 
Neglectful Tactics \\
\hline Denying Emotional Responsiveness \\
- failing to provide care sensitively and \\
responsively \\
- interacting in a detached and unin- \\
volved way \\
- interacting only when necessary \\
- ignoring the other person's attempts \\
to interact (for example, treating an \\
older adult who lives in a residence or \\
institution as though she/he is "a job \\
to be done")
\end{tabular}

Discounting

- not giving any credence to the person's point of view

- not validating the person's feelings

- claiming the behavior was meant as

a joke
Deliberate Tactics

Accusing, blaming, and jealous control

- telling a person repeatedly that he/she has caused the abuse

- blaming the person unfairly for everything that goes wrong

- accusing the person of having affairs or flirting with others

- making the person feel they cannot be trusted

- checking up on their activities

- demanding the personal account for every moment of the day

- using anger to control the other person

Criticizing behavior and ridiculing traits

-continuously finding fault with the other person or making the person feel nothing he/she does is ever right

- setting unrealistic standards

- belittling the person's thoughts, ideas, and achievements

- diminishing the identity, dignity, and

self-worth of the person

Degrading

- insulting, ridiculing, name-calling, imitating, or infantilizing

- yelling, swearing, publicly humiliating, or labeling the other person as stupid

\section{Harassing}

- repeatedly contacting, following, or watching the other person

- 'keeping tabs' on him/her through others

- sending unwanted gifts 


\begin{tabular}{|c|c|}
\hline Neglectful Tactics & Deliberate Tactics \\
\hline $\begin{array}{l}\text { Countering } \\
\text { - implying something is wrong with } \\
\text { the person who has hurt feelings or } \\
\text { complains about not liking his/her } \\
\text { treatment as a result of the abuse } \\
\text { - contradicting what the other person } \\
\text { says }\end{array}$ & $\begin{array}{l}\text { Corrupting/Exploiting } \\
\text { - socializing a person to accept ideas or } \\
\text { behaviors that are illegal } \\
\text { - using a person for advantage or } \\
\text { profit } \\
\text { - training him/her to serve the } \\
\text { abuser's interests } \\
\text { - enticing him/her into the sex trade } \\
\text { permitting a child to use alcohol or } \\
\text { drugs }\end{array}$ \\
\hline $\begin{array}{l}\text { Rejecting } \\
\text { - refusing to acknowledge a person's } \\
\text { presence, value, or worth } \\
\text { - communicating to a person that } \\
\text { he/she is useless or inferior } \\
\text { - devaluing his/her thoughts and feel- } \\
\text { ings } \\
\text { - repeatedly treating a child differently } \\
\text { from other siblings in a way that sug- } \\
\text { gests resentment, rejection, or dislike } \\
\text { for the child }\end{array}$ & $\begin{array}{l}\text { Isolating } \\
\text { - physically confining the person } \\
\text { - restricting regular contact with oth- } \\
\text { ers } \\
\text { - limiting freedom and excluding an } \\
\text { older adult from personal decisions } \\
\text { - locking a person in a closet or room } \\
\text { - refusing a person access to his/her } \\
\text { own or jointly owned money } \\
\text { - depriving a person of mobility aids or } \\
\text { transportation } \\
\text { using others as pawns in relationships }\end{array}$ \\
\hline
\end{tabular}

Source: Doherty, 2008, p. 5

\section{Structural violence}

Galtung (1969, p. 171) refers to structural violence as "social injustice wherein some social structure or social institution may harm people by preventing them from meeting their basic needs." Structural violence, according to Scriver (2015, p. 4), is "violence that is built into the structure of the society and reflects wide-spread inequalities that are not confine to the individual relationship between the perpetrator(s) and the victim(s)." Structural violence, unlike personal violence, also tends to show considerable stability over time. The norms and values that guide structural violence are difficult to change and slow to adapt as there are normatively taken as a way of life. Similarly, Galtung (1969) notes that with structural violence, it could be imagine that a relatively egalitarian structure that is insufficiently protected against sudden power display will result in a more stable, even petrified, hierarchical structure. Moreover, Krogull, Scheunpflug and Rwambonera (2014) posit that this might happen as well 
through creating taboos, prohibiting conversations and excluding certain ethnic or religious minorities.

Thus, this is what Dicklitch (2011) elucidates that Cameroon lacks a rights-respective society and a protective rights regime that undermines the prospects for democratic consolidation and heightens the potential for violence and violation of human rights. It has resulted in the current Anglophone crisis with students' inability to attend school for four years and counting in the Anglophone region of Cameroon from October 2016 till this moment, violating their rights of education.

In summation, Ho (2007) re-orientates the concept of structural violence to be contingent on merely a violation of the fundamental rights of humans that leads to inequality but paired with images of various natures such as poverty-stricken children and the absence of a rights regime in the diverse contexts (Dicklitch, 2011; Ho, 2007). Such conditions can lead to people's killing, psychologically harming them, maldevelopment, or depriving them through violent socio-economic and political structures (Salvage et al. 2012).

Cultural violence is seen as "the element of a culture that can legitimize violence in its direct, physical, or structural form" (Galtung, 1990, p. 291). This is "very rife in the family environment and other spheres of society" (ibd.). Therefore, structural violence is more visible with students as there are pair with images of different nature like starving children, diseased bodies, and desperate poverty (Ho, 2007). Parents and homes are among the highest risk factors for developing antisocial behavior due to its prevalence. Bullying in this regard is associated with violence within the family context (Baldry, 2003). Child neglect continues to be the most commonly reported form of child maltreatment affecting almost 30 children out of every 1000 approximately. It is self-evident that neglected children face many risk factors known to impair normal development. Such risk factors are "chronic poverty, severe caregiving deficits, parental state, substance abuse, homelessness, family breakup, and inadequate prenatal and postnatal care associated with neglect" (Hildyard \& Wolfe, 2002, p. 680). 
The Cameroon educational setting has been a problematic area for structural violence, which is notice from implicit actions such as the exchange of favors with marks and linguistic torture of students. Still, most importantly, Cameroon is far from a rights-protective regime, especially institutionally. There have been widespread social (educational) violations, economic, and cultural rights (Dicklitch, 2002). By way of an example, teachers' strike action in Anglophone Cameroon, which started in November 2016, is a clear indicator of the lapses inherent in the structural handling of education by the Cameroon authorities. This situation does not seem likely to improve shortly (Dicklitch, 2002).

Besides, it has been observed that the students' emotional neglect, especially those in Cameroonian schools, has been associated with worse consequences than when it was accompanied by just physical abuse. Their abuse and neglect have considerable psychological importance because they occur within ongoing relationships expected to be protective, supportive, and nurturing (Hildyard \& Wolfe, 2002). It combines the distinction between natural and structural violence, as seen in the typology of violence involving survival needs (negating death and mortality), well-being needs (negating misery and morbidity), identity needs (rejecting alienation) and freedom needs (negating repression). Direct violence is felt, unlike structural violence that is embedded and utilized as a norm (Galtung, 1990). Galtung undertakes a distinction and distinguishes between exploitation A, in which inequalities result in death (such as through starvation or disease), and exploitation $B$, whereby structural inequalities result in on-going human misery, for instance, malnutrition (Scriver et al., 2015, p. 4). The negation of needs approach is practical in recognizing how violence is perpetrated indirectly and against whole population sectors, notably applicable concerning the student's needs. It permits recognition that is both direct and structural, and its impacts are evident in the negation of all forms of conditions (Scriver et al., 2015). This is seen in table 2 below. 
Table 2: Direct and Structural Typology of Violence

\begin{tabular}{|c|c|c|c|c|}
\hline & $\begin{array}{l}\text { Survival } \\
\text { Needs }\end{array}$ & $\begin{array}{l}\text { Well-being } \\
\text { Needs }\end{array}$ & $\begin{array}{l}\text { Identity } \\
\text { Needs }\end{array}$ & $\begin{array}{l}\text { Freedom } \\
\text { Needs }\end{array}$ \\
\hline Direct Violence & Killing & $\begin{array}{l}\text { Maiming } \\
\text { Siege, Sanctions } \\
\text { Misery }\end{array}$ & $\begin{array}{l}\text { Desocialization } \\
\text { Resocialization } \\
\text { Secondary Citizen }\end{array}$ & $\begin{array}{l}\text { Repression } \\
\text { Detention } \\
\text { Expulsion }\end{array}$ \\
\hline Structural Violence & Exploitation A & Exploitation B & $\begin{array}{l}\text { Penetration } \\
\text { Segmentation }\end{array}$ & $\begin{array}{l}\text { Marginalization } \\
\text { Fragmentation }\end{array}$ \\
\hline
\end{tabular}

Source: Galtung, 1990, p. 292

Freire (2005) points out that structural violence in a society is a form of dehumanization and power. Structural power is a part of the Cameroonian society, especially in the English speaking sector. The Englishspeaking population has complained of systemic marginalization and destruction of the education, linguistic, legal, and cultural norms (Tangwe \& Kiawi, 2014). In September 2017, after fifty-six years of institutionalized discrimination in all facets of national life, the situation escalated, leading to sustained violence and instability. UNICEF (2013) attributes this phenomenon to the bijural (the two legal systems, the English Common Law system and the French Civil law). The bicultural situation emanated from their colonial past and the attendant effects. It indicates that all the children in Cameroon schools and specifically in Cameroon's English speaking region might have suffered from this though not in the same capacity, by discrimination, institutionalize assaults on their dignity, sex or other aspects. Structural inequalities systematically deny basic human needs and constitute a structural violation of human rights. The essence of structural violence is physical and psychological harm that results from exploitative and unjust social, political, and economic systems, is the most lethal and latent indicator of this instable political structures (Murkejee, 2007; Galtung, 1990). These scholars identify structural violence as family income, food, security, health care and education, and gender inequality.

In addition to these political factors, Cameroon's case is characterized by a high societal level of discrimination and violence against women and girls (Caprioli, 2005). Domestic culture's role in predicting intrastate conflicts is very important (Caprioli, 2005) due to structural origins. Most 
would also agree that insidious assaults on dignity, such as institutionalized hatred and sexism, also cause tremendous and unjust injury (Farmer, 2009), including several structural inequalities (Ho, 2007).

All over, the situation is characterized by the violence coming from parents' actions, the school, and from the state. Schools themselves contribute to violence by the way they do classroom management as this has a meaningful and positive effect on decreasing problematic behaviors in the classroom (Yildirim, Akan \& Yalcin, 2016). Critical pedagogy can strengthen democracy, create a more egalitarian and just society, and promote a process of progressive social change (Kellner, 1998). However, schools may as well contribute to an increase in violence. Hyde-Nolan \& Juliao (2012) approached the phenomenon with the dependency relations theory outlining that victims of abuse are dependent on their abusers. Hence, teachers and students take advantage of the weaker ones.

\section{Sexual Violence}

"Sexual violence entails several forms of non-consensual sexual acts, including unwanted comments, kissing, touching sexual parts of the body, forced masturbation, attempted rape and rape" (Berlo \& Ploem, 2018, p. 4). These actions of a sexual nature are deemed to be against a person's will and without their consent, commonly conceived as rape and seen as completed or attempted penetration of some kind (Lisak et al., 2010; Basile \& Smith, 2011). Sexual violence becomes complex when limited to sexual abuse that are sexual acts involving an "adult and a child, or any other situation in which there is a power imbalance and the victim is vulnerable, e.g., in the case of a teacher and a pupil" (Berlo \& Ploem, 2018, p. 4). It is commonly referred to as gender-based violence involving sexual acts, attempts to obtain a sexual act, unwanted sexual comments or advances, or otherwise directed against a person's sexuality using coercion by any person (Plesko, 2014).

The sexuality of all individuals is use to ascertain their sexual risk behavior and promote their sexual health (UNESCO, 2009) in the face of the HIV/AIDS pandemic and other diseases and health challenges. Sexuality 
education or sex and relationship education has been defined as "a curriculum used to teach youth about sex, sexual identity, the opposite sex, and sexual behavior" (Kwachou, 2015, p. 1).

In Cameroon's educational landscape, the incidence of sexual violence remains an arduous task because its treatment is ineffective and instead seen as a taboo (Nchia et al., 2015) and not handled as a violent form in a transparent manner. It is rather treated in an obscure dimension. This is noticeable in Cameroon primarily with regards to sensitization and information programs on AIDS that have been implemented along with efforts to promote the use of condoms and family planning programs (Rwenge, 2000; Kwachou, 2015). Cameroon has adopted strategies to eliminate violence against women, including ratification of international policies, penal codes, and support of local and international efforts that promote women. Still, these initiatives are under lock and rarely implemented by the stakeholders. The implementation of comprehensive sex education is not yet been taken seriously, even if with the Joint Ministerial Decision No. 281/07 of 18/01/2007 Family Life Education was introduced. Thus, it handle population issues, and HIV in the program of primary, secondary, and teachers' training schools in Cameroon using a trans-disciplinary approach (Nchia et al., 2015). Cameroon, like most countries in sub-Saharan Africa, does not have institutionalized sex education mechanisms and frameworks. Cameroon still faces problems in the successful implementation of sexuality education by the sparse training of teachers and unseriousness of lesson delivery (Heslop \& Banda, 2013). This has led to failure to adequately educate students for a responsible sexual life as well as to support students victimized by sexual violence (Magnussen \& Shankar, 2019).

In addition, the setting and situation in Cameroon schools are closely linked to dimension of sexual violence in schools that deals with power relations and refers to patriarchal structures in society as the male dominance through the overall subordination of women (Le Mat, 2016). Schools are refer to as safe sites. Ironically, tolerating sexual violence in these supposedly safe sites, which are in principle supportive of sexual and reproductive health promotion, can be unsettling in terms of gender identities (Le Mat, 2016). As Cameroon is a patriarchal society with male dominance and hyper-masculinity or dangerous masculinity, holding 
sway, compounded by repression in all community facets, especially the students remain preoccupying with their parents refusing to talk about sex and reproduction (Kwachou, 2015). The sexual repression is multifaceted from rape, exploitation, breast ironing, and female genital mutilation-FGM (Kwachou, 2015), and at school, the available structures and content completely negate sexual education and see it as a cultural taboo.

However data show that "women and girls have already had sexual intercourse, and $20 \%$ did so for the first time against their will, while $30 \%$ had the intercourse before the age of 15" (Abena, 2013, p.2). Moreover, $49 \%$ of young people attending middle-school education had had intercourse before age 16, and especially girls against their will while the boys are sexually abused but submerged in dangerous masculinity and suffer in silence (Rwenge, 2000).

This indicates an alarming scenario of sexual violence in Cameroon schools. Sexual abuse and victimization of the students take place at home and in school, and probably out of fear, embarrassment, and frustration, the students, are uncomfortable talking about their experiences and are not given a listening ear (Meincke, 2002). According to multiple studies (Kwachou, 2015; Nchia, 2015; Rwenge, 2000), the Cameroonian society is patriarchal, sexist, gender-biased with the students sexually victimized by teachers and school stakeholders, forced into early marriages with the victims accepting silence, pains and fear with the resultant effect seen in their dismal school outcomes.

Data on "sexual violence typically comes from the police, clinical settings, non-governmental organizations, and survey research" (Krug et al., 2002, p. 150). The relationship between these various sources and institutions regarding the global trend of sexual violence corresponds to an iceberg floating in water (Krug et al., 2002) (see fig. 1 below). 


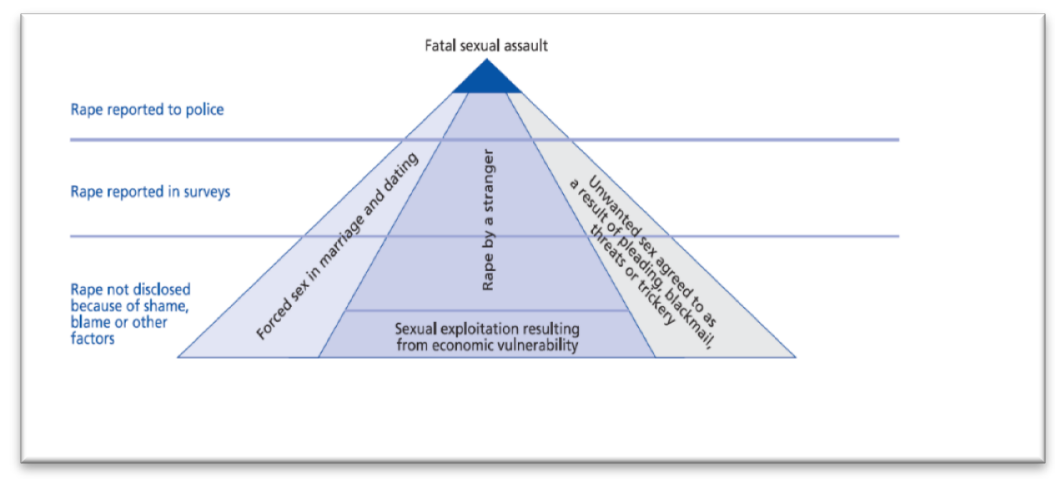

Figure 1: Magnitude of the Problem of Sexual Violence, Krug et al., 2002, p. 151

Given the figure above, the tiny visible tip on a global scale represents cases reported to the police. A more extensive section may have expatiated through survey research and the work of other institutions. But beneath the surface remains a substantial and the unquantified dimension of the problem for sexual violence, which remains a neglected problem that is handle by research (Krug et al. 2002). A vast majority of the discourse on sexual violence has been tailored through partner relationships, at the workplace, and more often than not, against women (Heslop \& Banda, 2013; OECD, 2019; Alberta Human Rights Commission, 2017; ILO, 2007). It is uncommon to see such discourse handling sexual harassment and victimization in sub-Saharan Africa in general and Cameroon in particular. Such studies are limited to gender sexual victimization and completely negate the influence of sexual victimization and violence on the students' learning outcomes emanating from their socioeconomic backgrounds. This study will modestly commence the discourse on this sensitive concept, even if the collected data may not show the whole problem.

\section{Summary}

The WHO's 2002 World Report on Violence and Health by Krug et al. (2002) summarizes the different forms of violence (see fig. 2). 


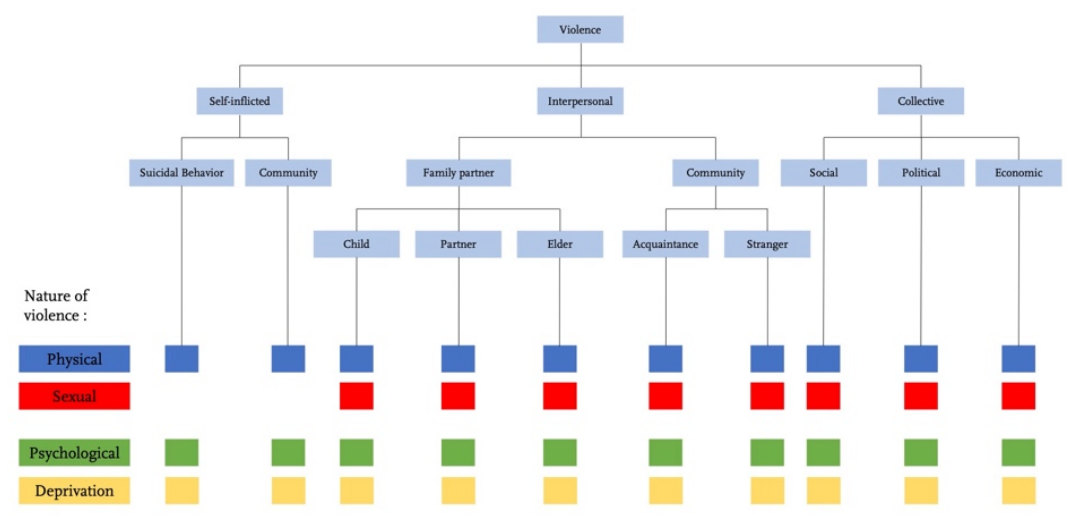

Figure 2: WHO: Types of Violence, Krug et al., 2002, p. 1084

According to the WHO model, violence is split into three categories: selfinflicted, interpersonal, and collective. Each class is subdivided to reflect specific violence, settings of violence, and nature of violent acts (physical, sexual, psychological, and deprivation/structural violence). For purposes of these studies, emphasis shall be on self-inflicted and interpersonal violence. For example, child abuse victims have an above-average chance of becoming involved in aggressive and violent behavior as adolescents and adults. Krug et al. (2002) presents violence as not limited to the use of force, though power emanating from political, economic, and social strand remains important. The pervasive nature of structural violence needs to be mentioned as those in power seek to maintain control through inequalities whose result is violence (Scriver et al., 2015).

\subsection{The Objectives of Schools: Developing the Person and Learning}

Education determines how much and how well children learn and the extent to which their education translates into a range of personal, social, and developmental benefits (Grima, 2008). UNESCO (2000) argues that educational is the peg on access to appropriate learning and life-skill programs by developing responsive, participatory, and accountable educational governance and management systems. Educational revolves around 
access to appropriate learning and life-skills programs by developing responsive, participatory, and accountable systems of educational governance and management (UNESCO, 2000). It is the assurance that children, youth, and adults gain the knowledge and skills they need to better their lives and play a role in building more peaceful and equitable societies (EFA, 2005). This means that the focus is on learning which strengthens the capacities of children to act progressively on their behalf through "the acquisition of relevant knowledge, practical skills, and appropriate attitudes; and which creates for children and helps them create for themselves and others places of safety, security and healthy interaction" (UNICEF, 2000, p. 4).

What is seen as "quality" in education, differs into two different paradigms, one focusing on the quality of the input into education (in investments, building, curricula, teacher education) and the other reflecting the output (in grades, qualified students) or outcome (in competencies) of schooling. The latter approach is sometimes seen more instrumental in focusing "learners' cognitive development as the major explicit objective of all education systems" (UNESCO 2005, p.17) or in a broader perspective, emphasizing "education's role in promoting values and attitudes of responsible citizenship and in nurturing creative and emotional development" (ibd.). Given this, others (EDQUAL WORKING PAPER 2006) go further to indicate the relevance of competencies in cultural and linguistic diversity in education, inclusive education, peace, and human rights education and education for sustainable development.

Fredriksson corroborated this when he avers that "quality education is an education that provides students with the tools to deal with and find solutions to the challenges confronting humanity." (2004, p. 4). Other authors summarize quality education at three levels "[...] first, classroom quality, which is concerned with the acquisition of measurable knowledge and learning skills as well as more challenging to measure behaviors and attitudes, including habits of industry [...], attitudes of respect for authority and love of country. At the second level, quality education must serve the community's economic goals in which learners live. At the third level, 
quality is judge by broader social criteria" (EDQUAL WORKING PAPER 2006, p. 3)

Fredriksson explains that "education must aim to give students the opportunities for personal development and confidence to adapt to new situations and change these when they find it necessary" (2004, p. 4.). UNICEF (2000) indicates that attaining educational quality is in addition to the healthy, well-nourished learners and ready to participate and learn, supported in learning by their families and communities in healthy, safe, protective, gender-sensitive environments and provide adequate resources and facilities. Above all, the outcomes encompass knowledge, skills, and attitudes and are the link to positive participation in society.

Educational quality in an international multicultural setting needs a dynamic, flexible approach that revolves around the notion of giving and taking. Fredriksson (2004) makes further allusion to this by stating that education in many parts of the world does not deal with what is sometimes referred to as life skills. For many children in sub-Saharan Africa, quality education would be an education that includes knowledge about HIV/AIDS and how to protect oneself.

Quality education is a universally accepted norm, however, in regards to the Cameroon situation, this is not achieved. Neither the absence of violence, nor the mentioned aspects of quality education are reached in Cameroonian schools. Schools in Cameroon only reach basic needs as they give room to some students to achieve basic competencies, but however fail to ensure education for all. Competencies and knowledge about basic life competencies and participation in the local and global society are not achieved.

\subsection{Violence and Learning}

How are violence and learning related? What are the mechanism by which violence is affecting learning? These questions will be discussed in the following subchapter.

The literature on family violence identifies adverse impact on children's physical, cognitive, emotional, and social development (Osofsky, 1999), which remains a hindrance to learning or motivation to be in 
school. However, it remains unclear to which extend this situation characterizes the situation in Cameroon. Previous research suggests the importance of school-based learning not only for skills acquisition but also for social development. First, the relation between the social background, violence and learning will be reflected, second the influence of violence on important motors of learning as self-esteem and motivation.

\subsubsection{Social Background}

Social development theory (Catalano, 2004) outlines that by violence the attachment and the interaction between the child and the parents are disconnected. Such interconnections lead to detachment and the capacity for motivated behavior in the child is hindered. Deviant behavior (Catalano, 2004) may occur, explained by the missing bonding in a school or family environment. Positive behavior is buttressed by four elements: "1) involvement in the unit, 2) attachment or affective relationships, 3) investment or commitment to the team, and 4) belief in the values of the unit" (Catalano, 2004, p. 252). Once firmly established, social bond exerts an informal control on behavior, inhibiting deviant behavior in particular. In understanding and handling this, therefore leads to the need for more relevance, more significant equity of access, outcome, and for the proper observance of individual rights (EFA, 2005; Hildyard \& Wolfe, 2002) that is supported and upheld. However, "most would also agree that insidious assaults on dignity, such as institutionalized discrimination, sexism, and cultural background also cause great and unjust injury" (Farmer, 2009, p. 11). Hence, this confirms the argumentation of (Dicklitch, 2011), which indicates its prevalence in the Cameroon setup because it lacks both a rights-respective society and a rights-protective regime and can make schooling exceedingly tricky and challenging.

Violence is unequally distributed within society and related to differential occurrences of stress and differences in socialization (Dietz, 2000). Violence within families results from two main factors. The first factor is structural stress. Thus, it is consider that people in certain positions within society (such as in the lower socio-economic strata-poverty level) suffer from more frustration and anxiety. The second factor is a cultural 
norm that encourages the use of force and violence as a typical response to this frustration and stress (Dietz, 2000).

Effects of violent exposure of all sorts can be carry over to the next generation. Violent actions are aped by the victims. Moreover, most parents indulged in physical violence because they had been subjected to it as wellindicating the spillover effect (Taylor, Hamvas \& Paris, 2012). So to them, this becomes justifiable and, as such, they are not able to develop good parent-child relations (Ellison \& Sherkat, 1993). In the Cameroon context, beating with the whip, insults, name-calling, bullying, sexual harassment, discrimination, institutionalized or structural violence has been widespread as a corrective norm.

Child neglect in families may be seen as a structural type of violence. It usually manifests itself in screaming and bullying at the kids, enhancing negative social feedbacks, insulting and abusing students living with the vestiges of broken homes, and sexual harassment of the students, amongst others (Arnstein, 2009).

Any violent acts are easily copied by the children and later replicated as a modus-operandi for their interaction. The negative effects of domestic and school violence on learning at school are reinforced by the co-learning of classmates. Spillovers caused by children from troubled homes are investigated by Carrell and Hoekstra (2009). First, they provide empirical evidence of the existence of the "bad apple, peer effects" model, which hypothesizes that a single disruptive student can negatively affect all other students' outcomes in the classroom. Second, their results suggest that policies that change a child's exposure to classmates from troubled families will have significant consequences for his educational outcomes and those of others. Finally, their results provide a compelling reason for policy-makers and society, in general, to be concerned about family problems such as domestic violence. Indeed, the results indicate that any policies or interventions that help improve the most troubled students' family environment may have positive benefits. In simple terms, motivation to be in school, risk of depression, fear, diminished ability to learn, and self-esteem is jeopardize by any student amid such difficulties looking for means and ways to evade school. 
Children of parents exposed to domestic violence conflict can experience health and education deficits themselves (Akresh, 2016), which may negatively impact their educational outcomes. Afolabi (2015) confirms a significant relationship between exposures to adverse life experiences and children's socio-cognitive functioning, especially in school. Some evidence suggests that the impact can be particularly pronounced if exposure occurs during adolescence (Akresh, 2016), a school-going age.

\subsubsection{Direct Influence of Violence to Learning}

Structural violence may directly hinder visiting in schools and by this not allowing formal learning

Over the years in Cameroon, structural violence has been seemingly rife and substantially felt. The child's safety, wellbeing, and development are, for various reasons, threatened due to political instability (Majanga, Mukonyi \& Vundi, 2015). It is very visible in Cameroon with the students reduced to unmitigated instances of victimization (Shields, Nadasen \& Pierce, 2009) and obliged to stay away from schools. It is recurrent especially in the Anglophone regions. The "psychological strand of violence explains this, which should be filter through the socialization mechanism and the normative structure of the society being examine" (Stanciu \& Rogers, 2011, p. 173). Teachers impart students' learning abilities (Gauthier $\&$ Dembele, 2004) and lead to results that enhance a socially constructed and responsive interplay when intentional use of physical force or power, threatened or actual, against oneself or another person lead to deprivation and shame. In addition, in the Cameroonian situation, especially related to schools and the policy orientation, the normative application of quality in education is difficult to attain as all norms against violence are implicitly ignored and explicitly a make-belief scenario. The child's safety, wellbeing, and development are, for various reasons, threaten and is prone to multiple forms of physical and psychological exploitation (Dicklitch, 2002; Majanga, Mukonyi \& Vundi, 2015).

The argumentations of (Anderson \& Bushman, 2002) approaching the issue of violence using the social interaction theory as an actor with social 
influence behavior or coercive action to produce some results in the subject's behavior, especially from high authority to get a position of subservience leaves the students more at risks. This explains why researchers (Glaser, 2002; Anderson \& Bushman, 2002) understand violence of children originating from the aggression of parents. Hyde-Nolan \& Juliao (2012) in the social learning theory underline that individuals learn social behavior by imitating and observing other individuals. The action of parents seems to blur their perceptions that the children as students in schools are victims of their actions. Family conflicts results from individuals obtaining and maintaining power and control on less powerful members (Hyde-Nolan \& Juliao, 2012). Such subjection of the children to the emotional abuse has psychological severe consequences (Campbell \& Lewandowski, 1997). It has a causal effect as well on their ability to learn. Therefore, Lynch \& Cicchetti, (1997) underline the link between motivation and violence, as students with experiences in violence do not see the world as a safe place to explore and therefore feel a lack of motivation. Those with an insecure attachment relationship view themselves, others, and the world tend to be more negative in self-esteem and motivation to learn for them.

Anderson \& Bushman (2002) argues that people acquire aggressive responses the same way they develop other complex forms of social behavior - either by direct experience or by observing others. This theory explains the acquisition of aggressive behaviors via observational learning processes and provides a proper set of concepts for understanding and describing the beliefs and expectations that guide social behavior.

According to the social learning theory, people acquire aggressive responses the same way they reach other complex forms of social behavioreither by direct experience or by observing others. Social learning theory explains the acquisition of aggressive behaviors via observational learning processes and provides a proper set of concepts for understanding and describing the beliefs and expectations that guide social behavior. Such knowledge of social ideas that guide perceptions related to frequent and harsh physical punishment has contributed to impairments in children's mental health, including depression, anxiety, alcohol and drug misuse, 
and general psychological maladjustment (Arnstein, 2009). The implicit undertone of such acts has led to (Anderson \& Bushman, 2002) to factor in their arguments that those in a position of authority use coercive actions to produce some change in the target's behavior. An actor can use coercive acts to obtain values like information, money, goods, sex, services, safety to exact retributive justice for perceived wrongs, or to bring about desired social and self-identities. This is where Cameroon and especially its different schools feature in such glaring and nefarious acts.

Social problems amongst students like poverty, unemployment, economic, political issues, in addition, to spread of drugs and alcohol are some elements that lead to violence, as well as other social problems like bullying, race and psychological defiance (Alrawwad \& Atif, 2014). It is more visible in the structuration of linguistic, religious, ideological, and formal sciences (Galtung, 1990) that make children uncomfortable with the school. Hence, the social interaction theory would provide an organized and logical perception of handling this study's problem. It is important to remark that from all available literature related to violence, the effect of any form of violence on the individual is not mutually exclusive but has a spiral or cyclical outcome. Because of this model, the child is completely detached and has no bearing on violence intricacies. The study's essence is to measure with the indicators the outcome of violence on the study of the children. It is a study guided by the quality dimension of education. Above all, the model indicates that though violence is individual and intrinsic, the effects after all education levels are seemingly resultant to multifaceted consequences. This research would therefore approach the problem from the micro to the macro levels. Noteworthy is the fact that social processes are going to guide it.

\subsubsection{Indirect Relations Between Violence and Learning}

Violence at school is delegitimizing school as a space for safety

After a high degree of physical and psychological violence from their teachers who practiced violence on them as a form of punishment (Ghorab \& Al-Khaldi, 2014), studying in schools is seriously compromised, thereby hampering the concept of quality education. Socially, 
school discipline caused by violence is often seen as a characteristic of high educational quality. However, this overlooks the fact that it does not achieve educational quality, but delegitimizes education through violence.

Education in Cameroon has not been able to serve as a violence reduction tool because it has instead been transformed and used through the process of action perpetuation rather than teaching (Tchombe, 2006). This has been seen through screaming and bullying at the kids, insulting and abusing, students living with the challenges of coming from broken homes, sexual harassment of the students (Arstein, 2009), thereby reducing access, inequity of education quality, and of learning outcomes making it to remain a formidable challenge for the Cameroonian educational stakeholders. Violence has been acting as a mitigating circumstance to the resolve of stakeholders in Cameroon, particularly the North West Region.

\section{Self-esteem and violence}

Violence hinders the development of self-esteem and by this learning is compromised. Self-system theories have helped to place in sharp focus the investigation of children's perception about their relationship as an essential step in their ability to succeed in school (Lynch \& Cicchetti, 1997). As such, children with a secure attachment see other people as trustworthy and see themselves as effective and worthy of love, and they view the world as a safe place to explore. In contrast, those with an insecure attachment relationship view themselves, others, and the world as more negative (Lynch \& Cicchetti, 1997). Children internalize these beliefs and expectations as they continue to interact with their environment, which shapes how children approach and handle such interactions with their various environments. Especially for those who live in societies where their group is poorly represented and ouvertly discriminated against (as this is the case with the Anglophone population in Cameroon), might reduce self-esteem (Smith \& Guerra, 2006). Furthermore, when youth are struggling with the consequences of low socioeconomic status, the impact of ethnicity on identity achievement is significant. 


\section{Motivation and violence}

In effect, object relations theory proposes that individuals' developmental representation of themselves and other individuals beginning in infancy and childhood, and these mental representations are carried over. They later influence interpersonal relationships throughout life (Hyde-Nolan \& Juliao, 2012). This lays credence to the arguments of Lynch \& Cicchetti (1997) and implicitly determines the individual perception in school. Neglected children face many risk factors known to impair normal development (Hildyard \& Wolfe, 2002). Thus, it manifest itself at the adolescent stage of life or school-going age and is linked to the 'borderline personality organization' and encompasses a range of psychological or emotional disorders' (Christopher, Bickhard \& Lambert, 2001). An individual diagnosed with a borderline personality disorder, for example, exhibits a characteristic pathological ego structure, including the presence of chronic anxiety, neurotic symptoms such as multiple phobias, perverse sexual behavior, and diminished impulse control (Christopher, Bickhard \& Lambert, 2001).

It has been stated that universal school-based efforts to promote students' social and emotional learning represent a promising approach to enhance children's success in school and life (Durlak et al., 2011). Thus, this represent a promising approach to improve children's success in school and life. Teachers find themselves in a preoccupying situation when trying to teach students engaging in violence, bullying each other, and other such harmful activities (Bissessar, 2014).

\subsection{The Conceptual Framework for this Study}

This study in the Cameroon context reflects how the mentioned various types of violence are present and how it affects the learners in their cognitive learning outputs, and achievements. The distinct difference between this study and all the mentioned literature on different forms of violence is that there is little research on peculiar forms of violence noticeable in Cameroon. This is specifically in regards to educational outcomes and the notion of educational quality in general. Above all, none of the studies handle the various strands of violence that are very visible in 
Cameroon, such as physical victimization and aggression at home and in school, psychological and structural violence in one bloc.

According to the state of research, a model has been developed reflecting the relation between violence and learning. It is inspired by the above mentioned reflections and theories. The independent variables are the different forms of violence, victimization and aggression at home and in school. They shall be mitigated by the mediating variables as self-esteem, motivation, and health impairment. The dependent variables are the learning at school (see fig. 3). The social background of the students as the economic situation of their parents' etc. needs to be controlled as this as well - as described above - has influence on the learning and on violence as well. The students' social background controlled these aspects, and the context emanating from school as well as from the family background of the students will also be brought into focus. The constructs on the left are the independent or predictor variables, while the dependent or outcome variables are found on the figure's right.

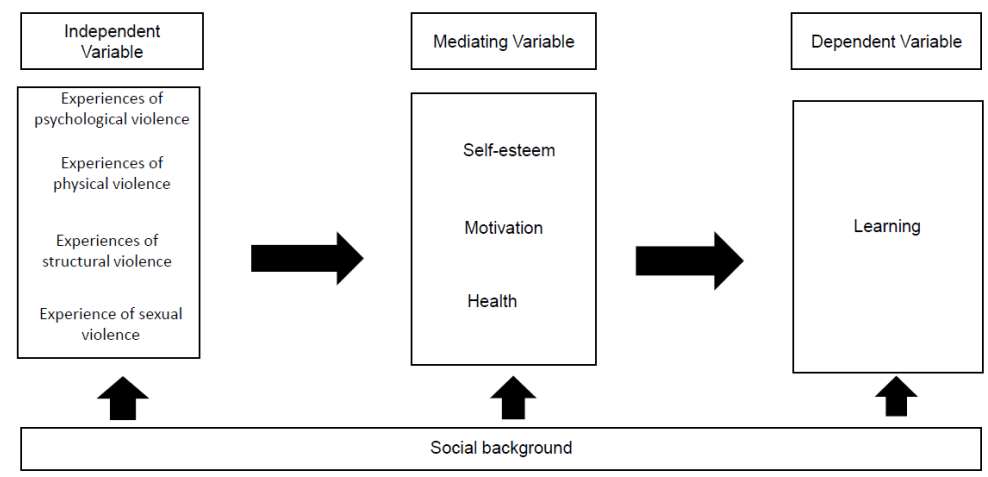

Figure 3: Conceptual Model of this Study: Forms of Violence and their Impact on Learning, Adapted from Krogull et al. 2014, p.110

This theoretical framework constitutes the blueprint for the collection, measurement, and analysis of data which will be described in the next chapter. 


\section{Methodological Approach and Methods}

In this chapter, I will explain the methodological approach that has been chosen for this study (as described in chapter 1 and 2) about the experienced violence in schools in Cameroun and its relation to the learning outcome.

The objectives of this study seek to identify the effects of violence on students learning outcomes in Cameroon. The study is based on the following research question: How does violence affect students' learning and understanding in Cameroon (chapter 1.3)?

The approach and methodology adopted for this study are located in the quantitative theory. This study's theoretical background, including the deducted model, was explained in chapter 2.4. The study is conceptualize based on questionnaires that were adopted to investigate the impact of violence on study outcomes of students in colleges in Cameroon by using self-reported questionnaires for students. (Savin-Baden \& Major, 2013, p. 360).

The following subchapters will examine the chosen methods in more detail. I will begin by identifying the instrumentation and measures of the study instruments (chapter 3.1), The pilot study and the process, including the changes effected, are then described (chapter 3.3), followed by the identification of the sample, sample size, and the sampling technique in (chapter 3.3). Furtherance to this, the data collection process description (chapter 3.4) and the data analysis follow (chapter 3.5). This chapter wounds off at the end with the ethical considerations (chapter 3.6).

\subsection{Instrumentation}

This subchapter undertakes a concise presentation of the questionnaires adopted for this study (chapter 3.1.1) and the scales used (chapter 3.1.2), differentiating into forms of violence as independent variables (chapter 3.1.2.1), the aspects of learning as mediating variables (chapter 3.1.2.2), the outcome as dependent variables (chapter 3.1.2.3) and the social background as control variables (3.1.2.4) 


\subsubsection{Conceptualization of the Questionnaires}

The essence and quest for this project's data are to ensure visibility of a hidden and not orally communicated concept, "experiences with violence." The data collection's objective was to fill a knowledge vacuum and, later on, related to the data, to develop evidence-based prevention programs concerning violence experiences in schools (see this concerning the objectives of data collections, Devries et al. 2016, p. 5). The young persons' perceptions and experiences made it essential to allow them to express themselves freely. Therefore, the study required a written questionnaire to respect the ambiguity and complexity of the students' feelings and assure them complete anonymity. Above all, students were informed that they are not constrained to answer all the questions (Devries et al., 2016) as they are free to withdraw from the process of data collection at any time.

\section{The Character of Questionnaires Related to the Concept of this Study}

Questionnaires were administered and tailored to suit the developed model (chapter 2.4). The questionnaire design was adapted from already existing scales (Hamburger et al. 2011, p. 84: Heatherton \& Polivy, 1991, p. 898: Midgley et al., 2000, pp. 10, 18 \& 30: PISA 2009, pp. 3-8: Furlong et al., 2005, p. 142: Stewart et al., 1988, p. 733: Zimet et al., 1988, p. 35) and composed concerning the explained model. These scales were already tested mainly in industrialized countries with high reliability of the scales as indicated later below (see appendix).

The questions were presented with the exact wording and in the same order to all respondents to ensure that respondents reply to the same set of questions. Most of the questions required students to rate the variables' degree (Satio, 2011; PISA, 2009). The questionnaire collection was carefully thought out by considering the nature, scope, and object of inquiry, availability of funds, time factor, and the precision of the study. 


\section{Language of the Questionnaire}

The language of instruction in all schools in Cameroon is a streamlined colonial cultural heritage pattern irrespective of the fact that Cameroon remains a multicultural society with more than 260 ethnic groups. Cameroon's official language is French or English related to the regions with diverse colonial heritage leading to two systems of education (see chapter 1.2).

The questionnaire's language was initially English because the studies were designed to take place in the English-speaking region of Cameroon. Because of the North West region's ensuing instability ${ }^{1}$, it had to be moved to the French part of Cameroon. Therefore, the questionnaire had to be translated to French in a process, ensuring the quality of the translation. First, a specialist French translator translated from English to French. Secondly, the text was re-translated by another specialist English translator, from French to English, to check the translation. The translated copy was placed side by side with the original text to check for originality and avoid ambiguity to control for quality and clarity. This was done with the two translators. To ensure the reliability of items or scales, care was taken to elucidate and make the concepts under observation to be contextualized $^{2}$ (Krogull, Scheunpflug \& Rwambonera, 2014; Zolotor et al., 2009).

1 Cameroon was made up of two territories at the time of independence with the French territory attaining its independence from the French in January 1960 and Southern Cameroons having its own independence through a United Nations organized plebiscite in February 1961 by joining "La Republique du Camerooun" with the English speaking Cameroonians constituting $20 \%$ of the people. The structural and institutional functioning of the state led to the marginalization of the English speaking Cameroonians. This led to a series of strikes by lawyers, teachers and the population and later metamorphosed into an armed conflict ongoing since October 2017 between the government and the separatist forces.

2 The contextualization process was facilitated by the data collection that started with the first pre-test, which was undertaken between January and February 2018 in Cameroon and the second pre-test, in the summer semester or July 2018 while the large assessment 


\subsubsection{The Selected Scales}

The scales were adapted from diverse sources but proven to be scientifically tested and validated. In the following subchapters, the various items of the questionnaire are described. The scales, their values, and the questionnaires are compiled in the annex of the study.

\subsubsection{Experienced Forms of Violence (Independent Variables)}

The independent variables covered the experienced forms of violence (see chapter 2.2.2)

\section{Experienced Physical Violence}

Experienced physical violence was operationalized by using scales about bullying, victimization, and aggressiveness at home and school.

Concept: Physical victimization or corporal violence is the intentional application of physical pain as a method of behavioral change (Adesope et al., 2017). It consists of the use of physical force intended to cause pain, but not injury, to correct or control a child's behavior and which do not result in significant bodily injury, e.g., hitting, slapping, spanking, punching, kicking, pinching and shaking (Straus \& Donnelly, 2005; Gershoff, 2002). Such abusive behavior by perpetrators is contingent on their resolve to gain power and control over others and originated from inequalities in society, such as the imbalance of power between those using violence against children and their victims (Aras, S. et al., 2016). Such physical violence is rife amongst parents, caregivers, teachers, peers, and other education stakeholders in Cameroon. However, data on predictors of staff's physical violence perpetration against students are scarce, particularly in low- and middle-income countries. Notably, only a small number

was carried out in the winter semester of 2018 between the months of October and December 2018 in Cameroon. The financial and logistical support of this project was given thanks to Bread for the World and the University of Bamberg. 
of studies have considered risk factors from the staff member's perspective as perpetrators of such acts (Merrill et al., 2017). In some contexts, especially in the global north, limited studies on the perpetration of violence against students are noticeable but sparingly visible in Africa (Merrill et al., 2017) and completely absent in Cameroon's context. It should be noteworthy that such physical and or corporal victimization are also injurious to the physical, mental, and personality development of the children as it affects their mentality, thereby resulting in harmful side effects, which becomes the risk for child development in schools and leads to their becoming a hazard to the society (Akhtar \& Awan, 2018).

Scale: Physical violence is instrumented with a Likert scale from Hamburger et al. (2011) with a twenty-two-item scale. It had the following example from the items "at home in the past three months, how often have you been slapped on your face or your head with the hand," with a fourlevel answering model from the Likert scale. This was never $=1$, often $=4$.

Consistency: The psychometric values of the scale were not provided, but from the test and retest of scale items in my study (see below the different pre-tests), it indicated a reliability output of Cronbach $(\alpha)$ of $=0.83$ for the physical violence at home and in school for similar items, the Cronbach $(\alpha)$ of $=0.80$ was registered.

\section{Experienced Psychological Violence}

Experienced psychological violence was operationalized by using scales about bullying, victimization, and aggressiveness at home and in school.

Concept: Kyriakides et al. (2006) regard bullying as a "situation in a school environment where a student is being bullied or victimized when he/she is exposed repeatedly and overtime to negative actions on the part of one or more other students" (p. 782). It is a harmful action when someone intentionally inflicts or attempts to inflict injury or discomfort upon another. Moreover, according to Kyriakides et al. (2006), the term 'negative actions' need not to refer only to physical contact but could also refer to verbal or other methods, such as making faces or obscene gestures, and intentional exclusion from the group. However, not every negative act 
could be considered bullying as this presupposes an imbalance in strength between the participants. More so, aggressiveness describes an overt behavior intended to harm another person (Abd-El-Fattah, 2007). He further alluded to the fact that "it is explicitly visible through verbal aggression, physical aggression, hostility and anger" (p. 237). According to Akmatov (2011), "child abuse undertaken by their parents or other guardians is a recognized public health and social problem both in developed and developing countries" (p. 220). In general, one distinguishes four forms of child abuse: emotional or psychological abuse, physical abuse, sexual abuse, and neglect (Akmatov, 2011). At any point in time, a combination of physical, mental, and social factors makes us feel a certain way, which is different for each of us (Akmatov, 2011).

Scale: Psychological violence at home and in school is instrumented with a scale from Hamburger et al. (2011) with a twenty-two-item scale. It had the following example from the items "at home in the past three months, how often have your parents said they wished you were dead or never born." The items had been answered with a four-level answering model from the Likert scale (never $=1$, often $=4$ ).

Consistency: The psychometric values of the scale were not provided, but from the test and retest of scale items in my study (see the different pretests described in chapter 3.2), it indicated a reliability output of Cronbach $(\alpha)=0.83$ for the physical violence at home and in school for similar items, the Cronbach $(\alpha)=0.80$ was reached.

Experienced Structural Violence

Experienced structural violence was operationalized by using scales about "perceived danger or hostile school environment", worries about the family and perceived support.

\section{Perceived Danger}

Concept: According to the pediatrician "T. Berry Brazelton and the child psychiatrist Stanley Greenspan, all children require physical protection, safety, and regulation to grow, learn, and flourish" (Gunzelmann, 2005, p. 66). Apparent safety issues are clear-cut and usually well addressed in 
schools. However, not only in Cameroonian schools, but less obvious hidden dangers also impact the social, cognitive, and emotional well-being of the students (Gunzelmann, 2005). The problem of school violence is multi-faceted and can be understood to include "violence perpetrators, victims of violence, feelings of fear and insecurity, criminal and antisocial behavior, and the disciplinary system established by the school" (Eisenbraun, 2007, p. 460). Several characteristics make schools more conducive to violent student behavior. School size, location, physical condition, ethic distribution, and policies all play a role in the amount, type, and severity of violence. A perceived general campus danger index will guide the students' perceptions of dangerous activities on campus.

Scale: Students will be asked to indicate how often each of the five kinds of behaviors occurs on their school campus (drug use, vandalism, alcohol consumption, fights, theft, bullying, and weapons possession) by utilizing a 5-point scale from Rosenblatt \& Furlong (1997, p. 193) with a five answer format (not at all $=1$ and very much $=5$ ).

Consistency: The original scale's psychometric properties indicated a Cronbach alpha $=.80$ and for the two factors, separately shown (alphas 0.76 and 0.76 ). In the pretest, it stated a Cronbach alpha $=.85$

\section{Communication and Worries about Family Members}

Concept: Communication in the teaching-learning process is a form of interpersonal influence aimed at changing another person's behavior potential. According to Rawat (2016), it is the teacher's knowledge and mastery over the communication skills for the transfer of the knowledge. There is, therefore, the interplay of parents' and teachers' communication with students learning, especially the kind of support received from parents. This is the link to the students' socio-economic background, pedagogical characteristics related to parents' interest in school achievements of their children, and parents' help with the child's wellbeing (Radojlovic et al., 2015). Therefore, the learner achievement aspirations are vital to the improvement of psychological well-being, primarily because aspirations are related to self-esteem, which is the overall evaluation of an individuals' worth (Fadiji \& Reddy, 2020). Hence, student achievement improves when parents become involved in their children's education at school 
(Nyagosia, 2011). The type of parental involvement that impacts student performance requires their direct participation and mutual liaising with teachers in school activities, especially material support to the children (Radojlovic et al., 2015; Fadiji \& Reddy, 2020; Nyagosia, 2011). Any defect in this regard hampers students learning. Parents' frequent coming to school reinforces the view in the child's mind that school and home are connected, and that school is an integral part of the whole family's life (Nyagosia, 2011). An important determinant in such interactions is the level of communication and each parent's socio-economic background, which plays a significant role in the students' psychological state. Communication, in this case, is the process of sharing ideas, thoughts, and feelings between the students, parents, and the teachers. The degree of communication is not unidimensional but divergently assessed by the receivers.

Scale: This was checked with a 5 items scale from Midley et al. (2000, pp. $10,18,30$ ) with the following example, "I feel upset because my parents and teachers have different ideas about what I should learn in school." It is scored with a five format scoring (not at all true $=1$, very true $=5$ ).

Consistency: The major scale had presented a psychometric value of Cronbach $(\alpha) .76$, and after the test and retest of the pretest items, the psychometric property slightly dropped to a Cronbach $(\alpha)$ of .63.

\section{Social Support}

Concept: The social support describes the interaction of favorable effects in which an orientation towards cooperation is involved. It shows, "an individualizing and supporting teacher-student-interaction, especially solicitousness, student-centered attitude, and an (individual) reference norm orientation appearing in connection with a cooperative and emotionally positive student-student-interaction. Above all, a strong enhancement especially of the school self-efficacy can be detected" (Krogull, Scheunpflug \& Rwambonera, 2014, p. 23).

Though this is visible in the school framework, the relationship between psychosocial climate and community sense extends beyond the expected personal networks and support. It also includes the demands for 
performance commonly perceived in the environment. "Students not only relate their sense of community to perceptions of their interactions with each other, but also to what they felt was expected of them as a group" (Pretty, 1990, p. 64) and as a network in the whole setup of the society. In like manner, social desirability tends to respond in a way that makes the respondent look good rather than accurately and truthfully. Individuals who present themselves in a socially desirable manner may attempt to appear overly moral, honorable, and virtuous by exaggerating desirable traits and denying undesirable characteristics. As such, social desirability can be considered in two ways, "self-deceptive enhancement and impression management” (Ragozzino, 2009, p. 1). Self-deceptive enhancement is a non-purposeful or intuitive way of viewing one's self exceedingly optimistically. It is possible to mention that high social desirability and confirmation desire slow down current motivation. That is, it is favorable that the relevant motivation is intensive in social desirability and confirmation desire. Social desirability is a psychological concept defined as a one-dimensional structure in originals, but there is not a tremendous theoretical definition (Üzümcü, 2016). Social desirability is regarded as tendencies for exaggeration of some behaviors (such as helping someone in difficulty) required and accepted in cultural values, for concealment of nonrequired actions (such as behaving like a patient to escape from fulfilling a duty. Social desirability is that the respondents falsify their responses when showing behaviors in favor of themselves (Üzümcü, 2016).

On the other hand, impression management is the purposeful tailoring of answers to be viewed more positively. Following self-deceptive enhancement also suggests that some individuals automatically dismiss their convictions and respond in a way that seems most socially desirable (Ragozzino, 2009, p. 1). This is visible with the scale of social support. (see chapter 94).

Scale: This would be examined with 13 items scale from Zimet et al. (1988, p. 35) with this example, "I can count on my friends when things go wrong" It would be examined with a seven answer format $(1=$ strongly disagree, 7 = strongly agree) 
Consistency: The original scale had a Cronbach validity and reliability coefficient $(\alpha)$ of $=.88$, and following the test and retest of the scale in the pretest, the Cronbach reliability attained a validity response of $(\alpha)=.84$.

\section{Experienced Sexual Violence}

Experienced sexual violence was operationalized by using scales about sexual violence.

Concept: Krug et al. (2002) identify sexual violence as

“... any sexual act, attempt to obtain a sexual act, unwanted sexual comments or advances, or acts to traffic, or otherwise directed, against a person's sexuality using coercion, by any person regardless of their relationship to the victim, in any setting, including but not limited to home (school) and work. Coercion can cover a whole spectrum of degrees of force. Apart from physical force, it involves psychological intimidation, blackmail, or other threats. For instance, it includes the threat of physical harm, suffering dismissal from a job, school, or not obtaining a job that is your passion. It may also occur when the person aggressed is unable to give consent - for instance, while drunk, drugged, asleep or mentally incapable of understanding the situation." (Krug et al. 2002, p. 149).

Meyer (2008) viewed sexual violence from the gender perspective and posited that gender harassment is any behavior, verbal, physical, or psychological, that polices the boundaries of traditional heterosexual gender norms. Common examples of such actions include name-calling, jokes, gestures, and physical and sexual assaults that are sexist, homophobic, or transphobic. She further argues that in "the strict legal understanding, sexual harassment includes two forms: quid pro quo and hostile environment sexual harassment" (Meyer, 2008, p. 556). Moreover, sexual violence based on the sexual abuse lens includes direct physical contact, such as unwanted touching or any kind of rape, known as "defilement" for young people under the legal age of consent. (USAID, 2016, p. 10) and this links up to the happenings in school that despises such practices. Given this, while boys faced a greater risk of physical violence than girls, girls faced a greater risk of sexual violence, neglect, and forced prostitution. Up to $21 \%$ of women in some countries reported having been sexually abused before 15. Nearly half of all sexual assaults worldwide are against girls 15 years 
or younger, and of the 700,000 individuals, each year forced into human trafficking, 80\% are women and girls (UNICEF, 2014, p. 8).

Scale: This was examined with a seven-item measure adapted from "The international child abuse screening tools-children versions" (ICAST- $\mathrm{CH}$ ) by Meincke et al., (2018). The items that were selected from ICAST-CH were like "Any teacher making you have sex in exchange for marks," "Anyone touching your private parts or made you touch theirs." This was measured with a four-answer format (never= 1 , many times $=4$ ).

Consistency: The psychometric properties of the scale showed a Cronbach Alpha of $=.72$, and after the test and retest of the items, it led to a Cronbach $(\alpha)$ of .77.

\subsubsection{Aspects of Learning (Mediating Variables)}

As mediating variables, various aspects of learning had been used (see chapter 2.4))

Self-Esteem

Concept: Gardner \& Pierce (1998, p. 49) refer to self-esteem as the degree to which people perceive themselves as capable, significant, and worthy. Other self-esteem scholars generally agree that self-esteem may form around in various dimensions of the self-related to various activities (e.g., physical self, social self). The aggregate of these evaluations is termed global self-esteem, the overall assessment of personal worth that people make and maintain concerning themselves. They proceed with argumentation that extends this by suggesting that the beliefs that people form about themselves, from their roles within an organization or school context, have substantial implications for their actions related to motivation, attitudes, and behaviors (Gardner \& Pierce, 1998). In other words, constructs like self-esteem refer to general feelings of self-worth or self-value and, therefore, motivate or shape a person's belief in themselves. 
Conversely, school self-concepts and self-efficacy relate to the fact that learners can only achieve what they believe they can achieve. It is the acceptance and belief in students' capability to achieve a goal or an outcome (Constantine et al., 2019). Bandura (1994), in his theoretical conception, sees self-efficacy as "the beliefs that determine how people feel, think, motivate themselves and behave" (p. 2). Strong self-efficacy is associated with confidence and a willingness to take risks in learning and has been positively linked with substantial student achievement (Constantine et al., 2019). Moreover, it enhances human accomplishment and personal wellbeing in many ways (Bandura, 1994). These are the critical determinants of intrinsic motivation. They both describe the experience of one's competencies. Students experience themselves as self-dependent and competent, and this emotionally positive experience enhances their motivation (Krogull, Scheunpflug \& Rwambonera, 2014). The experience of "school self-esteem and self-efficacy can be promoted in the school and the class when students work self-dependently on exercises. With the help of their obtained performance results and corresponding feedback from their teachers experience themselves as the cause for their success" (ibid. p. 21).

Scale: Self-esteem in the study is instrumented with a 20 items scale from Heatherton and Polivy (1991, p. 898) with this example "I feel confident about my abilities" and "I am worried about whether I am regarded as a success or a failure." It was tested with a five format scoring from the Likert scale (not at all $=1$, extremely $=5$ ).

Consistency: This scale's psychometric property indicated a coefficient alpha for the whole scale $=.92$, which refers to corrected item-total correlations. Some items were reversed, and the pretest Cronbach $(\alpha)$ stood at 0.77 .

\section{Motivation}

Concept: Motivation is "an integral part of the [...] attempt to interpret human and infrahuman behavior, a fundamental part of our efforts to achieve valid psychology of learning, of perception, of thinking and social behavior of all forms, whether normal or abnormal" (Bunch, 1958, p. 189). 
These motivating variables are variously conceived as intervening variables with "associated stimuli, as central nervous states, as sensitizing factors and as symbolic processes" (Bunch, 1958). This can be view intrinsically and extrinsically. Students are intrinsically motivated to engage in an activity because the activity in itself evokes interest or pleasure or because they identify with reasons for performing that activity. Extrinsic motivation comes from external pushes, reinforcement, or internal pressures that cause feelings of obligation or guilt. "Extrinsic motivation comes in various forms that vary in their degree of relative autonomy" (Hornstra et al., 2018, p. 2). Extrinsic motivation is entirely external when students feel controlled by others or by contextual pressures to engage in an activity they would not otherwise want to engage in (i.e., external regulation). Alternatively, students can also pressure themselves to engage in a move out of guilt, shame, or concerns about what others might think of them (introjected regulation). As such, self-determination theory (Deci et al., 1991), when applied to the realm of education, is concerned primarily with promoting in students an interest in learning, a valuing of education, and confidence in their capacities and attributes. These outcomes are manifestations of being intrinsically motivated and internalizing values and regulatory processes. Research suggests that these processes result in high-quality learning and conceptual understanding and enhanced personal growth and adjustment. It is this interest and volition, we offer, that lead students to display greater flexibility in problem-solving, more efficient knowledge acquisition, and a strong sense of personal worth and social responsibility (Deci et al., 1990). It is when there is an understanding of the logic of each actor's perspective that a workable solution to the problem would be identified (Muller, 2001). Student evaluations of advising interactions comprise the main form of assessment in academic advising. However, some scholars assert that satisfaction measures reflect student bias created by unrealistic or uninformed expectations of the advisor; others point out that student satisfaction measures fail to provide long-term data on the effects of academic advising on student outcomes, including persistence (Vianden, 2016). 
Scale: This would be examined with a five-item scale from Midgley et al. (2000, pp. 10, 18, 30) with the following example (extrinsic) "It is important for me that I learn many new ideas this year" and (intrinsic), "one of my goals in class is to learn as much as I can." This is assess with a fivelevel scoring format (not at all true $=1$, very true $=5$ )

Consistency: The original scale's psychometric property indicated a Cronbach alpha of $=.85$ and a test-retest correlation of $=.79$ by the authors of the scale. After the pretest of the same scale, the scale's reliability and validity were $(\alpha)=.639$. It is unclear why the situation was like this after the pretest.

\section{Health}

Concept: Former American President J.F. Kennedy said this about physical health "intelligence and skill can only function at the peak of their capacity when the body is healthy and strong." This has been corroborated by the Colorado Education Initiative (2014), which states inter-alia that "social and emotional learning programming with health has been found to improve students' achievement test scores" (p. 10). Educationally relevant health disparities, such as vision, mental health needs, aggression and violence, physical activity, breakfast, and inattention/hyperactivity, impede motivation and ability to learn through some causal pathways: such as sensory perceptions, cognition, connectedness, and engagement with school (Colorado Education Initiative, 2014). Physical health also appears to promote other important aspects in terms of learning, such as classroom behavior, concentration on assignments, and participation in classwork - and, subsequently, learning itself. "Physically active pupils also have higher goals for further studies after comprehensive school. Moreover, physically fit pupils are absent from school less frequently than their less-fit peers" (Vitikka, Salminen \& Annevirta, 2012, p. 6). However, the impact of all violence on the physical health of learners should not be underestimated.

Scale: This is examined with eight items scale from Stewart et al. (1988, p. 733) with this example, "Does your health prevent you from doing work 
in the house or going to school?" It would be answered with a three-level answer format (yes, for more than three months $=1$, yes, for three months or less $=2, \mathrm{No}=3$ ).

Consistency: The internal consistency reliability of the health perception measure from the original scale was $(\alpha)=0.88$, and after the pretest of the scale, the Cronbach $(\alpha)$ was $=.84$.

\subsubsection{Outcome/Output (Dependent Variables)}

Concept: The essence of quality learning is consonant with the paradigm that the children and youths acquire skills by transferring knowledge that serves to better their lives and invent them to undertake responsibilities in building more peaceful and equitable societies (EFA, 2005). Learning outcomes are derived from the evaluation, which commonly involves making comparisons with a standard, or against criteria derived from stated objectives or with other programs, curricula, or organizational situations (UNESCO, 2000). It may require the measurement of educational outcomes, and it may involve the testing of both individuals and groups. Most judgments of an evaluative kind made in education would seem to be holistic and based on a global examination of a situation (UNESCO, 2000; EFA, 2005). Schools often marginalize these so-called 21st-century learning outcomes due to their low status and their invisibility in summative assessments. In the instance, there is underdeveloped curricula and teachers' low skills in these areas (UNICEF; 2018). As such, all educational initiatives and policies must first focus on the intended educational outcomes rather than on the various technologies introduced to schooling and learning and the detriment of learning outcomes (UNICEF, 2018). The research tools were not sufficiently adept at assessing the learning outcomes of the learners. Grades are used to test the knowledge acquired in a given concept and not life skills. Therefore, in cases where it is impossible to measure competence as the outcome, output variables are used as grades. These are not seen as good measurement tools for competencies but are easily adapted to get some research directions and indicators. 
Moreover, quality education indicates a strong correlation between achievement in reading and mathematics at the national level (GPE, 2019). This relationship starts in early grades and becomes more potent by the end of primary education, with achievement in mathematics being correlated with reading achievement. Data shows that learners with low achievement in reading are more likely to perform poorly in mathematics (GPE, 2019). The achievement is measured in grades of schooling as it was not possible to assess the competencies, as the questionnaire would have become too long.

Scale: The assessment was undertaken with selected subject grades, and the students were allowed to indicate their scores in the following subjects, French Language, English language, Mathematics, and ICT or science grades. The grading was limited to a five-level grading format (fail = 1 , average $=2$, fair $=3$, good $=4$, very good $=5$ )

\subsubsection{Social Background (Control Variables)}

The control variable is a variable that is not the focus or planned part of the study, but its existence affects the dependent variable and the independent variable (Rahman, 2015; Schjoedt \& Sangboon, 2015). The control variables are "the variables held constant in the study to avoid influencing the results or making them biased, thereby confounding" (Schjoedt \& Sangboon, 2015, p. 239) the output of the independent and dependent variables. Hence, it is vital to control their effect to avoid its influence on the outcome. These are important because though not at the center of the study, they facilitate the generalizability to the population by identifying the confounding variables present but are beyond the unit of analysis of interest. Moreover, it minimizes uncertainty in the results of the study. When participants are samples for a between-group unit of analysis comparison, individual attributes in each participant often differ, and the control variables are used to handle this irregularity (Schjoedt \& Sangboon, 2015). 
Concept: The questions utilized involved the students' background herein mentioned and included the age, gender, socio-economic status of parents, a question for repetition, orphans or refugees, location of the school, and school type, whether it was boarding or a day school. The student's socioeconomic background in Cameroon's context has not been consciously correlated with the students' academic attainment by sheer neglect or not well informed on the effect it has on learning outcomes. This notwithstanding, Marjoribanks (2005) observes that family social status, ethnic background, and adolescents' educational aspirations combine to have significant associations with young adults' educational attainment and the fact that such accomplishment is moderated, in part, by young adults' family social status. Models that investigate factors that affect academic achievement usually take structural, student attitudes, and behavioral variables (Aypay, 2002). Favorable attitudes regarding educational attainment lead to more significant effort and achievement, while unfavorable attitudes lead to lowered anticipations and less effort among students' low self-esteem (Aypay, 2002). The strategic thrust and importance of the socioeconomic background of the students made it imperative to serve as the control variable to all the other variables of this study.

Scale: The items selected for the student social background were adapted from the PISA ISCED 2009 student questionnaire with items that asked them to indicate their sex, "male/female," age, "day - month - year," class, and the type of school they were attending. They were asked to distinguish their schools from public, non-public (mission or denominational), and general and technical schools. In addition to this, they indicated their parents' occupation (mothers' job/fathers' job) by writing the occupation type and the parents' educational level by marking an (x) on the corresponding levels per parent (FSLC / OL / AL/ BA / MA / MSC / Ph.D.). Books at home had been asked as additional information on the academic background. Moreover, the students were asked if they were refugees or orphans and asked to answer with a "yes or no" Above all, they were asked to mark an (x) on the location of their schools (urban / semi-urban / rural) and "how many times have you repeated a class." The answer format was, (once $=1$, twice $=2$, many times $=3$ ) 


\subsubsection{Summary of Instrumentation}

The outlined framework is now outlined including its instrumentation (see fig. 4).

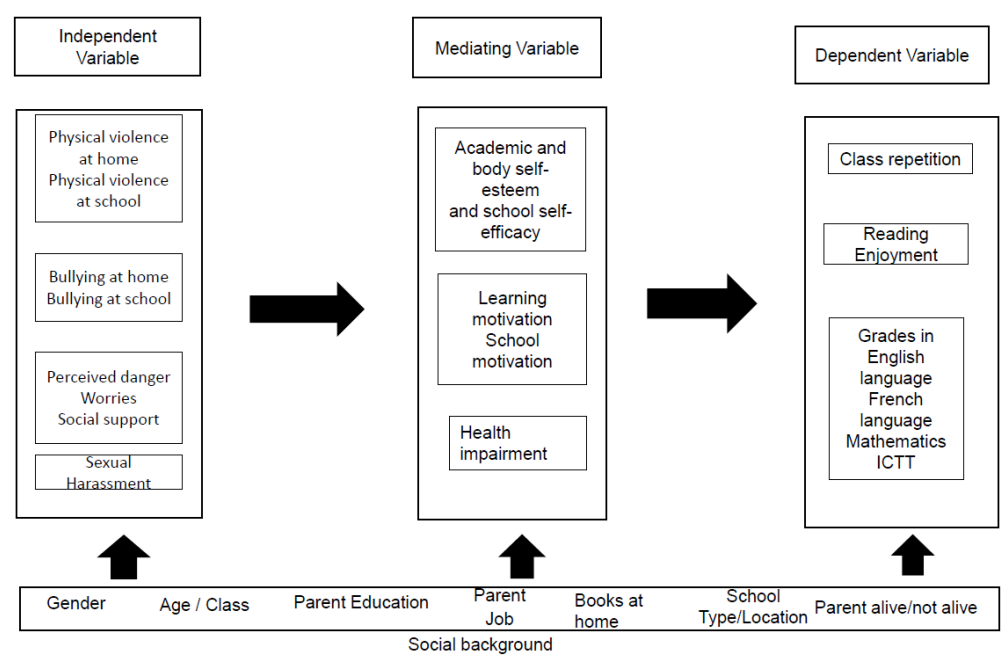

Figure 4: Framework with Instrumentation, Adapted from Krogull, Scheunpflug \& Rwanbora, 2014, p. 110

\subsection{Pretesting and Pilot Study}

Two pre-tests were carried out to check the reliability of the questionnaires.

\subsubsection{First Pretest}

The first pilot study was conducted in the winter term of 2017/2018 with a sample of $(n=100)$ respondents in Cameroon's North West Region. The sample population of this pilot study was obtained from two urban center schools. They were informed of the process by the administrative authorities and their teachers and were encouraged to participate. They were further encouraged to feel free to take part or conversely, to be in the library, reading rooms, or to be involved in extra-curricular activities during the exercise. The schools were all boarding schools, and the data collection 
process took place during the weekend during extra-curricular activities to encourage those participating in taking part without duress. They were students from grades five and seven from the final years of the first and second cycles of secondary school to facilitate and ensure their understanding of the items or variables under examination and avoid ambiguity. The questionnaire was comprised of 77 items, and students completed them in 40 minutes. The students were each given a pen to appreciate them for taking part in the process. The questionnaires were done in English.

The questionnaires were adapted from different scales of diverse instruments and constructs (as described in chapter 3.1.2 above) that were already tested with proven reliability and the constructs were physical, psychological, structural, and cultural violence measured by victimization, bullying, anger, self-esteem, motivation, and communication, physical health, learning, social and emotional violence (see the documentation in annex vi).

This pilot study's data was analyzed using the Statistical Package for Social Sciences version 25 of (IBM SPSS) with descriptive statistics. Based on the psychometric properties, the alpha levels of the different subscales indicated a poor inter-items consistency with Cronbach alpha coefficients ranging between .87 for school violence and victimization, .46 for anger, bullying, and aggressiveness, .47 for self-esteem, .55 for perceived danger, .51 for communication, .35 for physical health, .64 for the social and learning climate. Despite such dismal output of the initial variables for this study, some research studies (Raykov, 2001) have indicated that Cronbach's alpha cannot generally be relied upon as an estimator of reliability. Still, as a customary provision in research, this was preoccupying. Hence, such an abysmal output of variable reliability required some changes in the operationalization of the questionnaire.

The first pre-test of the scales was not showing enough reliability in the test instruments, probably for various reasons: First, the initially selected scales were not contextualized, especially in the case of sub-Saharan Africa. Second, the respondents might have been reading without understanding the items embedded in the different variables, as the wording 
might have been too difficult for easy comprehension. Above all, the respondents undertook it without interest in the study. This, therefore, led to a re-adaptation and overhaul of the test instruments, which brought about some profound changes. The changes were intended to ensure a check of the items, more simplification of the language, and contextualizing some of the test items (see the changes in annex iii).

These changes were effected at the beginning of the summer semester of 2018 before undertaking the second pilot study of the data collection instruments.

\subsubsection{Second Pretest}

Based on the poor output of the first pilot study results, the second pilot study was undertaken.

The data collection phase of the second pilot study took place in the summer semester of 2018. It was conducted in two private, non-governmental denominational public schools in the North West region of Cameroon. 100 respondents from grades five and seven participated. The two schools were found in an urban center, with one of the schools providing 54 respondents or $54 \%$ and the second school providing 46 respondents or $46 \%$. The school administration permitted the administration of the questionnaires during the weekend, and there were immediately collected as the students were finishing. The students were asked to feel free to take part or not and further assured that all the questionnaires were to be treated anonymously with no attempt to divulge any information about them. They were, also, presented the document from a public institution charged with a guarantee of their privacy and that no attempt was going to be made to expose any information from them or their schools. Above all, the students were called not to respond to any item that made them uncomfortable. They were each given a pen as motivation.

The questionnaires were designed in English as the pilot schools were selected from the English-speaking region of Cameroon. Regarding the gender spread of the sample, 63 males constituted $63 \%$ and 47 females or $47 \%$. In the data, the respondents' age composition ranged between 15 - 
21 years, with a mean score of 17.75 years. The questionnaire for this second pilot study was made up of 65 variables, which was shortened from the initial 77 items of the first pilot study. The students completed the questionnaires during the weekend in less than 35 minutes.

The second pilot study used a re-design of the first study. The inclusion of new items took note that the selected variables had a lot of semblance with what could be easily recognizable in the sub-Saharan African context with the different forms of violence common in schools and at home. The researcher created and adapted variables on psychological violence that were contextually relevant (see appendix 2: scales $2 \& 3$, 'questions. 10k, 10l, 10o, 10p, 10q, 10r \& 111, 11n). It proved to be very successful. The selected scales came from tested instruments and were validated by diverse bodies and international institutions. The constructs under examination included physical, psychological, and structural violence measured by victimization, bullying, self-esteem, motivation and communication or worries about family background, physical health, social learning support, and sexual violence. Cultural violence was discarded because of inadequate instrumentations to make it relevant and acceptable. The test items came from

- Bullying victimization, perpetration, and bystander experiences: A compendium of assessment tools (Hamburger, Basile \& Vivolo, 2011) which was maintained from the first pilot study because it had shown that it was reliable.;

- Development and validation of a scale for measuring state selfesteem (Heatherton \& Polivy 1991),

- $\quad$ Manual for the patterns of adaptive learning scales (Midgley et al., 2000),

- $\quad$ Student questionnaire for PISA (2009) to the background variables

- Development of the California school climate and safety survey short form (Furlong et al., 2005),

- The MOS short-form general health survey: reliability and validity in a patient population. (Stewart et al., 1988), 
- The multidimensional scale of perceived social support (Zimet et al., 1988) and

- Adapted instruments from the child abuse screening tool children's version ICAST-CH (Meincke et al., 2018).

The Alpha levels for the diverse subscales indicated a good inter-item consistency and reliability for more than $80 \%$. The scales indicated a Cronbach alpha ranging from .83 for bullying, victimization, and aggressiveness at home, .71 for bullying, victimization and aggressiveness in school, .77 for self-esteem, .63 for motivation, .76 for communications and worries about family background, .85 for school violence and victimization, .83 for physical health, .84 for learning and social climate, and .77 for sexual victimization. There is a possibility that the size of the second sample that was limited to 100 might have affected the psychometric properties of the different scales.

The re-adapted data collection instruments proved more reliable than the tools of the first pilot study. In consultation and collaboration with my supervisor and colleagues, the instruments were adopted to collect the data for the main study in the winter semester of 2018.

\subsection{The Sample of the Main Study}

The study focused on Cameroon, and the questionnaires had been distributed in the West region, found in the French part of Cameroon. This region was chosen because the two Anglophone section's ongoing civil war led to a close-down of all schools in the English speaking region. Therefore, in the French speaking region, schooling was still ongoing. There are 1000 secondary schools in this region with 323.040 students (UNDP Cameroon Development Report, 2016).

\section{Permission Process}

The investigated schools' choice was made by the local authorities by giving access to schools and allowing the study. State educational officials in 
the west region gave the authorization for the collection of data. They approved the collection of data from eight public and lay-private public schools in two districts in the west region of Cameroon. The public schools are low tuition paying schools and by this, having a poor estimation by the public regarding the standards and secondly, intended for those with a challenging social background. In regards to the lay-private public schools, public estimation is as well very doubtful because of the standards enforced in these schools by the proprietors who are using it for business purposes. It is important to note that most of the students of these schools are usually those that have dropped out of another school for one reason or the other. In general this choice was representative for rural areas and cities and for different school providers. However, as by some political reasons of the authorities, for schools with high tuitions a permission was not given, the sample is biased. The sample is covering schools with low tuitions and a low social prestige. As this represents the majority of schools, the findings will cover a broad population; however, it is not a representative choice including the upper social classes in Cameroon.

The collection of the data was conducted from September to November 2018. This study's sample is drawn from eight schools from the public and private sector and encompasses the general and vocational sector in secondary schools. There are approximately $70 \%$ government public schools, $20 \%$ denominational or non-governmental public schools. $90 \%$ of the schools are related to the available secondary system, and $10 \%$ are vocational schools. The schools of the sample are briefly described below (see table 3).

In the Cameroon context, secondary schools can be either day or boarding schools. Furtherance to this, the day schools, usually state public schools, and non-state denominational public schools are both involved in general and vocational education. Noteworthy is that non-state denominational public institutions predominantly run boarding schools and are mainly located in the Anglophone regions of Cameroon. The few exceptions are the non-state private institutions that also operate some boarding 
schools. Boarding schools in Cameroon incarnate the children's intellectual and moral upbringing and are very prestigious. They provide inclusive, serene, well-disciplined, and ethical educational environments. Above all, boarding schools offer an implicit and structural ethos of robust planning of all phases of the academic year, ranging from the school's financial, academic, and infrastructural development. It is essential to underscore that more than $90 \%$ of all boarding schools in Cameroon are denominational, with more than $90 \%$ owned by various denominations in Cameroon's Anglophone regions. In comparison, 10\% is share between non-state private schools in the two subsystems of education. Proof of this assertion is that out of the eight schools of the sample of this study, only one of them turned out to be a boarding school and was a non-state denominational public school.

Table 3: Characteristics of Schools in the Sample

\begin{tabular}{|c|c|c|c|c|c|c|c|c|c|}
\hline \multirow[t]{2}{*}{ Categories } & \multicolumn{2}{|c|}{ Location } & \multirow[t]{2}{*}{ State } & \multirow[t]{2}{*}{$\begin{array}{c}\text { Non-State } \\
\text { Denomina } \\
\text { tional }\end{array}$} & \multirow[t]{2}{*}{$\begin{array}{l}\text { Non-State } \\
\text { Private }\end{array}$} & \multirow[t]{2}{*}{$\begin{array}{l}\text { General } \\
\text { Secondary }\end{array}$} & \multirow[t]{2}{*}{$\begin{array}{l}\text { Vocational } \\
\text { Secondary }\end{array}$} & \multirow[t]{2}{*}{ Boarding } & \multirow[t]{2}{*}{$\begin{array}{c}\text { Non- } \\
\text { Boarding }\end{array}$} \\
\hline & Rural & City & & & & & & & \\
\hline School A & $x$ & & & & $x$ & $x$ & $x$ & & $x$ \\
\hline School B & & $x$ & & $x$ & & $x$ & & $x$ & \\
\hline School C & & $x$ & & & $x$ & $x$ & & & $x$ \\
\hline School D & $x$ & & & & $x$ & $x$ & $x$ & & $x$ \\
\hline School E & & $x$ & $x$ & & & $x$ & & & $x$ \\
\hline School F & $x$ & & $x$ & & & $x$ & & & $x$ \\
\hline School G & $x$ & & $x$ & & & $x$ & & & $x$ \\
\hline School H & & $x$ & $x$ & & & $x$ & $x$ & & $x$ \\
\hline Sum & 4 & 4 & 4 & 1 & 3 & 8 & 3 & 1 & 7 \\
\hline
\end{tabular}

Comment: In the region where the data of the study was conducted, only a single non-state denominational and boarding school was available but from the selected schools, the sample spread was heterogeneous with a multicultural, multi-faith and bilingual background and thereby, an acceptable representation.

Source: Primary data, 2018

The urban region provided four schools comprised of two public institutions, one non-state private and one non-state denominational school. In 
the rural area, there were four schools made up of two public and two nonstate private secondary schools. Together, these schools had a total population size of 22,122 participants. According to Hague (2006), a sample size of about 900 individuals had been seen sufficient as a sample size. With the aid of Survey Monkey, I used it to tabulate the number of participants for my research with the confidence level placed at $95 \%$ and the margin of error of $5 \%$. The sample size was expected to be 378 participants. Still, to avoid any doubtful findings, the margin of error was slightly dropped to 3\%, and it resulted in 1,019 participants serving as the sample. To stretch the meager resources at the disposal of the researcher and the situation in the schools, the sample was limited to 924 participants.

In each of the eight selected colleges, sampling was limited to 100 participants, with some providing just above 50 participants for these schools with less than 500 students. The selection of participants from each of the colleges was undertaken regularly with the care of ensuring a considerable gender representation of the male and female sexes between the ages of 11-18 years of students, which is the average secondary school age of Cameroon, though frequently flawed by some a degree of inconsistency. The classes selected for the acquisition of the sample were classes four and five in the first cycle of secondary school and classes six and seven in the second cycle of secondary school that is commonly known and referred to as high school. The students received a pencil as an incentive for their participation.

In the sampling method, the simple random sampling approach was employed to endeavor to offer each participant and or respondents from the bulk of the student population that anyone of such element was accorded that same probability of inclusion in the sample (Gall et al., 2003). What is vital with such random selection of a sample is that it yields generalizable results to a much larger population in the confines of a margin of error, which is determined with statistical formulas (Gall et al. 2003). Over and above all, there was an implicit stratification of the sample in the sample population's selection process. The stratification process took cognizance of the last two classes of the first cycle of secondary school and all the two high school classes or the sixth and seven classes. This led to a 
slightly bigger sample from high school because the students were mature and could understand and explain better than those in the first cycle of secondary schools.

A total of $(n=924)$ students out of the eight selected schools in these two divisions of the West region of Cameroon were determined. In each of these selected schools, each day was spent for the collection of data, while in some of the schools, especially those of the rural areas, about two or three days were needed because of the school's program. Table 4 shows the sample distribution of the participants

The data from the (completed survey questionnaires $(n=924)$ indicated 522 females with a percentage of $57.2 \%$ and 390 males and $42.8 \%$. From this lot, the missing data were excluded giving validity to only 912 cases.

Table 4: Sample Distribution

\begin{tabular}{|c|c|c|c|c|c|}
\hline$S / N$ & $\begin{array}{l}\text { Catego- } \\
\text { ries }\end{array}$ & $\begin{array}{l}\text { School Popu- } \\
\text { lation }\end{array}$ & $\begin{array}{l}\text { The sam- } \\
\text { ple size of } \\
\text { students }\end{array}$ & $\begin{array}{l}\% \text { of the stu- } \\
\text { dents of the } \\
\text { school in the } \\
\text { sample }\end{array}$ & $\begin{array}{l}\text { Sample } \\
\text { tech- } \\
\text { nique }\end{array}$ \\
\hline 1 & School A & 1050 & 64 & $6.1 \%$ & $\begin{array}{l}\text { Simple } \\
\text { random } \\
\text { sam- } \\
\text { pling }\end{array}$ \\
\hline 2 & School B & 1230 & 83 & $6.7 \%$ & " \\
\hline 3 & School C & 4500 & 182 & $4.4 \%$ & “ \\
\hline 4 & School D & 3562 & 132 & $3.7 \%$ & “ \\
\hline 5 & School E & 4230 & 140 & $3.3 \%$ & “ \\
\hline 6 & School F & 1650 & 97 & $5.8 \%$ & " \\
\hline 7 & School G & 4050 & 140 & $3.4 \%$ & “ \\
\hline 8 & School H & 1850 & 86 & $4.6 \%$ & " \\
\hline 9 & Total & 22.122 & 924 & $4.2 \%$ & \\
\hline
\end{tabular}

Source: Primary data, 2018

\subsection{Data Collection for the Main Study}

This subchapter presents the process of the data collection of the study and explains the process in detail. 


\section{Procedure}

The primary collection of the data was undertaken from September to November 2018. The administration of the questionnaires for the main study was during school hours, and the students were allowed to fill and return them. Moreover, the filling of the questionnaires lasted a maximum of 40 minutes. Students received consent from their authorities and the education stakeholders in the region to participate. They were encouraged by the researcher to feel free to join in the process or not to do so if they did not feel like doing it. Each school had an allocated day of collecting the data, based on the internal programs for that particular school. There had to be some follow-up for some days for the data to be collected in some schools.

In each of the schools, the respondents were helped to take their seats by a teacher or school authority, and the researcher and research assistants were introduced to the respondents. After the introduction, the researcher encouraged the respondents to be as independent as possible and were also encouraged not to sit near their friends. This was to help them to avoid influence from their friends concerning filling the questionnaires. In the course of completing the questionnaires, students sat separately. The researcher and the research assistants were available for all worries and questions from the respondents. Above all, the respondents were allowed to leave the hall when they expressed the need to go or when they had completed filling the questionnaires. All dispositions were taken to ensure that the questionnaires' filling was carried out without any influence from the school authorities, teachers, peers, researcher, and or research assistants. At the end of the process, each respondent was given a pen for their time and participation.

Further to this, all the schools collaborated with the researcher and identified extra-curricular periods to collect data to avoid any distortion of the learning period. They provided a suitable venue and or space for the completion of the questionnaires. Hence, the researcher and all the research assistants received the necessary support they needed to realize the work. At the end of the process, the questionnaires' return rate was $100 \%$ because all the questionnaires were completed in each of the schools. No 
name was written on any questionnaire to treat it anonymously. Each questionnaire was given a particular code to know from which school the questionnaire was collected.

\section{Training and selection of the research assistants}

The recruitment of the research assistants to collect data in Cameroun of this project was meticulous and systematic. The research assistants chosen for the project were experienced in dealing with young persons. They had been experienced in schools and involved in projects against violence in schools. In their training, the research assistants were guided on the protection guidelines by first working with them for adequate supervision to avoid any unforeseen situation. They were trained on adopting a favorable disposition with the young persons and upholding their secrecy and confidentiality. They were introduced to the virtues of patience and explicit communication without any ambiguity, especially if the students indicated that they were not interested in continuing with the process (see for this necessity Devries et al. 2016). The research assistants' binding code of conduct spelled out their functions and responsibilities, given the daunting tasks of collecting data from young persons concerning violence. Part of the assignment was the fact that they were to administer structured questionnaires and not to carry out any interviews.

Confidentiality

The interviewed persons were informed beforehand of the data collection and assured of the confidentiality of the information they were about to provide. They were explicitly informed that the information was intended for scientific research, and no information about their schools or themselves could be disclosed to anyone for any reason whatsoever. They were also informed to disregard the answer to any question that they were not comfortable in answering. The questionnaire was structured such that the problems were orderly, partition into sections with evident and concise use of language. This was intended to allow the respondent to approach the questionnaire with no complexity or tension and be free with the kind of information they were making available to the researcher. 
Concerted efforts were made to inform the various institutions of the research. Through the delegation of education for the North West Region and West regions of Cameroon, the government of Cameroon was informed and accorded their permission first for the conduct of the pilot studies in the North West region and the main study in the West region of Cameroon.

\subsection{Data Analysis and Interpretation}

The data, after collection, had to be processed and analyzed. The data processing implies editing, coding, classification, and tabulation of collected data to be amenable to analysis. After the collection of the data from the field, an immediate process was editing which was done to assure that the data was accurate, consistent with other facts gathered, uniformly entered, as completed as possible, and have been well arranged to facilitate coding and tabulation (Kothari, 2004).

I started the analysis by an exploratory data analysis (EDA) that permitted me to look at the data files to get an idea of what was there. EDA ended with confidence that one had a clean dataset. Editing the data was a process of examining the collected raw data (especially in surveys) to detect errors and omissions and to correct these when possible. Editing involved scrutiny of the completed questionnaires and schedules. Editing was done to assure that the data was accurate, consistent with other facts gathered.

Soiferman (2010) posits that quantitative research uses numerical statistical analysis, which allows researchers to either reject the hypotheses or determine the effect size. Analyzing the data involves addressing the research questions individually. He identifies two types of statistical analysis: descriptive and inferential. Consequently, researchers need "descriptive statistics that indicate central tendencies in the data (mean, mode, median), the spread of scores (variance, standard deviation, and range), or a comparison of how one score relates to others, z-scores, percentile rank" (Soiferman, 2010, p. 9). The term analysis refers to the computation of specific measures and searching for patterns of relationship among datagroups (Kothari, 2004). The data was studied from as many angles as possible to explore the new and revealing facts (Pandey \& Pandey, 2015). 
The data results from the 924 completed survey questionnaires were entered and analyzed using the "statistical package of social science" (SPSS) as well as JAMOVI 0.9.0.1. To acquiesce to a simplified process of data management and clarity in the presentation, JAMOVI was adopted as the operational tool for processing and interpreting the data. The data were analyzed using descriptive statistics, frequencies, means, standard deviations, percentages, linear regressions, correlations, and factor analy$\operatorname{sis}^{3}$.

\subsection{Ethical Considerations}

The questionnaire or data collection instruments were certified by my university, my supervisor, and my institution's team in Cameroun, the InService Teacher Training Program in Bamenda. It was very relevant to ensure that the information was protected and anonymity of the students was given.

The research started with an explicit sensitization of stakeholders. The young persons' involvement was reached by seeking their informed opinions and explaining to them the relevance and importance of the process. The researcher chose only schools for the procedure, where he was not known from his career as working in teacher training and other schoolrelated positions. This was to ensure accountability and openness related to ethical aspects that had to be taken into consideration.

\section{Description of the Findings and Analysis}

In this chapter, the results of the study at hand are presented. Based on the conceptual model's description (chapter 2.4) and the methodology chosen (chapter 3), the study sets out to identify the effects of violence on Cameroon's learning and learning outcomes. The following chapters show the results emanating from the data.

${ }^{3}$ I use this opportunity to thank Dr. Matthias Borgstede for his support and assistance in the data processing and analyzing. 


\subsection{Descriptive Statistics: Social Background of Students, Experiences of Violence, Learning Mediators and Learning Output}

This subchapter gives an overview of the data set following the model described (chapter 2.4). I will begin by describing the general trend noticed in the statistics regarding the questionnaire's findings and the composition of the respondents' demographic patterns (chapter 4.1.1). This is followed by the experience of violence using the frequencies in the independent variable, dealing with the different types of violence (chapter 4.1.2). Moreover, the aspects of learning as seen with the mediating variables and specifically related to their self-esteem and motivation (chapter 4.1.3) and the learning outcomes are seen from the output of the dependent variables were selected subject grades (chapter 4.1.4).

\subsubsection{Demographic Description of the Sample}

\section{Gender}

924 students contributed with a reported missing of 12 in the data set. 390 students, or $42.8 \%$, are male, 522 or $57.2 \%$ are female. The sample composition related to the gender composition is not balanced. This gender imbalance is due to the fact that - as mentioned above - the permission for data collection was only given for schools with low tuitions and a lower academic prestige. This is the reason for the imbalance of girls as families with better socio-academic background would send boys to schools with better reputation, which had not been represented in the sample. 
Age and school-levels

The respondents' age ranged from 12 to 30 years for the first and second cycles of secondary school with the $(\mathrm{M})=18.1$, median $=18.0$, and the $(\mathrm{SD})=2.54$ (see table 5 below).

Table 5: Age Range of Respondents

$\mathrm{N}$

Missing

Mean

Median

Standard deviation
890

34

18.1

18.0

2.54

$\begin{array}{lccc}\text { Age } & \text { Counts } & \text { \% of Total } & \text { Cumulative \% } \\ 12 & 2 & 0.2 \% & 0.2 \% \\ 13 & 6 & 0.7 \% & 0.9 \% \\ 14 & 46 & 5.2 \% & 6.1 \% \\ 15 & 79 & 8.9 \% & 14.9 \% \\ 16 & 138 & 15.5 \% & 30.4 \% \\ 17 & 121 & 13.6 \% & 44.0 \% \\ 18 & 130 & 14.6 \% & 58.7 \% \\ 19 & 136 & 15.3 \% & 73.9 \% \\ 20 & 77 & 8.7 \% & 82.6 \% \\ 21 & 70 & 7.9 \% & 90.4 \% \\ 22 & 46 & 5.2 \% & 95.6 \% \\ 23 & 19 & 2.1 \% & 97.8 \% \\ 24 & 11 & 1.2 \% & 99.0 \% \\ 25 & 4 & 0.4 \% & 99.4 \% \\ 26 & 1 & 0.1 \% & 99.6 \% \\ 28 & 3 & 0.3 \% & 99.9 \% \\ 30 & 1 & 0.1 \% & 100.0 \%\end{array}$

Source: Primary data, 2018

The age distribution shows a noticeable difference display of the age range. The respondents with ages below 15 years were 54 and constituted 6.1\%, while those from 15 but below 20 years were $67.8 \%$ (see table 6). The rest of the respondents from 20 years and above were 232 and constituted $26.1 \%$. This indicated the mean (M) for the males at 18.1, and for 
the females, the (M) was 18.0. The standard deviation (SD) for the males was 2.57 , and the $(\mathrm{SD})$ of the females was 2.48 .

Table 6: Age Distribution of Respondents

\begin{tabular}{lcc}
\hline Age & Frequency & Valid Percent \\
\hline Below 15 & 54 & $6.1 \%$ \\
15 but below 20 & 604 & $67.8 \%$ \\
20 and above & 232 & $26.1 \%$ \\
\hline Total & 890 & $100 \%$ \\
\hline
\end{tabular}

Source: Primary Data, 2018

The sample students mainly visited were found in grades $4-7$, but most of the students were from the second cycle of secondary school in the $6^{\text {th }}$ and $7^{\text {th }}$ grades, respectively. In view of the age distributions as can be seen in (table 6) above, the mean (M) average of age for the students in grade 4 was 16.5 (median $=17$ ), grade $5=15.7$ (median $=16$ ), grade $6=18.1$ (median $=18)$ and grade $7=20($ median $=20)$. This can be seen in table 7 below.

Table 7: Class Distribution of Respondents

\begin{tabular}{lllll}
\hline Levels & Counts & \% of Total & Mean of Age & $\begin{array}{l}\text { Median of } \\
\text { Age }\end{array}$ \\
\hline Grade 4 & 57 & $6.3 \%$ & 16.5 & 17 \\
Grade 5 & 176 & $19.2 \%$ & 15.7 & 16 \\
Grade 6 & 446 & $48.6 \%$ & 18.1 & 18 \\
Grade 7 & 237 & $25.8 \%$ & 20 & 20
\end{tabular}

Source: Primary data, 2018

In each of the classes from lower to upper secondary schools, the gender spread of the respondents in each of the classes was unevenly distributed. 
Each of the classes had more females than the males, as explained (chapter 4.1) and seen in table 8 below.

Table 8: Gender Distribution by Class

\begin{tabular}{cccccc}
\hline Class & $\begin{array}{c}\text { students in } \\
\text { total }\end{array}$ & \multicolumn{2}{c}{ Male } & \multicolumn{2}{c}{ Female } \\
\hline & & $\mathbf{n}$ & $\%$ & $\mathbf{n}$ & $\%$ \\
\hline Grade 4 & 54 & 24 & 44,4 & 30 & 55,6 \\
Grade 5 & 175 & 85 & 48,6 & 90 & 51,4 \\
Grade 6 & 442 & 195 & 44,1 & 247 & 55,9 \\
Grade 7 & 235 & 82 & 34,9 & 153 & 65,1
\end{tabular}

Source: Primary data, 2018.

The table shows that the balance between female and male students was in grade 7 different to the balance in the overall sample as here the share of female students was even higher than in the average of the sample.

The respondents in lower secondary schools had more difficulties to understand the depth of the different variables on the questionnaires. This led to a conscious decision to work with more students from high school, which explained why more students in the 6th and 7th grades showed more understanding of the different variables on the questionnaires. This data is unusual compared with the so-called developed countries, but common in countries with high repetition rate, low educational quality, and tuitions in secondary schools like in Cameroon (UNESCO, 2019; Barakat \& Bengtsson, 2018; Davis \& Bauman, 2013).

Socio-economic background

The parents' job had been asked as an indicator of socio-economic background.

On the parents' job, which is a crucial indicator of wealth, this presented some worrying trends. The key professions of mothers' were primarily homemakers, indicating 377 (42.6\%), traders ( $\mathrm{N}=253 ; 28.6 \%)$, farmers $(\mathrm{N}=54 ; 6.1 \%)$, civil servants $(\mathrm{N}=158 ; 17.9 \%)$, All others profes- 
sions constituted 43 (4.9\%). Homemakers, farmers, and others put together indicated 474 (52\%), thereby forming the bulk with less productive or lucrative professions that in international ratings were below average on the job scale. This is a sign of general poverty, and in addition, of gender challenges (see table 9).

Table 9: Mother's Job

\begin{tabular}{llll}
\hline \multicolumn{1}{c}{ Levels } & Counts & \% of Total & \multicolumn{1}{c}{ Remarks } \\
\hline Homemaker & 377 & $42.6 \%$ & Below Average \\
Trader & 253 & $28.6 \%$ & Average \\
Farmer & 54 & $6.1 \%$ & Below Average \\
Civil servant & 158 & $17.9 \%$ & Above average \\
Others & 43 & $4.9 \%$ & Unknown
\end{tabular}

Source: Primary data, 2018

The profession of the fathers' of respondents, 272 (32.5\%) were not gainfully endowed with a source of income and were in professions such as mechanics, drivers, pastors, construction or masonry including others which in the international listing, constituted below average jobs. Those who had a source of income were 568 (62.2\%), however, $37 \%$ of fathers did not have a regular income (see table 10 ).

Table 10: Father's Job

\begin{tabular}{lrrl}
\hline \multicolumn{1}{c}{ Levels } & Counts & \% of Total & \multicolumn{1}{c}{ Remarks } \\
\hline Trader & 294 & $35.0 \%$ & Average \\
Mechanic & 20 & $2.4 \%$ & Below Average \\
Driver & 87 & $10.4 \%$ & Below Average \\
Civil servant & 235 & $28.0 \%$ & Above Average \\
Engineer & 20 & $2.4 \%$ & Above Average \\
Lawyer & 8 & $1.0 \%$ & Above Average \\
Pastor & 6 & $0.7 \%$ & Below Average \\
Accountant & 11 & $1.3 \%$ & Above Average \\
Construction & 88 & $10.5 \%$ & Below Average \\
Others & 71 & $8.5 \%$ & Unknown
\end{tabular}

Source: Primary data, 2018 
The level of parent's education also provided insights into the status. As such, most of the respondents' mothers indicate that $33 \%$ only finished primary school and 65, $2 \%$ did not have finished secondary school. In comparison, $19.3 \%$ had a high school certificate while $7.0 \%$ had a bachelor's degree. This and other levels of their education are seen in table 11 below.

Table 11: Mother's Level of Education

\begin{tabular}{lrr}
\hline \multicolumn{1}{c}{ Levels } & Counts & \% of Total \\
\hline End of Primary School (FSLC) & 270 & $33.3 \%$ \\
End of First Cycle of Secondary School (O Level) & 258 & $31.9 \%$ \\
End of Second Cycle of Secondary school (A-Level) & 156 & $19.3 \%$ \\
BA/BSc & 57 & $7.0 \%$ \\
Vocational Certificate (Diploma) & 40 & $4.9 \%$ \\
MA/MSc & 18 & $2.2 \%$ \\
PhD & 11 & $1.4 \%$
\end{tabular}

Source: Primary data, 2018

The level of education for respondents' fathers indicated that $46.9 \%$ did not have a certificate from the second level of secondary school, and 23.3\% were effectively in possession of the high school certificate. $11.2 \%$ had a Bachelor level of education. The details are seen in table 12 with the other levels of education.

Table 12: Father's Level of Education

\begin{tabular}{lrr}
\hline Levels & Counts & \% of Total \\
\hline End of Primary school (FSLC) & 179 & $22.7 \%$ \\
End of First Cycle of Secondary School (O' Level) & 191 & $24.2 \%$ \\
End of Second Cycle of Secondary School (A 'Level) & 184 & $23.3 \%$ \\
BA/BSc & 88 & 11.2 \\
Vocational Certificate (Diploma) & 67 & 8.5 \\
MA/MSc & 45 & 5.7 \\
PhD & 35 & 4.4
\end{tabular}

Source: Primary data, 2018

By looking to the formal educational background, it should be however understood that certificates, especially Master and PhD can be bought or gotten through unaccredited educational institutions. 
Above all, the level of parents' education indicates a low social background for the students. The mothers' education levels showed that their level of education is less than or equal ( $\leq$ ) to the level of education of their children with 684 (75\%) of mothers, and the fathers' situation was not significantly different. As such, the fathers with $\leq$ of education were 554 (60.7\%). Therefore, with such educational background at the level of their parents, the students depended on their teachers' competencies for their education.

Moreover, this also shows that the students' population is heterogeneous as more than $50 \%$ of their parents' level of education is below the accepted standards concerning those with the basic level of education. Moreover, the heterogeneity of parents is visible at the different types of jobs and professional occupations.

The respondent's status shows that some of the students are orphans and refugees. 31 males and 37 females were orphans; 21 males and 48 females were refugees (see table 13). That means that $12,0 \%$ students of the sample are orphans and $14,2 \%$ of the students see themselves as refugees.

Table 13: Orphans and Refugees

\begin{tabular}{cccccc}
\hline & Orphans & & \multicolumn{3}{c}{ Refugees } \\
\hline & Male & Female & & Male & Female \\
\hline Yes & 31 & 37 & Yes & 21 & 48 \\
No & 250 & 316 & No & 225 & 260
\end{tabular}

Source: Primary data, 2018

The number of books in the homes of the students, are an indicator of the wealth and academic level of the students. The measurement used an adjusted scale to the situation in Cameroon. 485 students (55.1\%) indicated that they had between 0-10 books at home, 245 (27.8\%) had between 1125 books and 151 (17.1\%) had between 25-100 books. If these data are compared to the situation in countries with higher income, the low level of literacy in Cameroonian families becomes visible. International studies 
(IGLU 2006) reported for Germany about $4 \%$ of students with $0-10$ books at home and $14 \%$ between 11 and 25 books (so $18 \%$ in both categories), for Sweden 8 percent in both categories or Moldavia $60 \%$ in both categories (Boos, Schwippert \& Stubbe 2007; p. 229).

Table 14: Books at Home

\begin{tabular}{lcc} 
Levels & Counts & \% of Total \\
\hline 1 & 485 & $55.1 \%$ \\
2 & 245 & $27.8 \%$ \\
3 & 151 & $17.1 \%$ \\
\hline
\end{tabular}

Source: Primary data, 2018

\subsubsection{Independent Variables: Experiences of Violence}

This subchapter describes the students' degree of the various forms of violence at home and in school, physical violence at home and in school, psychological violence at home and school, structural violence, and sexual harassment.

The descriptive statistics on physical violence experienced at home were on a scale of $1=$ never, $4=$ often with items as "how often have you been badly beaten at home". These students suffered from violence at home with $\mathrm{M}=1.40$ ( $\mathrm{SD}=0.47$ ). For the case of physical violence in school, the measurement scale was the same as the one at home with items as "how often have you been hit by a staff". The students experienced violence with $\mathrm{M}=1.30$, $(\mathrm{SD}=0.33)$.

Concerning psychological violence at home, the scale was $1=$ never, $4=$ often with items as "has anyone in your family said they wish you were dead or never born?" Students reported experiences with psychological violence at home, indicating $\mathrm{M}=1.30$ ( $\mathrm{SD}=0.49$ ). Regarding the psychological violence at school on a scale with items as "how often have you been verbally or emotionally abused by a school staff?" students experienced psychological violence in school, indicating $\mathrm{M}=1.42(\mathrm{SD}=0.86)$. On the level of single items, students reported when asked, "How often 
you are referred to as a devil", $6.4 \%$ of respondents indicated that this happened "sometimes" and $4.2 \%$ said, this was "often". On being "bewitched" by their parents, $6.0 \%$ of respondents answered it was "sometimes" and $4.2 \%$ reported it was "often". On "how often you are verbally or emotionally abused", $17.0 \%$ indicated it was "sometimes" and $8.6 \%$ said it was "often".

Structural violence was measured on a scale of $1=$ not at all, $3=$ very often. The students were i.e. asked, "how often does alcohol consumption and drug abuse occur in your school?" This was related to their safety and comfort in school. Students found their school environment to be hostile and not conducive for their studies with $\mathrm{M}=1.71$ ( $\mathrm{SD}=0.53$ ).

The following table (15) gives an overview about different forms of experienced violence.

Table 15: Levels of Experienced Violence

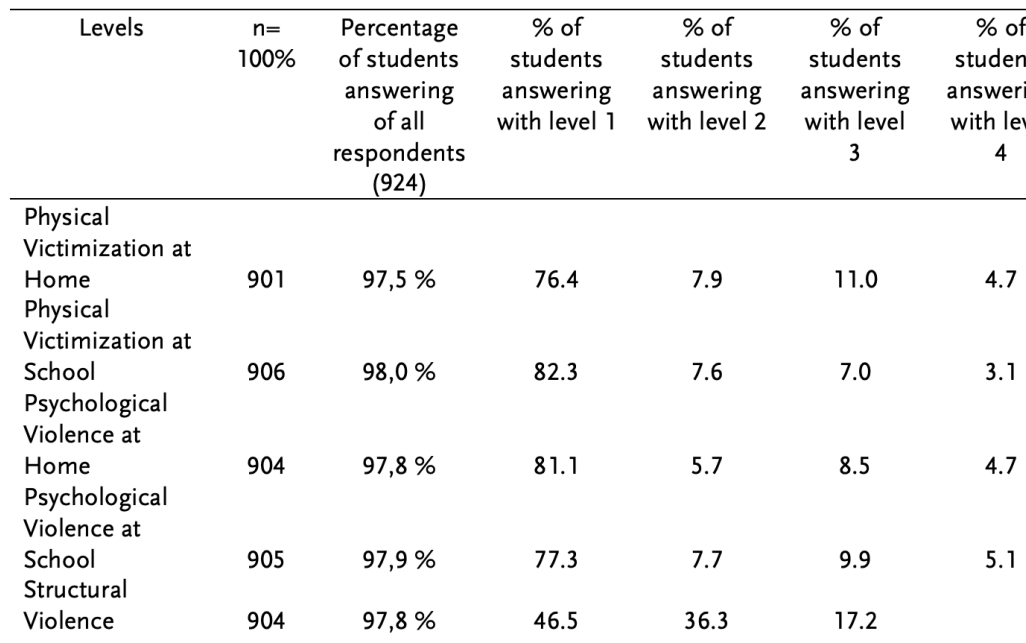

Source: Primary data, 2018.

About $20 \%$ of students experience physical violence and psychological violence. Violence is experienced at school and at home. More than half of the students experience structural violence. 
Sexual harassment was measured on a scale of $1=$ never, $4=$ many times, and sought to know from the students information as "any teacher has made you have sex in exchange for marks?" Students reported to the scale indicating a mean $\mathrm{M}=1.44(\mathrm{SD}=0.55) .24 .0 \%$ of all the students had experiences with sexual violence. Both, girls and boys had been affected equally. 201 students, or $22.7 \%$ of the reported 885 respondents, indicated to have experienced sexual abuse by being asked by teachers for sexual practices in exchange for marks. These data show that sexual victimization is a serious experience of violence among the sample of this study. Table 16 summarizes experiences of sexual violence.

Table 16: Experienced Sexual Violence

\begin{tabular}{lrr}
\hline \multicolumn{1}{c}{ Level } & $\mathrm{n}$ =number of students & \% of respondents \\
\hline (1) never & 680 & 76.0 \\
(2) not in the past year, but this has happened & 73 & 8.1 \\
(3) sometimes & 107 & 12.0 \\
(4) many times & 35 & 3.9
\end{tabular}

Note: As sexual harassment is a traumatic experience which should have zero probability; the scale was related to the different levels by using 1 for 1,$0 ; 2=1,01$ to 2,$0 ; 3=2,1$ to 3,$0 ; 4=3,1$ to 4,0

$\mathrm{n}=924$; as 895 students did respond to the scale $=96,8 \%$

Source: Primary data, 2018

The following table (tab. 17) gives an overview about the different levels of experienced violence by harmonized scales.

Table 17: Summary of Experienced Violence

\begin{tabular}{lcccc}
\hline \multicolumn{1}{c}{ Forms of experienced violence } & $\begin{array}{c}\mathbf{n} \text { = students } \\
\text { who answered }\end{array}$ & $\begin{array}{c}\text { \% on level } \\
\text { never }\end{array}$ & $\begin{array}{c}\text { \% on level in } \\
\text { between }\end{array}$ & $\begin{array}{c}\text { \% on level } \\
\text { often/many } \\
\text { times }\end{array}$ \\
\hline Physical Victimization at Home & 901 & 76.1 & 11.0 & 4.7 \\
Physical Victimization in School & 905 & 76.8 & 6.9 & 3.0 \\
Psychological Violence at Home & 904 & 81.1 & 8.2 & 4.7 \\
Psychological Violence in School & 905 & 77.3 & 9.8 & 5.1 \\
Structural Violence & 904 & 46.1 & 36.3 & 17.2 \\
Sexual Violence & 895 & 76.0 & 20,1 & 3.9 \\
\hline
\end{tabular}

Comment: Physical and Psychological victimization had a four level measure, $1=$ Never, 2 = Once, $3=$ Sometimes, $4=$ Often. Structural Violence had a three level measure 1 = Not at all, 2 = Sometimes, $3=$ Very Often. Sexual Violence had a four measure level, 1 = Never, 2 = Not in the past year but this has happened, $3=$ Sometimes, $4=$ Many times

Source: Primary data, 2018. 
As violence is an experience which may harm already by being used once, and "no violence" in education should be the standard, it may be stated from tab. 17 that $23.9 \%$ of students suffer from physical violence at home and $23.2 \%$ from physical violence at school; $18.9 \%$ of students from psychological bullying at home and $22.7 \%$ of psychological violence at school; $53.9 \%$ from structural violence, and $24.0 \%$ from sexual violence. This are experiences of violence which are very high, especially in regard to physical violence at school and sexual violence.

\subsubsection{Mediating Variables: Aspects of Learning}

In this subchapter, I am going to presents the mediating variables and or aspects of learning that determines the students' cognitive ability to learn, resulting in skills acquisition that was used in the study as definitive proof to show the effects and influence of the different types of violence on the learning of the students. These aspects were academic, body, and general self-esteem as well as knowledge and school motivation.

\section{Self-esteem}

Self-esteem was measured in regard to body self-esteem, general self-esteem and academic self-esteem. Concerning body self-esteem, students were asked to rate about themselves on items like "I am pleased with my appearance" from $1=$ not all, to $5=$ extremely positive. This led to a $\mathrm{M}=$ $3.48(\mathrm{SD}=0.15)$. Furtherance to this, on the general self-esteem, the students indicated how they were feeling in relation to others by items as "I feel that others respect are." The scale lead to a mean with $\mathrm{M}=3.04$ ( $\mathrm{SD}=$ 1.31). The academic self-esteem of the students was assessed on a scale of $1=$ not all, $5=$ extremely and they were asked to rate this statement "I feel confident that I understand things" leading to mean $\mathrm{M}=2.78(\mathrm{SD}=0.13$ ).

\section{Motivation}

The learning motivation of the students showed a determining and upbeat situation by the students. On a scale of $1=$ not at all, $3=$ very true, the students were asked to indicate what they were willing to learn, "one of my 
goals in class is to learn as much as I can.” The scale was answered with a mean $\mathrm{M}=2.86(\mathrm{SD}=0.28)$. Moreover, the students responded on their school motivation. They were asked to rate some statements about their motivation to be or not to be in school. For instance, "I really feel that I am wasting my time in school." Students responded to this scale with a mean $\mathrm{M}=2.78(\mathrm{SD}=0.40)$. Above all, the health impairment was examined with the scale of $1=$ not limited at all, $3=$ limited for more than three months. They were therefore asked to indicate, "how long has your health limited you from eating, studying, bathing, and dressing?" Students responded with $\mathrm{M}=1.50$ ( $\mathrm{SD}=0.65)$.

From the statistics, it indicated that on their health impairment, they were relatively healthy. School and learning motivation was average. The general self-esteem may be seen as stable. These findings are summarized in table 18 below.

Table 18: Summary of Learning Mediators

\begin{tabular}{lcccc}
\hline \multicolumn{1}{c}{ Descriptions } & Counts & \% of Total & M & SD \\
\hline Academic Self-esteem & 814 & $88.1 \%$ & 3.70 & 0.92 \\
Body Self-Esteem & 819 & $88.6 \%$ & 3.37 & 0.72 \\
General Self-Esteem & 811 & $87.8 \%$ & 3.48 & 0.50 \\
Learning Motivation & 810 & $87.7 \%$ & 2.86 & 0.28 \\
School Motivation & 759 & $82.1 \%$ & 2.78 & 0.40 \\
Health Impairment & 785 & $85.0 \%$ & 1.50 & 0.65 \\
\hline
\end{tabular}

Comment: Self-Esteem had a five level measure, $1=$ Not at all, $2=$ A little bit, $3=$ Somewhat, $4=$ Very much, $5=$ Extremely. Motivation had a three level measure, $1=$ Not at all true, $2=$ Somewhat true, $3=$ Very true. Health impairment had a three leve measure, 1 = Limited for more than three months, 2 = Limited for three months or less, $3=$ Not limited at all

Source: Primary data, 2018

\subsubsection{Dependent Variables: Learning Outcomes}

The following subchapter presents the learning outcome, reflected by the students' different subject grades and the repetition rate. It shall explain the different levels used in the grading of the various subjects and the subject grades as they are on the students' questionnaire.

The school subject grades under examination were the English language, French language, Mathematics, and ICT or Science grades. The respondents were asked to indicate their grades in the subjects mentioned below. The grades were calculated using five levels (see table 20). 
Table 19: Grading Level of Subjects

\begin{tabular}{lrrrr}
\hline & French Language & English Language & Mathematics & \multicolumn{1}{c}{ ICTs } \\
\hline $\mathrm{N}$ & 896 & 896 & 894 & 873 \\
Missing & 28 & 26 & 30 & 51 \\
Mean & 3.01 & 2.57 & 2.26 & 3.35 \\
Standard deviation & 1.18 & 1.19 & 1.28 & 1.27 \\
\hline Grading had five measurement levels, 1 = Fail, $2=$ Average, 3 = Fair, 4 = Cood, $5=$ Very good & &
\end{tabular}

Source: Primary data, 2018

French language had 896 respondents, 28 missing with 100 (11.2\%) respondents having top grades and $\mathrm{M}=3.01$, $(\mathrm{SD}=1.18)$. English language had 898 respondents with 26 missing, 55 (6.1\%) students with top grades, and an average $\mathrm{M}=2.57(\mathrm{SD}=1.19)$. French is the first language in French-speaking Cameroon and English is regarded as the second language. The fact that one quarter of student fail to reach the minimum level in English is an indicator for the poor teaching quality in schools. French grades are gradually better as learning French is not only depending from school.

For grades in mathematics, they were 894 respondents and 30 missing. $58(6.5 \%)$ respondents answered having top grades; the mean of the scale indicated $\mathrm{M}=2.26$ ( $\mathrm{SD}=1.28$ ) (table 20$)$. When compared to international standards (Carey \& Ernst, 2006; Brophy, 2006), many of the students get inferior grades and live with the feeling of failing in mathematics, as nearly $40 \%$ of students answered that the fail in mathematics (see table 21). 
Table 20: Grades in English and French Language

\begin{tabular}{lccc}
\multicolumn{4}{c}{ French Language } \\
\hline Levels & Counts & $\%$ of Total & Cumulative \% \\
\hline 1 & 101 & $11.3 \%$ & $11.3 \%$ \\
2 & 214 & $23.9 \%$ & $35.2 \%$ \\
3 & 258 & $28.8 \%$ & $64.0 \%$ \\
4 & 223 & $24.9 \%$ & $88.8 \%$ \\
5 & 100 & $11.2 \%$ & $100.0 \%$ \\
\hline & English Language & \\
\hline Levels & Counts & $\%$ of Total & Cumulative \% \\
\hline 1 & 225 & $25.1 \%$ & $25.1 \%$ \\
2 & 186 & $20.7 \%$ & $45.8 \%$ \\
3 & 294 & $32.7 \%$ & $78.5 \%$ \\
\hline 5 & 138 & $15.4 \%$ & $93.9 \%$ \\
\hline
\end{tabular}

Grading had five measurement levels, $1=$ Fail, $2=$ Average, $3=$ Fair, $4=$ Good, $5=$ Very good Source: Primary data, 2018

Table 21: Grades in Mathematics

\begin{tabular}{lcc} 
Levels & Counts & \% of Total \\
\hline 1 & 355 & $39.7 \%$ \\
2 & 175 & $19.6 \%$ \\
3 & 195 & $21.8 \%$ \\
4 & 111 & $12.4 \%$ \\
5 & 58 & $6.5 \%$
\end{tabular}

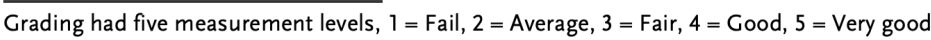
Source: Primary data, 2018

The final grade of ICTs or science grades had 873 respondents, 51 missing in the system. 183 (21\%) respondents had top grades; the mean of the scale reached $\mathrm{M}=3.35$ ( $\mathrm{SD}=1.27$ ). This, therefore, implied that it was the only subject having a modest favorable score among the respondents,

$11,2 \%$ of students failed. This is the subject with a 'doing' practical approach as a method and a relation to everyday life (table 22). 
Table 22: Grades on ICTs

\begin{tabular}{lcc} 
Levels & Counts & \% of Total \\
\hline 1 & 98 & $11.2 \%$ \\
2 & 129 & $14.8 \%$ \\
3 & 202 & $23.1 \%$ \\
4 & 261 & $29.9 \%$ \\
5 & 183 & $21.0 \%$
\end{tabular}

The selected grades had five measurement levels, $1=$ Fail, $2=$ Average, $3=$ Fair, $4=$ Good, $5=$ Very good Source: Primary data, 2018

By reflecting the data on grading together 779 (85.4\%) of students (out of the sum of 912) indicated fail scores in at least one of the important subjects. This shows sincere problems of educational quality already on the level of the output of the system.

These problems are correspondingly also reflected in the rate of class repetition. The dependent variable of class repetition indicated $\mathrm{N}=898$ and 26 missing data. Only $26.3 \%$ of the students or 236 individuals had never repeated a class, 369 or $41.1 \%$ had repeated once, and 293 (32.6\%) had repeated their classes twice or more times with an $\mathrm{M}=2.06$ ( $\mathrm{SD}=$ 0.765). (table 23) 662 (73.7\%) students were repeaters of at least one class. This repetition rate in comparison to international standards (Carey \& Ernst, 2006; Brophy, 2006) is very high, and this shows a low level of teaching quality in Cameroon. 
Table 23: Class Repetition

\begin{tabular}{|c|c|c|}
\hline Number of repetition & Counts & $\%$ of Total \\
\hline No, never & 236 & $26.3 \%$ \\
\hline Yes, once & 369 & $41.1 \%$ \\
\hline Yes, twice or more & 293 & $32.6 \%$ \\
\hline \multicolumn{3}{|l|}{ Descriptive } \\
\hline $\mathrm{N}$ & & 898 \\
\hline Missing & & 26 \\
\hline Mean & & 2.06 \\
\hline Standard deviation & & 0.76 \\
\hline
\end{tabular}

Source: Primary data, 2018

Extra Reading is an indicator for showing engagement in reading as the base for all learning. Out of the 889 respondents (35 missing), 253 or (28.3\%) of the respondents indicated that they never spend time reading for extra enjoyment or leisure. 223 (25.1\%) of the respondents read for 30 minutes or less in a day while $118(13.3 \%)$ of the respondents read for more than 30 minutes but less than 60 minutes a day, and only 147 (16.5\%) read for one to two hours day $(\mathrm{M}=2.68$; $\mathrm{SD}=1.46)$ (table 24). 
Table 24: Extra Reading Enjoyment

\begin{tabular}{lll} 
Descriptive & \\
\hline $\mathrm{N}$ & & \\
Missing & & \\
Mean & & \\
Standard deviation & & \\
\hline & & \\
\multicolumn{1}{c}{ Levels } & Counts & $\%$ of Total \\
\hline & 253 & $28.5 \%$ \\
Never reading & 223 & $25.1 \%$ \\
30 minutes or less a day & 118 & $13.3 \%$ \\
Between 30 and 60 minutes a day & 147 & $16.5 \%$ \\
1-2 hours a day & 148 & $16.6 \%$ \\
More than 2 hours a & & \\
\hline
\end{tabular}

Source: Primary data, 2018

That means that 476 students $(53.5 \%)$ do not read at all for leisure or extra enjoyment or spend less than thirty minutes reading a day. This correspond to the few books at home in families, mentioned above. Against this background, there is a high probability that student lack reading competences, reading very slow or even as functional illiterate having difficulties to understand what they read.

\subsubsection{Summary: Descriptive Findings}

The descriptive data can be summarized as follows.

(1) Descriptive of the students: The sample shows a higher proportion of girls, reflecting the higher proportion of girls in schools with low tuitions. The resulting low social status is also evident in the socio-economic data of the parents, who are below the Cameroonian average in terms of income. The pupils in the sample are on average around 18 years old, with a standard deviation of three years. The youngest pupils are 12 years old, the oldest 30; the majority of pupils are between 14 and 23 years old. Nearly $70 \%$ of the students are in the sixth or seventh grade, i.e. grade 12 and 13 (final grades) by international count. Over $83 \%$ of all pupils find 
less than 25 books at home, of which over $53 \%$ have less than ten. This is also an indicator for predominantly poor parental homes with a low educational background.

(2) Experiences of violence: The descriptive data outputs show that many students have experiences with the different types of violence. As violence is an experience which may very much harm already by being used once, and "no violence" in education should be the standard. The findings showed that about $23 \%$ of students suffer from physical violence at home at school, about $20 \%$ of students from psychological bullying at home and at school; $53.9 \%$ from structural violence, and $24.0 \%$ from sexual violence. In addition to structural violence, students do not see themselves as very healthy as having nearly three months experience of being limited by health problems. The overall experiences of violence are high, especially in regard to physical violence at school and sexual violence.

(3) Mediating aspects of learning: Students show high learning motivation of 2.86 on a scale from 1 to 3 as well a high motivation to school motivation. General self-esteem is rated on a scale from 1 to 5 at 3.48.

(4) Output of education: The data show that more than $85 \%$ of students in the sample did go through the experience of failing in school in one or more subjects. 74\% of student's repeated at least one year of schooling, and $33 \%$ of students made the experience to repeat more than twice. This shows the general low quality of education in families as well in schools. More than $50 \%$ of students do not read at all or less than 30 minutes a day. This relates to the mentioned fact that there are only a few families with significant book ownership. Public library facilities are generally rare in the country, schools in general do not have libraries. Therefore access to written products is difficult to get.

\subsection{Analysis: The Influence of Violence in Learning}

This chapter reflects on the relations between the background of the students, the experiences of violence and the effects regarding the learning of students.

The statistical data was analyzed with the use of regression analysis. The examination was on the effects of the demographic variables on the 
outcome or dependent variables, demographic variables on independent variables (IV), independent variables (IV) on the mediating variables (MV) and finally, the independent and mediating variables on the dependent variables.

\subsubsection{Social Background and Learning Outcomes}

First, the relation between the social background of students and the learning outcome is reported. Table 25 shows the effects of the demographic variables on the dependent variables.

Table 25: Effects of the Social Background on the Learning Outcome of the Students

\begin{tabular}{|c|c|c|c|c|c|c|}
\hline Predictors & $\begin{array}{c}\text { Class } \\
\text { Repetition } \\
\text { Estimates }\end{array}$ & $\begin{array}{c}\text { Extra } \\
\text { Reading } \\
\text { Estimates }\end{array}$ & $\begin{array}{l}\text { English } \\
\text { Crades } \\
\text { Estimates }\end{array}$ & $\begin{array}{l}\text { French } \\
\text { Grades } \\
\text { Estimates }\end{array}$ & $\begin{array}{l}\text { Maths } \\
\text { Grades } \\
\text { Estimates }\end{array}$ & $\begin{array}{l}\text { Science } \\
\text { Grades } \\
\text { Estimates }\end{array}$ \\
\hline Intercepts & $\begin{array}{l}-0.72^{*} \\
(0.31)\end{array}$ & $\begin{array}{c}3.91 k k * \\
(0.66)\end{array}$ & $\begin{array}{c}4.57 \cdots k * \\
(0.55)\end{array}$ & $\begin{array}{c}4.04 * k * k \\
(0.54)\end{array}$ & $\begin{array}{l}1.76 * k \\
(0.61)\end{array}$ & $\begin{array}{c}2.86^{* k * k} \\
(0.61)\end{array}$ \\
\hline Sex (Female) & $\begin{array}{l}-0.06 \\
(0.06)\end{array}$ & $\begin{array}{l}0.41^{k \times} \\
(0.14)\end{array}$ & $\begin{array}{l}0.26^{\star} \\
(0.12)\end{array}$ & $\begin{array}{c}0.13 \\
(0.11)\end{array}$ & $\begin{array}{c}0.06 \\
(0.13)\end{array}$ & $\begin{array}{l}-0.33^{2} \\
(0.13)\end{array}$ \\
\hline Age & $\begin{array}{c}0.16 * x * \\
(0.01)\end{array}$ & $\begin{array}{c}-0.10^{* k * k} \\
(0.03)\end{array}$ & $\begin{array}{c}-0.09 * * * * \\
(0.02)\end{array}$ & 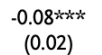 & $\begin{array}{c}0.01 \\
(0.03)\end{array}$ & $\begin{array}{c}0.01 \\
(0.03)\end{array}$ \\
\hline $\begin{array}{l}\text { Education } \\
\text { Mother } \\
\text { (Medium vs. } \\
\text { Low) }\end{array}$ & $\begin{array}{c}0.11 \\
(0.08)\end{array}$ & $\begin{array}{c}0.02 \\
(0.16)\end{array}$ & $\begin{array}{l}-0.11 \\
(0.14)\end{array}$ & $\begin{array}{l}-0.08 \\
(0.14)\end{array}$ & $\begin{array}{c}0.26 \\
(0.15)\end{array}$ & $\begin{array}{c}0.26 \\
(0.15)\end{array}$ \\
\hline $\begin{array}{l}\text { Education } \\
\text { Mother } \\
\text { (High vs. }\end{array}$ & $\begin{array}{c}0.02 \\
(0.11)\end{array}$ & $\begin{array}{l}-0.17 \\
(0.24)\end{array}$ & $\begin{array}{l}-0.05 \\
(0.21)\end{array}$ & $\begin{array}{l}0.25 \\
(0.20)\end{array}$ & $\begin{array}{c}0.20 \\
(0.23)\end{array}$ & $\begin{array}{c}0.22 \\
(0.23)\end{array}$ \\
\hline $\begin{array}{l}\text { Education } \\
\text { Father } \\
\text { (Medium vs. } \\
\text { Low) }\end{array}$ & $\begin{array}{l}-0.11 \\
(0.08)\end{array}$ & $\begin{array}{c}0.30 \\
(0.18)\end{array}$ & $\begin{array}{c}0.00 \\
(0.15)\end{array}$ & $\begin{array}{l}0.35 * \\
(0.15)\end{array}$ & $\begin{array}{l}0.34^{*} \\
(0.17)\end{array}$ & $\begin{array}{l}0.38^{*} \\
(0.17)\end{array}$ \\
\hline $\begin{array}{l}\text { Education } \\
\text { Father (High } \\
\text { vs. Low) }\end{array}$ & $\begin{array}{l}-0.27 * \\
(0.11)\end{array}$ & $\begin{array}{l}0.70 \% * \% \\
(0.23)\end{array}$ & $\begin{array}{l}-0.37 \\
(0.19)\end{array}$ & $\begin{array}{l}0.48 * \\
(0.19)\end{array}$ & $\begin{array}{l}0.53 * \\
(0.21)\end{array}$ & $\begin{array}{c}0.28 \\
(0.22)\end{array}$ \\
\hline Orphan & $\begin{array}{l}-0.00 \\
(0.14)\end{array}$ & $\begin{array}{c}0.48 \\
(0.31)\end{array}$ & $\begin{array}{l}-0.41 \\
(0.26)\end{array}$ & $\begin{array}{l}-0.30 \\
(0.25)\end{array}$ & $\begin{array}{l}-0.16 \\
(0.28)\end{array}$ & $\begin{array}{c}0.03 \\
(0.28)\end{array}$ \\
\hline Refugee & $\begin{array}{c}0.06 \\
(0.10)\end{array}$ & $\begin{array}{l}-0.42^{\star} \\
(0.21)\end{array}$ & $\begin{array}{l}-0.25 \\
(0.17)\end{array}$ & $\begin{array}{l}0.41^{*} \\
(0.17)\end{array}$ & $\begin{array}{c}0.07 \\
(0.19)\end{array}$ & $\begin{array}{c}0.10 \\
(0.19)\end{array}$ \\
\hline $\begin{array}{l}\text { Observation } \\
\mathrm{s}\end{array}$ & 421 & 424 & 427 & 428 & 426 & 416 \\
\hline $\begin{array}{l}\mathrm{R}^{2} / \\
\text { Adjusted } \mathrm{R}^{2}\end{array}$ & $\begin{array}{l}0.319 / \\
0.305\end{array}$ & $\begin{array}{l}0.099 / \\
0.082\end{array}$ & $\begin{array}{l}0.079 / \\
0.062\end{array}$ & $\begin{array}{l}0.091 / \\
0.074\end{array}$ & $\begin{array}{l}0.041 / \\
0.023\end{array}$ & $\begin{array}{l}0.046 / \\
0.028\end{array}$ \\
\hline
\end{tabular}

Source: Primary data, 2018 
As results reflected by the summary, the social background from the intercepts shows a very strong connection and influence on the study outcomes of students. Some of the predictors emanating from the social background indicated no statistical effect, particularly the level of mother's education which showed no statistical significance on the students grades. Fathers education had a significant effect, indicating that the higher father education gets, the higher the school grades of the children gets and the lower father education gets, the lower the class repetition gets. This shows the importance of the socio-economic status of the father figure in this study.

The significance of the age is strong and this implies that, as often as you repeat a class, the older a student becomes, the results do not get better. Repeating a class does not lead to higher learning outcome. This shows again the poor quality of instruction.

Moreover, the table indicates that the girls read more at home and have better English grades while the boys have better science grades. These findings are in line with international findings on gender role models and study outcome (i.e. as shown in many assessments of PISA; see PISA, 2018; Silfver, 2019). Refugees also indicate a better reading attitude and have better French grades in school.

In view of this, what is the influence of the social background on class repetition of the students?

Table 26: Social Background on the Class Repitition

\begin{tabular}{lcccccc} 
Model & $\mathbf{R}^{2}$ & Adjusted $\mathbf{R}^{2}$ & $\mathbf{F}$ & $\mathbf{d f 1}$ & $\mathbf{d f 2}$ & $\mathbf{P}$ \\
\hline 1 & 0.32 & 0.31 & 24.1 & 8 & 412 & $<.001$ \\
\hline
\end{tabular}

Source:

Primary data, 2018

Table 26 concerning the outcome of class repetition, led to a coefficient of determination $\mathrm{R}^{2}(0.32)$ and adjusted $\mathrm{R}^{2}(0.31)$. This therefore indicated that the social background solely predicted $31 \%$ explanation of the variance of students' academic outcomes with reference to class repetition and had a significant effect $(\mathrm{p}<.001)$. 
Further still, how does the social background of the students influence them from undertaking extra reading at home?

Extra reading of the students showed a coefficient of determination $\mathrm{R}^{2}$ $(0.10)$,adjusted $\mathrm{R}^{2}(0.08)$ and in which case the social background or predictors accounted for $9 \%$ explanation of the academic achievement or outcome of students in relation to extra reading with a significant effect $(\mathrm{p}<.001)$ (table 27). This indicates that the student's social background plays influences for $9 \%$ the interest in extra reading at home.

Table 27: Social Background on Rading Enjoyment

\begin{tabular}{ccccccc} 
Model & $\mathrm{R}^{2}$ & Adjusted $\mathrm{R}^{2}$ & $\mathrm{~F}$ & $\mathrm{df1}$ & $\mathrm{df2}$ & $\mathrm{P}$ \\
\hline 1 & 0.10 & 0.08 & 5.70 & 8 & 415 & $<.001$ \\
\hline
\end{tabular}

Source: Primary data, 2018

In addition to this, is the social background having an influence on the English language grades of the students?

Table 28: Social Background Explaining English Grades

\begin{tabular}{|c|c|c|c|c|c|c|}
\hline Model & $\mathrm{R}^{2}$ & Adjusted $\mathrm{R}^{2}$ & $\mathrm{~F}$ & $\mathrm{df1}$ & $d f 2$ & $\mathrm{p}$ \\
\hline 1 & 0.08 & 0.06 & 4.49 & 8 & 418 & $<.001$ \\
\hline
\end{tabular}

Source: Primary data, 2018

English language grades indicated a coefficient of determination $\mathrm{R}^{2}(0.08)$ and adjusted $\mathrm{R}^{2}(0.06)$. This showed that the social background could predict $8 \%$ explanations of the variance of student achievements in relation to English grades and reported a significant effect $(p<.001)$ as seen in table 28.

Similarly, how do these predictors influence the French grades of the students? An examination showed that the French language grades had a coefficient of determination $\mathrm{R}^{2}(0.09)$, adjusted $\mathrm{R}^{2}(0.07)$ as seen from table 29 below. This indicated that the predictor variables explained $9 \%$ of variance of students outcomes related to the French language grades indicating also a significant effect $(\mathrm{p}<.001)$. This indicated that the social 
background has a stronger influence of $9 \%$ on French grades of the students when compared to the English language grades that was $8 \%$.

Table 29: Social Background Explaining French Grades

\begin{tabular}{ccccccc} 
Model & $\mathrm{R}^{2}$ & Adjusted $\mathrm{R}^{2}$ & $\mathrm{~F}$ & $\mathrm{df1}$ & $\mathrm{df2}$ & $\mathrm{P}$ \\
\hline 1 & 0.09 & 0.07 & 5.27 & 8 & 419 & $<.001$ \\
\hline
\end{tabular}

Source: Primary data, 2018

Moreover, does the social background have an influence on the mathematics grades of the students? The coefficient of determination of mathematics grades was $\mathrm{R}^{2}(0.04)$, adjusted $\mathrm{R}^{2}(0.02)$. This showed that the predictors could account for 4\% explanations of the students' achievement related to mathematics grades with a significant effect (p.023). This indicates that the social background has a moderate influence $4 \%$ on the mathematics grades of the students (table 28). The implication is the fact that mathematics grades are slightly influence by the social background of the students as this is less learned at home compared to languages.

Table 30: Social Background Explaining Mathematics

\begin{tabular}{ccccccc} 
Model & $\mathrm{R}^{2}$ & Adjusted $\mathrm{R}^{2}$ & $\mathrm{~F}$ & $\mathrm{df1}$ & $\mathrm{df} 2$ & $\mathrm{P}$ \\
\hline 1 & 0.04 & 0.02 & 2.26 & 8 & 417 & 0.023 \\
\hline
\end{tabular}

Source: Primary data, 2018

Lastly, what is the effect of the social background of the students on their ICT or science grades? The science grades presented a coefficient of determination in table 31 below of $\mathrm{R}^{2}(0.05)$, adjusted $\mathrm{R}^{2}(0.03)$. This therefore indicated that the social background accounted for $5 \%$ explanations of students' achievement in regards to science grades with a significant effect (p.001). 
Table 31: Social Background Explaining Science Grades

\begin{tabular}{lcccccc} 
Model & $\mathrm{R}^{2}$ & Adjusted $\mathrm{R}^{2}$ & $\mathrm{~F}$ & $\mathrm{df1}$ & $\mathrm{df2}$ & $\mathrm{P}$ \\
\hline 1 & 0.05 & 0.03 & 2.47 & 8 & 407 & 0.013 \\
\hline
\end{tabular}

Source: Primary data, 2018

In view of the results above, the social background indicates a significant effect on the study outcomes of the students. From the results, the socioeconomic status acts as a determinant to the performance at school. This shows a high degree of social injustice and a low quality of instruction, not being able to compensate the family background. This can be interpreted as a form of structural violence that does not allow young people free advancement and provides inadequate learning and schooling.

\subsubsection{Social Background and Experiences of Violence}

In the following, the relation between the social background and the experiences of violence is investigated. The social background has an influence on some of the different types of violence (table 32). 
Table 32: Effects of the Social Background on Different Types of Violence

\begin{tabular}{|c|c|c|c|c|c|c|c|}
\hline Predictors & $\begin{array}{c}\text { Physical } \\
\text { Victimization at } \\
\text { Home } \\
\text { Estimates }\end{array}$ & $\begin{array}{c}\begin{array}{c}\text { Physical } \\
\text { Victimization in } \\
\text { School }\end{array} \\
\text { Estimates }\end{array}$ & $\begin{array}{c}\begin{array}{c}\text { Psychological } \\
\text { Victimization }\end{array} \\
\text { Estimates }\end{array}$ & $\begin{array}{l}\begin{array}{c}\text { Structural } \\
\text { Violence }\end{array} \\
\text { Estimates }\end{array}$ & 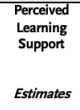 & $\begin{array}{c}\begin{array}{c}\text { Worries } \\
\text { Concerning } \\
\text { Family } \\
\text { Background }\end{array} \\
\text { Estimates }\end{array}$ & 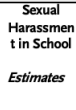 \\
\hline Intercepts & $\begin{array}{c}2.11^{\frac{1}{x-1}} \\
(0.21)\end{array}$ & $\begin{array}{l}1.78^{1 \times k} \times \\
(0.15)\end{array}$ & $\begin{array}{l}1.70^{+\alpha \cdot k x} \\
(0.22)\end{array}$ & $\begin{array}{c}2.06^{x+x+x} \\
(0.25)\end{array}$ & $\begin{array}{c}2.80^{* \alpha \times k} \\
(0.26)\end{array}$ & $\begin{array}{c}1.58^{2} \times x \times \\
(0.21)\end{array}$ & $\begin{array}{c}0.41 \\
(0.26)\end{array}$ \\
\hline Sex (Female) & $\begin{array}{l}-0.06 \\
(0.04)\end{array}$ & $\begin{array}{c}-0.13 * * * \\
(0.03)\end{array}$ & $\begin{array}{l}-0.04 \\
(0.05)\end{array}$ & $\begin{array}{l}-0.08 \\
(0.05)\end{array}$ & $\begin{array}{c}0.06 \\
(0.05)\end{array}$ & $\begin{array}{c}-0.12 * * \\
(0.04)\end{array}$ & $\begin{array}{l}-0.06 \\
(0.06)\end{array}$ \\
\hline Age & $\begin{array}{c}-0.03^{* x *} \\
(0.01)\end{array}$ & $\begin{array}{c}-0.02^{\text {कर }} \\
(0.01)\end{array}$ & $\begin{array}{c}0.00 \\
(0.01)\end{array}$ & $\begin{array}{c}-0.02 \\
(0.01)\end{array}$ & $\begin{array}{l}-0.00 \\
(0.01)\end{array}$ & $\begin{array}{c}0.01 \\
(0.01)\end{array}$ & 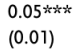 \\
\hline $\begin{array}{l}\text { Education } \\
\text { Mother } \\
\text { (Medium vs. } \\
\text { Low) }\end{array}$ & $\begin{array}{c}0.01 \\
(0.05)\end{array}$ & $\begin{array}{c}0.02 \\
(0.04)\end{array}$ & $\begin{array}{l}-0.07 \\
(0.06)\end{array}$ & $\begin{array}{l}-0.01 \\
(0.06)\end{array}$ & $\begin{array}{l}-0.03 \\
(0.06)\end{array}$ & $\begin{array}{c}0.02 \\
(0.05)\end{array}$ & $\begin{array}{c}-0.09 \\
(0.07)\end{array}$ \\
\hline $\begin{array}{l}\text { Education } \\
\text { Mother } \\
\text { (High vs. } \\
\text { Low) }\end{array}$ & $\begin{array}{c}0.04 \\
(0.08)\end{array}$ & $\begin{array}{c}0.04 \\
(0.06)\end{array}$ & $\begin{array}{c}0.04 \\
(0.08)\end{array}$ & $\begin{array}{c}0.12 \\
(0.09)\end{array}$ & $\begin{array}{l}-0.00 \\
(0.09)\end{array}$ & $\begin{array}{l}-0.01 \\
(0.08)\end{array}$ & $\begin{array}{c}0.00 \\
(0.10)\end{array}$ \\
\hline $\begin{array}{l}\text { Education } \\
\text { Father } \\
\text { (Medium vs. } \\
\text { Low) }\end{array}$ & $\begin{array}{c}-0.04 \\
(0.06)\end{array}$ & $\begin{array}{c}0.01 \\
(0.04)\end{array}$ & $\begin{array}{c}0.03 \\
(0.06)\end{array}$ & $\begin{array}{l}-0.04 \\
(0.07)\end{array}$ & $\begin{array}{c}0.02 \\
(0.07)\end{array}$ & $\begin{array}{c}0.09 \\
(0.06)\end{array}$ & $\begin{array}{l}-0.00 \\
(0.07)\end{array}$ \\
\hline $\begin{array}{l}\text { Education } \\
\text { Father (High } \\
\text { vs. Low) }\end{array}$ & $\begin{array}{c}0.05 \\
(0.07)\end{array}$ & $\begin{array}{c}0.01 \\
(0.05)\end{array}$ & $\begin{array}{c}0.07 \\
(0.08)\end{array}$ & $\begin{array}{c}0.05 \\
(0.09)\end{array}$ & $\begin{array}{l}-0.01 \\
(0.09)\end{array}$ & $\begin{array}{l}-0.01 \\
(0.07)\end{array}$ & $\begin{array}{c}-0.03 \\
(0.09)\end{array}$ \\
\hline Orphan & $\begin{array}{c}-0.09 \\
(0.10)\end{array}$ & $\begin{array}{c}-0.03 \\
(0.07)\end{array}$ & $\begin{array}{l}-0.16 \\
(0.10)\end{array}$ & $\begin{array}{l}-0.06 \\
(0.11)\end{array}$ & $\begin{array}{c}0.04 \\
(0.12)\end{array}$ & $\begin{array}{l}-0.13 \\
(0.10)\end{array}$ & $\begin{array}{c}0.18 \\
(0.12)\end{array}$ \\
\hline Refugee & $\begin{array}{c}-0.09 \\
(0.07)\end{array}$ & $\begin{array}{l}-0.05 \\
(0.05)\end{array}$ & $\begin{array}{l}-0.08 \\
(0.07)\end{array}$ & $\begin{array}{c}0.05 \\
(0.08)\end{array}$ & $\begin{array}{c}0.12 \\
(0.08)\end{array}$ & $\begin{array}{l}-0.11 \\
(0.06)\end{array}$ & $\begin{array}{l}-0.05 \\
(0.08)\end{array}$ \\
\hline Observations & 431 & 430 & 431 & 429 & 431 & 428 & 425 \\
\hline $\begin{array}{l}\mathrm{R}^{2} / \text { adjusted } \\
\mathrm{R}^{2}\end{array}$ & $\begin{array}{c}0.058 / \\
0.040\end{array}$ & $\begin{array}{c}0.075 / \\
0.057\end{array}$ & $\begin{array}{l}0.024 / \\
0.006\end{array}$ & $\begin{array}{c}0.044 / \\
0.026\end{array}$ & $\begin{array}{l}0.008 / \\
-0.010\end{array}$ & $\begin{array}{c}0.039 / \\
0.021\end{array}$ & $\begin{array}{l}0.069 \\
10.051\end{array}$ \\
\hline
\end{tabular}

Source: Primary data, 2018

Especially boys suffer from physical victimization at school. They have as well higher worries about their family background than the girls do. Age is indicating significant effects as physical victimization occur more often with younger students. However, older the students suffer significantly from sexual harassment (see similar findings by Zengarini, 2018). The education level of parents, the socio-economic status, and the status as orphans or as refugees, all do not significantly influence the different forms of experienced violence. 
Is there any influence between the social background and the victimization of the students at home? The statistics in table 33 below having physical victimization at home as the independent variable under consideration presents a coefficient of determination of $\mathrm{R}^{2}(0.06)$, adjusted $\mathrm{R}^{2}$ (0.04). Consequently, the background variables were able to predict a $6 \%$ explanation of variance of physical victimization at home from the responses of the students with a significant value $(\mathrm{p}<.001)$. This implies that the social background of the students has a significant influence of 6 $\%$ on the physical victimization of the students at home.

Table 33: Social Background on Physical Violence at Home

\begin{tabular}{lcccccc} 
Model & $\mathrm{R}^{2}$ & Adjusted $\mathrm{R}^{2}$ & $\mathrm{~F}$ & $\mathrm{df1}$ & $\mathrm{df2}$ & $\mathrm{P}$ \\
\hline 1 & 0.06 & 0.04 & 3.25 & 8 & 422 & 0.001 \\
\hline
\end{tabular}

Source: Primary data, 2018

How does the social background influence physical victimization of the students in school?

Table 34: Social Background on Physical Violence at school

\begin{tabular}{ccccccc} 
Model & $\mathrm{R}^{2}$ & Adjusted $\mathrm{R}^{2}$ & $\mathrm{~F}$ & $\mathrm{df1}$ & $\mathrm{df2}$ & $\mathrm{P}$ \\
\hline 1 & 0.07 & 0.06 & 4.24 & 8 & 421 & $<.001$ \\
\hline
\end{tabular}

Source: Primary data, 2018

In view of table 34 above, on physical victimization at school, the coefficient of determination was $\mathrm{R}^{2}(0.07)$, adjusted $\mathrm{R}^{2}(0.06)$. Hence, the social background is able to account for $7 \%$ variance explanations of the physical victimization suffered at school by the students and reported a significant statistical effect of ( $\mathrm{p}<$. 001). So not only parents from low social background use violence at home, however the low social background leads as well to experiences of physical violence at school. 
What is the influence of the social background on the psychological victimization of the students at school?

Table 35: Social Background on Psychlogical Violence

\begin{tabular}{ccccccc} 
Model & $\mathrm{R}^{2}$ & Adjusted $\mathrm{R}^{2}$ & $\mathrm{~F}$ & $\mathrm{df1}$ & $\mathrm{df2}$ & $\mathrm{P}$ \\
\hline 1 & 0.02 & 0.01 & 1.32 & 8 & 422 & 0.233 \\
\hline
\end{tabular}

Source: Primary data, 20018

The figures on table 35 on experiences of psychological violence at school provides a coefficient of determination of $\mathrm{R}^{2}(0.02)$, adjusted $\mathrm{R}^{2}(0.01)$ which is not significant. This indicates that the social background does not predict psychological victimization and bullying suffered in school by the students

Is there any influence of the social background on hostile environment? Table 36 indicate that the effect of social background on hostile environment in school came up with a coefficient of determination $\mathrm{R}^{2}$ (0.04), adjusted $\mathrm{R}^{2}(0.03)$. As such, the predictor variables were therefore able to explain $4 \%$ variance related to hostile environment in school by the students and presented a statistical significant value $(\mathrm{p}=0.014)$. This shows that the social background has a considerable influence on the hostile environment in school.

Table 36: Social Background on Hostile Environment in School

\begin{tabular}{ccccccc} 
Model & $\mathrm{R}^{2}$ & Adjusted $\mathrm{R}^{2}$ & $\mathrm{~F}$ & $\mathrm{df1}$ & $\mathrm{df2}$ & $\mathrm{P}$ \\
\hline 1 & 0.04 & 0.03 & 2.43 & 8 & 420 & 0.014 \\
\hline
\end{tabular}

Source: Primary data, 2018

How are the worries related to family background or communication influence by the social background of the students? The social background influences worries related to family indicating a coefficient of determination $R^{2}(0.04)$, adjusted $R^{2}(0.021)$. The social background could therefore account for $4 \%$ explanation of the variance of worries with a significant 
effect $(\mathrm{p}=0.030)$. This implies that the social background impart worries. Furtherance to this, when the social background or socio-economic situation is unstable, it indicates a drop in their study abilities thereby correlating to structural violence (see table 37).

Table 37: Social Background on Worries about Family Background

\begin{tabular}{lcrcccc} 
Model & $\mathrm{R}^{2}$ & Adjusted $\mathrm{R}^{2}$ & $\mathrm{~F}$ & $\mathrm{df} 1$ & $\mathrm{df2}$ & $\mathrm{P}$ \\
\hline 1 & 0.04 & 0.02 & 2.15 & 8 & 419 & 0.030 \\
\hline
\end{tabular}

Source: Primary data, 2018

What is the influence of the social background on perceived social support of the students?

Table 38: Social Background on Perceived Social Learning Support

\begin{tabular}{ccccccc} 
Model & $\mathrm{R}^{2}$ & Adjusted $\mathrm{R}^{2}$ & $\mathrm{~F}$ & $\mathrm{df1}$ & $\mathrm{df2}$ & $\mathrm{P}$ \\
\hline 1 & 0.01 & -0.01 & 0.452 & 8 & 422 & 0.889 \\
\hline
\end{tabular}

Source: Primary data, 2018

Table 38 indicated an $\mathrm{R}^{2}(0.008)$, adjusted $\mathrm{R}^{2}(-0.010)$. This predicted $0 \%$ of the variance explanations of perceived social learning support by students and indicated a non-significant statistical effect ( $p=0.89)$. This implied that the social background has no influence on the perceived social learning support of the students and indicating a poor quality of the school.

How does social background influence the sexual harassment of the students? The social background on sexual harassment in school presented a coefficient of determination $\mathrm{R}^{2}(0.07)$, adjusted $\mathrm{R}^{2}(0.051)$ and this indicated that the predictors could account for $7 \%$ explanation of the variance of sexual harassment in school with a significant effect $(p<.001)$ (see table 39). This shows that the social background has a significant influence on the sexual harassment suffered by students in school. As age 
was already mentioned as having an influence as well, especially older students from low social background might be effected.

Table 39: Social Background on Sexual Violence

\begin{tabular}{ccccccc} 
Model & $\mathrm{R}^{2}$ & Adjusted R & $\mathrm{F}$ & $\mathrm{df1}$ & $\mathrm{df2}$ & $\mathrm{P}$ \\
\hline 1 & 0.07 & 0.05 & 3.88 & 8 & 416 & $<.001$ \\
\hline
\end{tabular}

Source: Primary data, 2018

\subsubsection{Social Background, Experiences of Violence and Mediators of Learning}

In the following, the relation between different forms of violence on students' self-esteem and motivation will be under investigation. As described (chapter 3.1.2.2), scales on self-esteem included academic self-esteem, body self-esteem and general self-esteem. Motivation was measured as learning motivation and school motivation. Another mediator for learning is the status of health. All these aspects are related to the different forms of violence as physical violence, psychological violence (both at home and at school), structural violence (measured as worries on the family background, the hostile environment at school, and the perceived learning support) and sexual violence. Table 40 gives an overview about the findings. 
Table 40: Different Forms of Violence on the Students' Self-Esteem and Motivation

\begin{tabular}{|c|c|c|c|c|c|c|}
\hline Predictors & $\begin{array}{c}\text { Academic } \\
\text { Self-Esteem }\end{array}$ & $\begin{array}{l}\text { Body Self- } \\
\text { Esteem } \\
\text { Estimates }\end{array}$ & $\begin{array}{c}\text { General Self- } \\
\text { Esteem }\end{array}$ & $\begin{array}{c}\text { Learning } \\
\text { Motivation } \\
\text { Estimates }\end{array}$ & $\begin{array}{c}\text { School } \\
\text { Motivation } \\
\text { Estimates }\end{array}$ & $\begin{array}{c}\text { Health } \\
\text { Impairment } \\
\text { Estimates }\end{array}$ \\
\hline $\begin{array}{l}\text { Physical } \\
\text { Victimization } \\
\text { at Home }\end{array}$ & $\begin{array}{l}-0.08 \\
(0.12)\end{array}$ & $\begin{array}{c}0.08 \\
(0.10)\end{array}$ & $\begin{array}{c}0.01 \\
(0.07)\end{array}$ & $\begin{array}{l}-0.01 \\
(0.03)\end{array}$ & $\begin{array}{l}-0.09 \\
(0.05)\end{array}$ & $\begin{array}{l}-0.02 \\
(0.06)\end{array}$ \\
\hline $\begin{array}{l}\text { Physical } \\
\text { Victimization } \\
\text { at School }\end{array}$ & $\begin{array}{l}-0.10 \\
(0.17)\end{array}$ & $\begin{array}{c}-0.48 * x \\
(0.15)\end{array}$ & $\begin{array}{l}-0.13 \\
(0.10)\end{array}$ & $\begin{array}{l}-0.02 \\
(0.05)\end{array}$ & $\begin{array}{c}0.04 \\
(0.07)\end{array}$ & $\begin{array}{c}0.03 \\
(0.09)\end{array}$ \\
\hline $\begin{array}{l}\text { Psycholo- } \\
\text { gical } \\
\text { Victimization }\end{array}$ & $\begin{array}{l}-0.37 * * \\
(0.12)\end{array}$ & $\begin{array}{c}0.10 \\
(0.11)\end{array}$ & $\begin{array}{l}-0.16 * \\
(0.07)\end{array}$ & $\begin{array}{c}0.02 \\
(0.04)\end{array}$ & $\begin{array}{c}0.05 \\
(0.05)\end{array}$ & $\begin{array}{c}0.05 \\
(0.06)\end{array}$ \\
\hline $\begin{array}{l}\text { Worries } \\
\text { Concerning } \\
\text { Family } \\
\text { Background }\end{array}$ & 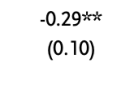 & $\begin{array}{l}-0.27 \times x \\
(0.09)\end{array}$ & $\begin{array}{c}-0.25^{\text {* } * x} \\
(0.06)\end{array}$ & $\begin{array}{l}-0.01 \\
(0.03)\end{array}$ & $\begin{array}{c}-0.30^{*-k \dot{x}} \\
(0.04)\end{array}$ & $\begin{array}{c}0.07 \\
(0.05)\end{array}$ \\
\hline $\begin{array}{l}\text { Hostile } \\
\text { Environment } \\
\text { at School }\end{array}$ & $\begin{array}{c}0.02 \\
(0.09)\end{array}$ & $\begin{array}{c}0.06 \\
(0.08)\end{array}$ & $\begin{array}{c}0.02 \\
(0.05)\end{array}$ & $\begin{array}{l}-0.01 \\
(0.03)\end{array}$ & $\begin{array}{l}-0.02 \\
(0.03)\end{array}$ & $\begin{array}{c}0.01 \\
(0.04)\end{array}$ \\
\hline $\begin{array}{l}\text { Perceived } \\
\text { Learning } \\
\text { Support }\end{array}$ & $\begin{array}{l}-0.05 \\
(0.09)\end{array}$ & $\begin{array}{c}0.38 * k * k \\
(0.08)\end{array}$ & $\begin{array}{c}0.20 * x * \\
(0.05)\end{array}$ & $\begin{array}{c}0.13 * k x \\
(0.03)\end{array}$ & $\begin{array}{l}0.09 \% \\
(0.04)\end{array}$ & $\begin{array}{c}-0.17 \hbar k * k \\
(0.05)\end{array}$ \\
\hline $\begin{array}{l}\text { Sexual } \\
\text { Harassment }\end{array}$ & $\begin{array}{l}-0.07 \\
(0.09)\end{array}$ & $\begin{array}{l}-0.01 \\
(0.08)\end{array}$ & $\begin{array}{l}-0.01 \\
(0.05)\end{array}$ & $\begin{array}{c}0.01 \\
(0.03)\end{array}$ & $\begin{array}{l}-0.02 \\
(0.03)\end{array}$ & $\begin{array}{l}-0.05 \\
(0.04)\end{array}$ \\
\hline $\begin{array}{l}\text { Observations } \\
\mathrm{R}^{2} / \\
\text { Adjusted } \mathrm{R}^{2}\end{array}$ & $\begin{array}{l}422 \\
0.123 / \\
0.090\end{array}$ & $\begin{array}{l}422 \\
0.138 / \\
0.106\end{array}$ & $\begin{array}{l}422 \\
0.145 / \\
0.113\end{array}$ & $\begin{array}{l}422 \\
0.084 / \\
0.050\end{array}$ & $\begin{array}{l}422 \\
0.210 / \\
0.181\end{array}$ & $\begin{array}{l}421 \\
0.089 / \\
0.055\end{array}$ \\
\hline
\end{tabular}

Source: Primary data, 2018

It can be seen in table 40 that some different forms of violence have effects on the mediating variables self-esteem, motivation in school and health impairment. Physical victimization at school has an effect on body-related self-esteem, which indicates that the higher the physical victimization at school gets, the lower the body self-esteem of the students gets. Moreover, psychological violence as bullying shows negative effects on academic and general self-esteem. This also implies that the higher the psychological victimization and bullying, the lower the academic and general self-esteem of the student gets. 
Very striking are the worries about the family background or communication as forms of structural violence on effects throughout all the different forms of self-esteem, and school motivation. This indicates that the more the students worry about their family background, their different self-esteem and motivation is significantly hamper or affected, and less worry about the family background strengthens their different levels of self-esteem and motivation. No variation has been explain related to sexual harassment from any of the mediating variables. Perceived support has an influence as the higher the perceived social support, the higher their different esteems get including their motivation and health. This is as well an indicator of structural violence as indicating that missing learning support effects negatively the self-esteem and motivation.

In regards to a general explanation of the independent variables (forms of violence) on the mediating variables (self-esteem and motivation), how then is the academic self-esteem influenced by the social background including the violence at home and at school? Table 41 reports the prediction of violence to academic self-esteem. As it was described before, social background does show an influence violence as well on the learning output. As academic self-esteem is a mediator for learning output, first the influence of the social background on the academic self-esteem will be reported (model 1); then violence will be included (model 2) and then both models will be compared.

Table 41: Social Background and Violence predicting Academic Self-Esteem

\begin{tabular}{|c|c|c|c|c|c|c|}
\hline \multirow[b]{2}{*}{ Model } & \multirow[b]{2}{*}{$\mathbf{R}^{2}$} & \multirow[b]{2}{*}{ Adjusted $\mathrm{R}^{2}$} & \multicolumn{4}{|c|}{ Overall Model Test } \\
\hline & & & $\mathrm{F}$ & df1 & df2 & $\mathbf{p}$ \\
\hline 1 & 0.02 & 0.01 & 1.29 & 8 & 413 & 0.245 \\
\hline 2 & 0.12 & 0.10 & 3.78 & 15 & 406 & $<.001$ \\
\hline \multicolumn{2}{|c|}{ Comparison } & \multirow[b]{2}{*}{$\Delta R^{2}$} & \multirow[b]{2}{*}{$\mathbf{F}$} & \multirow[b]{2}{*}{ df1 } & \multirow[b]{2}{*}{ df2 } & \multirow[b]{2}{*}{ p } \\
\hline Model & Model & & & & & \\
\hline 1 & 2 & 0.0982 & 6.49 & 7 & 406 & $<.001$ \\
\hline
\end{tabular}

Source: Primary data, 2018 
Table 41 reports the results of a linear regression analysis predicting academic self-esteem from experienced violence. As it was described before, social background significantly predicts violence as well as learning output. As academic self-esteem is assumed to be a mediator for learning output, first the influence of the social background on the academic selfesteem will be reported (model 1); then violence will be included (model 2) and then both models will be compared.

The calculation shows that the social background does not significantly predict self-esteem $(\mathrm{p}=.245)$. Also, $\mathrm{R}^{2}(0.02)$ and adjusted $\mathrm{R}^{2}(0.01)$ are low. However, the inclusion of the different types of violence as independent variables raises the coefficient of determination to $\mathrm{R}^{2}=0.12$ (adjusted $\left.\mathrm{R}^{2}=0.09\right)$, which becomes significant $(\mathrm{p}=<.001)$. This means that social background in combination with different types of violence explain $12 \%$ of the variance in academic self-esteem with a difference of $\Delta \mathrm{R}^{2}=$ $0.098(\mathrm{p}=<.001)$. This shows that experienced violence may substantially affect academic self-esteem.

In like manner, what is the influence of the social background and experienced violence on the body self-esteem of students? This is reported in the following table (table 42).

Table 42: Social Background and Violence Predicting Body Self-Esteem

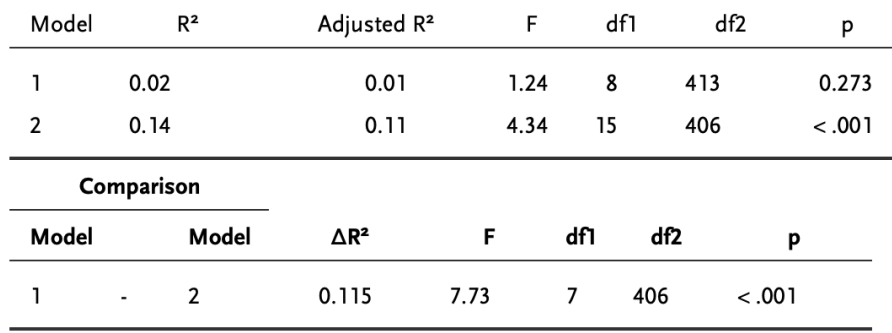

Source: Primary data, 2018

As for the academic self-esteem, body self-esteem is not influenced by the social background, however by social background and experienced violence. The social background showed a coefficient of determination, $\mathrm{R}^{2}$ (0.02), adjusted $R^{2}(0.01)$ with an insignificant effect $(p=0.237)$. Including 
the forms of violence raised the coefficient of determination $\mathrm{R}^{2}$ to 0.14 (adjusted $\mathrm{R}^{2} \mathrm{0.11}$ ). That means that these factors explain 14\% of the variance on body self-esteem with a significant effect $(\mathrm{p}=<.001)$ and a difference $\left(\Delta R^{2}=11\right)$ indicating a significant effect $(p<.001)$ for the whole model. This shows that experiences of violence have a negative influence on body self-esteem of the students.

As well, the general self-esteem was measured, the influence of social background and experiences of violence to the general self-esteem is reported (table 43).

Table 43: Social Background and Violence predicting General Self-Esteem

\begin{tabular}{lccccccc} 
Model & $\mathrm{R}^{2}$ & Adjusted $\mathrm{R}^{2}$ & $\mathrm{~F}$ & $\mathrm{df1}$ & $\mathrm{df2}$ & $\mathrm{P}$ \\
\hline 1 & 0.01 & -0.01 & 0.607 & 8 & 413 & 0.772 \\
2 & 0.14 & 0.11 & 4.574 & 15 & 406 & $<.001$ \\
\hline \multirow{2}{*}{ Model } & Model & $\Delta \mathrm{R}^{2}$ & $\mathrm{~F}$ & $\mathrm{df1}$ & $\mathrm{df2}$ & $\mathrm{P}$ \\
\hline 1 & 2 & 0.133 & 9.01 & 7 & 406 & $<.001$ & \\
\hline
\end{tabular}

Source: Primary data, 2018

Table 43 showed that the social background as predictor had a coefficient determinant of $\mathrm{R}^{2}(0.01)$, adjusted $\mathrm{R}^{2}(-0.01)$. This indicated that these predictors do not have a significant influence on the general self-esteem $(\mathrm{p}=$ 0.772). The inclusion of the different types of violence as independent variable led to an increase in the coefficient of determination $\mathrm{R}^{2}$ to 0.14 and adjusted to $\mathrm{R}^{2}=0.11$. This indicated a variance explanation of $14 \%$ with the addition of the violence to the social background on general self-esteem having a significant effect $(\mathrm{p}<.001)$. The difference was pegged at $\left(\Delta R^{2}=13\right)$, with a significant effect $(p<.001)$ for the entire model.

To summarize, experienced forms of violence, controlled by the social background do therefore have an influence on the general self-esteem, the body self-esteem and the academic self-esteem.

Moreover, what is the effect of the social background and the forms of experienced violence on the learning motivation of the students? (Table 44) 
Table 44: Social Background and Violence Predicting Learning Motiviation

\begin{tabular}{|c|c|c|c|c|c|c|}
\hline Model & $\mathrm{R}^{2}$ & Adjusted $\mathrm{R}^{2}$ & $\mathrm{~F}$ & $\mathrm{df} 1$ & $\mathrm{df} 2$ & $p$ \\
\hline 1 & 0.02 & 0.00 & 1.14 & 8 & 413 & 0.336 \\
\hline 2 & 0.08 & 0.05 & 2.47 & 15 & 406 & 0.002 \\
\hline \multicolumn{2}{|c|}{ Comparison } & & & & & \\
\hline Model & Model & $\Delta R^{2}$ & $F$ & df1 & $d f 2$ & $\mathrm{p}$ \\
\hline 1 & 2 & 0.0621 & 3.93 & 7 & 406 & $<.001$ \\
\hline
\end{tabular}

Source: Primary data, 2018

The model on table 44 shows that the first model in calculating the influence of the social background on Learning motivation presented a coefficient of determination of $\mathrm{R}^{2}(0.02)$ adjusted $\mathrm{R}^{2}(0.00)$ showing an insignificant effect ( $p=0.336$ ). The addition of the variables of the different types of violence showed an increase in the coefficient of determination $\mathrm{R}^{2}$ (0.08), adjusted at $\mathrm{R}^{2}(0.05)$. This therefore indicated an explanation of $8 \%$ variance of learning motivation with a significant effect $(\mathrm{p}=0.002)$. The difference was $\left(\Delta \mathrm{R}^{2}=06\right)$, and a combine significant effect $(\mathrm{p}<.001)$ of the whole model. This implies that experienced violence explains $8 \%$ variation on the learning motivation.

Further still, how is school motivation influenced by social background and the different experiences of violence by the students at home and in school? 
Table 45: Social Background and Violence Predicting School Motivation

\begin{tabular}{lcccccc} 
Model & $\mathbf{R}^{2}$ & Adjusted $\mathbf{R}^{2}$ & $\mathbf{F}$ & $\mathbf{d f 1}$ & $\mathbf{d f 2}$ & $\mathbf{P}$ \\
\hline 1 & 0.07 & 0.05 & 3.87 & 8 & 413 & $<.001$ \\
2 & 0.21 & 0.18 & 7.21 & 15 & 406 & $<.001$ \\
\hline
\end{tabular}

\begin{tabular}{cccccccc}
\multicolumn{2}{c}{ Comparison } & & & & & \\
\cline { 1 - 2 } Model & Model & & $\Delta \mathbf{R}^{\mathbf{2}}$ & $\mathbf{F}$ & $\mathbf{d f 1}$ & $\mathrm{df2}$ & $\mathbf{P}$ \\
\hline 1 & 2 & & 0.140 & 10.3 & 7 & 406 & $<.001$ \\
\hline
\end{tabular}

Source: Primary data, 2018

In table 45, the social background on school motivation had a coefficient of determination of $\mathrm{R}^{2}(0.07)$, adjusted $\mathrm{R}^{2}(0.05)$, showing that the social background was able to explain $6 \%$ of variance related to school motivation having a significant effect $(\mathrm{p}<.001)$. Adding various types of violence raised the coefficient of determination to $\mathrm{R}^{2}$ to 0.21$)$, adjusted to $\mathrm{R}^{2}(0.18)$. The experiences of violence and the social background were therefore able to explain $21 \%$ of variance of school motivation having a significant effect $(\mathrm{p}=<.001)$ for the whole model, a difference $\left(\Delta \mathrm{R}^{2}=14\right)$. This shows that the social background and the different types of violence do have a significant influence on the school motivation of the students. The social background has indicated a $6 \%$ variance explanation and the different experiences of violence presented $21 \%$ variance in school motivation. The implication of this is that the social background and the different types of violence strongly and negatively influence the school motivation of the students.

Lastly, is there any influence by the social background and the different forms of violence at home and in school on the health impairment of the students? Table 46 indicates that the social background showed a coefficient of determination $\mathrm{R}^{2}(0.04)$ and adjusted to $\mathrm{R}^{2}(0.02)$. Here, the social background explained $4 \%$ of the variance of the health impairment with a significant effect $(p=0.021)$. With the inclusion of the types of violence at home and in school, it led to a slight addition in the coefficient of determination $\mathrm{R}^{2}(0.09)$ and was adjusted $\mathrm{R}^{2}(0.05)$. This means that social background and experienced violence explain about $9 \%$ of the variance 
on health impairment and had a significant effect $(\mathrm{p}<.001)$ and indicating a difference of $\left(\Delta \mathrm{R}^{2}=04\right)$, and a significant effect for the whole model ( $\mathrm{p}$ $<.001)$. This therefore showed that the social background had a considerable influence of $4 \%$ while the experienced violence indicated in addition and influence on the health impairment of students about $9 \%$.

Table 46: Social Background and Violence Predicting Health Impairment

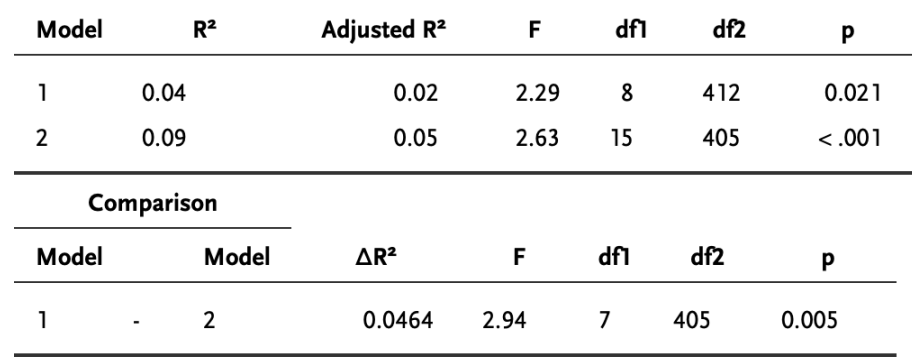

Source: Primary data, 2018

To summarize, the study showed that the experienced violence does effect the academic self-esteem, the body self-esteem and the general self-esteem. It does effect the learning motivation and the motivation to visit a school and it has consequences for the health of the students. How this now influences the learning output will be examined in the next chapter.

\subsubsection{Social Background, Experiences of Violence, Mediators of Learn- ing and Learning Outcome}

In the following, the relation between different forms of violence and the learning output will be under investigation. Violence is differentiated into physical violence, psychological violence, structural violence and sexual violence. As described (chapter 3.1.2.3), the learning output was operationalized by grades in different school subjects, by time dedicated to reading and by the repetition of class. As introduced (chapter 2.3), violence is mediated to the learning output by self-concept, motivation and health. Social background is as well influencing all aspects and needs therefore to be statistically controlled. Table 47 gives an overview about the findings. 
A critical examination of the statistics on table 47 shows that there are hardly any direct effects of all the independent variables on the outcomes which becomes significant. What is visible is that hostile environment at school has a negative effect on extra reading and the worries on family background has a negative effect on French grades. General self-esteem has positive effects on science grades and school motivation.

I am going to use the following subchapter to explain the relations further by a detailed examination of each of the variables. First, I will look at the effects of violence, self-esteem, motivation on class repetition, controlled by the social background (table 48). 
Table 47: Effects of Violence, Self-Esteem and Motivation on School Grades (Estimates from full Models, Control Variables not displayed)

\begin{tabular}{|c|c|c|c|c|c|c|c|c|c|c|c|c|}
\hline Predictors & $\begin{array}{l}\text { Class } \\
\text { Repetitio } \\
\text { n } \\
\text { (M2) } \\
\text { Estimate } \\
\text { s }\end{array}$ & $\begin{array}{l}\text { Class } \\
\text { Repetition } \\
\text { (M3) } \\
\text { Estimate } \\
\text { s }\end{array}$ & $\begin{array}{l}\text { Extra } \\
\text { Reading } \\
\text { (M2) } \\
\text { Estimate } \\
\text { s }\end{array}$ & $\begin{array}{l}\text { Extra } \\
\text { Reading } \\
\text { (M3) } \\
\text { Estimate } \\
\mathbf{s}\end{array}$ & $\begin{array}{l}\text { English } \\
\text { Grades } \\
\text { (M2) } \\
\text { Estimate } \\
\text { s }\end{array}$ & $\begin{array}{l}\text { English } \\
\text { Grades } \\
\text { (M3 } \\
\text { Estimate } \\
\text { s }\end{array}$ & $\begin{array}{l}\text { French } \\
\text { Grades } \\
\text { (M2) } \\
\text { Estimate } \\
\text { s }\end{array}$ & $\begin{array}{l}\text { French } \\
\text { Grades } \\
\text { (M3) } \\
\text { Estimate } \\
\text { s }\end{array}$ & $\begin{array}{l}\text { Math } \\
\text { Grades } \\
\text { (M2) } \\
\text { Estimate } \\
\text { s }\end{array}$ & $\begin{array}{l}\text { Math } \\
\text { Grades } \\
\text { (M3) } \\
\text { Estimate } \\
\text { s }\end{array}$ & $\begin{array}{l}\text { Science } \\
\text { Grades } \\
\text { (M2) } \\
\text { Estimate } \\
\text { s }\end{array}$ & $\begin{array}{l}\text { Science } \\
\text { Grades } \\
\text { (M3) } \\
\text { Estimate } \\
\text { s }\end{array}$ \\
\hline $\begin{array}{l}\text { Physical } \\
\text { Victimizatio } \\
n \\
\text { at home }\end{array}$ & $\begin{array}{l}-0.04 \\
(0.09)\end{array}$ & $\begin{array}{l}-0.05 \\
(0.09)\end{array}$ & $\begin{array}{c}0.33 \\
(0.18)\end{array}$ & $\begin{array}{c}0.31 \\
(0.19)\end{array}$ & $\begin{array}{l}-0.22 \\
(0.16)\end{array}$ & $\begin{array}{l}-0.19 \\
(0.16)\end{array}$ & $\begin{array}{c}0.18 \\
(0.15)\end{array}$ & $\begin{array}{l}-0.15 \\
(0.17)\end{array}$ & $\begin{array}{l}-0.15 \\
(0.17)\end{array}$ & $\begin{array}{l}-0.11 \\
(0.17)\end{array}$ & $\begin{array}{c}0.20 \\
(0.17)\end{array}$ & $\begin{array}{c}0.20 \\
(0.17)\end{array}$ \\
\hline $\begin{array}{l}\text { Physical } \\
\text { Victimizatio } \\
\mathrm{n} \\
\text { at School }\end{array}$ & $\begin{array}{c}0.06 \\
(0.12)\end{array}$ & $\begin{array}{c}0.07 \\
(0.13)\end{array}$ & $\begin{array}{c}0.15 \\
(0.27)\end{array}$ & $\begin{array}{c}0.20 \\
(0.27)\end{array}$ & $\begin{array}{c}0.12 \\
(0.22)\end{array}$ & $\begin{array}{c}0.09 \\
(0.22)\end{array}$ & $\begin{array}{c}0.15 \\
(0.22)\end{array}$ & $\begin{array}{c}0.12 \\
(0.22)\end{array}$ & $\begin{array}{c}0.11 \\
(0.25)\end{array}$ & $\begin{array}{c}0.12 \\
(0.25)\end{array}$ & $\begin{array}{l}-0.08 \\
(0.25)\end{array}$ & $\begin{array}{l}-0.02 \\
(0.25)\end{array}$ \\
\hline $\begin{array}{l}\text { Psychologic } \\
\text { al } \\
\text { Victimizatio } \\
\text { n }\end{array}$ & $\begin{array}{c}0.07 \\
(0.09)\end{array}$ & $\begin{array}{c}0.04 \\
(0.09)\end{array}$ & $\begin{array}{l}-0.11 \\
(0.20)\end{array}$ & $\begin{array}{l}-0.11 \\
(0.20)\end{array}$ & $\begin{array}{c}0.20 \\
(0.16)\end{array}$ & $\begin{array}{c}0.23 \\
(0.17)\end{array}$ & $\begin{array}{l}-0.09 \\
(0.16)\end{array}$ & $\begin{array}{l}-0.04 \\
(0.16)\end{array}$ & $\begin{array}{l}-0.19 \\
(0.18)\end{array}$ & $\begin{array}{l}-0.17 \\
(0.18)\end{array}$ & $\begin{array}{l}-0.05 \\
(0.18)\end{array}$ & $\begin{array}{c}0.03 \\
(0.18)\end{array}$ \\
\hline $\begin{array}{l}\text { Worries } \\
\text { Concerning } \\
\text { Family } \\
\text { Background }\end{array}$ & $\begin{array}{l}0.03 \\
(0.08)\end{array}$ & $\begin{array}{l}-0.04 \\
(0.08)\end{array}$ & $\begin{array}{l}-0.04 \\
(0.17)\end{array}$ & $\begin{array}{c}0.00 \\
(0.18)\end{array}$ & $\begin{array}{l}-0.12 \\
(0.14)\end{array}$ & $\begin{array}{c}0.02 \\
(0.15)\end{array}$ & $\begin{array}{l}-0.28^{*} \\
(0.14)\end{array}$ & $\begin{array}{l}-0.22 \\
(0.15)\end{array}$ & $\begin{array}{l}-0.22 \\
(0.16)\end{array}$ & $\begin{array}{l}-0.02 \\
(0.17)\end{array}$ & $\begin{array}{l}-0.24 \\
(0.16)\end{array}$ & $\begin{array}{l}-0.20 \\
(0.17)\end{array}$ \\
\hline $\begin{array}{l}\text { Hostile } \\
\text { Environmen } \\
t \text { at School }\end{array}$ & $\begin{array}{l}-0.11 \\
(0.06)\end{array}$ & $\begin{array}{l}-0.11 \\
(0.06)\end{array}$ & $\begin{array}{l}-0.34 \text { ' } \\
(0.14)\end{array}$ & $\begin{array}{l}-0.35^{*} \\
(0.14)\end{array}$ & $\begin{array}{c}0.11 \\
(0.11)\end{array}$ & $\begin{array}{c}0.12 \\
(0.11)\end{array}$ & $\begin{array}{l}-0.04 \\
(0.11)\end{array}$ & $\begin{array}{l}-0.03 \\
(0.11)\end{array}$ & $\begin{array}{c}0.06 \\
(0.12)\end{array}$ & $\begin{array}{c}0.06 \\
(0.12)\end{array}$ & $\begin{array}{l}-0.14 \\
(0.12)\end{array}$ & $\begin{array}{l}-0.14 \\
(0.12)\end{array}$ \\
\hline $\begin{array}{l}\text { Perceived } \\
\text { Social } \\
\text { Learning } \\
\text { Support }\end{array}$ & $\begin{array}{l}0.07 \\
(0.06)\end{array}$ & $\begin{array}{c}0.06 \\
(0.07)\end{array}$ & $\begin{array}{c}0.10 \\
(0.14)\end{array}$ & $\begin{array}{c}0.08 \\
(0.15)\end{array}$ & $\begin{array}{c}0.13 \\
(0.12)\end{array}$ & $\begin{array}{c}0.05 \\
(0.12)\end{array}$ & $\begin{array}{l}-0.05 \\
(0.11)\end{array}$ & $\begin{array}{l}-0.12 \\
(0.12)\end{array}$ & $\begin{array}{l}-0.02 \\
(0.13)\end{array}$ & $\begin{array}{l}-0.10 \\
(0.14)\end{array}$ & $\begin{array}{c}0.24 \\
(0.13)\end{array}$ & $\begin{array}{c}0.17 \\
(0.14)\end{array}$ \\
\hline $\begin{array}{l}\text { Sexual } \\
\text { Harassmen } \\
t \text { at School }\end{array}$ & $\begin{array}{l}0.11 \\
(0.06)\end{array}$ & $\begin{array}{c}0.09 \\
(0.06)\end{array}$ & $\begin{array}{l}-0.06 \\
(0.14)\end{array}$ & $\begin{array}{l}-0.05 \\
(0.14)\end{array}$ & $\begin{array}{l}-0.20 \\
(0.11)\end{array}$ & $\begin{array}{l}-0.19 \\
(0.11)\end{array}$ & $\begin{array}{c}0.06 \\
(0.11)\end{array}$ & $\begin{array}{c}0.05 \\
(0.11)\end{array}$ & $\begin{array}{c}0.01 \\
(0.12)\end{array}$ & $\begin{array}{c}0.02 \\
(0.12)\end{array}$ & $\begin{array}{c}0.09 \\
(0.12)\end{array}$ & $\begin{array}{c}0.09 \\
(0.12)\end{array}$ \\
\hline $\begin{array}{l}\text { Academic } \\
\text { Self-Esteem }\end{array}$ & & $\begin{array}{l}-0.04 \\
(0.04)\end{array}$ & & $\begin{array}{c}0.02 \\
(0.09)\end{array}$ & & $\begin{array}{l}-0.07 \\
(0.07)\end{array}$ & & $\begin{array}{c}0.04 \\
(0.07)\end{array}$ & & $\begin{array}{c}0.05 \\
(0.08)\end{array}$ & & $\begin{array}{c}0.08 \\
(0.08)\end{array}$ \\
\hline $\begin{array}{l}\text { Body Self- } \\
\text { Esteem }\end{array}$ & & $\begin{array}{c}0.03 \\
(0.04)\end{array}$ & & $\begin{array}{c}0.11 \\
(0.10)\end{array}$ & & $\begin{array}{l}-0.12 \\
(0.08)\end{array}$ & & $\begin{array}{c}0.13 \\
(0.08)\end{array}$ & & $\begin{array}{c}0.02 \\
(0.09)\end{array}$ & & $\begin{array}{l}-0.02 \\
(0.09)\end{array}$ \\
\hline $\begin{array}{l}\text { General } \\
\text { Self-Esteem }\end{array}$ & & $\begin{array}{l}-0.11 \\
(0.07)\end{array}$ & & $\begin{array}{c}0.02 \\
(0.15)\end{array}$ & & $\begin{array}{l}0.43^{*} \times \dot{x} \\
(0.13)\end{array}$ & & $\begin{array}{c}0.17 \\
(0.12)\end{array}$ & & $\begin{array}{c}0.16 \\
(0.14)\end{array}$ & & $\begin{array}{c}0.28^{*} \\
(0.14)\end{array}$ \\
\hline $\begin{array}{l}\text { Learning } \\
\text { Motivation }\end{array}$ & & $\begin{array}{c}0.06 \\
(0.13)\end{array}$ & & $\begin{array}{l}-0.06 \\
(0.27)\end{array}$ & & $\begin{array}{c}0.15 \\
(0.23)\end{array}$ & & $\begin{array}{c}0.43 \\
(0.22)\end{array}$ & & $\begin{array}{l}-0.07 \\
(0.25)\end{array}$ & & $\begin{array}{c}0.37 \\
(0.25)\end{array}$ \\
\hline $\begin{array}{l}\text { School } \\
\text { Motivation }\end{array}$ & & $\begin{array}{l}-0.12 \\
(0.09)\end{array}$ & & $\begin{array}{c}0.01 \\
(0.20)\end{array}$ & & $\begin{array}{c}0.29 \\
(0.16)\end{array}$ & & $\begin{array}{c}0.08 \\
(0.16)\end{array}$ & & $\begin{array}{c}0.43^{*} \\
(0.18)\end{array}$ & & $\begin{array}{l}-0.16 \\
(0.18)\end{array}$ \\
\hline $\begin{array}{l}\text { Health } \\
\text { Impairment }\end{array}$ & & $\begin{array}{l}-0.07 \\
(0.07)\end{array}$ & & $\begin{array}{c}0.11 \\
(0.15)\end{array}$ & & $\begin{array}{c}0.06 \\
(0.13)\end{array}$ & & $\begin{array}{l}-0.15 \\
(0.12)\end{array}$ & & $\begin{array}{l}-0.07 \\
(0.14)\end{array}$ & & $\begin{array}{c}0.08 \\
(0.14)\end{array}$ \\
\hline Observation & 412 & 411 & 417 & 416 & 420 & 420 & 421 & 420 & 419 & 419 & 410 & 410 \\
\hline $\begin{array}{l}\mathrm{R}^{2} / \\
\text { Adjusted } \mathrm{R}^{2}\end{array}$ & $\begin{array}{l}0.335 \\
10.309\end{array}$ & $\begin{array}{l}0.348 \\
10.313\end{array}$ & $\begin{array}{l}0.125 \\
/ 0.092\end{array}$ & $\begin{array}{l}0.128 \\
/ 0.082\end{array}$ & $\begin{array}{l}0.098 \\
10.065\end{array}$ & $\begin{array}{l}0.138 \\
10.093\end{array}$ & $\begin{array}{l}0.109 \\
/ 0.076\end{array}$ & $\begin{array}{l}0.133 \\
/ 0.088\end{array}$ & $\begin{array}{l}0.057 \\
/ 0.022\end{array}$ & $\begin{array}{l}0.083 \\
/ 0.034\end{array}$ & $\begin{array}{l}0.073 \\
10.038\end{array}$ & $\begin{array}{l}0.101 \\
/ 0.053\end{array}$ \\
\hline
\end{tabular}

Source: Primary Data, 2018 
Table 48: Summary of Combined Predictors on Class Repetition

\begin{tabular}{lcccccc} 
& & & \multicolumn{4}{c}{ Overall Model Test } \\
\cline { 5 - 8 } Model & $\mathbf{R}^{\mathbf{2}}$ & Adjusted $\mathbf{R}^{\mathbf{2}}$ & $\mathbf{F}$ & $\mathbf{d f 1}$ & $\mathbf{d f 2}$ & $\mathbf{P}$ \\
\hline 1 & 0.32 & 0.31 & 23.71 & 8 & 402 & $<.001$ \\
2 & 0.33 & 0.31 & 13.20 & 15 & 395 & $<.001$ \\
3 & 0.35 & 0.31 & 9.91 & 21 & 389 & $<.001$ \\
\hline
\end{tabular}

\begin{tabular}{|c|c|c|c|c|c|c|}
\hline \multicolumn{2}{|c|}{ Comparison } & \multirow[b]{2}{*}{$\Delta \mathrm{R}^{2}$} & \multirow[b]{2}{*}{$\mathbf{F}$} & \multirow[b]{2}{*}{ df1 } & \multirow[b]{2}{*}{ df2 } & \multirow[b]{2}{*}{$\mathbf{p}$} \\
\hline Model & Model & & & & & \\
\hline 1 & 2 & 0.0133 & 1.13 & 7 & 395 & 0.345 \\
\hline 2 & 3 & 0.0146 & 1.45 & 6 & 389 & 0.194 \\
\hline
\end{tabular}

Source: Primary data, 2018

On table 48 with the first model having the social background as the control variables (model 1 ), the coefficient of determination is $\mathrm{R}^{2}(0.32)$, adjusted to $R^{2}(0.31)$. This shows that the social background explains $32 \%$ of the variance of class repetition indicating a significant effect $(\mathrm{p}<.001)$. This led to the inclusion of experienced violence (model 2), showing a coefficient of determination of $\mathrm{R}^{2}(0.33)$, adjusted $\mathrm{R}^{2}(0.31)$. Hence, these predictors were able to explain $33 \%$ of variance on the class repetition and had a significant effect $(\mathrm{p}<.001)$ showing a difference of $\left(\Delta \mathrm{R}^{2}=01\right)$ and an $\mathrm{f}$ value of (1.13) but with an insignificant output $(\mathrm{P}=.345)$. This led to the addition of the mediating variables self-esteem and motivation (model 3 ), which, resulted to a coefficient of determination $\mathrm{R}^{2}(0.35)$, adjusted value $\mathrm{R}^{2}$ (0.31). It was therefore used to explained $35 \%$ variance on class repetition with a significant effect $(\mathrm{p}<.001)$ and led to a slight additional difference of $\left(\Delta R^{2}=01\right)$ and an $f$ value (1.45) with an insignificant effect for the combine model (p.194). This shows that violence does not have a huge impact on the school output and that the social background is the biggest predictor. As in the previous chapter it was shown that violence had an influence on the mediators; it becomes here visible that the mediators do not have a considerable impact on learning and therefore the experienced 
violence does not have a huge impact either. This indicates poor instructional quality and a loose relation between psychological dispositions for learning and the learning output in form of class repetition.

Regarding the dependent variable of extra reading, what is the effect that the social background, the different levels of violence as of the mediators' (self-esteem and motivation) have on it? Looking at table 49, the social background had a coefficient of determination of $\mathrm{R}^{2}(0.10)$, adjusted $R^{2}(0.08)$. It indicated that the social background explained $10 \%$ of the variance on extra reading and having a significant effect $(\mathrm{p}<.001)$. The addition of the different forms of violence led to a coefficient of determination $\mathrm{R}^{2}(0.12)$ and when adjusted, to $\mathrm{R}^{2}(0.09)$. In view of this, the different forms of violence were able to explain $12 \%$ variance of extra reading. It came up with a significant effect $(\mathrm{p}<.001)$ and a difference of $\left(\Delta \mathrm{R}^{2}=02\right)$ with an insignificant effect $(\mathrm{p}=0.118)$. The inclusion of self-esteem and motivation in the model showed a coefficient of determination $\mathrm{R}^{2}(0.13)$, adjusted to $\mathrm{R}^{2}(0.08)$. This therefore meant that this explains $13 \%$ variance of extra reading and still indicating a significant effect $(\mathrm{p}<.001)$. The difference $\left(\Delta R^{2}=00\right)$ shows no addition in variance explanation with an $f$ value $(0.346)$ with an insignificant effect ( $p$.912) for the whole model. This implies that social background has a strong effect of $9 \%$ on extra reading of the students and when related to the different forms of violence, it resulted to an increase explanation of $13 \%$ and the further inclusion of selfesteem and motivation still led to $13 \%$, the differences however did not become significant. This therefore means that the social background dominates the lack of extra reading. This as well underlines the already mentioned situation that the learning in school is not the dominant factor leading to extra reading; as the descriptive figures already showed the poor possibilities to read due to the difficult social background with very few books at home. 
Table 49: Summary of Combined Predictors on Extra Reading

\begin{tabular}{|c|c|c|c|c|c|c|c|}
\hline \multirow[b]{2}{*}{ Model } & \multirow{2}{*}{\multicolumn{2}{|c|}{$\mathbf{R}^{2}$}} & \multirow[b]{2}{*}{ Adjusted $R^{2}$} & \multicolumn{4}{|c|}{ Overall Model Test } \\
\hline & & & & $\mathbf{F}$ & df1 & $\mathrm{df2}$ & $\mathbf{p}$ \\
\hline 1 & \multicolumn{2}{|c|}{0.10} & 0.08 & 5.53 & 8 & 407 & $<.001$ \\
\hline 2 & \multicolumn{2}{|c|}{0.12} & 0.09 & 3.75 & 15 & 400 & $<.001$ \\
\hline 3 & \multicolumn{2}{|c|}{0.13} & 0.08 & 2.75 & 21 & 394 & $<.001$ \\
\hline \multicolumn{3}{|c|}{ Comparison } & & \multirow[b]{2}{*}{$\mathbf{F}$} & \multirow[b]{2}{*}{ df1 } & \multirow[b]{2}{*}{$d f 2$} & \multirow[b]{2}{*}{$\mathbf{p}$} \\
\hline Model & & Model & $\Delta R^{2}$ & & & & \\
\hline 1 & - & 2 & 0.02540 & 1.656 & 7 & 400 & 0.118 \\
\hline 2 & - & 3 & 0.00460 & 0.346 & 6 & 394 & 0.912 \\
\hline
\end{tabular}

Source: Primary data, 2018

How do the different forms of violence in addition to self-esteem and motivation, controlled by the social background affect the English grades of the students? In view of this, the social background (model 1) had a coefficient of determination $\mathrm{R}^{2}(0.08)$, adjusted to $\mathrm{R}^{2}(0.06)$. and this indicated that the social background explained $8 \%$ of the variance of the English grades with a significant effect $(\mathrm{p}<.001)$. The addition of the forms of violence (model 2) led to a coefficient of determination of $\mathrm{R}^{2}(0.10)$ and adjusted, $R^{2}(0.06)$. This showed that the different forms of violence explained $10 \%$ of the variance of English grades and indicated a significant effect $(\mathrm{p}<.001)$ with a difference of $\left(\Delta \mathrm{R}^{2}=02\right)$, an $\mathrm{f}$ value of $(1.23)$ and an insignificant effect $(\mathrm{P}=.283)$ of the combined model. The inclusion of self-esteem and motivation presented a coefficient of determination $\mathrm{R}^{2}$ (0.14) and adjusted to $\mathrm{R}^{2}(0.09)$. This meant that it explained $14 \%$ of the variance of English grades with a significant effect $(\mathrm{p}<.001)$ and the difference between the models was $\left(\Delta R^{2}=03\right)$, with an $f$ value of (3.05) and a significant effect of (p.006) (see table 50). 
Table 50: Summary of Combined Predictors on English Grades

\begin{tabular}{lcrrrrrr} 
& & & \multicolumn{5}{c}{ Overall Model Test } \\
\cline { 5 - 8 } Model & $\mathbf{R}^{\mathbf{2}}$ & Adjusted $\mathbf{R}^{\mathbf{2}}$ & $\mathbf{F}$ & $\mathbf{d f 1}$ & $\mathbf{d f 2}$ & $\mathbf{P}$ \\
\hline 1 & 0.08 & 0.06 & 4.42 & 8 & 411 & $<.001$ \\
2 & 0.10 & 0.06 & 2.94 & 15 & 404 & $<.001$ \\
3 & 0.14 & 0.10 & 3.04 & 21 & 398 & $<.001$ \\
\hline
\end{tabular}

\begin{tabular}{|c|c|c|c|c|c|c|}
\hline \multicolumn{2}{|c|}{ Comparison } & \multirow[b]{2}{*}{$\Delta R^{2}$} & \multirow[b]{2}{*}{$\mathbf{F}$} & \multirow[b]{2}{*}{ df1 } & \multirow[b]{2}{*}{ df2 } & \multirow[b]{2}{*}{ p } \\
\hline Model & Model & & & & & \\
\hline 1 & 2 & 0.0193 & 1.23 & 7 & 404 & 0.283 \\
\hline 2 & 3 & 0.0396 & 3.05 & 6 & 398 & 0.006 \\
\hline
\end{tabular}

Source: Primary data, 2018

In addition, is there any effect of the social background, different forms of violence in addition to self-esteem and motivation on the French grades of the students on table 51 ?

Table 51: Summary of Combined Predictors on French Grades

\begin{tabular}{llrrrrr} 
& & & \multicolumn{5}{c}{ Overall Model Test } \\
\cline { 5 - 7 } Model & $\mathbf{R}^{\mathbf{2}}$ & Adjusted $\mathbf{R}^{2}$ & $\mathbf{F}$ & df1 & df2 & $\mathbf{P}$ \\
\hline 1 & 0.09 & 0.08 & 5.29 & 8 & 411 & $<.001$ \\
2 & 0.11 & 0.07 & 3.26 & 15 & 404 & $<.001$ \\
3 & 0.13 & 0.09 & 2.92 & 21 & 398 & $<.001$ \\
\hline
\end{tabular}

\begin{tabular}{|c|c|c|c|c|c|c|}
\hline \multicolumn{2}{|c|}{ Comparison } & \multirow[b]{2}{*}{$\Delta R^{2}$} & \multirow[b]{2}{*}{$\mathbf{F}$} & \multirow[b]{2}{*}{ df1 } & \multirow[b]{2}{*}{ df2 } & \multirow[b]{2}{*}{$\mathbf{p}$} \\
\hline Model & Model & & & & & \\
\hline 1 & 2 & 0.0146 & 0.943 & 7 & 404 & 0.473 \\
\hline 2 & 3 & 0.0255 & 1.953 & 6 & 398 & 0.071 \\
\hline
\end{tabular}

Source: Primary data, 2018 
In view of table 51 above, the social background indicates the coefficient of determination $R^{2}(0.09)$, adjusted to $R^{2}(0.07)$. Thus, the social background was able to explain $9 \%$ of variance of French grades with a significant effect. $(\mathrm{p}<.001)$. The inclusion of the forms of violence raised the coefficient of determination slightly to $\mathrm{R}^{2}(0.11)$ and adjusted to $\mathrm{R}^{2}(0.07)$. Thus, model 2 is able to explain $11 \%$ variance of French grades with a significant effect of $(\mathrm{p}<.001)$. The difference was $\Delta \mathrm{R}^{2}=01$, with an insignificant effect $(\mathrm{p}=0.473)$ of the combined model. The inclusion of selfesteem and motivation (model 3 ) led to a coefficient of determination of $\mathrm{R}^{2}(0.13)$, adjusted to $\mathrm{R}^{2}(0.09)$ with a significant effect $(\mathrm{p}<.001)$ and a difference of $\left(\Delta R^{2}=02\right)$ with a combined insignificant $p$-value $(0.071)$. This therefore means that the social background contributed with $9 \%$ to the grades in French; with different forms of experienced violence this raised to $10 \%$ explanation of the variance, and inserting self-esteem and motivation the explained variation raised to $13 \%$.

The results in relation to the grades in mathematics differ (see table 52). As a result, the social background (model 1) explains $4 \%$ of variance in the grades of mathematics with a coefficient of determination $\mathrm{R}^{2} 0.04$ and an adjusted $R^{2} 0.02$ and a still significant effect $(p=0.031)$. The different forms of violence (model 2 ) raise the coefficient of determination of $\mathrm{R}^{2}(0.06)$ and adjusted to $\mathrm{R}^{2}(0.02)$ and are able to explain $6 \%$ of variance of mathematics grades, however without being significant $(p=0.064)$. The difference was $\left(\Delta \mathrm{R}^{2}=01\right)$ with an insignificant effect (p.403) for the two models. 
Table 52: Summary of Combined Predictors on Grades in Mathematics

\begin{tabular}{|c|c|c|c|c|c|c|c|}
\hline \multirow[b]{2}{*}{ Model } & \multirow{2}{*}{\multicolumn{2}{|c|}{$\mathbf{R}^{2}$}} & \multirow[b]{2}{*}{ Adjusted $\mathrm{R}^{2}$} & \multicolumn{4}{|c|}{ Overall Model Test } \\
\hline & & & & $\mathbf{F}$ & df1 & df2 & $p$ \\
\hline 1 & \multicolumn{2}{|c|}{0.04} & 0.02 & 2.14 & 8 & 410 & 0.031 \\
\hline 2 & \multicolumn{2}{|c|}{0.06} & 0.02 & 1.63 & 15 & 403 & 0.064 \\
\hline 3 & \multicolumn{2}{|c|}{0.08} & 0.03 & 1.70 & 21 & 397 & 0.028 \\
\hline \multicolumn{3}{|c|}{ Comparison } & \multirow[b]{2}{*}{$\Delta \mathbf{R}^{2}$} & \multirow[b]{2}{*}{$\mathbf{F}$} & \multirow[b]{2}{*}{ df1 } & \multirow[b]{2}{*}{$\mathrm{df} 2$} & \multirow[b]{2}{*}{$\mathbf{p}$} \\
\hline Model & & Model & & & & & \\
\hline 1 & - & 2 & 0.02 & 1.04 & 7 & 403 & 0.403 \\
\hline 2 & - & 3 & 0.02 & 1.84 & 6 & 397 & 0.090 \\
\hline
\end{tabular}

Source: Primary data, 2018

The addition of self-esteem and motivation (model 3) lead to a coefficient of determination $\mathrm{R}^{2} 0.08$ and was adjusted to $\mathrm{R}^{2} 0.03$, having a significant effect $(p=0.028)$. This explains $8 \%$ of the variance of grades in mathematics. The difference between the models showed an insignificant effect ( $p$ $=0.090)$. All over, this shows a small effect of the social background to the grading in mathematics (4\%), experiences forms of violence having no direct influence, however showing some influence adding the mediator's self-esteem and motivation with $8 \%$ of variance.

Finally, is there any effect of the social background, forms of violence including the self-esteem and motivation on ICTs or science grades of the students (see table 53)? 
Table 53: Summary of Combined Predictors on Science Grades

\begin{tabular}{|c|c|c|c|c|c|c|c|}
\hline \multirow[b]{2}{*}{ Model } & \multirow{2}{*}{\multicolumn{2}{|c|}{$\mathrm{R}^{2}$}} & \multirow[b]{2}{*}{ Adjusted $R^{2}$} & \multicolumn{4}{|c|}{ Overall Model Test } \\
\hline & & & & $\mathbf{F}$ & dfl & df2 & $\mathbf{p}$ \\
\hline 1 & \multicolumn{2}{|c|}{0.05} & 0.03 & 2.72 & 8 & 401 & 0.006 \\
\hline 2 & \multicolumn{2}{|c|}{0.07} & 0.04 & 2.08 & 15 & 394 & 0.010 \\
\hline 3 & \multicolumn{2}{|c|}{0.10} & 0.05 & 2.08 & 21 & 388 & 0.004 \\
\hline \multicolumn{3}{|c|}{ Comparison } & \multirow[b]{2}{*}{$\Delta R^{2}$} & \multirow[b]{2}{*}{$\mathbf{F}$} & \multirow[b]{2}{*}{ df1 } & \multirow[b]{2}{*}{$d f 2$} & \multirow[b]{2}{*}{$\mathbf{p}$} \\
\hline Model & & Model & & & & & \\
\hline 1 & - & 2 & 0.02 & 1.33 & 7 & 394 & 0.236 \\
\hline 2 & - & 3 & 0.03 & 2.01 & 6 & 388 & 0.064 \\
\hline
\end{tabular}

Source: Primary data, 2018

The social background in model 1 influences the grades in social sciences with a coefficient of determination of $\mathrm{R}^{2}=0.05$ and adjusted to $\mathrm{R}^{2}=0.03$ with a significant effect $(\mathrm{p}=0.006)$. Thus, $5 \%$ of the variance of grades in ICT or science are explained grades and the effect. With the addition of the forms of violence (model 2), the coefficient of determination has an increase $\left(\mathrm{R}^{2}=0.07\right.$; adjusted to $\left.\mathrm{R}^{2}=0.04\right)$, with a significant effect (p.010). Thus, social background and forms of violence explain $7 \%$ variance of the science grades, however with a very small difference between the models which is not getting significant $\left(\Delta \mathrm{R}^{2}=0.02\right.$ difference). In view of the addition of self-esteem and motivation, the coefficient of determination is $\mathrm{R}^{2}(0.101)$ and adjusted to $\mathrm{R}^{2}(0.052)$. This explains $10 \%$ of the variance of science grades with a significant effect (p 0 0.004). The difference between model 2 and 3 is small $\left(\Delta \mathrm{R}^{2}=0.03\right)$ and does not show a significant effect $(p=0.064)$ of the model.

To summarize, the effect from the experiences of violence to the output of learning does not become significant. The relation between the social background and the output is visible. There is as well as shown in the previous chapter, a visible influence of more than $10 \%$ explanation of variance from the experiences of violence to the mediator self-esteem and motivation to learn and for schooling. However, these mediators seem to have small influence on the learning output. This shows that due to the 
poor instructional quality and the high volatility of grading, the influence of violence to the learning process does not become visible.

\subsubsection{Summary of the Analysis of Data}

The analysis showed the following results:

a) The influence of the social background of the learning outcome: The analysis made visible that class repetition and an older age of students does not positively affect the learning output. The better grading of refugees are related to the situation in Cameroon, as families are fleeing from the Anglophone region in which traditionally, the educational system had been stronger. Therefore, refugee students come with better competencies into the French system. Obviously, the quality of instruction is not good enough to reduce the influence of an economically bad or distant from education social background on the outcome of education.

b) The relation between social background and experienced violence: The findings show that being a boy does lead to higher experiences of violence at school and to higher experienced structural violence. As younger students are, as more they suffer from psychological violence, as older students are, sexual violence becomes an issue. The socio-economic status, the status as orphans or as refugees, do not significantly influence the different forms of experienced violence.

c) Experienced violence and learning mediators: Experienced forms of violence, controlled by the social background do therefore have an influence on the general self-esteem, the body self-esteem and the academic self-esteem. Experienced violence does effect the learning motivation and especially to a high level the motivation to visit a school.

d) Experienced violence and learning output: Effects from the experiences of violence to the output of learning are not significant. Even if the mediators for learning are effected by experiences of violence, this does only little influence the grading at schools and the repetition of classes. This shows that due to the poor instructional quality and the high volatility 
of grading, the influence of violence to the learning process does not become visible.

\section{Results and Discussion}

This chapter presents the answers to the research questions by summarizing the study results that have been presented in detail (chapter 4) in the light of the conceptual and theoretical framework (chapter 2). First, the research questions are answered and summarized (chapter 5.1), followed by a discussion and interpretations related to the discourse on violence at home and school (chapter 5.2).

This study aimed to examine whether there is a link between violence and the learning outcome of students in Cameroon. The background of this study was the meaning of quality education (UNESCO, 2001; UNESCO, 2005) as a global value paradigm (Grima, 2008) to be pursued as well as the right of the child to be raised in a nonviolent education setting (chapter 1.1). My study aimed to enhance the understanding of the concept of violence and to contribute to the knowledge related to violence and its effect on students' study outcomes (chapter 2). The study focused on the impact of the often use of violence in education in Cameroon. The study, therefore, was intended to enhance the process of understanding violence and its consequences on the learning output.

\subsection{Summary: Results of the Study}

This chapter briefly presents a summary of the findings, starting with a recapitulation of this study's problem, research questions, the methods used to carry out the analysis, and a summary of the subchapters' findings. It concludes with the answers to each of the research questions of the project.

Over the years, the policy-papers in Cameroon have ensured the protection of the child's rights (UDHR 1948; Mumthass, Munavirr, Gafoor, 2014). They have done this by highlighting the notion of gender disparity, of accessibility of schools, a positive school climate, and democratic values (EFA, 2005; Dakar Framework for Action UNESCO, 2000). The desire of upholding quality education without violence was expressed. However, 
this remained a norm but was not put in practice as the post-colonial legacy of violence is still inherited as a medium of education and instruction (UNICEF, 2016). This has resulted in students' lack of social-emotional competencies, less connected to school from all levels, thereby negatively affecting their academic performance, behavior, and health in schools (Durlak et al., 2011). From this background, education in Cameroon instead of serving as a violence reduction agent has rather been transformed into a violent indoctrination scheme (Tchombe, 2006). Thus, the study followed these research questions:

- What experiences of violence do students in colleges in Cameroon report?

- In what ways does violence affect the learning of students in colleges in Cameroon?

- What are the effects of violence on student learning outcomes in colleges in Cameroon?

All over, this study investigated how violence affects students' learning outcomes in schools in Cameroon.

The study was following the quantitative paradigm, using a questionnaire with structured or closed-ended questions (Savin-Baden \& Major, 2013), which has led to information generation (Pandey \& Pandey, 2015). The sample was randomly selected from schools which had been chosen from the regional educational administration, belonging to two districts out of a total number of eight communities in the west region of Cameroon. Of these schools a total of 924 students out of a whole population size of 22,122 students (UNDP Cameroon Development Report, 2016) had been randomly selected. As these schools were more often visited by girls due to their low reputation, and as in some classes proportionally even more girls than boys took part of the study, more girls than boys participated. By this, the study was biased on gender and socio-economic background.

The data had been collected by a paper and pencil questionnaire. All data had been integrated by hand into the electronic system. The data was transformed by calculating scales. 
Given the results collated from the data of this study and the main research question, it showed a presence of physical, psychological, and structural violence effecting students' self-esteem and motivation. The results show in addition that the students' poor socio-economic background affected poor learning outcomes. These results trends are further summarized in the sections below.

\section{A Poor Social Background Affects Learning Outcomes}

According to the regressive statistical analysis of the data, it indicated that the social background has a strong influence on the study outcomes of the students and therefore influences all the research questions. Consequently, the socioeconomic background was controlled for the other variables under observation. All in all, the students showed a low socio-economic background from the occupational as well as the educational background of the families. The access to book at homes was very limited. This brings about difficulties in school accessibility with social injustice fraught with inequality, financial challenges, and unhealthy conditions, thereby leading to acute structural violence. This implies that the poor social background led to students staying longer in school through class repetition $\left(\mathrm{R}^{2}=0.32 ; \mathrm{p}<.001\right)$ and a high variation in the age of students.

\section{A Poor Social Background Affects All Forms of Violence}

The socio-economic background enhances the different types of violence that students suffer in school and compliments the effects of socioeconomic background on learning outcomes. It showed experienced violence at all levels of education of the child, be it at home but most especially in school. Despite these strong effects at all levels, the findings indicate a slight gender division of the influence of violence between males and females. Males suffer more from physical violence at home and school, while the elder females have a higher potentiality for being sexually harassed. 


\section{Sexual Violence as a Strong Violent Indicator in School}

Moreover, the results provide robust evidence of the overbearing influence of sexual violence in school $\mathrm{R}^{2}(0.07 ; \mathrm{p}<.001)$. This shows that sexual victimization of the girls and boys is tremendously a huge problem. As 23 $\%$ of the respondents answered that they experienced sexual violence in schools, it shows alarmingly the fact that schools cannot be considered as safe spaces, where students can feel free, express their personality develop and discuss their sexuality. In addition, it indicates as well a cultural hierarchical power setup, a homophobic disposition, hostile home and school environment, and a very low standard of teacher ethics, giving space for sexual harassments at schools of both sexes. It is a severe and preoccupying challenge and not articulated as an emotional-psychological hiccup in Cameroon's educational discourse because it has adopted a taciturn contextual structure.

Violence has a Strong Effect on the Students' Self-Esteem and Motivation in School.

The various forms of violence affect the different aspects of the student's cognitive and physical wellbeing, such effects are felt on the selfesteem and the motivation with the overall impact visible on their study outcomes. This is noticeable because the higher the different levels of violence unleashed, the self-esteem $\mathrm{R}^{2}(0.15 ; \mathrm{p}<.001)$ and the motivation $\mathrm{R}^{2}$ $(0.21 ; \mathrm{p}<.001)$ of the student suffered, making it to be intrinsically felt and experienced by the victim. In addition to this, it was evident that the worries they had about their socioeconomic background significantly lowers their motivation and self-esteem. The results showed that motivation decreases when violence increases.

\section{The Effects of Violence at Home and School on Learning Outcomes}

The outputs of the data on violence were controlled with the socioeconomic background and self-esteem and showed a very strong interrelation with the educational outcomes of the learners in relation to class repetition $\left(\mathrm{R}^{2}=0.35 ; \mathrm{p}<.001\right)$. As such, the influence of violence on the learning outcomes has been moderated by the result of the violence on self-esteem and motivation. As violence is pulling down the students' self-esteem and 
motivation, this has influence on their learning outcomes. Concerning performance in subject grades in addition to extra reading at home show that because of a poor social background, the influence of violence on selfesteem and motivation, study abilities are affected. This is compounded and worsen by poor school quality.

The hypothesis, which stated that "violence at home and in school badly affects the self-esteem of the students," has been confirmed as the results showed an influence of violence on their esteem, thereby implying that their self-esteem decreases when violence increases.

\section{Summary Answers to Research Questions}

By the results of the descriptive findings (chapter 5.1) the first research question "What experiences of violence do students in colleges in Cameroon report?" (Chapter 1.4) may be answered as following: Students in Cameroon are affected by four ways of violence. About $20 \%$ of students feel physical violence and psychological violence. More than half of the students' experiences structural violence and about $23 \%$ have experiences of sexual violence. As a zero-policy on experienced violence is the wished standard, the huge ratio of violence in the life of students in Cameroon becomes visible.

By the results of the analysis of data (chapter 4.2), the second and third research question of this study (chapter 1.4.) may be answered. This study aimed to investigate the question "In what ways does violence affect the learning of students in colleges in Cameroon?" (Chapter 1.4). The results of the study show that experiences of violence mainly affect negatively the self-esteem of students, the motivation of learning and especially the motivation to go to school.

Concerning the third research question "What are the effects of violence on student learning outcomes in colleges in Cameroon?" (Chapter 1.4) the study did not show a big effect, even if the effects of the learning mediators had been significant and visible. Obviously, the instructional quality in general is so low that motivation and self-esteem, which are reported in international studies as influential on learning-outcomes, do not develop significant influence. 


\subsection{Discussion of the Findings}

In this chapter, an incisive reflection of the study is undertaken in light of the various discourses and the study's theoretical framework with an interconnection of the findings. It shall explicitly show the contribution of the study to the scientific discourse.

First, an interpretation of the findings with regards to the experiences of violence and its meaning for learning will be given (chapter 5.2.1). Class repetition in the African context is often seen as an individual failure of the student, however the meaning of structural violence linked with this phenomena will be discussed (chapter 5.2.2) The need of a systemic understanding of violence is examined (chapter 5.2.3) The autonomy of sexuality as a challenge to the educational discourse (chapter 5.2.4) is reflected. Finally, the findings are reflected in the light of the fundamental rights of the child (chapter 5.2.5). A plea for a view on latent violence in education rounds of the discussion of the findings (chapter 5.3).

\subsubsection{Schooling in the Light of Experiences of Violence}

This subchapter seeks to reflect the role of schools and their provided educational quality concerning the influence of violence and seeks to relate the findings to the discourse on educational quality.

The results of the study showed that violence at home and school affects learning outcomes and negatively influences educational quality. Therefore, the study results indicated the crucial role of violence in general. This showed an acute prevalence of violence at home and in school, in the dimension of physical victimization, psychological victimization in regards to their self-esteem, motivation, and sexual violence. This has been aggravated by the bad socioeconomic or, better still, the students' demographic background.

School played a double role in regard to this experiences of violence: Firstly, schools had not been able to compensate the negative experiences at home. The social background played a crucial role in experienced violence as well as in regard to academic outcome. Secondly, schools added to these negative experiences of violence especially to those students, who did already have negative experiences. Alarming are results of those who 
showed that more of $20 \%$ of students had the experience to be offered better marks for sexual services. So schools do not serve as safe places for education.

Low educational quality of schools does not compensate the poor social background of students and by this, deepen social injustice

The diverse scientific discourses on educational quality extrapolate that it determines how much and how well children learn through access to appropriate learning and life-skill programs by developing responsive, participatory, and accountable systems of educational governance and management (Grima, 2008; UNESCO, 2000).

The findings of this study showed, that in Cameroon's context, educational quality remains elusive as the social background was still responsible for academic outcome and for experiences of violence at school. By this social injustice is manifested by schools. Participatory and responsive learning are missing, thereby affecting the school outcome of students and putting into jeopardy the quality of education. UNESCO (EDQUAL WORKING PAPER NO. 3 2006) argues that quality of schools is based on what happens in schools and in the classroom where learners acquire attitudes and cultural values. This has been corroborated by Fredriksson (2004), who perceives quality education as the relevance of what is taught and learned to how well it fits the present and future needs of the particular learners. Quality education allows learners to participate and learn, and to be supported by their families and communities. They evolve in healthy, safe, protective, gender-sensitive environments and provide adequate resources and facilities (UNICEF, 2000).

The educational inputs from Cameroon's setting indicate that the academic achievement related to the parents' social and educational background played an essential role in the study. The socio-economic background is usually seen as being determined by occupational status, education, and wealth (PISA, 2009). The socio-economic background explained $32 \%$ of variance of learning output (measured by class repetition). This indicated a fragile socio-economic status of the students, which was too high compared to international studies (APA factsheet, 2019; PISA, 2009). This is responsible for the students' diminished self-esteem and 
learning motivation (Usman et al., 2016). Students from well-to-do socioeconomic backgrounds have an apparent advantage in their school achievement levels over those from weak socio-economic backgrounds, as the school quality does not compensate any difference in the background. Students from a low socio-economic home are disadvantaged in school because they lack a conducive and academic home environment (Evans et al., 2018).

Schools as unsafe places

In addition, it is noticeable that sexual violence is visible in Cameroon. Already at the level of school attendance as seen in this sample, men are preferred to be the ones to be eligible for unlimited levels of education while the females are allowed the basic level of education because it is evident that they would be married off someday. This, therefore, is hierarchical, symptomatic gender and structural violence (Hughes, 2020), which needs great attention. In addition, more than $20 \%$ of girls and boys had been affected by sexual violence. Schools do in this regard not function as safe places.

A part of the students is coming with experiences of domestic violence to school. Domestic violence is a scourge that is hardly manifest through physical violence though inert and considerably felt through psychological and emotional intimidation (Kithonga \& Mbogo, 2018). Therefore, domestic violence is a serious issue of human rights, public health, and significant social consequences (Ferrara, 2019). One cause of violence is domestic, and while in school, this is intensified.

In addition to this and as a contribution to the evolution of scientific discourse, despite the theories on violence (Li \& Zeqi, 2018; PISA 2009; Bufacchi, 2005; Krug et al., 2014; Galtung, 1990; Ember \& Ember 2005; Freire, 2005) with the following results of this study, it shows that the system of education in the context of Cameroon needs a concerted action because it is preoccupying from the findings thereby lacking quality. 


\section{Summary}

The finding of the students make visible, that the discourse of educational quality, needs to take into account the basic understanding as schools as safe places against violence. Violence at schools is not acceptable, and especially sexual harassments by teachers do contradict the role of schools. In addition educational quality plays an important role in overcoming social imbalances in society. However, if schools do add to violence experienced at home, they do even deepen social barriers and manifest social injustice. As the international discourse on educational quality is mainly studied in high- and middle-income countries, this dimension of educational quality needs to be considered especially when working on low income countries.

5.2.2 Repetition as a Challenge to the Educational Quality Discourse The results of this study indicate a very high and prevalent repetition rate by the students with more than $70 \%$ haven repeated at least once from the sample population of the study. This is interconnecting with experiences of violence and poor school quality in Cameroon.

\section{Class repetition as a wide spread phenomenon}

Class repetition is a problem in Cameroon. In the study, more than $70 \%$ of students had repeated at least once and the age range was broad. Many aspects are discussed in relation to class room repetition. Overcrowded classrooms, the mixture of children of different ages and abilities in the same classroom without proper adaptation of teaching methods to improve learning are seen as one reason (UNESCO 2012). Furtherance to this, induce school engagement, including family-level factors such as illhealth, malnutrition, and poverty that limit meaningful access to education for many children are seen as other reasons (UNESCO 2012). As a result, many children are registered in schools but fail to attend, participate, and learn, are enrolled for several years but fail to progress and are obliged to repeat or drop out of a grade (UNESCO 2012). Moreover, a student can also be held back due to insufficient social or physical maturity in the early stages of schooling and not just achievement as well as their 
being held back by the school administration (UNESCO Global Education Digest, 2012). Teacher absenteeism, school location, and inadequate school quality provision do add to class repetition. Such interplay of socioeconomic factors and the schooling of the children results in class repetition and a fall out of aging leading to disinterest to be in school and subjected to pressure to drop out and start earning an income for the family.

Moreover, historically, Cameroon being a former French colony in Africa, for example, tend to follow the French tradition whereby repetition was applied to students who fail to make the grade (UNESCO Global Education Digest, 2012). Repetition leading to drop out is often a process rather than the result of one single event, and therefore has more than one proximate cause and globally not consistent and attainable (UNESCO Global Education Digest, 2012). Class repetition is not a remedy and is, in most cases, not objectively reflected (UNESCO Global Education Digest, 2012). It represents a significant drain on the limited resources that countries have to use in fostering education (Sabates et al., 2010). Repetition can never be a quality dimension in education as the teaching-learning process is not mutually exclusive as an actual test of the abilities, skills, and competencies of diverse learners anywhere in the world.

\section{Violence as a Key Cause of Class Repetition by Students}

In addition, this study shows high repetition rates and can link these in addition to what is discussed in the international discourse to the often overseen experiences of students of violence. It is evident that grade repetition is stressful to the students and associated with reduced self-esteem, motivation, impaired peer relationship and alienation from school and sharply increased the likelihood of eventual dropout (Brophy, 2006) which in itself is a violent act imposed by the school. The findings also show an increasing prevalence of poverty from their socioeconomic background (see previous chapter). Hence, as students grow, the opportunity cost to remain in school increases, especially the majority that comes from poor homes. Consequently, this brings about pressures towards child labor and taking up household functions (Sabates et al., 2010). This violence is inert, structural, and wholly psychological, with the effects, tremendous. It 
needs a better understanding of the fallouts of repetition and a complete rejection of the phenomenon.

\section{Summary}

The international discourse on class repetition is outlining that class repetition is seldom a contribution to learning, however indicates problems in the quality of instruction and schooling. The discourse on the various reasons for high repetition rates had been summarized. The findings of this study highlights the perspective that experiences in violence in society and school might be for the context of low income and developing countries an often neglected reason for class repetition.

\subsubsection{Schooling in a Violent Environment: Towards a Systemic under- standing}

Until now in Cameroon, the discourse regarding violence at school and its effects relate to teachers and students in schools, but my results show parents' influential role and the notion of the school environment. Therefore, the discourse needs to be broadened to include the educational landscape and parents in a systemic dimension. The quest to confront the scourge of violence embedded in the findings from inhibiting the learning abilities of the students has, more often than not, been reduced to an issue between the teachers and students at school. This is due to a fixation to a non-systemic understanding of school, interacting with the family and not only the students. Therefore the findings of my study will be discussed in the relation to a systemic understanding of schooling and a whole-school approach, in regard to include families and concerning the understanding of an educational landscape.

Systemic understanding of schools

This notwithstanding, it is evident from the data's output that violence is a systemic problem. Given this position, it would appear prudent and proactive to approach the phenomenon from a systems perspective that can lead to a change in school systems' culture and this at the disciplinary, curricular, pedagogical, and cultural levels (Coleman \& Deutsch, 2000). 
The school's systemic orientation encompasses various elements that shape the relationships in schools. In such a scenario, peer-mediation training as a tool is an essential curriculum indicator. Besides the fact that violence and conflict resolution that focuses more on students' disregards the fact that most teachers and other stakeholders in schools are not trained or adequately prepared to face the violent challenges. Consequently, teachers and school leaders should also receive training in nonviolent behavior, in cooperation, and conflict resolution (Coleman \& Deutsch, 2000). Non-violent communication and conflict management needs to be seen as an integral component of the school's overall functioning (Coleman \& Deutsch, 2000). Such systems are required in interconnecting the process of system development with special teacher training and ensure the adoption of a landscape that works with parents and all the stakeholders to improve the situation (see below). Summarily, the systemic level should be seen first as the school itself. In this case, the input processes involve infrastructure, financial resources, a clear and shared focus, effective school leadership, collaboration and communication, curriculum, instruction and assessments aligned with standards, frequent monitoring of learning and teaching, and focused professional development. As Betts (1992) posits, in both education and school-management, changes from deterministic systems toward purpose-seeking systems should be taken into consideration, wherein "dictatorial" are transforming to "participative" organizational styles. Hence, a systemic approach brings collaborative and compassionate supportive dealings leading to trust, respect, and inclusive postures with the competitive attitude pull under the rug in a responsible value-based paradigm.

\section{Theory of Education as a Landscape}

Second, the environment should be holistically shaped and associated with the systemic and structurally oriented manner. The theory of education as a landscape in a systemic perspective takes the reflection into a new dimension with the findings. The system-level should embody the early childhood care education or pre-primary, primary, lower secondary, and upper secondary rung of schooling as well all institutions linked to 
education in an informal way, as i.e. churches. Considering the education landscape as an abstract idealist transmission of skills and values requires an interconnected practical orientation in a systemic approach. The school as an institution is situated in spatial and social surroundings that are of importance not only for students' everyday school life but also for the neighborhood in which the school is located (Jahnke et al., 2019). Systemic education in different contexts primarily related to Cameroon's case should be strategically coordinated from the pre-primary, primary, lower secondary to upper secondary with policy decisions and the structures including the content to be reflected well and gear at sustainably managing the process of skills and value inculcation including to work for a nonviolent environment for students. Violence at school is not a single event between one student and one teacher, however emerge through a system which is not enough aware of the influence of violence on hindering learning already starting in pre-primary education.

The theoretical ideals of education as a landscape in a systemic change require concerted stakeholder engagement and ownership of the process, a mindset overhaul related to education, policy, and curriculum designs that are compassionate, inclusive, and environmentally sustainable guided by responsible freethinking. Such a framework needs the diverse landscapes of education in the system to explore how the understanding of violence-free education can lead to educational change and reforms (Roberto \& Reigeluth, 2010). In Cameroon's case the understanding of schools in a systemic landscape remains an innovative push that needs systemic reflexivity. It revolves and should involve personnel development. The systems concept can help students see how they are part of larger entities and how they include natural and artificial environments in a more encompassing whole. Thus, systems thinking can help students to appreciate non-violent communication and to give them ideas about peaceful conflict solutions (Porter \& Córdoba, 2009) and responsibly appropriating their action by respect and tolerance. 


\section{Education as a landscape including families and informal learning}

Moreover, the study's findings show how much the academic outcome is related to factors beyond the school and its teaching. Implicitly, these factors are in play both during the years before these students started formal schooling and enrolled in elementary and secondary schools in Cameroon. A glaring finding is the parental influence related to the level of education. This implies a difficult psychological situation for the learners coupled with the structural socioeconomic status that they are subjected to from their background.

The substantial shift of mothers' roles in children's education in Cameroon needs deeper studies and knowledge. This role is undergoing a monumental change in Cameroon and should be keenly assessed. This is because parents are very important for the quality of care for the young children. For schools as well, it is important to connect to parents and to provide offers to their development. The role of schools in Cameroon in regard to parents' education should be a further topic of investigation. Researchers might begin to seek answers about the government's roles in reducing poverty among households and eradicating all forms of violence against children if early childhood education makes a meaningful impact in Cameroon and Africa in general.

Above all, schooling should be seen in a systemic orientation of the child's whole life, thereby connecting social care and education. This implies the experiences of the natural, social and cultural environment in the systemic paradigm can be conceptualized as a learning experience by the students (Jahnke et al., 2019). It incorporates a holistic deployment of all qualitative input and output processes of schooling and is shaped by a collaborative, loving, and caring socioeconomic background in all aspects of education and at the various levels. Any child's quality education in all societies is thrust upon them through the informal acquisition of social norms and values. Thus, the education provided by churches and Sunday schools and their relation to violence becomes important. Churches role in education is not present in the discourse about education, however might have a role to play. The systemic lane of education in the child's life 
requires joint and concerted policy overhaul, deep pedagogical and content rebranding in the framework of intense teacher training, personnel development and research. This takes place in an environmental space that should assure a propitious setting that is void of violence, poverty, and discrimination. Given all these, the systemic approach requires a reflective policy orientation from stakeholders. This should involve all processes, infrastructure, and environmental precepts in a sustainable manner.

\section{Summary}

The discourse about school quality in Sub-Sahara Africa focus on the instruction and the school. This study has showed how violence at home affects learning in schools. By this, the study adds to a holistic understanding of schooling, addressing the problematic influence of violence in education not only to teachers, however to parents, early childhood education, primary and secondary schools as well as school environments as churches and Sunday schools.

\subsubsection{The Autonomy of Sexuality}

The study has shown, that more than $20 \%$ of students have suffered from sexual harassments. This is embedded in a culture of taboo with intense repression by diverse power structuration and extreme abuse in society. This is visible from the parents' undying distaste to talk about sex and how it leads to reproduction to their kids refusing to identify sexual organs by their names but replacing them with meaningless appellations such as 'tou-tou' 'juju' (for vagina) (Kwachou 2015; Rwenge, 2000). This is compounded with the actions of educators in a patriarchal, sexist context that supports tampering of sexual body parts like the breast (breast ironing) and the vagina (female genital mutilation-FGM) (Kwachou, 2015). In Cameroon's case, sexual education is a no-go area and has no place in Cameroon's schools and in educational research. Sexual violence affect both girls and boys. The sexual harassment of students in Cameroon schools has in the public opinion been reduced to a scourge against girls. 
However, boys are silent victims as the dangerous masculinity and a homophobe society is not aware about sexual violence against boys. These results may indicate a hidden adherence of latent homosexuality by teachers against the male students who cannot talk freely about it due to the hostile backlash from the society. Such a homophobic attitude show again the necessity of a development in society towards the tolerance of homosexuality and awareness against sexual violence. In addition, sexual violence against boys may as well be caused by female teachers.

Administrative efforts in this field as sex education are ineffective. Documents such as the Ministerial Decision No. 281/07 of 18/01/2007, which introduced Family Life Education, Population Issues (Nchia et al., 2013) are not strong enough to create change to these practices. The youth population below 20 years old constitutes more than $50 \%$ of Cameroon's population. They are exposed to HIV/STIs, and the fear of compromising health is dominating education (Nchia, 2013). It is common to discuss sex concerning the HIV/AIDS pandemic, but it remains problematic for parents, teachers, and other education stakeholders to freely discuss issues of sexuality. Education for life has been made archaic by a patriarchal system that poses an affront to especially the girls in Cameroon about their sexual and reproductive rights. This need to be confronted by redesigning the teaching-learning content to shared and reflective theories, with the sexual freedom of the student at the center. This needs a shift in mindset related to the male teaching corps and engraining such crucial and sensitive concepts in the training manuals and content in teacher training colleges. Above all, it should be an ethical and normative orientation in upholding child's and human's rights in Cameroon. Teachers offering marks for sexual practices or do other forms of sexual harassment need to fear to be prosecuted by law and may not remain in the system and sexual violence needs to be banned from schools.

\section{Empowering the Female Students in Cameroon on their Sexual Rights}

Furtherance to this, the findings show how important sex education is concerning acknowledging the protection of young women and young girls to learn to defend themselves and say "no," understanding and being 
able to identify incidences of sexual violence and to resist. Moreover, they should be able to denounce such acts without persecution and intimidation and, above all, turn down sexual advances from teachers posing as "sugar daddies" than just to remain victims without the ability to speak up.

This is crucial if the socio-cultural dynamics are streamlined in the policy and content and explicitly espoused in the discourse prevalent in Cameroon's context. Practices like breast ironing dehumanize and intends to check pre-marital and sexual drive with men, including Female Genital Mutilation and circumcision (Kwachou, 2015; WHO, 1995). These practices epitomize sexual rights violation and abuse of young women in Cameroon. Cameroon prominently represents a prevalence rate of $1.4 \%$ of young girls still suffering today from circumcision (Kwachou, 2015). Such actions are repressive, violent and reduce the female youth to sexual manipulative objects, as males are not subservient to these actions.

\section{Summary}

Thus, the findings of this study indicate how important adequate sexual education is for quality education and the fight against violence in schools and in society. There is a need to be enriched in sensitive concepts against sexist, patriarchal and homophobe thought patterns and re-igniting a discourse that embraces sexual autonomy of young students in Cameroon.

\subsubsection{Violence as a Hindrance to the Fundamental Rights of Students}

The study results extrapolated from the diverse forms of violence shown in a compelling and unabashed manner that the child's fundamental rights are compromised. Pillay (2014) sees a child's rights as a 'provision' (which relates to the right to adequate education and health services) and 'protection' (the right to be protected from forms of abuse, neglect, and discrimination). Dinbabo (2013) explicitly argued that there is a need for a high-quality, long-term national plan for the collection, analysis, and dissemination of information on child rights. This position is coming to reinforced the government stance with article 35 of the Law of Cameroon 
National Educational Guidelines No. 98/004 1998, nullifying all forms of child abuse. This is cognizance of its adherence to international conventions (like the UDHR, 1948; CRC, 1990 \& NGO Council on the Rights of the Child, 2012). The violence in school and at home made visible by study indicates a need to strengthen the awareness of human rights and of the rights of the child in families, society and in schools. In addition, related to the poor economic background of households, students may be subjected to child labor to assist the parents to the farm or raise money for their education, thereby uncomfortable with their parents' status while in school and hence, unwilling to be in school.

As such, respecting and supporting children's rights requires preventing harm and actively safeguarding children's best interests (UNICEF, 2013) in all aspects. This becomes a tenable base in accordance with a systemic and holistic orientation that is all-embracing. Human rights education is not possible if the social background disconnects from the school setup. It remains a synergic, systemic dynamic that responds to the educational quality determinants.

The challenge presented by the results of this study in Cameroon's context is not exclusive, especially the uncontrolled rights abused (Dicklitch, 2002; Tchombe, 2006). The lack of requisite skills and competencies for life as a fundamental right in Cameroon by students resulting from rampant violence is inadvertently opening a considerable problem in African educational discourse (Pillay, 2014, p. 227). In the era of the UNO's SDGs, the respect and ensuring of the child's rights in keeping with education for all (UNESCO, 2005) and the adoption of the sustainable development goals, becomes a fundamental challenge to education stakeholders concerning policy and context.

\section{Summary}

The study reveals that children and students should be treated with respect and dignity, afforded equal opportunities to develop and function optimally in society irrespective of race, gender, class, creed, ethnicity, or (dis)ability. Pillay (2014) factors in this by stating that all educational and 
psychological endeavors should support children and students with opportunities to develop their full potential in all facets of their lives. This ultimately brings about a shift from a needs-based view of children to a rights-based perspective. This, therefore, indicates it as not just an educational problem for Cameroon but a problem for the sub-Saharan African region needing concerted global reflection and action.

\subsection{A Plea for a View on Latent Violence in Education}

The discourse on violence and study outcomes in school indicated that educational quality as per accepted trends in the global context (FredriksSon, 2004; UNESCO, 2000; UNICEF, 2000; UNESCO, 2005; Grima, 2008; Pak Tee, 2015), was relegated to the background in the context of Cameroon schools. From science, it is noted that Cameroon's practice was outmoded, de-formative, and not transformative to lead to competencies acquisition. This has been due to the prevalence of an archaic pedagogic orientation with a strong prevalence of violence (Krug et al., 2014; McGuigan \& Pratt, 2001; Galtung, 1990; Ho, 2007; Dicklitch, 2016). Hence, it reduces the degree to which someone can meet their formative needs below the expected point of learning the desired skills from school. In Cameroon's case, the schools that exhibited violence from the study negate the cognitive adaptability of the learner to new knowledge (Straus \& Paschall, 2009 , p. 461) and destroys the essence of creative education. These various forms and instances of violence led Doherty (2008) to infer the systemic destruction of a person's self-esteem and sense of safety, often occurring in relationships where there are differences in power and control. This contributes to the violent action indoctrination (Tchombe, 2006, p. 14) by the schools' educational stakeholders in Cameroon.

The absence of studies of this nature exacerbated the situation. This study has contributed to the addition of the limited lack of knowledge related to violence and how it contributes to the learning outcomes of students in Cameroon.

Systems of education with a colonial origin often are embedded with violent structures. The educational landscape in diverse contexts has lim- 
ited such internecine, structured, and systemic violence into simplistic violent strands that belittle the accurate picture. Education is massively and understandably presented in mainstream discourses that are overwhelmingly positive and lead to a more peaceful and productive world (UNESCO, 2005; Hughes, 2020). Despite this, educational systems should as well be seen as violent because often, neither learning nor justice is promoted by schooling. In other words, education tends to be violent by the very nature of its hierarchical grading system and exclusivist effect on society, for it polarized the population into those who are formally educated and those who are not (Hughes, 2020). Implicitly, education may be a violent social, organizational system that permeates all facets of human desires, cultures and utterly void of anything natural. These social power structures are considerably and unconsciously violently express, especially in educational settings where power control is seen and felt. Consequently, an interesting finding of this research and addition to the discourse is the fact that violence in the case of Cameroon and other contexts has been handle from the perspective of the effects of the problem and not from the causes of it. These reflections had been consistently alluded to these emerging insights.

The social asymmetry of society's potential and the actual (Scriver, 2015) leads to the exercise of power by the strong on the weak, intending to inflict psychological pain or injury (Krug et al., 2014). The incessant practice of violence in Cameroons society and schools negates and destroys the cognitive development and application of knowledge that ensures life skills' inculcation (Straus \& Paschall, 2009). Therefore, this prevalent violence in schools rubbishes the enhancement and protection of the students' fundamental rights (UDHR 1948; Mumthass, Munavirr, Gafoor, 2014) and belittles the enhancement of educational quality. The absence of studies on violence in education has hampered the transmission of freethinking values and action for live and responsible behavior that is globally relevant and acceptable (EFA, 2005; Dakar Framework for Action UNESCO, 2000). This study shows that violence is a tremendous 
challenge to educational quality. It contributes to the systemic disorientation of education in Cameroon and the violent structuration of society and humanity as a whole.

\section{Implications of the Study}

This chapter reflects the implications of this study. It begins with the implications for further research (chapter 6.1) in the light of different thematic dimensions, the limitations and difficulties noticed in carrying out the study (chapter 6.2). This is followed by the possible implications of professional practice (chapter 6.3).

\subsection{Implications for Further Research}

In this section, identifying possible suggested themes for further research in the light of best practices in educational quality provision has been undertaken.

\subsubsection{Research on Parents' Involvement}

It will be interesting to understand how parents can claim to love their children and still perpetuate multiple violence dimensions on them. This will expand this study by undertaking an empirical examination of the socioeconomic indicators of the violence and its influence on the study of the children. This will scientifically provide more evidence on what it would mean to have a violent-free socioeconomic background concerning children's study outcomes. The fundamental objective of such a study is to see how violence from the school environment can influence students' study outcomes if the students' social background is violent free. Considering the relevance of the studies related to violence in Cameroon's case and the sub-Saharan African context, such a review would be important to create awareness and sensitize such a vital stakeholder for education as parents. The study could be undertaken with a qualitative approach to understand the sample's perception of such a task.

Furtherance to this, it would be interesting to compare parents being involved in practices of violence from those who are not. The study results 
indicated a strong influence of violence from the perspective of the students' socioeconomic background and related most especially to levels of education and employment. These results can be replicated comparatively with the inclusion of additional variables that may identify parents who are more involved in victimization and those parents who are not involved with violence. This will provide greater clarity to the phenomenon of violence in Cameroon's context. Such a study will need a sensitive approach as none will readily admit their propensity to violence.

\subsubsection{Research on Teacher Training about Violence and Violence Man- agement}

The study results showed that the students are affected by incidences of various forms of violence. Against this background, research on teacher training about strategies concerning violence management strategies acquired in the pre-service and in-service training processes would be important. This will open avenues for future work and or research that would throw more light and insights on educational policy and teacher training regarding the role and importance of human capital development in the framework of educational quality. Such conceptions should be reinforced with stringent mechanisms to monitor and ensure teachers' willingness and competencies in fighting against violence in education. It is apparent that in the dispensation of teachers' training in the case of Cameroon, the policy and curriculum from the government do not make provision for such guiding precepts. The absence is another sign of chauvinism in the society. It should therefore be the subject of further investigation to ascertain the reality of the situation concretely. It would be prudent to limit the study to the Cameroon context because the absence of such a teacher training curriculum in Cameroon's case is not mutually exclusive for other contexts. The empirical research should assess the perception of these teachers and how it can be handled.

\subsubsection{The Perception of Churches and Pastors Concerning Violence}

The influence and moral stance of faith-based education provision in subSaharan Africa is significant and vital considering that churches are in 
charge of more than $14 \%$ of all schools in Cameroun that are faith based schools (Njobati \& Njoya 2021). The understanding of religious leaders' or pastors' perception of violence in the family and school and how it affects the learning of students is important to study as they influence society and education as important stakeholders. Therefore, it is essential to create a link with the church's policies on how they approach violence and whether pastors are aware of violence and its implications on the children and youth. The realization of such a project will provide more insights into the church's social orientation concerning violence. Above all, it will understand the Church's leaders' ability to intervene and mediate in their followers' social cohabitation as a diaconic duty in instances where peace, love, justice, and understanding are jeopardize. Noteworthy is that with the significant influence of churches in setting up denominational institutions, the checking of violence among all the Christians in sub-Saharan Africa and Cameroon will contribute to a value base. The result will contribute to the peaceful molding of its followers, and the spiral effect for the society. Considering the pivotal role exercised by denominations in the educational landscape of Cameroon and cognizance of the influence of religious leaders on more than $70 \%$ of a predominantly Christian population of Cameroon, it is essential and crucial to investigate the perception and the role played by the clergy in the struggle to check violence amongst their followers, including sexual violence against young women and young men. This is important to understand their preaching's influence on the peaceful and tolerant cohabitation of their followers.

\subsubsection{Research on Sexual Violence and Human Rights}

Sexual violence and humans rights violation in education in Sub-Sahara Africa needs to further investigated as being an important aspect of quality in education and a peaceful society. In sub-Saharan Africa and particularly the case of Cameroon, violent victimization of girls and boys is often not reported and simply ignored. Future research should be undertaken to investigate teachers' behavior and sexual violence at schools as well in- 
tense type of sexual violence as female genital mutilations or sexual violence against boys. This will contribute to the child's fundamental right and to human rights in Cameroon.

\subsubsection{Class Repetition as a Challenge to Educational Discourse}

Class repetition is a challenge and there is the need to accompany this practice with in depth research assessing its causes, impact, and the inherent processes. This will contribute to a professional understanding of exams and assessments as well assist in following constructively the students learning process in the context of Cameroon.

\subsubsection{The Development of a Contextual Scale of Violence}

Furtherance to this, identifying a contextual and reliable scale for the measurement of the various strands of violence peculiar to the sub-Saharan Africa setting remains a significant challenge. Initially, this study's instrumentation posed a problem as precise tools were not available. What cannot be underestimated is that the violence suffered by students at home and in school is opposed to each other depending on the different contexts. In the context of Cameroon and Africa in general, it is important to identify scales which refers to cultural acts of violence like, "you are a devil" or "you are a curse" and reflect the culture of witchcraft. Such a scale should be tested and retested for reliability and standardized psychometric properties. Therefore, it is incumbent on African research institutions to work on the identification and development of specific and peculiar types of violence expected in the African setting and standardize such instruments for future use.

\subsection{Limitations of the Study}

The study has been done under difficult circumstances, which limit its power and should be compensated by further research.

In the first place, the volatile and precarious security situation in Cameroon fundamentally perturbed this study. The study was designed to be investigated with the sample population expected to come from Cameroon's North West Region. Still, the security challenges resulting from the 
ongoing civil war between separatists and the government compelled the researcher to relocate to the West Region of Cameroon. Such a change comprised the language from English to French. In addition it changed the context of the study as the experiences in violence in the English part of Cameroon are historically deeply rooted. Further investigation should therefore reflect the situation in the English speaking part as well.

Second, the design of the study was quantitative and adopted the administration of questionnaires. Hence, it did not allow getting the learners' perceptions on some of the trends noticed in the answers to be able to substantiate if the information provided in the questionnaires correlated with their perceptions. On the one hand, this was helpful as many students would not have spoken about sexual violence. On the other hand, problems with inverse items in the pretest showed general problems of understanding questionnaires. The participants' self-responding to sensitive topics might have negatively affected their comfort level and, hence, influenced their responses. Even though submitted responses were anonymous, the participants still may have felt uncomfortable answering questions relating to their attitudes and previous domestic violence history. Additionally, some questions in the questionnaire may have been too personal. Therefore, the quality of the answers should be checked again by a repetition of the study.

The absence of instruments related to the cultural background and the age diversity of students was a challenge. The development of instruments related to the cultural background and their availability including statistic background information are still a necessity.

The study did not have the possibility to get a fully randomized sample as the government was preselecting schools. By this faith-based institutions and better schools had not been part of the sample and girls had been overrepresented. Further investigations might overcome these problems. 


\subsection{Implication for Practice}

The probability of successfully applying the results of this study in stemming violence in school and transforming them into values-based institutions cannot be overemphasized. This is seen in the light of denouncing violence and remodeling the schools as open spaces (chapter 6.3.1), transforming educational institutions into landscapes (chapter 6.3.2), streamlining the process into special teacher training and sensitization of teachers (chapter 6.3.3), and sensitizing the society concerning violence (chapter 6.3.4).

\subsubsection{Development of Schools to Open Spaces without Violence}

The study results show a high prevalence of violence in school which makes the school space hostile and un-accommodative of the students' study needs. To shift the paradigm regarding schools as open spaces provides students with learning opportunities to explore real-world issues through authentic learning experiences within collaborative learning environments (Doering, 2006) should be objective of the development of schools by change processes. Such school environments should give room for individual development and ensure no pressure to become or pretend to be like somebody else, without pressure to impose one's perspective on another and no fear of being denied. In such a setting, there is safety for learning to live with differences, conflicts, uncertainty, and freedom to express one's views with respect, and changing one's mind when one is faced with something new. Above all, there is the opportunity to contemplate inclusion of different perspectives by learning to understand the world (Barker, 2017). Open learning spaces enhance opportunities for group discussions, collaborative project learning, and individual student training. Most importantly, they enable teachers to function as mentors, rather than purely as an instructor (Rubin, 2019). Schools should be developed in such direction by in-service training and by a public debate on their self-understanding. 


\subsubsection{Education of Students in a Holistic Landscape}

Based on the study's findings, the praxis of education as a landscape is of importance. The narrative should endeavor to consciously shift towards the education of a broader, mutual, and inclusive perspective. Landscapes should be pluralistic and centered on preparing students to make informed choices and fully participate in society in ways that are reflective, democratic and discursive, by this erasing violence in society. The pluralistic landscapes represent cultures, gender, race, ethnicity, religious backgrounds, class, and socioeconomic status. The diversity and different ways humans come to know and express their voices as equal stakeholders in democratic life and natural environments do constitute a social reality and contribute to equal opportunities in society (Mueller \& Bentley, 2007). Plurality in education relates to cultural pluralism, promoting diversity, learning to appreciate and to value others' contributions, and respecting cultural identities (Terepyshchyi, 2018). It builds an education paradigm with accepted knowledge and values. Taking conscious steps in Cameroon can begin to breach the poverty, violence, funding issues, and unequal educational opportunities for minority students still at the root of achievement gaps.

\subsubsection{Human Capital Development through Teacher Training}

Given the study's ensuing findings and consciousness of the treatment meted out on the students by the teachers, it shows severe pitfalls in teachers' training for educational responsibilities and provision in Cameroon. It is incumbent on educational stakeholders and service providers of education to allow all their teachers to access pre-service, in-service, and to be steep in continuous professional support. Consequently, teacher training and management strategies against violence in schools need to be included in teacher training and made more explicit. Observations on violent behavior in schools should be part of inspectors' responsibility to supervise and make sure that strategies against violence are effectively applied. Such training should comprise a tested and approved program with streamlined modules such as pedagogy, curriculum and planning, child 
protection, wellbeing and inclusion, and teachers' role and well-being (Birungi \& Onyango, 2017). Such training should be reinforced at the inservice level with additional modules on specific skills development. Fullan (2014) views such professional development as an expectation of quality teaching and learning that has to be embedded in the school's culture and became an integral and contributing factor in teachers' capacity building. This should be enhanced with ethical modules that insure peace education and nonviolent communication. In addition, it is important to get the right persons to become teachers. Trainings should be provided to allow effective instructors and ensure that the system can deliver the best possible instruction for every student (Hammond et al., 2010). To avoid and to erase violent structures in schools and in the behavior of teachers, human capital development through teacher training is of huge importance.

\subsubsection{Sensitization of the Society}

Considering the study's results, it will be in the whole society's interest to begin by reflecting the impact of violence in all facets of society. The sensitization can target various spheres and institutions of the community (Eyeoku et al., 2013), beginning with the family, all educational stakeholders, and the print and audiovisual media organs. The sensitization should be structured. Violence of power, gender, and culture needs to be explicitly articulated and extrapolated. By the systemic pursuance of the process, the State should be convinced through institutions spearheaded by the civil society to adopt policy and legislation to check violent entrenched cultural practices. Reflecting the ongoing war in the country and Cameroon society's multicultural setting, the sensitization of the society is difficult and will need the engagement of the state, of churches, civil organizations and media, especially the audiovisual media. 


\section{Conclusion: Violence as a Challenge}

This study was intended to examine the impact of violence on the learning outcome of students in Cameroon. The study results show the negative effect of violence on the students' self-esteem and motivation and compounded by a school quality that is precarious and substandard. Teachers and education stakeholders should open the debate on violence in the school system in Cameroon and explicitly articulate its devastating effects on the child's development. Furtherance to this, the results of the study are indicating that the violence suffered by students in school is a combination of factors. By delving and analyzing the various forms of violence at home and in school in regards to quality education, this study motivates to shape educational policy reforms in Cameroon.

The review of the literature related to violence indicates that it is a global problem. Competencies of peace, nonviolent communication, tolerance, justice, democratic values, human rights, remain a challenge for teacher training and the organization of schools. Schools need to be developed to open spaces for the inculcation of such values. These challenges specific to the situation in developing countries need more investigation. In addition it was noticed that scales for contextual and specific cultural violence for the African context were inexistent.

In this study, it was as well expressed that structures of violence depend on people. Teachers are important stakeholders who can enhance non-violent pedagogy to become a reality in the classroom and who, through their actions, contribute to schools being safe places for the development of young people. Therefore, this study concludes with a quote from the Latin American Alba Luz Arrieta Cabrales, who, following Paulo Freire's "Pedagogy of the Oppressed", calls on teachers today to contribute to a non-violent school:

"Let`s work on our inner capacity to build peace by transforming violence to nonviolence, building community, cooperating in common well-being, communicating assertively, and respecting each other ideas and thoughts. Doing that in your daily life, you will be a model of building peace, a teacher of peace through your actions by promoting Human Rights, by trusting and caring for yourself and others around you." (Alba Luz Arrieta Cabrales) 



\section{References}

Abd-El-Fattah, S. M. (2007). Is the Aggression Questionnaire bias-free? A Rasch analysis. International Education Journal, 8(2), 237-248.

Abochol, S. I. \& Adegboye, O. O. (2015). The semantic implication of media reports on violence in Nigeria. Journal on English Language Teaching, 5(1), 35-44.

Adesope, A. O. et al. (2017). Effects of Corporal Punishment On Learning Behavior And Students' Academic Performance In Public Secondary Schools In Ibarapa East Local Government, Oyo State. International Journal of Advanced Academic Research | Arts, Humanities \& Education, 3(10), 14-20.

Afolabi, O. E. (2015). Domestic violence, risky family environment, and children: A biopsychology perspective. International Journal of Special Education, 30(2), 44-56.

Agbenyega, J. S. (2006). Corporal Punishment in the Schools of Ghana: Does Inclusive Education Suffer? The Australian Educational Researcher, 33(3), 107-121.

Agbenyega, J. (2017). Early Childhood Education in Sub-Saharan Africa. Retrieved from https://www.oxfordbibliographies.com/view/document/ obo-9780199756810/obo-9780199756810-0079.xml, February 24 $4^{\text {th }} 2020$.

Akhtar, S. I. \& Awan, A. G. (2018). The Impact of Corporal Punishment on Students' Performance in Public Schools. Global Journal of Management, Social Sciences and Humanities, 4(3), 606-621.

Akmatov, M. K. (2011). Child abuse in 28 developing and transitional countries-results from the Multiple Indicator Cluster Surveys. International Journal of Epidemiology, 40, 219-227. https://doi.org/10.1093/ije/dyq168 Akresh, R. (2016). Climate Change, Conflict, and Children. The Future Children, 26(1), 51-71. Retrieved from www.futureofchildren.org, May $17^{\text {th }} 2019$.

Aldig, E., \& Arseven, A. (2017). The Contribution of Learning Outcomes for Listening to Creative Thinking Skills. Journal of Education and Learning, 6(3), 41. https://doi.org/10.5539/jel.v6n3p4.

Alrawwad, T. M., \& Alrfooh, A. E. (2014). Causes of Students' Violence at AL-Hussein Bin Talal University. International Education Studies, 7(3), 30-39. https://doi.org/10.5539/ies.v7n3p30, May $13^{\text {th }} 2019$. 
Alvi, M. H. (2016, March 23). A Manual for Selecting Sampling Techniques in Research (No. 70218). Retrieved from University of Karachi website: https://mpra.ub.uni-muenchen.de/70218/, March $27^{\text {th }} 2018$.

American Humane (2003). American Humane Fact Sheet. Retrieved from www.americanhumane.org, June $10^{\text {th }} 2018$.

Anderson C. A. \& Bushman, B. J. (2002). Human aggression. Annu. Rev. Psychol., 53, 27-51. Retrieved from https://www.annualreviews.org /doi/abs/10.1146/annurev.psych.53.100901.135231, October $5^{\text {th }} 2017$.

APA factsheet (2019). Education and Socio-Economic Status. Retrieved from https://www.apa.org/pi/ses/resources/publications/factsheet-education.pdf, February $29^{\text {th }} 2020$.

Arstein, E. (2009). Associations between Corporal Punishment and Behavioral Adjustment in Preschool-Aged Boys and Girls (Bachelor thesis). University of Michigan, USA. Retrieved from https://www.semanticscholar.org/paper/Corporal-Punishment-and-Behavioral-Adjustment1-\%3A-Arnstein/f163116ef4fda8da2099b0f33936f9ce2cadcb9b, January $10^{\text {th }} 2019$.

Asla, N. T. (1999). Educational Landscapes: Developing School Grounds as Learning Places (Vol. 3). Virginia: Thomas Jefferson Center for Educational Design. Retrieved from https:/files.eric.ed.gov/fulltext/ ED428530.pdf, March 14 2020.

Avci, R. \& Guçray, S. S. (2013). The Relationships among Interparental Conflict, Peer, Media Effects and the Violence Behaviour of Adolescents: The Mediator Role of Attitudes towards Violence. Educational Sciences: Theory \& Practice, 13(4). https://doi.org/10.12738/estp.2013.4.1950

Aypay, A. (2002). Social Background Effects and Academic Achievement during Transition to High School. Mediterranean Journal of Educational Studies, 7(1), 87-103.

Baker, P. S. (2018). A Multicultural Education Praxis: Integrating Past and Present, Living Theories, and Practice. International Journal of Multicultural Education, 20(1), 48-66.

Baldry, A. C. (2003). Bullying in schools and exposure to domestic violence. Child Abuse \& Neglect, 27(7), 713-732. https://doi.org/10.1016/S01452134 (03)00114-5

Bamiwuye, S. O. \& Odimegwu, C. (2014). Spousal violence in sub-Saharan Africa: does household poverty-wealth matter? Reproductive Health, 11(45), 1-10. 
Bandura, A. (1994). Self-Efficacy. In V. S. Ramachaudran (Ed.), Encyclopedia of Human Behavior (pp. 71-81). New York.

Barakat, B. \& Bengtsson, S. (2018). What do we mean by school entry age? Conceptual ambiguity and its implications: The example of Indonesia. Comparative Education, 54(2), 203-224. https://doi.org/10.1080 /03050068.2017.1360564

Barker, R. L. (2017). Introduction to Open Spaces for Dialogue and Enquiry Critical literacy in Higher Education. Retrieved from Center for Citizenship Study and Education website: https://docplayer.net/17727751-Introduction-to-open-spaces-for-dialogue-and-enquiry-critical-literacy-inhigher-education-linda-ramirez-barker.html, April 212020.

Betts, F. (1992). How Systems Thinking Applies to Education. Educational Leadership, 50(3), 38-41.

Bhat, M, S. (1996). Learning: The Treasure Within. (Delor's Report-1996). Paris. Retrieved from UNESCO website: https://www.cukashmir.ac.in > departmentdocs_16 > Delor's Report-1996, June $9^{\text {th }} 2019$.

Birungi, D. \& Onyango, J. (2017). Teacher Training and Capacity Development Strategy. Retrieved from https://data2.unhcr.org/en/documents/download/58971, July $4^{\text {th }}, 2020$.

Bissessar, C. S. (2014). An Exploration of the Relationship between Teachersâ.Ž Psychological Capital and Their Collective Self-Esteem. Australian Journal of Teacher Education, 39(9), 35-52.

Bloustein Center for Survey Research (2017). School Climate Survey, School Staff. Retrieved from https://www.pridesurveys.com/index.php/schoolclimate-surveysteachers-faculty-staff https://doi.org/10.1016/j.chiabu.2009.09.004

Böckler, N. et al. (Eds.) (2013). School Shootings: International Research, Case Studies and Concepts for Prevention. New York, NY: Springer New York. Retrieved from https://link.springer.com/content/pdf/10.1007\%2F978- 1-4614-5526-4.pdf https://doi.org/10.1007/ 978-1-4614-5526-4, October $5^{\text {th }} 2017$.

Bos, W., Schwippert, K. \& Stubbe, T. (2007). Die Koppelung von sozialer Herkunft und Schülerleistung im internationalen Vergleich. [The relation between social background and students'outcome in international comparison] In: Bos. W.; Hornberg, S., Arnold, K.H. Faust, G., Fried, L., Lankes, E.-M., Schwippert, K. \& Valtin, R. (eds.): IGLU 2006. Lesekompe- 
tenzen von Grundschulkindern im Deutschland im internationalen Vergleich [Reading competences of primary school students in Germany in international comparison]. Waxmann: Münster, p.225-248.

Bufacchi, V. (2005). Two Concepts of Violence. Polititcal Studies Review, 3, 193-204. Retrieved from journals.sagepub.com/doi/10.1111/j.14789299.2005.00023.x

Building a Culture of Hope (2013). Staff and Team Questionnaire: A Sense of Pride, Self-Esteem, and Self-Confidence. Retrieved from http://go.solution-tree.com/schoolimprovement, October $10^{\text {th }} 2017$.

Bunch, M. E. (1958). The Concept of Motivation. The Journal of General Psychology, 58(2), 189-205. https://doi.org/10.1080/00221309.1958. 9920394

Campbell, J. C., \& Lewandowski, L. A. (1997). Mental and physical health effects of intimate partner violence on women and children. Psychiatric Clinics of North America, 20(2), 353-374. https://doi.org/10.1016/S0193953X(05)70317-8

Caprioli, M. (2005). Primed for Violence: The Role of Gender Inequality in Predicting Internal Conflict. International Studies Quarterly, 49, 161-178. Retrieved from https://onlinelibrary.wiley.com/doi/abs/10.1111/j.00208833.2005.00340.x, August $1^{\text {st }}, 2017$.

Carrel, S. E. \& Hoekstra, M.L. (June 2009). Externalities in the classroom: How children exposed to domestic violence affect everyone's kids (University of Kentucky Center for Poverty Research Discussion Paper). Pittsburg. Retrieved from University of Kentucky website: http://www.ukcpr.org/, September $1^{\text {st }} 2017$.

Carey, D. \& Ernst, E. (2006). "Improving Education Achievement and Attainment in Luxembourg", OECD Economics Department Working Pape (No. 508). OECD Publishing. Retrieved from OECD website: www.oecd.org/eco/working_papers

https://doi.org/10.1787/431707836184

Cash, P., Stanković, T. \& Štorga, M. (2016). An Introduction to Experimental Design Research. In P. Cash, T. Stanković, \& M. Štorga (Eds.), Experimental design research: Approaches, perspectives, applications (Vol. 42, pp. 3-12). Switzerland: Springer. https://doi.org/10.1007/978-3-31933781-4_1

Cash, P., Stanković, T. \& Štorga, M. (Eds.) (2016). Experimental design research: Approaches, perspectives, applications. Switzerland: Springer. https://doi.org/10.1007/978-3-319-33781-4 
Catalano, R. F. et al. (2009). The Importance of Bonding to School for Healthy Development: Findings from the Social Development Research Group. Journal of School Health, 74(7). https://doi.org/10.1111/j.17461561.2004.tb08281.x

Christopher, J. C., Bickhard, M. H. \& Lambert, G. S. (2001). Otto Kernberg's Object Relations Theory: A Metapsychological Critique. Theory \& Psychology, 11(5), 687-711. https://doi.org/10.1177/0959354301115006

Coleman, P. T. \& Deutsch, M. (2000). Cooperation, Conflict Resolution, and School Violence: A Systems Approach. Choices Briefs Number 5. Retrieved from https://www.academia.edu/37174159/Cooperation_Conflict_Resolution_and_School_Violence_A_Systems_Approach._Choices_Briefs_Number_5, June $6^{\text {th }} 2020$.

Colorado Education Initiative (2014). Colorado's Student Perception Survey. Retrieved from http://www.coloradoedinitiative.org/our-work/educatoreffectiveness/studentsurvey/sps-administration/, April $22^{\text {nd }} 2019$.

Constantine, J. et al. (2019). Best Practices Guidebook Supporting Students' Self-Efficacy. Barbourville, KY.: Bluegrass Center for Teacher Quality, Inc. Retrieved from https://eric.ed.gov/?id=ED592850, January $11^{\text {th }} 2021$.

Costley, J. \& Lange, C. (2018). The Moderating Effects of Group Work on the Relationship between Motivation and Cognitive Load. International Review of Research in Open and Distributed Learning, 19(1), 69-89.

Craig A. Anderson and Brad J. Bushman (2002). Human aggression. Annu. Rev. Psycho, 53, 27-51.

Daoust, G. d. (2012). Actions and interactions: Gender equality in teaching and education management in Cameroon. Retrieved from https://www.vsointernational.org/sites/default/files/vso-cameroon-actions-and-interactions-full-report_tcm76-39133.pdf, October $15^{\text {th }} 2019$.

Davis, J. \& Bauman, K. (2013). School Enrollment in the United States: 2011: Population Characteristics. Retrieved from https://files.eric.ed.gov/fulltext/ED579118.pdf, October $14^{\text {th }} 2019$.

Deci, E. L. et al. (1991). Motivation and Education: The Self-Determination Perspective. Educational Psychologist, 26(3 \& 4), 325-346.

Decker, M. R. et al. (2016). Gender-Based Violence against Female Sex Workers in Cameroon: Prevalence and Associations with Sexual HIV Risk and Access to Health Services and Justice. Sexually Transmitted Infections, 92(8), 599-604. https://doi.org/10.1136/sextrans-2015-052463 
Devries, K. et al. (2016). Collecting Data on Violence against Children and Young People: Need for a Universal Standard. International Health, 8(3), 4-11. https://doi.org/10.1093/inthealth/ihv076

Devries, K. (2016). Violence against children and education. International Health, 8(1), 1-2. https://doi.org/10.1093/inthealth/ihv076

DeWall, C. N., Anderson, C. A., \& Bushman, B. J. (2011). The general aggression model: Theoretical extensions to violence. Psychology of Violence, 1(3), 245-258. https://doi.org/10.1037/a0023842

Di Carlo, M. (2011). In Research, What Does A "Significant Effect" Mean? Retrieved from http://www.shankerinstitute.org/blog/research-whatdoes-significant-effect-mean, September $9^{\text {th }} 2019$.

Dicklitch, S. (2002). The Southern Cameroons and minority rights in Cameroon: Failed Democratic Transition in Cameroon: A Human Rights Explanation. Journal of Contemporary African Studies, 152-176. https://doi.org/10.1080/02589001.2011.533059

Dietz, T. L. (2000). Disciplining Children: Characteristics Associated with the Use of Corporal Punishment. Child Abuse \& Neglect, 24(12), 15291542. Retrieved from https://pdfs.semanticscholar.org/f8af/327d0e 9b63992f88b454b039ac163cce411a.pdf, August 22 2019.

Dixon et al. (Ed.) (2017). Hello reader! The Wiley Handbook of What Works in Child Maltreatment: An Evidence-Based Approach to Assessment and Intervention in Child Protection. New York: John Wiley \& Sons Ltd.

Dinbabo, M. (2013). Child Rights in sub-Saharan Africa: A Call for a RightBased Global Research Agenda. Social Work Journal, 49(3), 271-293. https://doi.org/10.15270/49-3-47.

Donnelly, M. \& Straus, M. (Eds.). (2005). Corporal Punishment of Children in Theoretical Perspective. New Haven; London: Yale University Press. Retrieved January 13, 2021, from http://www.jstor.org/stable/j.ctt1njkrb

Doering, A. (2006). Adventure Learning: Transformative hybrid online education. Distance Learning, 27(2), 197-215.

Doherty, D. \& Berglund, D. Psychological Abuse A Discussion Paper (No. HP20-12/2008E-PDF). Ottawa. Retrieved from Public Health Agency of Canada, website: www.phac-aspc.gc.ca/nc-cn, September $5^{\text {th }} 2017$.

Durlak, J. A. et al. (2011). The Impact of Enhancing Students Social and Emotional Learning: A Meta-Analysis of School Based Universal Interventions. Child Development, 82(1), 405-435. https://doi.org/10.1111/j. 1467-8624.2010.01564.x 
EDQUAL (2006). The Concept of Quality in Education: A Review of the International Literature on the Concept of Quality in Education (No. 3). Retrieved from University of Bristol website: www.edqual.org, June $9^{\text {th }} 2019$.

EFA global monitoring report (2005). Education for all: The quality imperative. Paris. Retrieved from UNESCO website: www.efareport.unesco.org, October $10^{\text {th }} 2017$.

Eisenbraun, K. D. (2007). Violence in schools: Prevalence, prediction, and prevention. Aggression and Violent Behavior, 12, 459-469.

Evans, M.D.R.et al. (2010). Family scholarly culture and educational success: Books and schooling in 27 nations. Research in Social Stratification and Mobility, 28(2), 171-197. https://doi.org/10.1016/j.rssm.2010.01.002

EKD (2013). Education from a protestant perspective: A collection of documents from the Evangelical Church in Germany (No. ISBN 978-3-57905965-5). Gütersloh. Retrieved from Evangelische Kirche in Deutschland website: www.gtvh.de, August 16th 2017.

Ellison, C.G. \& Sherkat, D.E. (1993). Conservative Protestantism and support for corporal punishment. American Sociological Review, 58(1), 131144.

Ember, C. R. \& Ember, M. (2005). Explaining Corporal Punishment of Children: ACross-Cultural Study. American Anthropologist, 107(4), 609-619.

Eyeoku, E. K. et al. (2013). Public Sensitization as a Tool for Preventing Domestic Violence Against Women in Nsukka Education Zone, Enug. USChina Education Review, 3(4), 245-252.

Fadiji, A. W. \& Reddy, V. (2020). Learners' Educational Aspirations in South Africa: The Role of the Home and the School. South African Journal of Education, 40(2), 1-13. https://doi.org/10.15700/saje.v40n2a1712

Farmer, P. (2009). On Suffering and Structural Violence: A View from Below. Race/Ethnicity: Multidisciplinary Global Contexts, 3(1), 11-28. https://doi.org/10.1353/rac.0.0025

Ferrara, P.et al. (2019). Physical, psychological and social impact of school violence on children. Italian Journal of Pediatrics, 45(1), 76. https://doi.org/10.1186/s13052-019-0669-z

Fredriksson, U. (September 2004). Quality Education: The Key Role of Teachers (No. 14). Retrieved from Educational International website: glotta.ntua.gr/posdep/Dialogos/Quality/ei_workingpaper_14.pdf, June $9^{\text {th }} 2019$. 
Freire, P. (2000). Pedagogy of the oppressed (30th anniversary Ed.). New York: Continuum. Retrieved from https://libcom.org/files/Paulo\%20 Freire,\%20Myra\%20Bergman\%20Ramos,\%20Donaldo\%20Macedo\%20\%20Pedagogy\%20of\%20the\%20Oppressed,\%2030th\%20Anniversary\% 20Edition\%20(2000,\%20Bloomsbury\%20Academic).pdf, June $5^{\text {th }} 2019$.

Fullan, M. (2014). The Principal. Three Keys to Maximizing Impact. San Francisco, CA: John Wiley.

Furlong, M. J. et al. (2005). Development of the California School Climate and Safety Survey Short Form. Psychology in the Schools, 42(2). https://doi.org/10.1002/pits.20053

Gall, M.et al. (2003). Educational Research: An Introduction (7th Ed.). Boston, MA: Allyn and Bacon. Retrieved from https://epdf.pub/queue/educational-research-an-introduction-7th-edition.html, August 30 2019.

Gallagher, M. J. \& Therbege, R. (2010): School Effectiveness Framework. A support for school improvement and student success. Retrieved from http://www.edu.gov.on.ca/eng/literacynumeracy/sef2013.pdf, November $1^{\text {st }} 2017$.

Galtung, J. (1990). Cultural Violence. Journal of Peace Research, 27(3), 295305.

Garbarino, J. (2001). An ecological perspective on the effects of violence on children. Journal of Community Psychology, 29(3), 361-378.

Gardner, D. G. \& Pierce, J. L. (1998). Self-Esteem and Self-Efficacy within the Organizational Context. An Empirical Examination. Group and Organization Management, 23(1), 48-70

Gauthier, C. \& Dembélé, M. (2005). Quality of teaching and quality of education: a review of research findings; Background paper for the Education for all global monitoring report 2005: the quality imperative; 2004. EFA Monitoring Report. Retrieved from https://www.researchgate.net/.../252993886_Quality_of_teaching_and_quality_of_educ, October $7^{\text {th }} 2017$.

George, D. \& Mallery, P. (2016). SPSS/Windows Step by Step: A Simple Guide and Reference, 11.0 update (14th Ed.). Boston, MA: Allyn and Bacon. Retrieved from https://lib.ugent.be/catalog/rug01:001424067, August $20^{\text {th }} 2019$.

Gershoff, E. T. (2002). Corporal Punishment by Parents and Associated Child Behaviors and Experiences: A Meta-Analytic and Theoretical Review. Psychological Bulletin, 128(4), 539-573. https://doi.org/10.1037/ /0033-2909.128.4.539 
Ghorab, Hisham \& Al-Khaldi, Jamal (2014). School Violence and its Effects on Children's Attitudes towards Education and their Academic Achievement: Research Study. Journal of Education and Practice, 5(3), 173-185.

Girmen, P., Kaya, M.F. \& Kilic, Z. (2018). Violence at Primary Schools and Its Reflections on the Press and the Visual Media in Turkey. International Journal of Research in Educational and Science (IJRES), 4(2), 703-713. https://doi.org/10.21890/ijres.438383

Glaser, D. (2002). Emotional abuse and neglect (psychological maltreatment): a conceptual framework. Child Abuse \& Neglect, 26, 697-714.

GPE (2019). Results Report 2019. Washington. Retrieved from Global Partnership for Education website: http://creativecommons.org/licenses/by/3.0/igo, October $14^{\text {th }} 2020$.

Greenberg, M. T. et al. (2003). Enhancing school-based prevention and youth development through coordinated social, emotional, and academic learning. American Psychologist, 58(6-7), 466-474. https://doi.org/10. 1037/0003-066X.58.6-7.466

Grima, G. (2008). What is quality education? Retrieved from https://timesofmalta.com/articles/view/what-is-quality-education. 234848, May $9^{\text {th }} 2019$.

Guerra, N. G. \& Smith, E. P. (Ed.) (2006). Preventing youth violence in a multicultural society. Washington D. C. Retrieved from http://dx.doi.org/10.1037/11380-003.

Gunzelmann, B. (2005). Safety in the Schools: Hidden Dangers within Our Schools: What Are These Safety Problems and How Can We Fix Them? Retrieved from https://files.eric.ed.gov/fulltext/EJ685013.pdf, July $10^{\text {th }}$ 2018.

Hague, P. (2006). A Practical Guide to Market Research. London: Grosvenor House Publishing Ltd. Retrieved from www.b2binternational.com, September 102018.

Hamburger, M. E., Basile, K. C. \& Vivolo, A. M. (2011). Measuring Bullying Victimization, Perpetration, and Bystander Experiences: A Compendium of Assessment Tools (2nd). Atlanta, GA. Retrieved from www.cdc.gov/violenceprevention, October $10^{\text {th }} 2017$.

Hammond, L. D., Wei, R. C. \& Andree, A. (August 2010). How HighAchieving Countries Develop Great Teachers. Dallas, TX. Retrieved from Stanford Center for Opportunity Policy in Education website: http://edpolicy.stanford.edu, July $4^{\text {th }} 2020$. 
Han, S. (2014). School mobility and students' academic and behavioral outcome. International Journal of Education Policy \& Leadership, 9(6), 1-14. Retrieved from https://files.eric.ed.gov/fulltext/EJ1050527.pdf, May $4^{\text {th }}$ 2018.

Hattie, J. (2010). Visible learning: A synthesis of over 800 meta-analyses relating to achievement (Reprinted.). London: Routledge. Retrieved from https://www.readpbn.com/pdf/Visible-Learning-A-Synthesis-of-Over800-Meta-Analyses-Relating-to-Achievement-Sample.pdf, December $18^{\text {th }}$ 2019.

Heatherton, T. E. \& Polivy, J. (1991). Development and Validation of a Scale for Measuring State Self-Esteem. Journal or Personality and Social Psychology, 60(6), 895-910. Retrieved from http://www.academia.edu/download/37381608/91_Heatherton_Polivy_JPSP.pdf, October $7^{\text {th }} 2017$.

Hershcovis, M. S. \& Barling, J. (2010). Towards a multi-foci approach to workplace aggression: A meta-analytic review of outcomes from different perpetrators: A meta-analytic review of outcomes from different perpetrators. Journal of Organizational Behavior, 31(1), 24-44. https://doi.org/ 10.1002/job.621

Hildyard, K. L., \& Wolfe, D. A. (2002). Child Neglect: Developmental Issues and outcomes. Child Abuse \& Neglect, 26(6-7), 679-695. https://doi.org/10.1016/S0145-2134 (02)00341-1

Ho, K. (2007). Structural Violence as a Human Rights Violation. Essex Human Rights Review, 4(2), 1-17.

Holt, S., Buckley, H., \& Whelan, S. (2008). The impact of exposure to domestic violence on children and young people: A review of the literature. Child Abuse \& Neglect, 32(8), 797-810. https://doi.org/10.1016 /j.chiabu.2008.02.004

Hood, C. L. (2017). Bringing Students' Voices into Campus Conversations about Essential Learning Outcomes: A Survey of Students at a Mid-Sized State University. International Journal for the Scholarship of Teaching and Learning, 11(2), 1-7. https://doi.org/10.20429/ijsotl.2017.110211

Honstra, L.et al. (2018). A dual pathway of student motivation: Combining an implicit and explicit measure of student motivation. Frontline Learning Research, 6(1), 1-18. https://doi.org/10.14786/flr.v6i1.305

Hughes, C. (2020). Addressing violence in education: From policy to practice. Prospects, 48(1-2), 23-38. https://doi.org/10.1007/s11125-01909445-1 
Hyde-Nolan, M.E. \& Juliao, T. (2012).Theoretical basis of family violence' 'in' Fife, R.S. \& Schrager, S. (Ed.) (2012). Family violence: What Health Care Providers Need to know. Ontario: Jones \& Bartlett. Retrieved from samples.jbpub.com/9780763780340/80340_FMxx_FINAL.pdf, October $29^{\text {th }} 2017$.

International Covenant on Economic, Social and Cultural Rights 1 (1976). Retrieved from https://www.ohchr.org/en/professionalinterest/pages/cescr.aspx, June $17^{\text {th }} 2018$.

International NGO Council (October 2012). Violating Children's Rights: Harmful practices based on tradition, culture, religion or superstition. Retrieved from The International NGO Council on the Rights of the Child website: http://www.crin.org/violence/adcouncil/index.asp, June $19^{\text {th }}$ 2020.

Ismail, D. \& Majeed, A. (2011). Student Self Esteem and Their Perception of Teacher Behavior: A Study of Class Grouping System in Pakistan. International Journal of Business and Social Science, 2(16), 103-113.

Jahnke, H. et al. (Ed.) (2019). Geographies of Schooling (Vol. 14). Cham: Springer International Publishing. Retrieved from https://link. springer.com/content/pdf/10.1007\%2F978-3-030-18799-6.pdf

https://doi.org/10.1007/978-3-030-18799-6

Jessor, R., Donovan, J. E. \& Costa, F. M. (1992). Health Behavior Questionnaire: High School Form. Retrieved from https://ibs.colorado.edu/jessor/questionnaires/questionnaire_hbq92.pdf, May $10^{\text {th }}$ 2018.

Jolly, R. (2010). Cultured Violence: Narrative, Social Suffering, and Engendering Human Rights in Contemporary South Africa (1st Ed.). Post colonialism across the Disciplines: Vol. 7. Liverpool: Liverpool University Press. Retrieved from https://www.jstor.org/stable/j.ctt5vjbcj https://doi.org/10.5949/UPO9781846315244.004, August 31 2017.

Jolly, R. (Ed.) (2012). Cultured Violence: Narrative, Social Suffering, and Engendering Human Rights in Contemporary South Africa. Cambridge: Cambridge University Press. https://doi.org/10.5949/UPO97 81846315244

Kazu, I. Y. \& İş, A. (2018). An Investigation about Actualization Levels of Learning Outcomes in Early Childhood Curriculum. Journal of Education and Training Studies, 6(3), 66. https://doi.org/10.11114/jets.v6i3.2928 
Keddie, A. (2003). On leadership and fitting in: Dominant understandings of masculinities within an early peer group. The Australian Educational Researcher, 30(1), 83-100.

Kellner, D. (1998). Multiple Literacies and critical pedagogy in a multicultural society. Educational Theory, 48(1), 103-122.

Kennedy, D. (2006). Writing and using learning outcomes: a practical guide. Cork. Retrieved from http://hdl.handle.net/10468/1613, September $8^{\text {th }}$ 2018.

Keshavarz, M. (2011). Measuring course-learning outcomes. Journal of Learning Design, 4(4), 1-8.

Khewu, N. P. D. (2008). A Study of the Practices in the Alternatives to Corporal Punishment Strategies Being Implemented in Selected Primary Schools in Buffalo City Metro Municipality. Implications for School Leadership (PhD). University of Fort Hare, South Africa. Retrieved from https://core.ac.uk/download/pdf/145040007.pdf, September $3^{\text {rd }} 2017$.

Kothari, C. R. (2004). Research Methodology: Methods and Techniques (2nd). New Delhi: New Age International Publishers Limited. Retrieved from www.newagepublishers.com, December $6^{\text {th }} 2017$.

Krogull, S., Scheunpflug, A. \& Rwambonera, F. (2014). Teaching social competencies in post-conflict societies: A contribution to peace in society and quality in learner-centred education. Münster: Waxmann. Retrieved from [Search domain www.uni-bamberg.de/fileadmin/uni/fakultaeten/ huwi_lehrstuehle/allgpaed/003Lehrstuhl_Projekte/Learnercentered_Education/Krogull_Scheunpflug_Rwambonera_Englisch_mit_Umschlag.pdf], July $5^{\text {th }} 2017$.

Krug, E. G. et al. (2002). The world report on violence and health. The Lancet, 360(9339), 1083-1088. https://doi.org/10.1016/S0140-6736 (02)111 33-0

Kwachou, T. M. E. (February 2015). Sexuality Education in Cameroon: The Necessity and Possibilities. London. Retrieved from UCL Institute of Education, website: https://www.academia.edu/17941213/Sexuality_Education_in_Cameroon_The_Necessity_and_Possibilities, March $26^{\text {th }} 2020$.

Kyriakides, L., Kaloyirou, C. \& Lindsay, G. (2006). An analysis of the Revised Olweus Bully/Victim Questionnaire using the Rasch measurement model. British Journal of Educational Psychology, 76, 781-801. https://doi.org/10.1348/000709905X53499 
Lange, S. (2016). Achieving Teaching Quality in Sub-Saharan Africa. Wiesbaden: Springer Fachmedien Wiesbaden. https://doi.org/10.1007/978-3658-14683-2

Laye, A. M. \& Mykota, D. B. (2014). Rural Canadian Youth Exposed to Physical Violence. Canadian Journal of School Psychology, 29(1), 21-39. https://doi.org/10.1177/0829573514521772

Li, Z. \& Qiu, Z. (2018). How does family background affect children's educational achievement? Evidence from Contemporary China. The Journal of Chinese Sociology, 5(1), 1. https://doi.org/10.1186/s40711-018-0083-8

Lloyd, M. (2018). Domestic Violence and Education: Examining the Impact of Domestic Violence on Young Children, Children, and Young People and the Potential Role of Schools. Frontiers in Psychology, 9, 2094. https://doi.org/10.3389/fpsyg.2018.02094

Lynch, M. \& Ciccheti, D. (1997). Children's Relationships with Adults and Peers: An Examination of Elementary and Junior High School Students. Society for the Study of School Psychology, 35(1), 81-99.

Majanga, E., Mukonyi, P. \& Vundi, S. (2015). Socio-Pedagogical Challenges facing Orphaned and Vulnerable Children in the Aftermath of the 20072008 Election Violence in Nakuru County, Kenya. Journal of Education and Practice, 6(6), 155-160.

Marjoribanks, K. (2005). Family Background, Adolescents' Educational Aspirations, and Australian Young Adults' Educational Attainment. International Education Journal, 6(1), 104-112.

Marmodoro, A. (Ed.) (2010). The Metaphysics of Powers. A Powerful Theory of Causation: Routledge. https://doi.org/10.4324/9780203851289.

Mbogo, R. W. (2018). The Impact of Domestic Violence on the Learning Process of High School Students. Advances in Social Sciences Research Journal, 5(8), 544-554. https://doi.org/10.14738/assrj.58.5138.

McGaha-Garnett, V. (2013). The Effects of Violence on Academic Progress and Classroom Behavior: From a Parent's Perspective. Retrieved from https://www.counseling.org/docs/default-source/vistas/the-effects-of-violence-on-academic-progress-and-classroom-behavior.pdf?sfvrsn=1828de3f_12, October $12^{\text {th }} 2019$.

McCloskey, L. A. et al. (2016). Determinants of Intimate Partner Violence in Sub-Saharan Africa: A Review of Prevention and Intervention Programs. Partner Abuse, 7(3), 277-315. https://doi.org/10.1891/19466560.7.3.277 
McGuigan, W. M. \& Pratt, C. C. (2001). The predictive impact of domestic violence on three types of child maltreatment. Child Abuse \& Neglect, 25(7), 869-883. https://doi.org/10.1016/S0145-2134 (01)00244-7

Mears, D. P. \& Bhati, A. S. (2006). No Community Is an Island: The Effects of Resource Deprivation on Urban Violence in Spatially and Socially Proximate Communities. Criminology, 44(3), 1-36. https://doi.org/10.1111/j. 1745-9125.2006.00056.x.

Meinck, F.et al. (2018). Adaptation and psychometric properties of the ISPCAN Child Abuse Screening Tool for use in trials (ICAST-Trial) among South African adolescents and their primary caregivers. Child Abuse \& Neglect, 82, 45-58. https://doi.org/10.1016/j.chiabu.2018.05.022

Mele, C., Pels, J. \& Polese, F. (2010). A Brief Review of Systems Theories and Their Managerial Applications. Service Science, 2(1/2), 126-135.

Mental health foundation (2008). Cool Down Anger and How to Deal with it. Retrieved from https://www.mentalhealth.org.uk/publications/cooldown/, October $6^{\text {th }} 2018$.

Meyer, E. J. (2008). Gendered harassment in secondary schools: understanding teachers' (non) interventions. Gender and Education, 20(6), 555570. https://doi.org/10.1080/09540250802213115

Meyer, K. \& Wurdinger, S. (2016). Students' Perceptions of Life Skill Development in Project-Based Learning Schools. Journal of Educational Issues, 2(1), 91-114.

Midgley, C.et al. (2000). Manual for the Patterns of Adaptive Learning Scales. Retrieved from www.umich.edu/ pals/PALS 2000_V13Word 97.pdf, July 102018.

Mncube, V. \& Harber, C. (2013). The dynamics of violence in schools in South Africa (No. 98822608). Pretoria. Retrieved from http://www.kre publishers.com/special_volume_The-Dynsmics-of-Voilence.html, September 252017.

Mueller, M. P. \& Bentley, M. L. (2007). Beyond the "decorated landscapes" of educational reform: Toward landscapes of pluralism in science education. Science Education, 91(2), 321-338. https://doi.org /10.1002/sce.20190

Muller, R. T., Lemieux, K. E. \& Sicoli, L. A. (2001). Attachment and Psychopathology among Formerly Maltreated Adults. Journal of Family Violence, 16(2), 151-169 
Mukherjee, J. S. (2007). Structural Violence, Poverty and the AIDS Pandemic. Development, 50(2), 115-121. https://doi.org/10.1057/palgrave.development.1100376

Muluneh, M. D. (2020). Gender Based Violence against Women in Sub-Saharan Africa: A Systematic Review and Meta-Analysis of Cross-Sectional Studies. International Journal of Environmental Research and Public Health, 17(3), 903. https://doi.org/10.3390/ijerph17030903

Mumthas, N. S., Munavvir, J. \& Gafoor, A. K. (2014). Student and Teacher Perception of Disciplinary Practices: Types, Reasons, Consequences and Alternatives. Guru Journal of Behavioral and Social Sciences, 2(4), 301308.

Nanyiri, K. (2014). Influence of Discipline Management of Students' Academic Performance in Private Secondary Schools in Mbale Municipality, Mbale District. (Master Thesis). Islamic University, Uganda. Retrieved from https://www.academia.edu/14929710/INFLUENCE_OF_DISCIPLINE_MANAGEMENT_O, November $7^{\text {th }} 2018$.

Nchia, L. N.et al. (2013). Teachers "e Conceptions and Obstacles to Sex Education in Primary and Secondary Schools in Cameroon. International Journal of Science and Research, 4(1), 2319-7064.

Nevo, E. \& Vaknin-Nusbaum, V. (2018). Enhancing language and print-concept skills by using interactive storybook reading in kindergarten. Journal of Early Childhood Literacy, 18(4), 545-569. https://doi.org /10.1177/1468798417694482

Ng, P. T. (2015). What is quality education? How can it be achieved? The perspectives of school middle leaders in Singapore. Educational Assessment, Evaluation and Accountability, 27(4), 307-322. https://doi. org/10.1007/s11092-015-9223-8

Njobati, F. \& Njoya, C. E. (2021, in print). Case Study: Faith Based Schooling in Cameroon. Background Paper to the Education for All Report 2021. UNESCO: Paris.

Nsamenang, A. B. (2010). Issues in and Challenges to Professionalism in Africa's Cultural Settings. Contemporary Issues in Early Childhood, 11(1), 20-28. https://doi.org/10.2304/ciec.2010.11.1.20

Nyagosia, P. O. (2011). Determinants of the Differential Kenya Certificate of Secondary Education Performance and School Effectiveness in Kiambu and Nyeri Counties, Kenya (Masters). Kenyatta University, Kenya. Retrieved from https://www.semanticscholar.org/paper/Determinants-ofdifferential-Kenya-Certificate-of- 
Nyagosia/8a54fd077972fa111bdbefb4a4523b7f23e8d71d, January $11^{\text {th }}$ 2021.

OECD (2009). Student Questionnaire for PISA 2009: Main Survey. Retrieved from https://www.oecd.org/pisa/pisaproducts/PISA09_Student_questionnaire.pdf

OECD (2010). Education at a Glance 2010: OECD Indicators (No. ISBN 97892-64-055988). Paris, France. Retrieved from OECD website: www.oecd.org/bookshop

OECD (2010). PISA 2009 Results: Overcoming Social Background: OECD. Retrieved from www.oecd.org/publishing/corrigenda. https://doi.org/10. 1787/9789264091504-en

OECD (2018). PISA 2015: PISA Results in Focus. Retrieved from OECD website: http://www.oecd.org/pisa

Okioga, C. K. (2013). The Impact of Students' Socio-economic Background on Academic Performance in Universities, a Case of Students in Kisii University College. American International Journal of Social Science, 2(2), 38-46. Retrieved from https://aijssnet.com/journals/Vol_2_No_2_March_2013/5.pdf, February $3^{\text {rd }} 2020$.

O'Neal, N. (2008). Corporal punishment in public schools: A call for legal reforms. African Human Rights Law Journal, 8(1), 1-257.

Osofsky, J. D. (1999). The Impact of Violence on Children. The Future of Children Domestic Violence and Children, 9(3), 33-49.

Owen, S. (2011). Briefing for the Human Rights Council Universal Periodic Review. Retrieved from End All Corporal Punishment of Children website: www.endcorporalpunishment.org, January $30^{\text {th }} 2018$.

Panorama Education (2015). User Guide. Social-Emotional Learning. Retrieved from https:/dpi.wi.gov/sites/default/files/imce/sspw/pdf/ seluserguide.pdf, September $5^{\text {th }} 2018$.

Pandey, P. \& Pandey, M. M. (2015). Research Methodology; Tools and Techniques. Romania. Retrieved from www.euacademic.org/BookUpload/9.pdf, June 25 2019.

Parkes, J. \& Heslop, J. (2011). Stop Violence against Girls in School: A crosscountry analysis of baseline research from Ghana, Kenya and Mozambique. Retrieved from https://www.researchgate.net/publication/ 320242441_Stop_Violence_Against_Girls_in_School_A_cross_country_ analysis_of_baseline_research_from_Ghana_Kenya_and_Mozambique, April 16 2018. 
Pillay, J. (2014). Advancement of children's rights in Africa: A social justice framework for school psychologists. School Psychology International, 35(3), 225-240. https://doi.org/10.1177/0143034313515990, June $19^{\text {th }}$ 2020.

Porter, T. \& Córdoba, J. (2009). Three Views of Systems Theories and their Implications for Sustainability Education. Journal of Management Education, 33(3), 323-347. https://doi.org/10.1177/1052562908323192

Radojlovic, J. et al. (2015). Family Background and School Achievement of Children with Motoric Disorders. Journal of Education in Science, Environment and Health, 1(2), 95-101.

Raggozini, R. L. (2009). A Study of Social Desirability and Self-Esteem. Retrieved from http://www.drspeg.com/research/2009/socialdesirability.pdf, May $25^{\text {th }} 2019$.

Rahman, M. K. (2015). Is there any different between 'control variable' and 'moderating variable? Retrieved from https://www.researchgate.net/ post/Is_there_any_different_between_control_variable_and_moderating_variable2, January $13^{\text {th }} 2021$.

Ramachaudran, V. S. (Ed.) (1994). Encyclopedia of Human Behavior. New York

Rawat, D. (2016). Importance of Communication in Teaching-Learning Process. Scholarly Research Journal Dor Interdisciplinary Studies, 4(3), 3058-3063.

Raykov, T. (2001). Bias of Coefficient $\alpha$ for Fixed Congeneric Measures with Correlated Errors. Applied Psychological Measurement, 25(1), 69-76. https://doi.org/10.1177/01466216010251005

Redondo, N.et al. (2017). Psychometric properties of the Aggression Questionnaire: A replication in a sample of partner-assaultive men in psychological treatment. Psicothema, 29(4), 584-589. https://doi.org/ 10.7334/psicothema2016.390

Ress, A. \& Azzolini, D. (2014). Primary and Secondary Effects of Social Background on Educational Attainment in Italy. Italian Journal of Sociology of Education, 6(1), 53-58. Retrieved from http://www.ijse.eu/wp-content/uploads/2014/02/2014_1_3.pdf, February $3^{\text {rd }} 2021$.

Roberto, J \& Reigeluth, C. M. (2010). The Systemic Change Process in Education: A Conceptual Framework. Contemporary Educational Technology, 1(2), 97-117. https://doi.org/10.30935/cedtech/5968 
Romano, J. L. (2015). Prevention theories for behavior change. In J. L. Romano, Prevention psychology: Enhancing personal and social well-being. American Psychological Association, 23-45. https://doi.org/10.1037 /14442-003

Rubin, C. M. (2019). The Global Search for Education: Open Spaces Open Minds. Retrieved from https://www.cmrubinworld.com/open-spacesopen-minds-school-environment, June $4^{\text {th }} 2020$.

Rwenge, M. (2000). Sexual Risk Behaviors among Young People in Bamenda, Cameroon. International Family Planning Perspectives, 26(3), 118-123+130.

Sabates, R. (July 2010). Paper commissioned for the EFA Global Monitoring Report 2011. The hidden crisis: Armed conflict and education (No. 2011/ED/EFA/MRT/PI/08). Retrieved from University of Sussex website: http://www.create-rpc.org/, March 31 2020.

Salvage, J. et al. (Ed.) (2012). MPW Course 4: Structural violence and the underlying causes of violent conflict (2nd). London: Medact. Retrieved from http://www.medicalpeacework.org/, October $9^{\text {th }} 2019$.

Savin-Badin, M. \& Major, C. H. (2013). Qualitative Research. The Essential Guide to Theory and Practice. New York: Routledge.

Scheunpflug, A. \& Wenz, M. (2012). Promoting critical knowledge, skills and qualifications for sustainable development in Africa: How to design and implement an effective response through education and training systems: Transnational Study on Core Social Competencies - a Sustainable Contribution to Quality in Education and Social Cohesion in Society, Ouagadougou, Burkina Faso.

Schjoedt L. \& Sangboon, K. (2015). Control Variables: Problematic Issues and Best Practices. In K. D. Strang (Ed.), The Palgrave Handbook of Research Design in Business and Management. New York: Palgrave Macmillan. Retrieved from https://doi.org/10.1057/9781137484956_15, January $12^{\text {th }} 2021$.

Schlack, R. et al. (2013). Physical and Psychological Violence Perpetration and Violent Victimization in the German adult population: Results of the German Health Interview and Examination Survey for Adults (DEGS1). Bundesgesundheitsblatt - Gesundheitsforschung - Gesundheitsschutz, 5(6), 755-764. https://doi.org/10.1007/s00103-013-1691-8

Scriver, S., Duvvury, N., Ashe, S., Raghavendra, S. \& O’Donovan, D. (2015). Conceptualising violence: A holidtic approach to understanding violence against women and girls. Retrieved from National University of Ireland, 
Galway website: https://www.researchgate.net/publication/290344003, October $10^{\text {th }} 2017$.

Shields, N., Nadasen, K. \& Pierce, L. (2009). A comparison of the effects of witnessing community violence and direct victimization among children in Cape Town, South Africa. Journal of Interpersonal Violence, 24(7), 1192-1208. https://doi.org/10.1177/0886260508322184

Silfver, E. (2019). Gender performance in an out-of-school science context. Cultural Studies of Science Education, 14(1), 139-155. https://doi.org/ 10.1007/s11422-017-9851-z

Soiferman, L. K. (2010). Inductive and Deductive Research Approaches: Compare and Contrast Inductive and Deductive Research Approaches. Retrieved from https://eric.ed.gov/?q=Compare+and+Contrast+Inductive+and+Deductive+Research+Approaches, March $23^{\text {rd }} 2018$.

Ssenyonga, J.et al. (2018). Reducing violence against children by implementing the preventative intervention Interaction Competencies with Children for Teachers (ICC-T): Study protocol for a cluster randomized controlled trial in Southwestern Uganda. Trials, 19(1), 435. https://doi.org/10.1186/s13063-018-2827-9

Stanciu, E. A. \& Rogers, J. L. (2011). Survivors of Political Violence: Conceptualizations, Empirical Findings, and Ecological Interventions. International Journal for the Advancement of Counselling, 33(3), 172-183. https://doi.org/10.1007/s10447-011-9120-x

Stewart, A. L., Hays, R.D. \& Ware, J. E. (1988). Communication The MOS Short-form General Health Survey Reliability and Validity in a Patient Population. Medical Care, 26(7), 724-735.

Strang, K. D. (Ed.) (2015). The Palgrave Handbook of Research Design in Business and Management. New York: Palgrave Macmillan. https://doi.org/10.1057/9781137484956_15

Straus, M. A. (1991). Discipline and Deviance: Physical Punishment of Children and Violence and Other Crime in Adulthood. Social Problems, 38(2), 133-154.

Straus, M. A. \& Paschall, M. J. (2009). Corporal Punishment by Mothers and Development of Children's Cognitive Ability: A Longitudinal Study of Two Nationally Representative Age Cohorts. Journal of Aggression, Maltreatment \& Trauma, 18(5), 459-483. https://doi.org/10.1080/109 26770903035168

Tangwe, A. T. (2015). School Discipline: Alternatives to Corporal Punishment (M.A. Thesis). University of Bamberg, Germany. 
Tangwe, A, T. \& Kiawi, P. (2014). Cameroon Since 1800: An Advanced Level Approach (3rd Ed.). Limbe: Presprint.

Taylor, C. A., Hamvas, L. \& Paris, R. (2011). Perceived Instrumentality and Normativeness of Corporal Punishment Use among Black Mothers. Family Relations, 60(1), 1-16. https://doi.org/10.1111/j.17413729.2010.00633.x

Tchombe, T. (2006, March 6). Education, Violence, Conflict and Prospect for Peace in Africa: An Evaluation of Research Endeavors for Peace Education. Yaounde, Cameroon.

Teke, J. T. \& Johnson, S. T-F. (2019). Causes, Prevention and Solutions to Domestic Violence against Women in Cameroon: A Qualitative Study of Opinions from Perpetrators and Victims. International Journal of Research and Innovation in Social Science (IJRISS), 3(3), 322-327.

Terepyshchyi, S. (2017). Educational Landscape as a Concept of Philosophy of Education. Retrieved from STUDIA WARMIŃSKIE 54 website: https://www.researchgate.net/publication/324063565_Educational_Land scape_as_a_Concept_of_Philosophy_of_Education?enrichId=rgreq-8fee fe9126ae8e19b00ef20b5f77dc82-XXX\&enrichSource=Y292ZXJQYWd1OzMyNDA2MzU2NTtBUzo2MDkxMzgzNTg4ODY0MDBAMTUyMjI0 MTMxMDM3OQ\%3D\%3D\&el=1_x_2\&_esc=publicationCoverPdf, July $8^{\text {th }} 2018$.

UK data archive (2014). Quantitative data ingest processing procedures. Retrieved from /licenses/bywww.creativecommons.org/licenses/by-nc $\mathrm{sa} / 3.0 / \mathrm{sa} / 3.0 / \mathrm{sa} / 3.0 / \mathrm{sa} /$, March 22nd 2018.

UNDP (2016). Cameroon Economic and Development Report. Retrieved from UNDP website: https://info.undp.org/docs/pdc/Documents/CMR/Synthese\%20RADEC\%202016\%20En.pdf, August $29^{\text {th }}$ 2019.

UNESCO (2000, April 26). The Dakar Framework for Action: Education for All: Meeting our Collective Commitments (No. ED-2000/WS/27). France. Retrieved from UNESCO website: www.unesco.org, September $3^{\text {rd }} 2017$. UNESCO (2000). Assessing Learning Achievement; Education for All: Status and Trends; Vol.:5; 2000. France. Retrieved from UNESCO website: www.education.unesco.org/efa, December $10^{\text {th }} 2020$.

UNESCO (2005). The Dakar Framework for Action - Education for All: meeting our collective commitments (No. ED-2000/WS/27). France. Retrieved from UNESCO website: www.unesco.org 
UNESCO (2006). Country profile prepared for the Education for All Global Monitoring Report 2007 Strong Foundations: Early Childhood Care and Education: Cameroon Early Childhood Care and Education (ECCE) programs (No. IBE/2006/EFA/GMR/CP/15). Geneva. Retrieved from UNESCO International Bureau of Education (IBE) website: https://unesdoc.unesco.org/ark:/48223/pf0000147945_eng, February $21^{\text {st }} 2020$.

UNESCO (2012). Opportunities lost: The impact of grade repetition and early school leaving. Global education digest: Vol. 2012. Montreal. Retrieved from http://www.uis.unesco.org/, March $31^{\text {st }} 2020$.

UNESCO (2012). Youth and skills: putting education to work; EFA global monitoring report. (No. ED -2012 / WS / 13). Paris. Retrieved from UNESCO website: www.efareport.unesco.org, July $5^{\text {th }} 2019$.

UNESCO (2019). New Methodology Shows that 258 Million Children, Adolescents and Youth Are Out of School. Retrieved from https://reliefweb.int/report/world/new-methodology-shows-258-million-childrenadolescents-and-youth-are-out-school

UNICEF. (2000). Changing lives of girls: Evaluation of the African girls' education initiative. Retrieved from https://www.unicef.org/search /search.php?q_en=Jomtien+report+2000\&, October $23^{\text {rd }} 2017$.

UNICEF (2002). Quality Education for All from a Girl's Point of View. New York. Retrieved from UNICEF website: www.unicef.org, October $10^{\text {th }}$ 2017.

UNICEF (2007). A National Study on Violence against Children and Young Women in Swaziland. Retrieved from https://www.unicef.org/swaziland/Violence_study_report.pdf

UNICEF (2013). Children's Rights in Impact Assessment: A guide for integrating children's rights into impact assessments and taking action for children. Geneva. Retrieved from Danish Institute of Human Rights website: www.unicef.org/csr/156.htm, June $19^{\text {th }} 2020$.

UNICEF (2018). An Everyday Lesson \#END violence in Schools. Retrieved from www.unicef.org, October $15^{\text {th }} 2019$.

UNICEF (September 2018). Raising Learning Outcomes: the Opportunities and Challenges of ICT for Learning. Nairobi. https://www.unicef.org /wca/media/2631/file/Summary.pdf, October $14^{\text {th }} 2020$.

United Nations Universal Declaration of Human Rights 1948. Retrieved from https://www.un.org/en/about-us/universal-declaration-of-humanrights, October $18^{\text {th }} 2017$. 
UNO (1990). Convention on the Rights of the Child. Retrieved from https://www.ohchr.org/Documents/ProfessionalInterest/crc.pdf, September $19^{\text {th }} 2019$.

USAID (2016). Literature Review on School Related Gender-Based Violence: How it is Defined and Studied: EdData II: Data for Education Research and Programming (DERP) in Africa. Retrieved from https://www.eccnetwork.net/sites/default/files/media/file/Literature\%20Review\%20on\%20SRGBV.pdf, March 23 2019.

Usman, M. T. et al. (2016). Parents Socio-Economic Status and Students Academic Performance in Nigeria Educational System. International Journal of Education and Information Technology, 2(3), 14-18.

Üzümcü, B. (2016). Study of Social Desirability Levels of Female Youth Camp Leader Candidates in Accordance with Some Variables. Journal of Education and Training Studies, 4(7), 92-99. https://doi.org/10.11114 /jets.v4i7.1433

Varney, S. (2018). Pre-primary Education - the Importance of Early Learning. Retrieved from https://www.edukaid.com/blog/pre-primary-education-and-the-importance-of-early-learning, February $2^{\text {nd }} 2020$.

Vianden, J. (2016). Ties That Bind: Academic Advisors as Agents of Student Relationship Management. NACADA Journal, 36(1), 19-29. https://doi.org/10.12930/NACADA-15-026a]

Vitikka, E., Salminen, J. \& Annevirta, T. (2012). Physical Activity and Learning: Status Review. Retrieved from www.oph.fi, June 22 2019.

Wairimu, M. J., Macharia, S. M. \& Muiru, A. (2016). Analysis of Parental Involvement and Self-Esteem on Secondary School Students in Kieni West Sub-County, Nyeri County, Kenya. Journal of Education and Practice, 7(27), 82-98.

Weybright, Elizabeth H. et al. (2017). Predicting secondary school dropout among South African adolescents: A survival analysis approach. South African Journal of Education, 37(2), 1-11. https://doi.org/10.15700 /saje.v37n2a1353

Wigfield, A.et al. (1996). A Questionnaire Measure of Children's Motivations for Reading (394137th Ed.). 22. Washington, DC: Office of Educational Research and Improvement (ED). Retrieved from https://files.eric.ed.gov/fulltext/ED394137.pdf, May 20 2018.

Willems, J. (January 2007). Children's Rights and the Prevention of Child Abuse and Neglect: Maastricht. Retrieved from Maastricht University 
website: https://www.researchgate.net/publication/312596724_Children\%27s_Rights_and_the_Prevention_of_Child_Abuse_and_Neglect_The_Quest_for_a_Trias_Pedagogica_of_Children_Parents_and_Society?enrichId=rgreq-4af768dcea9b3e98404c7c1aaec15b24XXX\&enrichSource=Y292ZXJQYWdlOzMxMjU5NjcyNDtBUzo0NTM2NDg4Mjk0MjM2MThAMTQ4NTE2OTcxNzQ3Nw\%3D\%3 D\&el=1_x_2\&_esc=publicationCoverPdf, June $19^{\text {th }} 2020$.

Williams, C. (2007). Research Methods. Journal of Business \& Economic Research, 5(3), 65-72.

Wodon, Q. (2014). Education in Sub-Saharan Africa: Comparing Faith-Inspired, Private Circular and Public Schools. Washington, DC: World Bank Group. Retrieved from http://creativecommons.org/licenses/by/3.0. https://doi.org/10.1596/978-0-8213-9965-1, April $5^{\text {th }} 2020$.

World Health Organization (1995). Female Genital Mutilation: Report of a WHO Technical Working Group. Geneva. Retrieved from WHO website: https://apps.who.int/iris/handle/10665/63602, March 30 2020.

Yildirim, I., Akan, D. \& Yalcin, S. (2016). Teacher Behavior Unwanted According to Student's Perceptions. International Education Studies, 9(11), 1-12. https://doi.org/10.5539/ies.v9n11p1

Zengarini, L. (2018). A look at Child Abuse at the Global Level. Retrieved from https://www.pbc2019.org/fileadmin/user_upload/abuse_as_ global_problem/Abuse_Global_Problem_Final.pdf, December $19^{\text {th }} 2019$. Zimet, D. G. et al. (1988). The Multidimensional Scale of Perceived Social Support. Journal of personality assessment, 52(1), 30-41.

Zolotora, A.et al. (2009). ISPCAN Child Abuse Screening Tool Children's Version (ICAST-C): Instrument development and multi-national pilot testing. Child Abuse \& Neglect, 33, 833-841. 


\section{Appendices}

\subsection{Pretest Questionnaires}

General information. SACMEQ (Satio, M., 2011). Q. 01-09 \& 54-58

Q01. I am...

\begin{tabular}{|ll|}
\hline$\square$ & male \\
$\square$ & female \\
\hline
\end{tabular}

Q02. Please indicate your year of birth!

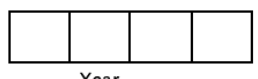

Year

Q03. Which of these schools do you attend? Mark either two or more (X) on the choices that apply to you.

\begin{tabular}{|c|c|c|c|c|c|c|}
\hline $\begin{array}{c}\text { Boarding } \\
\text { School }\end{array}$ & Day School & $\begin{array}{c}\text { Mission } \\
\text { school }\end{array}$ & Public school & $\begin{array}{c}\text { General } \\
\text { education }\end{array}$ & $\begin{array}{c}\text { Technical } \\
\text { education }\end{array}$ & $\begin{array}{c}\text { Lay Private } \\
\text { school }\end{array}$ \\
\hline$\square$ & $\square$ & $\square$ & $\square$ & $\square$ & $\square$ & $\square$ \\
\hline
\end{tabular}

Q04. What is the level of education of your parents?
FSLC
$\mathrm{O} / \mathrm{L}$
A/L
B.A.
M.A.
PhD
Diploma
$\square$
$\square$
$\square$
$\square$
$\square$
口
口

Q05. What is the profession of your father and mother?
a) Father
b) Mother

Q06. Are you...
a) An orphan?
b) A refugee
c) Not a refugee
Yes $\square \quad$ No
Yes $\square \quad$ No $\square$
d) Both parents are alive
Yes $\square \quad$ No
Yes $\mathrm{No}$ 음

Q07. What is your school location?

Urban center

口
Semi-urban center

ㅁ
Rural

口 
Q08. How many times have you repeated a class?

$\begin{array}{ccc}\text { Once } & \text { Twice } & \text { None } \\ \square & \square & \square\end{array}$

(OECD 2010, PISA 2009 Results; Hamburger et al., 2011) Q. 10-31 \& 66-75

This section is asking about your situation at home.

\begin{tabular}{|c|c|c|c|c|c|c|}
\hline & & $\begin{array}{c}\text { Never } \\
1\end{array}$ & $\begin{array}{c}\text { Occasionally } \\
2\end{array}$ & $\begin{array}{c}\text { Sometimes } \\
3\end{array}$ & $\begin{array}{c}\text { Often } \\
4\end{array}$ & $\begin{array}{c}\text { Regularly } \\
5\end{array}$ \\
\hline Q09 & $\begin{array}{l}\text { Are you beaten at } \\
\text { home with a whip? }\end{array}$ & $\square$ & 口 & 口 & $\square$ & $\square$ \\
\hline Q10 & $\begin{array}{l}\text { Are you shouted down } \\
\text { at home? }\end{array}$ & $\square$ & $\square$ & $\square$ & $\square$ & $\square$ \\
\hline Q11 & $\begin{array}{l}\text { Are you called funny } \\
\text { names in the house? }\end{array}$ & $\square$ & $\square$ & $\square$ & $\square$ & $\square$ \\
\hline Q12 & $\begin{array}{l}\text { Do you express } \\
\text { yourself freely at } \\
\text { home? }\end{array}$ & $\square$ & $\square$ & 口 & 口 & 口 \\
\hline Q13 & $\begin{array}{l}\text { Do you see the } \\
\text { learning atmosphere } \\
\text { at home as good? }\end{array}$ & $\square$ & $\square$ & ㅁ & $\square$ & $\square$ \\
\hline Q14 & $\begin{array}{l}\text { Do you provoke } \\
\text { anyone at home? }\end{array}$ & $\square$ & $\square$ & $\square$ & $\square$ & 口 \\
\hline Q15 & $\begin{array}{l}\text { Do your parents pay } \\
\text { your fees on time? }\end{array}$ & $\square$ & $\square$ & $\square$ & $\square$ & $\square$ \\
\hline Q16 & I feel very sad at home & $\square$ & $\square$ & $\square$ & $\square$ & $\square$ \\
\hline Q17 & $\begin{array}{l}\text { Do you read books at } \\
\text { home? }\end{array}$ & $\square$ & $\square$ & $\square$ & $\square$ & $\square$ \\
\hline
\end{tabular}

\begin{tabular}{|c|c|c|c|}
\hline $\begin{array}{c}\text { Much less money than the } \\
\text { average }\end{array}$ & $\begin{array}{l}\text { Less } \\
\text { money }\end{array}$ & $\begin{array}{l}\text { More } \\
\text { money }\end{array}$ & $\begin{array}{l}\text { Much more } \\
\text { money }\end{array}$ \\
\hline 1 & 2 & 3 & 4 \\
\hline
\end{tabular}

Q18 My parents have...

Think of what happened in the last month in school when you answer these questions.

$\begin{array}{llcccc} & \text { Never } & \text { Occasionally } & \text { Sometimes } & \text { Often } & \text { Regularly } \\ \text { Q19 } & \begin{array}{l}\text { I fought back when hit by } \\ \text { someone }\end{array} & \square & 2 & 4 & \square \\ \text { Q20 } & \begin{array}{l}\text { I encourage other students to } \\ \text { fight }\end{array} & \square & \square & \square & \square \\ \text { Q21 I call other students bad names } & \square & \square & \square & \square & \square \\ \text { Q22 } \quad \text { I threatened or hit someone } & \square & \square & \square & \square & \square \\ \text { Q23 } \quad \text { I was beaten in school with a cane } & \square & \square & \square & \square\end{array}$




\begin{tabular}{|c|c|c|c|c|c|c|}
\hline Q24 & Students mock at me & $\square$ & $\square$ & 口 & 口 & 口 \\
\hline Q25 & $\begin{array}{l}\text { Students took something of mine } \\
\text { without permission }\end{array}$ & $\square$ & $\square$ & $\square$ & ㅁ & 口 \\
\hline Q26 & They stole something from me & $\square$ & $\square$ & $\square$ & $\square$ & 口 \\
\hline Q27 & $\begin{array}{l}\text { They hurt me physically in some } \\
\text { way }\end{array}$ & $\square$ & $\square$ & $\square$ & $\square$ & 口 \\
\hline Q28 & $\begin{array}{l}\text { Teachers make sexual advances at } \\
\text { me }\end{array}$ & $\square$ & $\square$ & $\square$ & $\square$ & $\square$ \\
\hline Q29 & Teachers shout at me regularly & $\square$ & $\square$ & $\square$ & $\square$ & 口 \\
\hline Q30 & $\begin{array}{l}\text { Teachers collect money and gifts } \\
\text { from me }\end{array}$ & $\square$ & $\square$ & 口 & $\square$ & 口 \\
\hline Q31 & $\begin{array}{l}\text { I encourage other students to } \\
\text { fight }\end{array}$ & $\square$ & $\square$ & 口 & $\square$ & ㅁ \\
\hline
\end{tabular}

In the next series of questions, I am interested to know what you think about learning. (Sarah, B. 2013; Krogull, Scheunpflug and Rwambonera, 2014). Qu. 32-47

\begin{tabular}{|c|c|c|c|c|c|c|}
\hline & & $\begin{array}{c}\text { Strongly } \\
\text { disagree } \\
1\end{array}$ & $\begin{array}{l}\text { Disagree } \\
2\end{array}$ & $\begin{array}{c}\text { Neutral } \\
3\end{array}$ & $\begin{array}{l}\text { Agree } \\
4\end{array}$ & $\begin{array}{c}\text { Strongly } \\
\text { Agree } \\
5\end{array}$ \\
\hline Q32 & $\begin{array}{l}\text { I make an effort to learn despite the } \\
\text { difficult conditions }\end{array}$ & $\square$ & $\square$ & 口 & $\square$ & $\square$ \\
\hline Q33 & I do not easily give up my learning & $\square$ & 口 & 口 & 口 & $\square$ \\
\hline Q34 & $\begin{array}{l}\text { I know I am important no matter } \\
\text { what others think of me }\end{array}$ & $\square$ & $\square$ & 口 & $\square$ & $\square$ \\
\hline Q35 & $\begin{array}{l}\text { If I make an effort, I can solve all the } \\
\text { difficult exercises }\end{array}$ & $\square$ & $\square$ & 口 & 口 & $\square$ \\
\hline Q36 & $\begin{array}{l}\text { I say what I want even if others do } \\
\text { not agree }\end{array}$ & $\square$ & $\square$ & $\square$ & $\square$ & $\square$ \\
\hline Q37 & $\begin{array}{l}\text { I easily understand everything I am } \\
\text { taught }\end{array}$ & $\square$ & $\square$ & $\square$ & $\square$ & $\square$ \\
\hline Q38 & $\begin{array}{l}\text { I feel afraid to make an error during } \\
\text { studying in class }\end{array}$ & $\square$ & $\square$ & $\square$ & $\square$ & $\square$ \\
\hline Q39 & $\begin{array}{l}\text { The key method in teaching is that } \\
\text { we copy notes a lot }\end{array}$ & $\square$ & $\square$ & $\square$ & $\square$ & $\square$ \\
\hline Q40 & $\begin{array}{l}\text { Teachers encourage me to say what I } \\
\text { want to say }\end{array}$ & $\square$ & $\square$ & 口 & $\square$ & $\square$ \\
\hline Q41 & $\begin{array}{l}\text { Learning is boring because there is } \\
\text { no support }\end{array}$ & 口 & $\square$ & $\square$ & $\square$ & $\square$ \\
\hline Q42 & $\begin{array}{l}\text { I am nervous and do not concentrate } \\
\text { in school }\end{array}$ & 口 & 口 & $\square$ & 口 & 口 \\
\hline
\end{tabular}


Q43 The school rules and regulations are not always respected

$\begin{array}{ll}\text { Q44 } & \begin{array}{l}\text { Teachers complain in class that they } \\ \text { are not well paid }\end{array} \\ \text { Q45 } \quad \begin{array}{l}\text { The school environment is harsh and } \\ \text { hostile }\end{array} & \end{array}$

The next series of questions seeks to know about your school. (Rosenblatt \& Furlong, 1996). Qu.49-54 How often are these acts committed in your school?

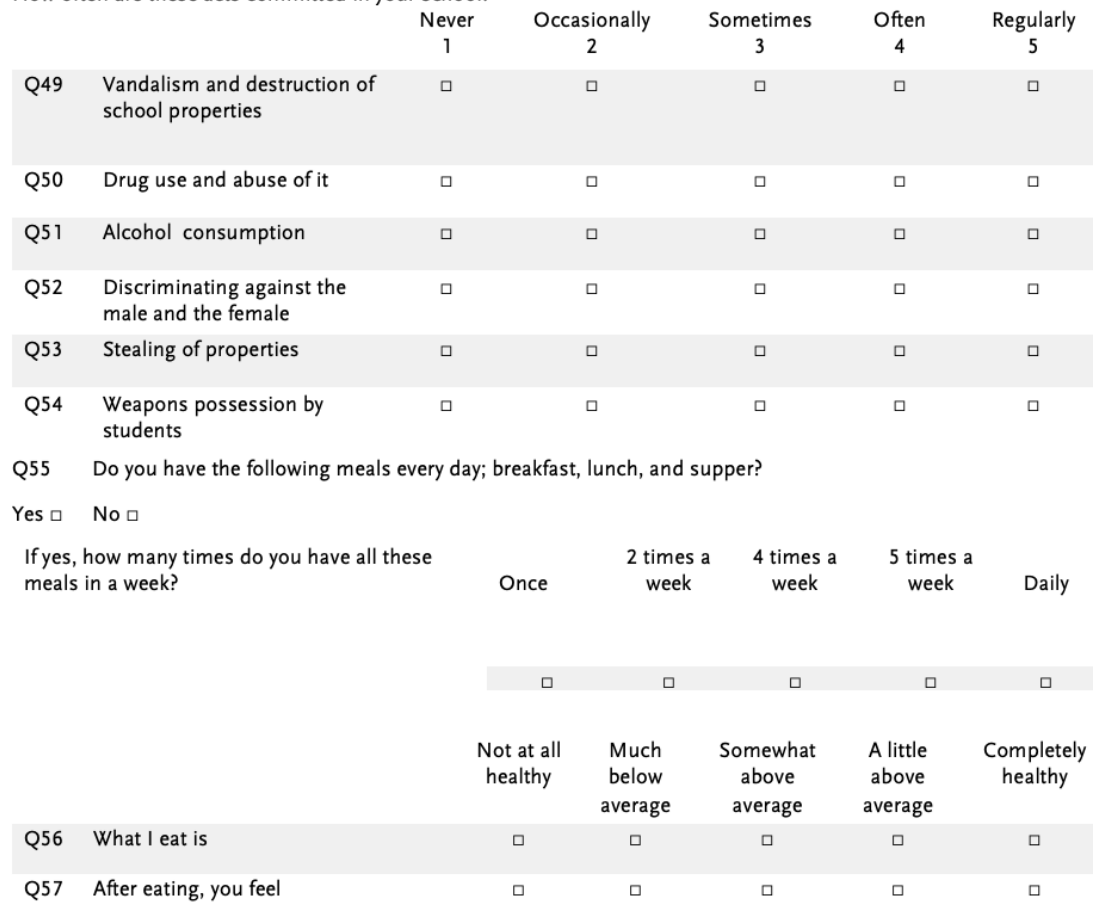


Q58 Your study in school is not interesting because you feel

$\square$

What do you think about: Now we are interested in your feelings about school? (Muller, 2001). Q. 59-65

\begin{tabular}{|c|c|c|c|c|c|c|}
\hline & & $\begin{array}{c}\text { Strongly } \\
\text { disagree } \\
1\end{array}$ & $\begin{array}{c}\text { Disagree } \\
2\end{array}$ & $\begin{array}{c}\text { Neutral } \\
3\end{array}$ & $\begin{array}{c}\text { Agree } \\
4\end{array}$ & $\begin{array}{c}\text { Strongly } \\
\text { agree } \\
5\end{array}$ \\
\hline Q59 & Students get along well with teachers & $\square$ & $\square$ & $\square$ & $\square$ & $\square$ \\
\hline Q60 & Teaching by teachers is good & $\square$ & 口 & $\square$ & $\square$ & 口 \\
\hline Q61 & $\begin{array}{l}\text { My teachers care about me and want my } \\
\text { success }\end{array}$ & $\square$ & $\square$ & $\square$ & $\square$ & $\square$ \\
\hline Q62 & My teachers listen to what I have to say & $\square$ & $\square$ & $\square$ & $\square$ & $\square$ \\
\hline Q63 & $\begin{array}{l}\text { In class, I often feel left out by my } \\
\text { teachers }\end{array}$ & 口 & 口 & 口 & $\square$ & ㅁ \\
\hline Q64 & Other students despise me in class & $\square$ & 口 & $\square$ & $\square$ & 口 \\
\hline Q65 & $\begin{array}{l}\text { After making an effort, other students } \\
\text { mock me }\end{array}$ & $\square$ & $\square$ & $\square$ & $\square$ & 口 \\
\hline
\end{tabular}

\begin{tabular}{|c|c|c|c|c|c|c|}
\hline & & $\begin{array}{l}\text { It hurts } \\
\text { my } \\
\text { feelings } \\
\text { about } \\
\text { school } \\
1\end{array}$ & $\begin{array}{l}\text { It makes } \\
\text { me want } \\
\text { to leave } \\
\text { school } \\
2\end{array}$ & $\begin{array}{l}\text { I feel } \\
\text { nothing } \\
\text { about what } \\
\text { happens } \\
3\end{array}$ & $\begin{array}{l}\text { It helps me } \\
\text { understand } \\
\text { better } \\
4\end{array}$ & $\begin{array}{l}\text { It makes } \\
\text { me like } \\
\text { school } \\
\text { even } \\
\text { more } \\
5\end{array}$ \\
\hline Q66 & $\begin{array}{l}\text { How does physical punishment affect } \\
\text { you? }\end{array}$ & 口 & 口 & ㅁ & ㅁ & ㅁ \\
\hline
\end{tabular}

Rank the following items with the most negative one as 10 , the next as 9 , and so on until you have ranked all the items from $1,2,3,4,5,6,7,8,9$, or 10 with the least negative item as 1

Violent act
Order of negative effect

Q67 Which of these violent acts disturbs your learning more?

i) Slapping and screaming by teachers and parents

ii) Bullying and asking for tips by teachers

iii) Sexual advances for marks by teachers

iv) The teaching of teachers is very bad

v) Employers lack support to the teachers

vi) Other students mock and make fond of me 
vii) Discrimination between the boys and the girls
viii) My efforts are not encouraged by the teachers
xi The school rules promote violence
$\mathrm{x}$

\begin{tabular}{|c|c|c|c|c|c|c|}
\hline & & $\begin{array}{c}\text { Strongly } \\
\text { disagree } \\
1\end{array}$ & $\begin{array}{c}\text { Disagree } \\
2\end{array}$ & $\begin{array}{c}\text { Neutral } \\
3\end{array}$ & $\begin{array}{c}\text { Agree } \\
4\end{array}$ & $\begin{array}{c}\text { Strongly } \\
\text { agree } \\
5\end{array}$ \\
\hline Q68 & $\begin{array}{l}\text { Insults from teachers and students } \\
\text { disturb me }\end{array}$ & $\square$ & $\square$ & $\square$ & ㅁ & $\square$ \\
\hline Q69 & $\begin{array}{l}\text { Schooling is boring because a lot of } \\
\text { things are repeated }\end{array}$ & $\square$ & $\square$ & $\square$ & $\square$ & $\square$ \\
\hline Q70 & $\begin{array}{l}\text { My brothers and sisters have not been } \\
\text { employed }\end{array}$ & $\square$ & $\square$ & $\square$ & 口 & $\square$ \\
\hline Q71 & I am insecure while in school & $\square$ & $\square$ & $\square$ & 口 & $\square$ \\
\hline Q72 & I am always threatened by mates & $\square$ & $\square$ & $\square$ & $\square$ & $\square$ \\
\hline Q73 & $\begin{array}{l}\text { The efforts I am making are not } \\
\text { recognized }\end{array}$ & $\square$ & 口 & $\square$ & 口 & $\square$ \\
\hline Q74 & I am intentionally hurt in school & 口 & $\square$ & $\square$ & 口 & $\square$ \\
\hline Q75 & I am in high spirits while in school & $\square$ & $\square$ & $\square$ & 口 & ㅁ \\
\hline
\end{tabular}

Q76 What is your mark in the following subjects?
a) English language
b) French Language
c) Mathematics

Q77 How do you assess yourself in these aspects?

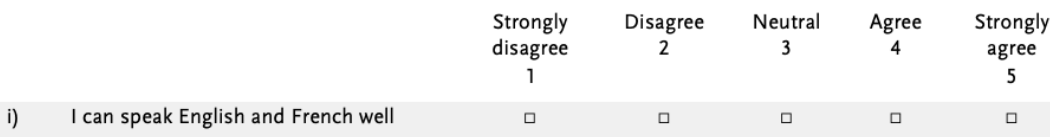


ii) I can solve a lot of problems in Mathematics

iii) I can work well with ICT tools

iv) I can create renewable energy with local waste material

V) I can explain well to my classmates
口

$\square$

$\square$

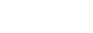

口

$\square$

口

$\square$ $\square$

$\square$ 
9.2Questionnaires

Student questionnaire

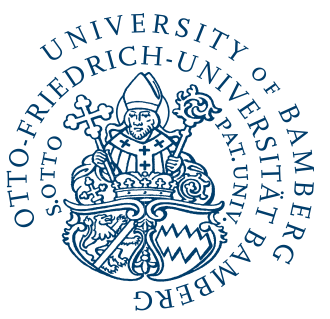

Interactions in school.

A study in educational quality in Cameroon.

Abraham Tamukum Tangwe

University of Bamberg

Department of Education

Tel. 237 677883640/237693379613

Email. abraham-tamukum.tangwe@stud.uni-bamberg.de 96045 Bamberg

Germany 
I am a student in the Faculty of Humanity and Educational Science in the University of Bamberg in Germany, where I am focusing on the study of interactions in the context of learning of children in colleges in Cameroon. This questionnaire focuses on

- Your background,

- Life at home and in the school and especially

- How you interact and are treated by others.

I am collecting data regarding the impact of such interactions on your learning. This information is collected for my PhD thesis.

\section{Confidentiality}

All information that is collected in this study will be treated with confidentiality. You are guaranteed that neither your name nor the name of your school will be identified in any report of the results of the study.

\section{About the Questionnaire}

- This questionnaire asks for information about school education, your background and how your interaction in school affects your learning.

- This questionnaire will take approximately $\mathbf{3 0}$ minutes to complete.

- This questionnaire consist of four parts. Please kindly answer all questions

- There are no right or wrong answers.

\section{Comments on completing the questionnaire}

\section{$\square \quad \searrow \quad \square \quad \square \quad \square$}

$\square \square \square \square \quad \square$
Please indicate the answer that applies to you with an (X)

If you want to change your answer, shade as indicated in the example and mark $(\mathrm{X})$ on the desired answer.

In some questions, you can be asked to write short sentences. 
General information.

Q01 I am...
$\square$ male
口 female

(Background)

Q02 Please indicate your date of birth!

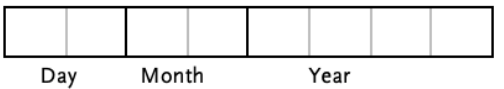

Q03 In what class are you?

Q04 Which of these schools do you attend? Mark an $(X)$ on the answers that relates to you. Mission school

ㅁ
Public school

ㅁ
Lay private school

口
General education
Technical educatio

ㅁ

Q05 a) What is your mother's main job?

Please write in the job title

Q05 b) What is the highest level of schooling completed by your mother?

FSLC

ㅁ
$\mathrm{O} / \mathrm{L}$

ㅁ
$\mathrm{A} / \mathrm{L}$

ㅁ
B.A.

口
Diploma

ㅁ
ㅁ

Q06 a) What is your father's main job?

Please write in the job title

Q06 b) What is the highest level of schooling completed by your father?
FSLC
$\mathrm{O} / \mathrm{L}$
$\mathrm{A} / \mathrm{L}$
B.A.
Diploma
ㅁ
M.A./M.Sc.
Ph.D.
口
口
ㅁ

Ph.D.

口

ㅁ 
Q07 Are you...

\begin{tabular}{|c|c|c|c|}
\hline & & Yes & No \\
\hline a & An orphan? (the death of both parents) & $\square 2$ & $\square 1$ \\
\hline$b$ & A refugee & $\square 2$ & $\square 1$ \\
\hline C & Both parents are alive & $\square 2$ & $\square 1$ \\
\hline \multirow[t]{3}{*}{ Q08 } & What is your school location? & \multirow[b]{2}{*}{ Semi-urban center } & \\
\hline & Urban center & & Rural \\
\hline & $\square 1$ & $\square 2$ & $\square 3$ \\
\hline$(\mathrm{Bac}$ & ound) & & \\
\hline
\end{tabular}

Q09 Have you ever repeated a class?

No, never

ㅁ

Yes, once

$\square 2$

Q10 a) At home, in the past year, how often have you been... (Light Violence)

a Hit.

Never

b Pushed or shoved.

c Slapped you on your face or head with the hand

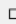

$\square$

$\square$
Once

$\square$

$\square$

口
Yes, twice or more

$\square 3$

Q10b) At home, in the past year, how often have you been (Heavy Violence)

\begin{tabular}{|c|c|c|c|c|c|}
\hline & & Never(1) & Once (2) & Sometimes(3) & Often \\
\hline a & Kicked. & $\square$ & $\square$ & $\square$ & $\square$ \\
\hline b & Badly beaten up. & $\square$ & $\square$ & $\square$ & 口 \\
\hline C & Threatened with a knife or sharp weapon. & $\square$ & $\square$ & $\square$ & $\square$ \\
\hline d & Attacked with a knife or sharp weapon & $\square$ & $\square$ & $\square$ & $\square$ \\
\hline e & Robbed & $\square$ & $\square$ & $\square$ & 口 \\
\hline$f$ & Hit with a closed fist & $\square$ & $\square$ & $\square$ & $\square$ \\
\hline
\end{tabular}


Q10 c) At home in the past year, has anyone in your family and living in your home like your natural parents, grandparents, stepparents, adoptive parents, caregivers, uncle, brothers, sisters... (Light Bullying)

Never (1) Once (2) Sometimes Often (4)

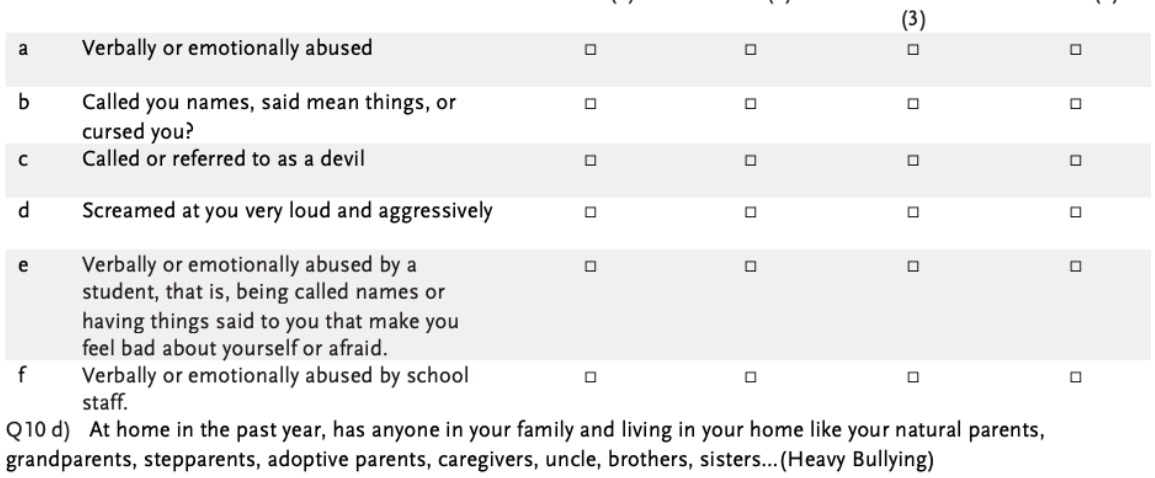

Never (1) Once (2) Sometimes Often (4)

\begin{tabular}{|c|c|c|c|c|c|}
\hline & & ( & 年 & (3) & - \\
\hline a & Bewitched & $\square$ & ㅁ & 口 & ㅁ \\
\hline b & $\begin{array}{l}\text { Said they wished you were dead or never } \\
\text { born }\end{array}$ & 口 & 口 & 口 & 口 \\
\hline c & $\begin{array}{l}\text { Threaten to leave you forever or abandon } \\
\text { you }\end{array}$ & $\square$ & ㅁ & $\square$ & $\square$ \\
\hline d & $\begin{array}{l}\text { Threatened to hurt or killed you, including } \\
\text { invoking evil spirits against you? }\end{array}$ & $\square$ & $\square$ & $\square$ & $\square$ \\
\hline
\end{tabular}

The next series of questions seeks to understand how the following actions affect you in school.

Q11 How often in the past year have you been... (Light Violence in School)

Never (1) Once (2) Sometimes Often (4)

$\begin{array}{llll}\text { a } & \text { Hit by a student. } & \square & \square \\ \text { b Hit by school staff. } & \square & \square & \square \\ \text { c } \quad \begin{array}{l}\text { Threatened with bad marks that you did not } \\ \text { deserve }\end{array} & \square & \square & \square \\ \text { d } \quad \text { Allowed to stand in the heat or cold } & \square & \square\end{array}$


The next series of questions seeks to understand how the following actions affect you in school.

Q11b) How often in the past year have you been (Heavy Violence in School)

$\begin{array}{llcc}\text { a } \quad \text { Kicked or pushed by a student. } & \text { Never (1) } & \text { Once (2) } & \text { Sometimes (3) } \\ \text { b } \quad \text { Kicked or pushed by school staff. } & \square & \square \\ \text { c } \quad \text { Badly beaten up. } & \square & \square \\ \text { d } \quad \text { Threatened with a knife or sharp weapon. } & \square & \square \\ \text { e } \quad \text { Attacked with a knife or sharp weapon. } & \square & \square \\ \text { f } \quad \text { Robbed } & \square & \square \\ \text { g } \quad \text { Thrown food or pepper on your body } & \square & \square \\ \text { h } \quad \text { Allowed to stand in the heat or cold } & \square & \square\end{array}$

Below is a list of statements how you feel about yourself and how others think about you.

Q12a) Please indicate how much the following statements apply to you. (General Self-Esteem)

\begin{tabular}{|c|c|c|c|c|c|c|}
\hline & & $\begin{array}{l}\text { Not at all } \\
\text { (5) }\end{array}$ & $\begin{array}{l}\text { A little bit } \\
\text { (4) }\end{array}$ & $\begin{array}{l}\text { Somewhat } \\
\text { (3) }\end{array}$ & $\begin{array}{l}\text { Very Much } \\
\text { (2) }\end{array}$ & $\begin{array}{l}\text { Extremely } \\
\text { (1) }\end{array}$ \\
\hline a & I feel confident about my abilities. & $\square$ & $\square$ & $\square$ & $\square$ & $\square$ \\
\hline$b$ & $\begin{array}{l}\text { I am worried about whether I am } \\
\text { regarded as a success or a failure }\end{array}$ & $\square$ & $\square$ & 口 & $\square$ & $\square$ \\
\hline c & I feel good about myself & 口 & $\square$ & 口 & 口 & $\square$ \\
\hline$d$ & $\begin{array}{l}\text { I am worried about what other people } \\
\text { think of me }\end{array}$ & $\square$ & $\square$ & $\square$ & 口 & $\square$ \\
\hline e & $\begin{array}{l}\text { I feel confident that I understand } \\
\text { things }\end{array}$ & $\square$ & $\square$ & 口 & $\square$ & $\square$ \\
\hline f & $\begin{array}{l}\text { I feel that others respect and admire } \\
\text { me. }\end{array}$ & $\square$ & $\square$ & $\square$ & $\square$ & $\square$ \\
\hline g & $\begin{array}{l}\text { I feel inferior to others at this } \\
\text { moment }\end{array}$ & 口 & $\square$ & $\square$ & 口 & $\square$ \\
\hline $\mathrm{h}$ & I feel self-conscious. & $\square$ & $\square$ & $\square$ & & $\square$ \\
\hline i & I feel as smart as others. & $\square$ & $\square$ & 口 & 口 & $\square$ \\
\hline j & I feel displeased with myself & 口 & 口 & 口 & 口 & 口 \\
\hline k & $\begin{array}{l}\text { I feel concerned about the impression } \\
\text { I am making }\end{array}$ & 口 & $\square$ & $\square$ & $\square$ & $\square$ \\
\hline I & I am worried about looking foolish & $\square$ & $\square$ & 口 & $\square$ & $\square$ \\
\hline
\end{tabular}


Below is a list of statements about how you feel about yourself and how others think about you.

Q12b) Please indicate how much the following statements apply to you. (Body Self-Esteem)

\begin{tabular}{|c|c|c|c|c|c|c|}
\hline & & $\begin{array}{l}\text { Not at all } \\
\text { (5) }\end{array}$ & $\begin{array}{l}\text { A little bit } \\
\text { (4) }\end{array}$ & $\begin{array}{l}\text { Somewhat } \\
\text { (3) }\end{array}$ & $\begin{array}{l}\text { Very Much } \\
\text { (2) }\end{array}$ & $\begin{array}{l}\text { Extremely } \\
\text { (1) }\end{array}$ \\
\hline a & $\begin{array}{l}\text { I feel satisfied with the way my body } \\
\text { looks right now }\end{array}$ & $\square$ & $\square$ & ㅁ & ㅁ & $\square$ \\
\hline$b$ & I am dissatisfied with my weight & $\square$ & $\square$ & $\square$ & $\square$ & $\square$ \\
\hline c & $\begin{array}{l}\text { I am pleased with my appearance } \\
\text { right now }\end{array}$ & $\square$ & $\square$ & $\square$ & $\square$ & $\square$ \\
\hline d & I feel unattractive & $\square$ & $\square$ & $\square$ & $\square$ & $\square$ \\
\hline
\end{tabular}

Below is a list of statements about how you feel about yourself and how others think about you.

Q12c) Please indicate how much the following statements apply to you. (Academic Self-Esteem)

\begin{tabular}{|c|c|c|c|c|c|c|}
\hline & & $\begin{array}{l}\text { Not at all } \\
\text { (5) }\end{array}$ & $\begin{array}{l}\text { A little bit } \\
\text { (4) }\end{array}$ & $\begin{array}{l}\text { Somewhat } \\
\text { (3) }\end{array}$ & $\begin{array}{l}\text { Very Much } \\
\text { (2) }\end{array}$ & $\begin{array}{l}\text { Extremely } \\
\text { (1) }\end{array}$ \\
\hline a & $\begin{array}{l}\text { I feel disappointed or rattled about my } \\
\text { performance }\end{array}$ & 口 & 口 & 口 & 口 & 口 \\
\hline$b$ & $\begin{array}{l}\text { I feel that I am having trouble } \\
\text { understanding things that I read }\end{array}$ & ם & 口 & 口 & 口 & 口 \\
\hline c & $\begin{array}{l}\text { I feel that I have less scholastic ability } \\
\text { right now than others }\end{array}$ & 口 & 口 & 口 & 口 & $\square$ \\
\hline
\end{tabular}

The following statements seek to understand what you want to achieve with your learning and your feelings when your parents visit you in school

Q13a) Please indicate how much you agree with the following statements

(Learning Motivation)

\begin{tabular}{|c|c|c|c|c|}
\hline & & Not at all true (1) & $\begin{array}{l}\text { Somewhat } \\
\text { True (2) }\end{array}$ & $\begin{array}{c}\text { Very } \\
\text { True (3) }\end{array}$ \\
\hline a & $\begin{array}{l}\text { It is important to me that I learn many new } \\
\text { concepts (ideas) this year. }\end{array}$ & ㅁ & $\square$ & $\square$ \\
\hline$b$ & $\begin{array}{l}\text { One of my goals in class is to learn as } \\
\text { much as I can. }\end{array}$ & 口 & $\square$ & 口 \\
\hline c & $\begin{array}{l}\text { One of my goals is to master many new } \\
\text { skills this year. }\end{array}$ & $\square$ & $\square$ & 口 \\
\hline$d$ & $\begin{array}{l}\text { It is important to me that I thoroughly } \\
\text { understand my classwork. }\end{array}$ & 口 & $\square$ & $\square$ \\
\hline e & $\begin{array}{l}\text { It is important to me that I improve my } \\
\text { skills this year }\end{array}$ & 口 & $\square$ & $\square$ \\
\hline
\end{tabular}


Q13b) Please indicate how much you agree with the following statements (Communication)

$$
\begin{array}{ccc}
\text { Not at all true (1) } & \text { Somewhat } & \text { Very } \\
\text { True (2) } & \text { True (3) }
\end{array}
$$

f I do not like to have my parents come to school because their ideas

$\square$

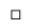

$\square$ are very different from my teachers' ideas.

g I feel uncomfortable when my parents come to school because they are different from the parents of many of my classmates.

h I feel troubled because my home life and my school life are like two different worlds.

i I am not comfortable talking to many of my classmates because my family is very different from theirs.

j I feel upset because my teacher and my parents have different ideas about what I should learn in school

\begin{tabular}{|c|c|c|c|c|}
\hline & & Not at all true (3) & $\begin{array}{l}\text { Somewhat } \\
\text { True (2) }\end{array}$ & $\begin{array}{c}\text { Very } \\
\text { True (1) }\end{array}$ \\
\hline k & $\begin{array}{l}\text { Honestly, I do not know; I really feel that I } \\
\text { am wasting my time in school. }\end{array}$ & $\square$ & 口 & 口 \\
\hline 1 & $\begin{array}{l}\text { I once had good reasons for going to } \\
\text { school; however, now I wonder whether I } \\
\text { should continue. }\end{array}$ & $\square$ & $\square$ & $\square$ \\
\hline $\mathrm{m}$ & $\begin{array}{l}\text { I cannot see why I go to school, and, } \\
\text { frankly, I could not care less. }\end{array}$ & $\square$ & $\square$ & $\square$ \\
\hline $\mathrm{n}$ & $\begin{array}{l}\text { I do not know; I cannot understand what I } \\
\text { am doing in school. }\end{array}$ & $\square$ & $\square$ & $\square$ \\
\hline \multirow[t]{2}{*}{ Q14a) } & \multicolumn{4}{|c|}{ Please indicate how often the following incidents occur in your school. (LIGHT VIOLENCE) } \\
\hline & & Not at all (1) & Sometimes (2) & Very often (3) \\
\hline a & Students threaten and bully others & $\square$ & $\square$ & $\square$ \\
\hline$b$ & Drug use and abuse of it by students & $\square$ & $\square$ & $\square$ \\
\hline c & Alcohol consumption in school & 口 & 口 & 口 \\
\hline
\end{tabular}

Q13c) Please indicate how much you agree with the following statements (School Motivation) 
Q14b) Please indicate how often the following incidents occur in your school. (Heavy Violence)

\begin{tabular}{|c|c|c|c|c|}
\hline & & Not at all (1) & Sometimes (2) & Very often (3) \\
\hline a & Vandalism and destruction of school properties & 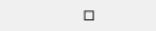 & ㅁ & 口 \\
\hline b & Students always fighting with teachers & $\square$ & $\square$ & $\square$ \\
\hline c & Stealing of properties by students & 口 & 口 & $\square$ \\
\hline d & $\begin{array}{l}\text { Students carrying weapons like knives or other } \\
\text { things }\end{array}$ & $\square$ & $\square$ & $\square$ \\
\hline \multirow[t]{2}{*}{ Q15 a) } & \multicolumn{4}{|c|}{ For how long has your health limited you in each of these activities? (Heavy Violence) } \\
\hline & $\begin{array}{l}\text { Limit } \\
\text { than }\end{array}$ & $\begin{array}{l}\text { for more } \\
\text { nonths (3) }\end{array}$ & $\begin{array}{l}\text { Limited for } 3 \\
\text { nonths or less (2) }\end{array}$ & Not limited at all (1) \\
\hline a & $\begin{array}{l}\text { The activities you can do like lifting } \\
\text { heavy objects, running, or } \\
\text { participating in strenuous sports }\end{array}$ & $\square$ & $\square$ & $\square$ \\
\hline$b$ & $\begin{array}{l}\text { The activities you can do like carrying } \\
\text { a table, carrying groceries or bought } \\
\text { supplies }\end{array}$ & $\square$ & $\square$ & $\square$ \\
\hline c & Bending down or lifting cargo & $\square$ & $\square$ & $\square$ \\
\hline
\end{tabular}

Q15b) For how long has your health limited you in each of these activities? (Light Violence)

a Eating, dressing, and bathing Limited for more than 3 months (3)

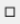

$\square$ kilometer

c Walking uphill, climbing stairs, or running around the football field

Q16 For how long has your health limited you in each of these activities? (Light Violence)

Prevent you from doing work in the Yes, for more than three months (3)

Yes, for three months or less (2)

Limited for 3 months or less (2)

Not limited at all (1)

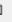

$\square$

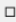
house or going to school Unable to do certain kinds of $\square$ $\square$ $\square$

$\square$ housework or schoolwork because of your health 
Q17 How do you view your social and emotional life in school and at home?

\begin{tabular}{|c|c|c|c|c|c|}
\hline & & $\begin{array}{c}\text { Strongly } \\
\text { disagree (4) }\end{array}$ & Disagree (3) & Agree (2) & $\begin{array}{l}\text { Strongly } \\
\text { agree (1) }\end{array}$ \\
\hline a & $\begin{array}{l}\text { There is a special person who is around when } \\
\text { I am in need. }\end{array}$ & $\square$ & $\square$ & $\square$ & $\square$ \\
\hline$b$ & $\begin{array}{l}\text { There is a special person with whom I can } \\
\text { share my joys and sorrows. }\end{array}$ & $\square$ & $\square$ & $\square$ & $\square$ \\
\hline c & My family really tries to help me. & $\square$ & $\square$ & $\square$ & $\square$ \\
\hline$d$ & $\begin{array}{l}\text { I get the emotional help and support I need } \\
\text { from my family. }\end{array}$ & $\square$ & $\square$ & $\square$ & $\square$ \\
\hline e & $\begin{array}{l}\text { I have a special person who is a real source of } \\
\text { comfort to me. }\end{array}$ & $\square$ & $\square$ & $\square$ & $\square$ \\
\hline f & My friends really try to help me. & $\square$ & $\square$ & $\square$ & $\square$ \\
\hline $\mathrm{h}$ & $\begin{array}{l}\text { I have friends with whom I can share my joys } \\
\text { and sorrows. }\end{array}$ & $\square$ & $\square$ & $\square$ & $\square$ \\
\hline i & $\begin{array}{l}\text { There is a special person in my life who cares } \\
\text { about my feelings. }\end{array}$ & $\square$ & $\square$ & $\square$ & 口 \\
\hline j & I can talk about my problems with my family. & $\square$ & $\square$ & $\square$ & $\square$ \\
\hline k & $\begin{array}{l}\text { My family is willing to help me make } \\
\text { decisions. }\end{array}$ & $\square$ & $\square$ & $\square$ & $\square$ \\
\hline I & I can talk about my problems with my friends. & $\square$ & $\square$ & $\square$ & $\square$ \\
\hline
\end{tabular}

Q18 Thinking about yourself. Has anyone done any of these things to you in the past? I mean...

Never (1) Not in the past Sometimes (3) Many times (4)
year, but this
has happened

$\begin{array}{lll}\text { a } \quad \begin{array}{l}\text { Touching you in a way that makes you } \\ \text { uncomfortable }\end{array} & \text { (2) } \\ \text { b } \quad \begin{array}{l}\text { Any teacher making you have sex in } \\ \text { exchange for marks }\end{array} & \square \\ \text { c Anyone kissing you when you do not } \\ \text { want to be kissed }\end{array}$


Q19 How many books are there in your home? (Do not include magazines, newspapers, or your schoolbooks.) (Please tick only one box.)

$0-10$ books

$\square 1$

11-25 books

$\square 2$

26-100 books

$\square 3$

Q20 About how much time do you usually spend reading for enjoyment?

(Please tick only one box)

I do not read for enjoyment $\quad$ l

30 minutes or less a day $\square 2$

More than 30 minutes to $\square 3$

less than 60 minutes a day

1 to 2 hours a day $\square 4$

More than 2 hours a day $\quad \square 5$

Q21 What are your marks in these subjects?

Fail (1) Average (2) Fair (3) Good (4) Very good

\begin{tabular}{|c|c|c|c|c|c|c|}
\hline & & & & & & (5) \\
\hline a & English language & $\square$ & $\square$ & $\square$ & $\square$ & $\square$ \\
\hline$b$ & French language & $\square$ & $\square$ & $\square$ & $\square$ & $\square$ \\
\hline c & Mathematics & $\square$ & $\square$ & $\square$ & $\square$ & $\square$ \\
\hline $\mathrm{d}$ & ICTs & $\square$ & $\square$ & $\square$ & $\square$ & $\square$ \\
\hline
\end{tabular}

Q22 Tell me your impressions about this questionnaire

$\begin{array}{llc}\text { a Was this a hard questionnaire to answer? } & \text { Yes } \\ \text { b Is there anything that you didn't understand? } & \square \\ \text { c Was it difficult to be completely open about what happened to you? } & \square\end{array}$




\section{Questionnaire destiné aux élèves}

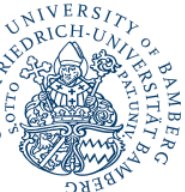

Les interactions à l'école.

Une étude sur la qualité de l'éducation au Cameroun.

Abraham Tamukum Tangwe

University of Bamberg

Department of Education

Tel. 237 677883640/237693379613

Email. abraham-tamukum.tangwe@stud.uni-bamberg.de 96045 Bamberg

Germany 
Je suis étudiant à la Faculté des Sciences Humaines et de l'Education de l'Université de Bamberg en Allemagne, où je m'intéresse à l'étude des interactions dans le contexte de l'apprentissage des enfants dans les collèges au Cameroun. Le présent questionnaire porte sur

- Votre parcours,

- La vie à la maison et à l'école

- Comment vous interagissez avec les autres et comment vous êtes traité(e) par eux.

Je collecte des données concernant l'impact de telles interactions sur votre apprentissage. Les informations collectées me seront utiles pour la rédaction de ma thèse de doctorat.

\section{Confidentialité}

Toutes les informations collectées dans le cadre de la présente étude seront traitées avec confidentialité. Soyez donc rassuré que ni votre nom, ni le nom de votre école ne pourront être identifiés dans les rapports des résultats de cette étude.

\section{Concernant le Questionnaire}

- Ce questionnaire vise les informations portant sur l'éducation scolaire, vos antécédents et comment votre interaction à l'école affecte votre apprentissage.

- Ce questionnaire prendra environ 30 minutes.

- Ce questionnaire comprend quatre parties. Je vous prie de bien vouloir répondre à toutes les questions

- Il n'y a pas de bonnes ou de mauvaises réponses.

\section{Voici comment remplir le questionnaire}

\begin{tabular}{|llll|}
\hline$\square \quad \square$ & $\square$ & $\square$
\end{tabular}$\quad$ Veuillez indiquer la réponse appropriée à l'aide d'une croix (X)

$\square \square \square \square \quad \square \quad$ Si vous voulez changer votre réponse, remplissez complétement la case comme indiqué dans l'exemple et cochez $(\mathrm{X})$ la réponse souhaitée

Pour certaines questions, il vous sera demandé de rédiger de courtes phrases. 
Informations générales.

Q01 Je suis ...
口 Un garcon
- Une fille

Q02 Veuillez indiquer votre date de naissance!

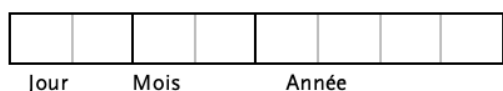

Q03 Dans quelle classe êtes-vous?

Q04 Quel type d'établissement fréquentez-vous ? Mettez une croix (X) dans la case correspondante.

\begin{tabular}{|c|c|c|c|c|}
\hline $\begin{array}{l}\text { Etablissement } \\
\text { missionnaire }\end{array}$ & $\begin{array}{c}\text { Etablissement } \\
\text { public }\end{array}$ & Etablissement privé & $\begin{array}{c}\text { Etablissement } \\
\text { d'Enseignement } \\
\text { général }\end{array}$ & $\begin{array}{c}\text { Etablissement } \\
\text { d'Enseignement } \\
\text { technique }\end{array}$ \\
\hline
\end{tabular}

ㅁ

ㅁ

口

口

口

Q05 a) Quelle est la profession de votre mère ?

Bien vouloir inscrire cette profession ici

Q05 b) Quel est le niveau scolaire de votre mère ?

$\begin{array}{ccccccc}\text { CEP } & \text { BEPC } & \text { BACC } & \text { Licence } & \text { Ingénieur } & \text { Master } & \text { Doctorat } \\ \square & \square & \square & \square & \square & \square & \square\end{array}$

Q06 a) Quelle est la profession de votre père ?

Bien vouloir inscrire cette profession ici

Q06 b) Quel est le niveau scolaire de votre père ?
CEP
BEPC
BACC
Licence
Ingénieur
Master
Doctorat
口
$\square$
$\square$
口
$\square$
口
$\square$

Q07 Etes-vous...
a Orphelin(e) ? (de père et de mère)
Oui
Non
b Refugié(e) ?
口
口
c Avec les deux parents sont vivants ?
口
$\square$
$\square$
口 
Où est située votre école ?

Dans un centre urbain

口
Dans un centre semi- urbain

口
En zone rurale

口
Non, jamais
Oui, une fois
Oui, deux fois ou plus

La prochaine série de questions cherche à comprendre comment les actions suivantes vous affectent chez vous.

Q10 a) A la maison au courant de l'année dernière, combien de fois avez-vous été ...

\begin{tabular}{|c|c|c|c|c|c|}
\hline & & Jamais & Une fois & Parfois & Souvent \\
\hline a & Frappé(e). & ㅁ & 口 & $\square$ & $\square$ \\
\hline b & Roué(e) de coups. & $\square$ & $\square$ & $\square$ & $\square$ \\
\hline c & Poussé(e) ou bousculé(e) & $\square$ & $\square$ & $\square$ & $\square$ \\
\hline d & Sauvagement battu(e). & $\square$ & $\square$ & $\square$ & $\square$ \\
\hline e & $\begin{array}{l}\text { Menacé(e) avec un couteau ou une arme } \\
\text { tranchante. }\end{array}$ & 口 & 口 & $\square$ & $\square$ \\
\hline f & $\begin{array}{l}\text { Attaqué(e) avec un couteau ou une arme } \\
\text { tranchante. }\end{array}$ & ㅁ & $\square$ & $\square$ & $\square$ \\
\hline g & $\begin{array}{l}\text { Giflé(e) au visage ou sur la tête avec la } \\
\text { main }\end{array}$ & $\square$ & $\square$ & $\square$ & $\square$ \\
\hline h & $\begin{array}{l}\text { Frappé(e) avec un objet lancé contre } \\
\text { vous. }\end{array}$ & $\square$ & $\square$ & $\square$ & $\square$ \\
\hline i & $\begin{array}{l}\text { Violenté(e) verbalement ou } \\
\text { émotionnellement. }\end{array}$ & $\square$ & $\square$ & $\square$ & $\square$ \\
\hline J & Volé(e) & $\square$ & $\square$ & $\square$ & $\square$ \\
\hline k & Traité(e) de sorcière & $\square$ & $\square$ & $\square$ & $\square$ \\
\hline I & Traité(e) de diable & $\square$ & $\square$ & $\square$ & $\square$ \\
\hline m & Frappé(e) avec un poing fermé & 口 & $\square$ & $\square$ & $\square$ \\
\hline
\end{tabular}


Q10 b) A la maison au cours de l'année dernière, quelqu'un dans votre famille et vivant à la maison tel que vos parents naturels, vos grands-parents, vos beaux-parents, vos parents adoptifs, des domestiques, un oncle, vos frères, vos sœurs...

\begin{tabular}{|c|c|c|c|c|c|}
\hline & & Jamais & Une fois & Parfois & Souvent \\
\hline$n$ & $\begin{array}{l}\text { A crié très fort après vous de manière } \\
\text { agressive? }\end{array}$ & $\square$ & $\square$ & $\square$ & 口 \\
\hline o & $\begin{array}{l}\text { Vous a attribué des noms, dit des choses } \\
\text { méchantes ou vous a maudit? }\end{array}$ & $\square$ & $\square$ & 口 & $\square$ \\
\hline$p$ & $\begin{array}{l}\text { A souhaité que vous soyez mort(e) ou } \\
\text { jamais né(e)? }\end{array}$ & $\square$ & $\square$ & ㅁ & 口 \\
\hline $\mathrm{q}$ & $\begin{array}{l}\text { A menacé de vous quitter pour toujours ou } \\
\text { de vous abandonner? }\end{array}$ & ㅁ & $\square$ & 口 & 口 \\
\hline$r$ & $\begin{array}{l}\text { A menacé de vous blesser ou de vous tuer, } \\
\text { ou a invoqué les mauvais esprits contre } \\
\text { vous? }\end{array}$ & $\square$ & $\square$ & $\square$ & 口 \\
\hline
\end{tabular}

La prochaine série de questions cherche à comprendre comment les actions ci-après vous affectent à l'école.

Q11 Combien de fois au cours de l'année dernière avez-vous été ...

a Frappé(e) par un(e) élève.

b Frappé(e) par un personnel de l'école.

c Botté(e) ou bousculé(e) par un(e) élève.

d Botté(e) ou bousculé(e) par un personnel de l'école.

e Sauvagement battu(e).

f Menacé(e) avec un couteau ou une arme tranchante.

g Attaqué(e) avec un couteau ou une arme tranchante.

h Menacé(e) de mauvaises notes que vous ne méritiez pas

i Violenté(e) verbalement ou émotionnellement par un(e) élève, c'està-dire être appelé(e) par des noms ou vous faire dire des choses qui vous mettent mal à l'aise ou vous font peur.

j Violenté(e) verbalement ou émotionnellement par un personnel de l'école.

k Volé(e).

I Amené(e) à recevoir de la nourriture ou du piment jeté sur vous

m Amené(e) à donner de l'argent en échange de notes
Jamais Une fois Parfois Souvent
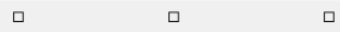

$\square$

$\square$

$\square$

$\square$

$\square$

$\square$

$\square$

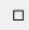

$\square$

$\square$

$\square$

$\square$

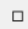

$\square$

$\square$

口

$\square$
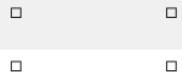

$\square$

(1)

口

$\square \quad \square \quad \square$

(1)

$\square \quad \square$

口

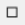

$\square$

$\square$

$\square$

$\square$

$\square$

$\square$

$\square$

口

$\square$

$\square$

ㅁ 
Amené(e) à rester dans la chaleur ou le froid

Vous trouverez ci-dessous une liste de déclarations sur ce que vous pensez de vous-même et sur ce que les autres pensent de vous.

Q12 Veuillez indiquer dans quelle mesure les déclarations suivantes s'appliquent à vous.

\begin{tabular}{|c|c|c|c|c|c|c|}
\hline & & $\begin{array}{l}\text { Pas du } \\
\text { tout }\end{array}$ & Un peu & $\begin{array}{l}\text { Quelque } \\
\text { peu }\end{array}$ & Beaucoup & $\begin{array}{c}\text { Extrêmeme } \\
\mathrm{nt}\end{array}$ \\
\hline a & J'ai confiance en mes capacités. & 口 & 口 & $\square$ & 口 & 口 \\
\hline$b$ & $\begin{array}{l}\text { Je suis inquiet(e) de savoir si l'on } \\
\text { me considère comme un succès } \\
\text { ou un échec }\end{array}$ & $\square$ & $\square$ & $\square$ & 口 & $\square$ \\
\hline c & $\begin{array}{l}\text { Je suis satisfait(e) de l'apparence } \\
\text { de mon corps en ce moment. }\end{array}$ & $\square$ & $\square$ & $\square$ & $\square$ & $\square$ \\
\hline d & $\begin{array}{l}\text { Je me sens frustré(e) ou ébranlé(e) } \\
\text { par ma performance }\end{array}$ & $\square$ & $\square$ & $\square$ & $\square$ & $\square$ \\
\hline e & $\begin{array}{l}\text { J'ai l'impression que j'ai du mal à } \\
\text { comprendre les choses que je lis. }\end{array}$ & $\square$ & $\square$ & $\square$ & $\square$ & $\square$ \\
\hline f & $\begin{array}{l}\text { Je sens que les autres me } \\
\text { respectent et m'admirent. }\end{array}$ & $\square$ & 口 & $\square$ & $\square$ & $\square$ \\
\hline g & Je suis insatisfait(e) de mon poids. & $\square$ & $\square$ & $\square$ & $\square$ & $\square$ \\
\hline h & Je me sens mal à l'aise. & $\square$ & $\square$ & $\square$ & & $\square$ \\
\hline i & $\begin{array}{l}\text { Je me sens aussi intelligent(e) que } \\
\text { les autres. }\end{array}$ & $\square$ & $\square$ & $\square$ & 口 & 口 \\
\hline j & Je me sens mécontent(e) de moi & $\square$ & $\square$ & $\square$ & $\square$ & $\square$ \\
\hline k & Je me sens bien dans ma peau & 口 & 口 & $\square$ & 口 & $\square$ \\
\hline I & $\begin{array}{l}\text { Je suis content(e) de mon } \\
\text { apparence pour le moment. }\end{array}$ & $\square$ & $\square$ & $\square$ & $\square$ & $\square$ \\
\hline $\mathrm{m}$ & $\begin{array}{l}\text { Je m'inquiète de ce que les autres } \\
\text { pensent de moi. }\end{array}$ & $\square$ & $\square$ & $\square$ & $\square$ & $\square$ \\
\hline $\mathrm{n}$ & $\begin{array}{l}\text { Je suis convaincu(e) que je } \\
\text { comprends les choses }\end{array}$ & $\square$ & 口 & $\square$ & $\square$ & $\square$ \\
\hline o & $\begin{array}{l}\text { Je me sens inférieur(e) aux autres } \\
\text { en ce moment. }\end{array}$ & $\square$ & $\square$ & $\square$ & $\square$ & $\square$ \\
\hline $\mathrm{p}$ & Je me sens peu attrayant(e). & $\square$ & $\square$ & $\square$ & $\square$ & $\square$ \\
\hline$q$ & $\begin{array}{l}\text { Je me sens préoccupé(e) par } \\
\text { l'impression que je donne. }\end{array}$ & $\square$ & $\square$ & $\square$ & $\square$ & ם \\
\hline$r$ & $\begin{array}{l}\text { J'ai l'impression que j'ai moins de } \\
\text { compétences scolaires en ce } \\
\text { moment par rapport aux autres }\end{array}$ & 口 & 口 & 口 & 口 & 口 \\
\hline $\mathbf{s}$ & $\begin{array}{l}\text { Je suis inquiet(e) à l'idée d'avoir } \\
\text { l'air stupide. }\end{array}$ & 口 & 口 & 口 & 口 & 口 \\
\hline$t$ & $\begin{array}{l}\text { J'ai l'impression que je ne vais pas } \\
\text { bien. }\end{array}$ & 口 & 口 & 口 & 口 & 口 \\
\hline
\end{tabular}


Les déclarations suivantes visent à comprendre ce que vous voulez réaliser avec votre apprentissage et vos sentiments lorsque vos parents vous rendent visite à l'école.

Q13 Veuillez indiquer dans quelle mesure vous êtes d'accord avec les déclarations suivantes.

a

Il est important pour moi d'apprendre beaucoup de nouveaux concepts (idées) cette année.

b L'un de mes objectifs en classe est d'apprendre autant que possible.

c Un de mes objectifs est de maîtriser de nombreuses nouvelles compétences cette année.

d Il est important pour moi de bien comprendre mon travail de classe.

e Il est important pour moi d'améliorer mes compétences cette année

$f \quad$ Je n'aime pas que mes parents viennent à l'école parce que leurs idées sont très différentes des idées de mes enseignants.

g Je me sens mal à l'aise quand mes parents viennent à l'école, car ils sont différents des parents de beaucoup de mes camarades de classe.

h Je me sens troublé parce que ma vie à la maison et ma vie scolaire sont comme deux mondes différents.

i Je ne suis pas à l'aise de parler à beaucoup de mes camarades de classe parce que ma famille est très différente de la leur.

j Je suis contrarié(e) parce que mon professeur et mes parents ont des idées

Pas du tout vrai

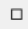

Un peu vrai

Très vrai

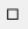

$\square$

$\square$

$\square$

$\square$

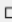

$\square$
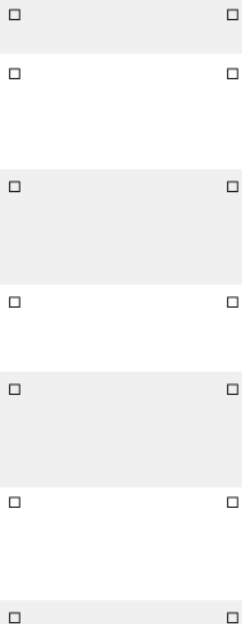

I Une fois, j'avais de bonnes raisons d'aller à l'école. Cependant, je me demande maintenant si je devrais continuer.

m Je ne vois pas pourquoi je vais à l'école et, franchement, je $m$ 'en fous.

n Je ne sais pas; je ne peux pas comprendre ce que je fais à l'école.

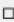

$\square$

$\square$

$\square$

(2)
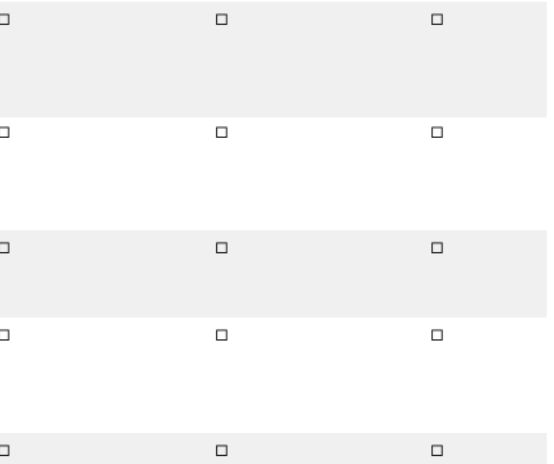

ㅁ $\square$ 
Q14 Veuillez indiquer à quelle fréquence les incidents suivants se produisent dans votre école.

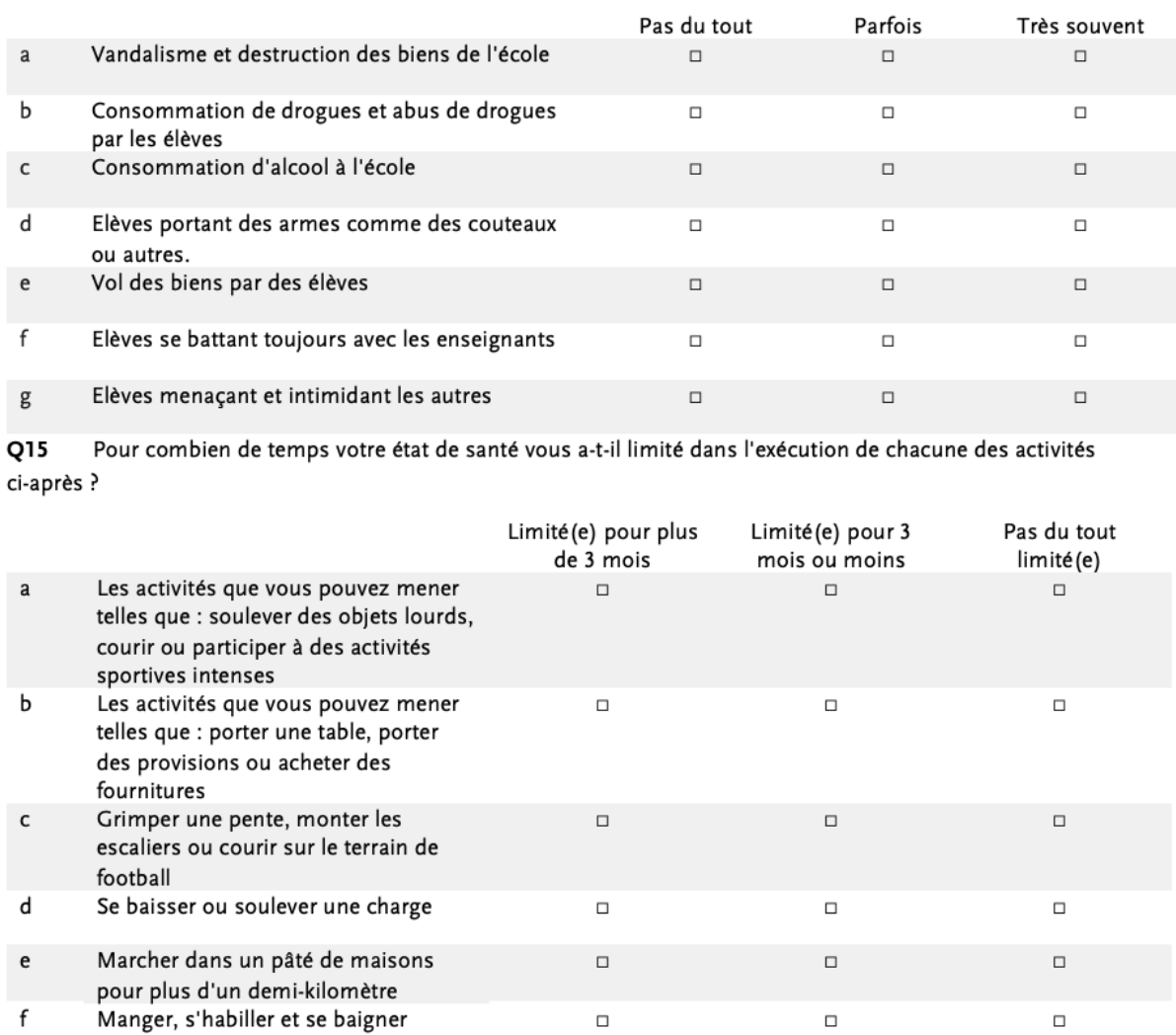

Q16 Pour combien de temps votre état de santé vous a-t-il limité dans l'exécution de chacune des activités ci-après ?

a Etre empêché(e) de travailler à la maison ou d'aller à l'école

b Etre incapable d'exécuter certaines tâches ménagères ou scolaires à cause de votre santé

$$
\begin{aligned}
& \text { Oui, pour plus de } \\
& \text { trois mois }
\end{aligned}
$$
Oui pour trois mois ou moins

$\begin{array}{ll}\square & \square \\ \square & \square\end{array}$

Non $\square$ 


\begin{tabular}{|c|c|c|c|c|c|}
\hline & & $\begin{array}{c}\text { Fortement } \\
\text { en } \\
\text { désaccord }\end{array}$ & $\begin{array}{c}\text { En } \\
\text { désaccord }\end{array}$ & D'accord & $\begin{array}{l}\text { Fortement } \\
\text { d'accord }\end{array}$ \\
\hline a & $\begin{array}{l}\text { Il y a une personne spéciale qui est là } \\
\text { quand je suis dans le besoin. }\end{array}$ & $\square$ & $\square$ & $\square$ & $\square$ \\
\hline b & $\begin{array}{l}\text { Il y a une personne spéciale avec qui je peux } \\
\text { partager mes joies et mes peines. }\end{array}$ & $\square$ & $\square$ & $\square$ & $\square$ \\
\hline c & Ma famille essaie vraiment de m'aider. & $\square$ & $\square$ & $\square$ & $\square$ \\
\hline$d$ & $\begin{array}{l}\text { Je reçois l'aide et le soutien émotionnels } \\
\text { dont j'ai besoin de ma famille. }\end{array}$ & $\square$ & $\square$ & $\square$ & $\square$ \\
\hline e & $\begin{array}{l}\text { J'ai une personne spéciale qui est une } \\
\text { véritable source de réconfort pour moi. }\end{array}$ & $\square$ & $\square$ & $\square$ & $\square$ \\
\hline f & Mes amis essaient vraiment de m'aider. & $\square$ & $\square$ & $\square$ & $\square$ \\
\hline g & $\begin{array}{l}\text { Je peux compter sur mes amis quand les } \\
\text { choses vont mal. }\end{array}$ & $\square$ & $\square$ & $\square$ & $\square$ \\
\hline h & $\begin{array}{l}\text { J'ai des amis avec qui je peux partager mes } \\
\text { joies et mes peines. }\end{array}$ & $\square$ & $\square$ & $\square$ & $\square$ \\
\hline i & $\begin{array}{l}\text { Il y a une personne spéciale dans ma vie qui } \\
\text { se soucie de mes sentiments. }\end{array}$ & $\square$ & $\square$ & $\square$ & $\square$ \\
\hline j & $\begin{array}{l}\text { Je peux parler de mes problèmes avec ma } \\
\text { famille. }\end{array}$ & $\square$ & $\square$ & $\square$ & $\square$ \\
\hline k & $\begin{array}{l}\text { Ma famille est prête à m'aider à prendre } \\
\text { des décisions. }\end{array}$ & 口 & 口 & 口 & 口 \\
\hline 1 & $\begin{array}{l}\text { Je peux parler de mes problèmes avec mes } \\
\text { amis. }\end{array}$ & 口 & 口 & 口 & 口 \\
\hline
\end{tabular}

Q18 En pensant à vous-même, quelqu'un vous a-t-il fait quelque chose par le passé ? Je veux dire...

\begin{tabular}{|c|c|c|c|c|c|}
\hline & & Jamais & $\begin{array}{l}\text { Pas au cours } \\
\text { de l'année } \\
\text { dernière, mais } \\
\text { cela est arrivé }\end{array}$ & Parfois & Plusieurs fois \\
\hline a & $\begin{array}{l}\text { Vous toucher de manière à vous } \\
\text { mettre mal à l'aise }\end{array}$ & $\square$ & $\square$ & $\square$ & 口 \\
\hline b & $\begin{array}{l}\text { Un enseignant qui demande à avoir } \\
\text { des relations sexuelles avec vous en } \\
\text { échange des notes }\end{array}$ & 口 & $\square$ & $\square$ & $\square$ \\
\hline c & $\begin{array}{l}\text { Quelqu'un qui vous embrasse alors } \\
\text { que vous ne voulez pas être } \\
\text { embrassé(e) }\end{array}$ & $\square$ & $\square$ & $\square$ & $\square$ \\
\hline d & $\begin{array}{l}\text { Quelqu'un qui touche vos parties } \\
\text { intimes ou vous fait toucher les } \\
\text { siennes }\end{array}$ & $\square$ & $\square$ & $\square$ & $\square$ \\
\hline e & $\begin{array}{l}\text { Vous énerver en vous parlant de } \\
\text { manière sexuelle ou en écrivant des } \\
\text { choses sexuelles sur vous }\end{array}$ & 口 & 口 & $\square$ & $\square$ \\
\hline$f$ & $\begin{array}{l}\text { Vous faire regarder leurs parties } \\
\text { intimes ou vouloir regarder les vôtres }\end{array}$ & $\square$ & $\square$ & 口 & $\square$ \\
\hline
\end{tabular}


g Essayer d'avoir des relations

$\square$ ㅁ sexuelles avec vous alors que vous ne le voulez pas.

Q19 Combien de livres y a-t-il dans votre maison? (Ne prenez pas en compte les magazines, les journaux ou vos manuels scolaires.) (Bien vouloir ne cocher qu'une seule case.)

0-10 livres

11-25 livres

26-100 livres

Q20 Environ combien de temps passez-vous habituellement à lire pour le plaisir ?

(Bien vouloir ne cocher qu'une seule case)

Je ne lis pas pour le plaisir

30 minutes ou moins par jour

Plus de 30 minutes à moins de 60 minutes par

1 à $2 \mathrm{~h}$ par jour

Plus de 2 heures par jour

Q21 Quelles sont vos notes dans les matières suivantes ?

\begin{tabular}{|c|c|c|c|c|c|c|}
\hline & & $\begin{array}{l}\text { Sous } \\
\text { moyenne }\end{array}$ & Moyen & Passable & Bien & Très bien \\
\hline a & Anglais & $\square$ & $\square$ & $\square$ & $\square$ & $\square$ \\
\hline$b$ & Français & $\square$ & $\square$ & $\square$ & $\square$ & $\square$ \\
\hline c & Mathématiques & $\square$ & $\square$ & $\square$ & $\square$ & $\square$ \\
\hline d & TIC & 口 & $\square$ & $\square$ & $\square$ & $\square$ \\
\hline
\end{tabular}

\section{Q22 Donnez-moi vos impressions sur ce questionnaire}

$\begin{array}{llc}\text { a Était-ce un questionnaire difficile à répondre ? } & \text { Oui } & \text { Non } \\ \text { b } \quad \text { Y a-t-il quelque chose que vous n'avez pas compris ? } & \square \\ \text { c Était-ce difficile d'être complètement ouvert sur ce qui vous est } \\ \text { arrivé ? }\end{array}$




\subsection{Questionnaire Data Set}

\begin{tabular}{|c|c|}
\hline Questionnaire & Data Set (Jamovi) \\
\hline $\mathrm{Q} 01$ & Background_Sex \\
\hline Q02 & Background_Yearofbirth \\
\hline Q03 & Background_Class \\
\hline Q04 & Background_Schoolowner \\
\hline Q05a & Background_Motherjob \\
\hline Q05b & Background_Mothereduc \\
\hline Q06a & Background_Fatherjob \\
\hline Q06b & Background_Fathereduc \\
\hline Q07a & Background_Orphan \\
\hline Q07b & Background_Refugee \\
\hline Q07c & Background_Paralive \\
\hline Q08 & Background_Schloc \\
\hline Q09 & Outcome_Classrep \\
\hline Q10a)a & L_VicAggress_Hithome \\
\hline Q10b & H_VicAggress_Kickedhome \\
\hline Q10c & L_VicAggress_Pushedhome \\
\hline Q10d & H_VicAggress_Badlybeaten \\
\hline Q10e & H_VicAggress_Knife \\
\hline Q10f & H_VicAggress_Attackknife \\
\hline Q10g & L_VicAggress_Slapface \\
\hline Q10h & H_VicAggress_Hitthrowingobject \\
\hline Q10i & L_PsyBull_Verballyabused \\
\hline Q10j & H_VicAggress_Robbed \\
\hline Q10k & H_PsyBull_Bewitched \\
\hline Q10l & L_PsyBull_Calldevil \\
\hline Q10m & H_VicAggress_Hitfist \\
\hline Q10b)n & L_PsyBull_Screamedat \\
\hline Q100 & L_PsyBull_Callnames \\
\hline Q10p & H_PsyBull_Wishdeath \\
\hline Q10q & H_PsyBull_Threatenleave \\
\hline Q10r & H_PsyBull_Threatenkilling \\
\hline Q11a & L_VicAgSch_Hitstudent \\
\hline Q11b & L_VicAgSch_Hitstaff \\
\hline Q11c & H_VicAgSch_Kickedstudent \\
\hline Q11d & H_VicAgSch_KickedStaff \\
\hline Q11e & H_VicAgSch_Badlybeatenatsch \\
\hline Q11f & H_VicAgSch_Threatenknifesch \\
\hline Q11g & H_VicAgSch_Attackknifesch \\
\hline Q11h & L_PsyBull_Threatenmarks \\
\hline Q11i & L_PsyBull_Verbalabuse \\
\hline Q11j & L_PsyBull_Verbalabusestaff \\
\hline Q11k & H_VicAgSch_Robbedsch \\
\hline Q111 & H_VicAgSch_Thrownfood \\
\hline Q11m & Sociallearning_Moneymarks \\
\hline Q11n & L_VicAgSch_Allowedstand \\
\hline
\end{tabular}




\begin{tabular}{|c|c|}
\hline Q12a & G_Selfesteem_Feelconfident \\
\hline Q12b & G_Selfesteem_Worriedsuccess \\
\hline Q12c & B_Selfesteem_Bodylooks \\
\hline Q12d & A_Selfesteem_Frustrated \\
\hline Q12e & A_Selfesteem_Trouble \\
\hline Q12f & G_Selfesteem_Respectme \\
\hline Q12g & B_Selfesteem_Myweight \\
\hline Q12h & G_Selfesteem_Selfconscious \\
\hline Q12i & G_Selfesteem_Smartothers \\
\hline Q12j & G_Selfesteem_Displeased \\
\hline Q12k & G_Selfesteem_Feelgood \\
\hline Q12I & B_Selfesteem_Appearance \\
\hline Q12m & G_Selfesteem_Worriedpeople \\
\hline Q12n & G_Selfesteem_Confident \\
\hline Q120 & G_Selfesteem_Inferior \\
\hline Q12p & B_Selfesteem_Unattractive \\
\hline Q12q & G_Selfesteem_Concerned \\
\hline Q12r & A_Selfesteem_Lessscholastic \\
\hline Q12s & G_Selfesteem_Foolish \\
\hline Q12t & G_Selfesteem_Notdoing \\
\hline Q13a & LM_Motivation_Newconcepts \\
\hline Q13b & LM_Motivation_Learnasmuch \\
\hline Q13c & LM_Motivation_Masterskills \\
\hline Q13d & LM_Motivation_Understandclass \\
\hline Q13e & LM_Motivation_Improveskills \\
\hline Q13f & Communication_Parentideas \\
\hline Q13g & Communication_Uncomfortable \\
\hline Q13h & Communication_Feeltroubled \\
\hline Q13i & Communication_Notcomfortable \\
\hline Q13j & Communication_Feelupset \\
\hline Q13k & Schoolmotivation_Waistingtime \\
\hline Q131 & Schoolmotivation_Goodreasons \\
\hline Q13m & Schoolmotivation_Cannotsee \\
\hline Q13n & Schoolmotivation-Cannotunderstand \\
\hline Q14a & H_Hostileenvironment_Vandalism \\
\hline Q14b & L_Hostileenvironment_Druguseabuse \\
\hline Q14c & L_Hostileenvironment_Acoholconsumption \\
\hline Q14d & H_Hostileenvironment_Carryingweapons \\
\hline Q14e & H_Hostileenvironment_Stealingproperties \\
\hline Q14f & H_Hostileenvironment_Studentsfightingteachers \\
\hline Q14g & L_Hostileenvironement_Studentsthreaten \\
\hline Q15a & H_Health_Heavyobjects \\
\hline Q15b & H_Health_Carryingtable \\
\hline Q15c & L_Health_Walkinguphill \\
\hline Q15d & H_Health_Bendingdown \\
\hline Q15e & L_Health_Walkingblock \\
\hline Q15f & L_Health_Eatingdressing \\
\hline Q16a & L_Health_Preventwork \\
\hline Q16b & L_Health_Unabletodowork \\
\hline Q17a & Sociallearning_Specialperson \\
\hline Q17b & Sociallearning_Sharejoys \\
\hline
\end{tabular}




\begin{tabular}{|l|l|}
\hline Q17c & Sociallearning_Familyhelp \\
\hline Q17d & Sociallearning_Emotionalhelp \\
\hline Q17e & Sociallearning_Sourceofcomfort \\
\hline Q17f & Sociallearning_Friendshelpme \\
\hline Q17g & Sociallearning_Thingsgowrong \\
\hline Q17h & Sociallearning_Havefriends \\
\hline Q17i & Sociallearning_Carefeelings \\
\hline Q17j & Sociallearning_Talkproblems \\
\hline Q17k & Sociallearning_Familywilling \\
\hline Q17l & Sociallearning_Problemfriends \\
\hline Q18a & Sexualharassment_Touchingway \\
\hline Q18b & Sexualharassment_Teachersex \\
\hline Q18c & Sexualharassment_Anyonekissing \\
\hline Q18d & Sexualharassment_Touchingprivatepart \\
\hline Q18e & Sexualharassment_Upsetyou \\
\hline Q18f & Sexualharassment_Lookprivatepart \\
\hline Q18g & Sexualharassment_Triedsex \\
\hline Q19 & Extrabooks_Bookshome \\
\hline Q20 & Outcome_Extrareadingenjoyment \\
\hline Q21a & Outcome_Englishlanguage \\
\hline Q21b & Outcome_Frenchlanguage \\
\hline Q21c & Outcome_Mathematics \\
\hline Q21d & Outcome_ICTs \\
\hline Q22a & Opinion_Hardquestionnaire \\
\hline Q22b & Opinion_Didnotunderstand \\
\hline Q22c & Opinion_Completelyopen \\
\hline
\end{tabular}




\subsection{Documentation of Scales}

Number of Respondents $(n)=924$

Scale 1: Students' Questionnaire for PISA 2009 (PP. 3-8) Questions 1-9

\begin{tabular}{|l|l|l|l|}
\hline $\begin{array}{l}\text { Item number in } \\
\text { questionnaire }\end{array}$ & Wording & Name in Data Frame & Transformation \\
\hline Q01 & I am & Background_Sex & \\
\hline Q02 & Please indicate your date of birth & Background_Yearofbrith & \\
\hline Q03 & In what class are you? & Background_Class & \\
\hline Q04 (a) & Which of these schools do you attend? & Background_Schoolowner & \\
\hline Q04 (b) & Mark an (X) on the answers that relates to you. & Background_Schooltype & \\
\hline Q05 a) & What is your mother's main job? & Background_Motherjob & Transformed \\
\hline Q05 b) & $\begin{array}{l}\text { What is the highest level of schooling completed by } \\
\text { your mother? }\end{array}$ & Background_Mothereduc & \\
\hline Q06 a) & What is your father's main job? & Background_Fatherjob & Transformed \\
\hline Q06 b) & $\begin{array}{l}\text { What is the highest level of schooling completed by } \\
\text { your father? }\end{array}$ & Background_Fathereduc & \\
\hline Q07 (a) & Are you an orphan? & Background_Orphan & \\
\hline Q07 (b) & Are you a refugee? & Background_Refugee & \\
\hline Q07 (C) & Are your parents alive? & Background_Paralive & Excluded \\
\hline Q08 & What is your school location? & Background_Schloc & \\
\hline Q09 & Have you ever repeated a class? & Background_Classrep & \\
\hline
\end{tabular}

Scale 2 Physical Victimization and Bullying at Home

Source: Hamburger et al. (2011) Measuring Bullying Victimization, Perpetration, and Bystander Experiences: A Compendium of Assessment Tools. Section D4. P.84.

\begin{tabular}{|c|c|c|c|}
\hline $\begin{array}{l}\text { Item number in } \\
\text { questionnaire }\end{array}$ & Wording & Name in Data Frame & Reverse \\
\hline 10. & \multicolumn{3}{|l|}{ At home in the past year, how often have been } \\
\hline $\mathrm{a}$ & Hit & VicAggress_Hithome & No \\
\hline $\mathrm{b}$ & Kicked & VicAggress_Kickedhome & No \\
\hline $\mathrm{c}$ & Pushed or shoved & VicAggress_Pushedhome & No \\
\hline $\mathrm{d}$ & Badly beaten up & VicAggress_Badlybeaten & No \\
\hline $\mathrm{e}$ & Threatened with a knife or sharp weapon & VicAggress_Knife & No \\
\hline$f$ & Attacked with a knife or sharp weapon & VicAggress_Attackedknife & No \\
\hline $\mathrm{g}$ & Slapped you on your face or head with the hand & VicAggress_Slapface & No \\
\hline $\mathrm{h}$ & Hit you by throwing an object at you. & VicAggress_Hitthrowing & No \\
\hline $\mathrm{i}$ & Verbally or emotionally abused & PsyBull_Verballyabused & No \\
\hline $\mathrm{j}$ & Robbed & VicAggress_Robbed & No \\
\hline $\mathrm{k}$ & Bewitched & PsyBull_Bewitched & No \\
\hline 1 & Called or referred to as a devil & PsyBull_Calldevil & No \\
\hline $\mathrm{m}$ & Hit you with a closed fist & VicAggress_Hitfist & No \\
\hline $\mathrm{n}$ & Screamed at you very loud and aggressively & PsyBull_Screamedat & No \\
\hline 0 & $\begin{array}{l}\text { Called you names, said mean things, or cursed } \\
\text { you? }\end{array}$ & PsyBull_Callnames & No \\
\hline $\mathrm{p}$ & Said, they wish you were dead or never born. & PsyBull_Wishdeath & No \\
\hline 9 & Threaten to leave you forever or abandon you? & PsyBull_Threatenleave & No \\
\hline$r$ & $\begin{array}{l}\text { Threatened to hurt or killed you, including } \\
\text { invoking evil spirits against you? }\end{array}$ & PsyBull_Threatenkilling & No \\
\hline
\end{tabular}


Scale 3 Physical Victimization and Bullying at School

Source: Hamburger et al. (2011) Measuring Bullying Victimization, Perpetration, and Bystander Experiences: A Compendium of Assessment Tools. Section D4. P.84.

\begin{tabular}{|c|c|c|c|}
\hline $\begin{array}{l}\text { Item number } \\
\text { in } \\
\text { questionnaire }\end{array}$ & Wording & Name in Data Frame & Reverse \\
\hline Q11 & How often in the past year have you been & & \\
\hline $\mathrm{a}$ & Hit by a student. & VicAgSch_Hitstudent & No \\
\hline $\mathrm{b}$ & Hit by school staff. & VicAgSch_Hitstaff & No \\
\hline c & Kicked or pushed by a student. & VicAgSch_Kickedstudent & No \\
\hline d & Kicked or pushed by school staff. & VicAgSch_Kickedstaff & No \\
\hline e & Badly beaten up. & VicAgSch_badlybeatenatsch & No \\
\hline$f$ & Threatened with a knife or sharp weapon. & VicAgSch_Threatenknifesch & No \\
\hline $\mathrm{g}$ & Attacked with a knife or sharp weapon. & VicAgSch_Attackedknifesch & No \\
\hline $\mathrm{h}$ & Threatened with bad marks that you did not deserve & PsyBull_Threatenmarks & No \\
\hline $\mathrm{i}$ & $\begin{array}{l}\text { Verbally or emotionally abused by a student, that is, } \\
\text { being called names or having things said to you that } \\
\text { make you feel bad about yourself or afraid. }\end{array}$ & PsyBull_VerbalAbuse & No \\
\hline j & Verbally or emotionally abused by school staff. & PsyBull_Verbalabusestaff & No \\
\hline k & Robbed. & VicAgSch_Robbedsch & No \\
\hline I & Thrown food or pepper on your body & VicAgSch_Thrownfood & No \\
\hline $\mathrm{m}$ & Giving money in exchange for marks & Sociallearning_Moneymarks & No \\
\hline $\mathrm{n}$ & Allowed to stand in the heat or cold & VicAgSch_Allowedstand & No \\
\hline
\end{tabular}

Scale 4 Students' Self-Esteem

Heatherton \& Polivy (1991) Development and Validation of a Scale for Measuring State Self-Esteem. (P.898)

\begin{tabular}{|l|l|l|l|}
\hline $\begin{array}{l}\text { Item number } \\
\text { in } \\
\text { questionnaire }\end{array}$ & Wording & \multicolumn{2}{l}{} \\
\hline $\mathbf{1 2}$ & Please indicate how much the following statements apply to you. & \multicolumn{2}{l|}{ Reverse } \\
\hline a & I feel confident about my abilities. & G_Selfesteem_Feelconfident & No \\
\hline b & $\begin{array}{l}\text { I am worried about whether I am regarded as a } \\
\text { success or a failure }\end{array}$ & G_Selfesteem_Worriedsuccess & Yes \\
\hline c & $\begin{array}{l}\text { I feel satisfied with the way my body looks right } \\
\text { now. }\end{array}$ & B_Selfesteem_Bodylooks & No \\
\hline d & I feel frustrated or rattled about my performance & A_Selfesteem_Frustrated & Yes \\
\hline e & $\begin{array}{l}\text { I feel that I have trouble-understanding things } \\
\text { that I read. }\end{array}$ & A_Selfesteem_Troubled & Yes \\
\hline f & I feel that others respect and admire me. & G_Selfesteem_Respectme & No \\
\hline g & I am dissatisfied with my weight. & B_Selfesteem_Myweight & Yes \\
\hline h & I feel self-conscious. & G_Selfesteem_Selfconscious & No \\
\hline i & I feel as smart as others do. & G_Selfesteem_Smartothers & No \\
\hline I & I feel displeased with myself & G_Selfesteem_Displeased & Yes \\
\hline k & I feel good about myself. & G_Selfesteem_Feelgood & No \\
\hline I & I am pleased with my appearance right now. & B_Selfesteem_Appearance & No \\
\hline
\end{tabular}




\begin{tabular}{|l|l|l|l|}
\hline$m$ & $\begin{array}{l}\text { I am worried about what other people think of } \\
\text { me. }\end{array}$ & G_Selfesteem_Worriedpeople & Yes \\
\hline $\mathrm{n}$ & I feel confident that I understand things & G_Selfesteem_Confident & No \\
\hline $\mathrm{o}$ & I feel inferior to others at this moment. & G_Selfesteem_Inferior & Yes \\
\hline $\mathrm{p}$ & I feel unattractive. & B_Selfesteem_Unattractive & Yes \\
\hline $\mathrm{q}$ & $\begin{array}{l}\text { I feel concerned about the impression I am } \\
\text { making. }\end{array}$ & G_Selfesteem_Concerned & Yes \\
\hline $\mathrm{r}$ & $\begin{array}{l}\text { I feel that I have less scholastic ability right now } \\
\text { than others }\end{array}$ & A_Selfesteem_Lessscholastic & Yes \\
\hline $\mathrm{s}$ & I am worried about looking foolish. & G_Selfesteem_Foolish & Yes \\
\hline $\mathrm{t}$ & I feel like I am not doing well. & G_Selfesteem_Notdoing & Yes \\
\hline
\end{tabular}

Scale 5: Academic Motivation Scale

A Measure of Intrinsic, Extrinsic and Motivation in Education by Vallerand, R. T. et al. (1992)
\begin{tabular}{|l|l|l|l|}
\hline $\begin{array}{l}\text { Item number } \\
\text { in } \\
\text { questionnaire }\end{array}$ & Wording & Name in Data Frame & \multirow{2}{*}{ Reverse } \\
\hline Q13 & Please indicate how much you agree with the following statements. & No \\
\hline a & $\begin{array}{l}\text { It is important to me that I learn many } \\
\text { new concepts (ideas) this year. }\end{array}$ & LM_Motivation_Newconcepts & No \\
\hline b & $\begin{array}{l}\text { One of my goals in class is to learn as } \\
\text { much as I can. }\end{array}$ & LM_Motivation_Learnasmuch & No \\
\hline c & $\begin{array}{l}\text { One of my goals is to master many new } \\
\text { skills this year. }\end{array}$ & LM_Motivation_Masterskills & No \\
\hline d & $\begin{array}{l}\text { It is important to me that I thoroughly } \\
\text { understand my classwork. }\end{array}$ & LM_Motivation_Understandclass & No \\
\hline e & $\begin{array}{l}\text { It is important to me that I improve my } \\
\text { skills this year }\end{array}$ & LM_Motivation_Improveskills & \\
\hline
\end{tabular}

Scale 6: $\quad$ Communication and Worries about Family Background

Midgley et al. (2000) Manual for the Patterns of Adaptive Learning Scales (PP. 10, 18, 30)

\begin{tabular}{|l|l|l|l|}
\hline $\mathrm{f}$ & $\begin{array}{l}\text { I do not like to have my parents come to } \\
\text { school because their ideas are very } \\
\text { different from my teachers' ideas. }\end{array}$ & Communication_Parentideas & No \\
\hline $\mathrm{g}$ & $\begin{array}{l}\text { I feel uncomfortable when my parents } \\
\text { come to school because they are } \\
\text { different from the parents of many of my } \\
\text { classmates. }\end{array}$ & Communication_Uncomfortable & No \\
\hline $\mathrm{h}$ & $\begin{array}{l}\text { I feel troubled because my home life and } \\
\text { my school life are like two different } \\
\text { worlds. }\end{array}$ & Communication_Feeltroubled & No \\
\hline $\mathrm{i}$ & $\begin{array}{l}\text { I am not comfortable talking to many of } \\
\text { my classmates because my family is very } \\
\text { different from theirs. }\end{array}$ & Communication_Notcomfortable & No \\
\hline J & $\begin{array}{l}\text { I feel upset because my teacher and my } \\
\text { parents have different ideas about what I } \\
\text { should learn in school }\end{array}$ & Communication_Upset & No \\
\hline
\end{tabular}




\begin{tabular}{|l|l|l|l|}
\hline $\mathrm{k}$ & $\begin{array}{l}\text { Honestly, I don't know; I really feel that I } \\
\text { am wasting my time in school. }\end{array}$ & Schoolmotivation_Wastingtime & Yes \\
\hline I & $\begin{array}{l}\text { I once had good reasons for going to } \\
\text { school; however, now I wonder whether I } \\
\text { should continue. }\end{array}$ & Schoolmotivation_Goodreasons & Yes \\
\hline $\mathrm{m}$ & $\begin{array}{l}\text { I cannot see why I go to school, and, } \\
\text { frankly, I couldn't care less. }\end{array}$ & Schoolmotivation_Cannotsee & Yes \\
\hline $\mathrm{n}$ & $\begin{array}{l}\text { I don't know; I cannot understand what I } \\
\text { am doing in school. }\end{array}$ & Schoolmotivation_Cannotunderstand & Yes \\
\hline
\end{tabular}

Scale 7: Violent School Environment

Furlong et al. (2005) Development of the California School Climate and Safety Survey Short Form (p. 142)

\begin{tabular}{|l|l|l|l|}
\hline $\begin{array}{l}\text { Item number } \\
\text { in } \\
\text { questionnaire }\end{array}$ & Wording & \multicolumn{1}{l|}{ Name in Data Frame } & \multicolumn{1}{l|}{ Reverse } \\
\hline Q14 Please indicate how often the following incidents occur in your school. & No \\
\hline a & $\begin{array}{l}\text { Vandalism and destruction of } \\
\text { school properties }\end{array}$ & H_Hostileenvironment_Vandalism & No \\
\hline b & $\begin{array}{l}\text { Drug use and abuse of it by } \\
\text { students }\end{array}$ & H_Hostileenvironment_Druguse & No \\
\hline c & Alcohol consumption in school & L_Hostileenvironment_Alcoholconsumption & No \\
\hline d & $\begin{array}{l}\text { Students carrying weapons like } \\
\text { knives or other things }\end{array}$ & H_Hostileenvironment_Carryingweapons & No \\
\hline e & Stealing of properties by students & H_Hostileenvironment_Stealingproperies & No \\
\hline f & $\begin{array}{l}\text { Students always fighting with } \\
\text { teachers }\end{array}$ & H_Hostileenvironment_Studentsfight & No \\
\hline
\end{tabular}

Scale 8: Physical Health of Students

Stewart et al. (1988). The MOS Short-Form General Health Survey: Reliability and Validity in a Patient Population. (p.733).

\begin{tabular}{|l|l|l|l|}
\hline $\begin{array}{l}\text { Item number } \\
\text { in } \\
\text { questionnaire }\end{array}$ & \multicolumn{1}{l|}{ Wording } & \multicolumn{2}{l}{} \\
\hline Q15 For how long has your health limited you in each of these activities? & \multicolumn{2}{l|}{ Name in Data Frame } & Reverse \\
\hline a & $\begin{array}{l}\text { The activities you can do like lifting heavy objects, running, } \\
\text { or participating in strenuous sports }\end{array}$ & Health_Heavyobjects & Yes \\
\hline b & $\begin{array}{l}\text { The activities you can do like carrying a table, carrying } \\
\text { groceries or bought supplies }\end{array}$ & Health_Carryingtable & Yes \\
\hline c & $\begin{array}{l}\text { Walking uphill, climbing stairs, or running around the } \\
\text { football field }\end{array}$ & Health_Walkinguphill & Yes \\
\hline d & Bending down or lifting cargo & Health_Bendingdown & Yes \\
\hline e & Walking for a block and at most half a kilometer & Health_Walkingblock & Yes \\
\hline f & Eating, dressing, and bathing & Health_Eatdressing & Yes \\
\hline g & $\begin{array}{l}\text { Prevent you from doing work in the house or going to } \\
\text { school }\end{array}$ & Health_Preventwork & Yes \\
\hline h & $\begin{array}{l}\text { Unable to do certain kinds of housework or schoolwork } \\
\text { because of your health }\end{array}$ & Health_Unabletowork & Yes \\
\hline
\end{tabular}


Scale 9: Social Learning Support

Zimet et al. (1988) The Multidimensional Scale of Perceived Social Support (p.35)

\begin{tabular}{|l|l|l|l|}
\hline $\begin{array}{l}\text { Item number } \\
\text { in } \\
\text { questionnaire }\end{array}$ & Wording & Name in Data Frame & Reverse \\
\hline Q17 How do you view your social and emotional life in school and at home? & \multicolumn{2}{l|}{} \\
\hline a & $\begin{array}{l}\text { There is a special person who is around when I am } \\
\text { in need. }\end{array}$ & Sociallearning_Specialperson & No \\
\hline b & $\begin{array}{l}\text { There is a special person with whom I can share } \\
\text { my joys and sorrows. }\end{array}$ & Sociallearning_Sharejoys & No \\
\hline c & My family really tries to help me. & Sociallearning_Familyhelps & No \\
\hline d & $\begin{array}{l}\text { I get the emotional help and support I need from } \\
\text { my family. }\end{array}$ & Sociallearning_Emotionalhelp & No \\
\hline e & $\begin{array}{l}\text { I have a special person who is a real source of } \\
\text { comfort to me. }\end{array}$ & Sociallearning_Sourceofcomfort & No \\
\hline f & My friends really try to help me. & Sociallearning_Friendshelpme & No \\
\hline g & I can count on my friends when things go wrong. & Sociallearning_Thingsgowrong & No \\
\hline h & $\begin{array}{l}\text { I have friends with whom I can share my joys and } \\
\text { sorrows. }\end{array}$ & Sociallearning_Havefriends & No \\
\hline i & $\begin{array}{l}\text { There is a special person in my life who cares } \\
\text { about my feelings. }\end{array}$ & Sociallearning_Carefeelings & No \\
\hline j & I can talk about my problems with my family. & Sociallearning_Talkproblems & No \\
\hline k & My family is willing to help me make decisions. & Sociallearning_Familywilling & No \\
\hline I & I can talk about my problems with my friends. & Sociallearning_Problemfriends & No \\
\hline
\end{tabular}

Scale 9: Sexual Harassement

Meincke et al. (2018), ICAST-CH Sexual Harassment Adapted Instruments
\begin{tabular}{|l|l|l|l|}
\hline $\begin{array}{l}\text { Item number } \\
\text { in } \\
\text { questionnaire }\end{array}$ & Wording & Name in Data Frame & Reverse \\
\hline Q18 Thinking about yourself. Has anyone done any of these things to you in the past? I mean & Sexualharassment_Touchingway & No \\
\hline a & $\begin{array}{l}\text { Touching you in a way that makes you } \\
\text { uncomfortable }\end{array}$ & Sexualharassment_Teachersex & No \\
\hline b & $\begin{array}{l}\text { Any teacher making you have sex in } \\
\text { exchange for marks }\end{array}$ & $\begin{array}{l}\text { Sexualharassment_Anyonekissing } \\
\text { to be kissed }\end{array}$ & No \\
\hline c & $\begin{array}{l}\text { Anyone touching your private parts or } \\
\text { made you touch theirs }\end{array}$ & Sexualharassment_Touchingprivateparts & No \\
\hline d & $\begin{array}{l}\text { Made you upset by speaking to you in a } \\
\text { sexual way or writing sexual things about } \\
\text { you }\end{array}$ & Sexualharassment_Upsetyou & No \\
\hline e & $\begin{array}{l}\text { Made you look at their private parts or } \\
\text { wanted to look at yours }\end{array}$ & Sexualharassment_Lookingprivate & No \\
\hline f & $\begin{array}{l}\text { Tried to have sex with you when you did not } \\
\text { want them to. }\end{array}$ & Sexualharassment_Triedsex & No \\
\hline g &
\end{tabular}


Reliability Verification

\begin{tabular}{|c|c|c|c|c|}
\hline Constructs & \multicolumn{4}{|l|}{ Social Background of the Students } \\
\hline Scale & \multicolumn{4}{|l|}{ PISA ISCED 2009 student questionnaire } \\
\hline Theoretical background & \multicolumn{4}{|c|}{$\begin{array}{l}\text { Socioeconomic status is an economic and sociological combined total measure of a person's } \\
\text { work experience and an individual's or family's economic and social position relative to others, } \\
\text { based on income, education, and occupation (Okioga, 2013, p. 38). This indicates the intensity } \\
\text { to which social origins affect individuals' educational transitions through acquired performance } \\
\text { usually measured by standardized achievement tests and school grades (Ress \& Azzolini, 2014, } \\
\text { p. 54). Hence, models that investigate factors that affect academic achievement usually take } \\
\text { structural, student attitudes, and behavioral variables (Aypay, 2002, p. 87). Favorable attitudes } \\
\text { regarding educational attainment lead to more significant effort and achievement, while } \\
\text { unfavorable attitudes lead to lowered anticipations and less effort among students' low self- } \\
\text { esteem (Aypay, 2002). Socio-economic background effects operate through family influences } \\
\text { on children and thus via the transmission of genetic traits but also through environmental } \\
\text { conditions and the daily interactions between parents and children, with the former } \\
\text { transmitting to the latter sociocultural resources that are key for the cognitive and non-cognitive } \\
\text { development since the early years (Ress \& Azzolini, 2014). Understanding children's } \\
\text { characteristics is an essential and first step for supporting their healthy development and } \\
\text { school readiness. Such a background is a crucial factor that contributes personal, social, } \\
\text { cultural, and future fulfillment of an adult (Kazu \& İs, 2018, p. 66) }\end{array}$} \\
\hline Source & \multicolumn{4}{|c|}{$\begin{array}{l}\text { Aypay, A. (2002). Social Background Effects and Academic Achievement during Transition to } \\
\text { High School. Mediterranean Journal of Educational Studies, 7(1), 87-103 } \\
\text { Okioga, C. K. (2013). The Impact of Students' Socio-economic Background on Academic } \\
\text { Performance in Universities, a Case of Students in Kisii University College. American } \\
\text { International Journal of Social Science, 2(2), 38-46. } \\
\text { Ress, A. \& Azzolini, D. (2014). Primary and Secondary Effects of Social Background on } \\
\text { Educational Attainment in Italy. Italian Journal of Sociology of Education, 6(1), 53-58. } \\
\text { Kazu, I. Y. \& İş, A. (2018). An Investigation About Actualization Levels of Learning Outcomes } \\
\text { in Early Childhood Curriculum. Journal of Education and Training Studies, } 6(3), 66\end{array}$} \\
\hline Number of items & \multicolumn{4}{|l|}{09} \\
\hline \multicolumn{5}{|l|}{ Scale } \\
\hline \multicolumn{5}{|l|}{ Reversed items } \\
\hline Transformed items & \multicolumn{4}{|l|}{02} \\
\hline Excluded items & \multicolumn{4}{|l|}{01} \\
\hline \multirow[t]{2}{*}{ Scale information } & Mean & & Cronbach's $\alpha$ & \\
\hline & $\mathrm{N} / \mathrm{A}$ & & $\mathrm{N} / \mathrm{A}$ & \\
\hline \multicolumn{5}{|l|}{ Student questionnaire } \\
\hline Item formulation & Name & Mean & SD & rit \\
\hline Q01 & Background_Sex & $\mathrm{N} / \mathrm{A}$ & $\mathrm{N} / \mathrm{A}$ & $\mathrm{N} / \mathrm{A}$ \\
\hline Q02 & Background_Yearofbrith & $\mathrm{N} / \mathrm{A}$ & $\mathrm{N} / \mathrm{A}$ & $\mathrm{N} / \mathrm{A}$ \\
\hline Q03 & Background_Class & $\mathrm{N} / \mathrm{A}$ & $\mathrm{N} / \mathrm{A}$ & $\mathrm{N} / \mathrm{A}$ \\
\hline Q04 (a) & Background_Schoolowner & $\mathrm{N} / \mathrm{A}$ & $\mathrm{N} / \mathrm{A}$ & $\mathrm{N} / \mathrm{A}$ \\
\hline Q04 (b) & Background_Schooltype & $\mathrm{N} / \mathrm{A}$ & $\mathrm{N} / \mathrm{A}$ & $\mathrm{N} / \mathrm{A}$ \\
\hline Q05 a) & Background_Motherjob (Transformed) & $\mathrm{N} / \mathrm{A}$ & $\mathrm{N} / \mathrm{A}$ & $\mathrm{N} / \mathrm{A}$ \\
\hline Q05 b) & Background_Mothereduc & $\mathrm{N} / \mathrm{A}$ & $\mathrm{N} / \mathrm{A}$ & $\mathrm{N} / \mathrm{A}$ \\
\hline Q06 a) & Background_Fatherjob (Transformed) & $\mathrm{N} / \mathrm{A}$ & $\mathrm{N} / \mathrm{A}$ & $\mathrm{N} / \mathrm{A}$ \\
\hline Q06 b) & Background_Fathereduc & $\mathrm{N} / \mathrm{A}$ & $\mathrm{N} / \mathrm{A}$ & $\mathrm{N} / \mathrm{A}$ \\
\hline Q07 (a) & Background_Orphan & $\mathrm{N} / \mathrm{A}$ & $\mathrm{N} / \mathrm{A}$ & $\mathrm{N} / \mathrm{A}$ \\
\hline Q07 (b) & Background_Refugee & $\mathrm{N} / \mathrm{A}$ & $\mathrm{N} / \mathrm{A}$ & $\mathrm{N} / \mathrm{A}$ \\
\hline Q07 (C) & Background_Paralive $\quad$ (Excluded) & $\mathrm{N} / \mathrm{A}$ & $\mathrm{N} / \mathrm{A}$ & $\mathrm{N} / \mathrm{A}$ \\
\hline Q08 & Background_Schloc & $\mathrm{N} / \mathrm{A}$ & $\mathrm{N} / \mathrm{A}$ & $\mathrm{N} / \mathrm{A}$ \\
\hline Q09 & Background_Classrep & $\mathrm{N} / \mathrm{A}$ & $\mathrm{N} / \mathrm{A}$ & $\mathrm{N} / \mathrm{A}$ \\
\hline
\end{tabular}




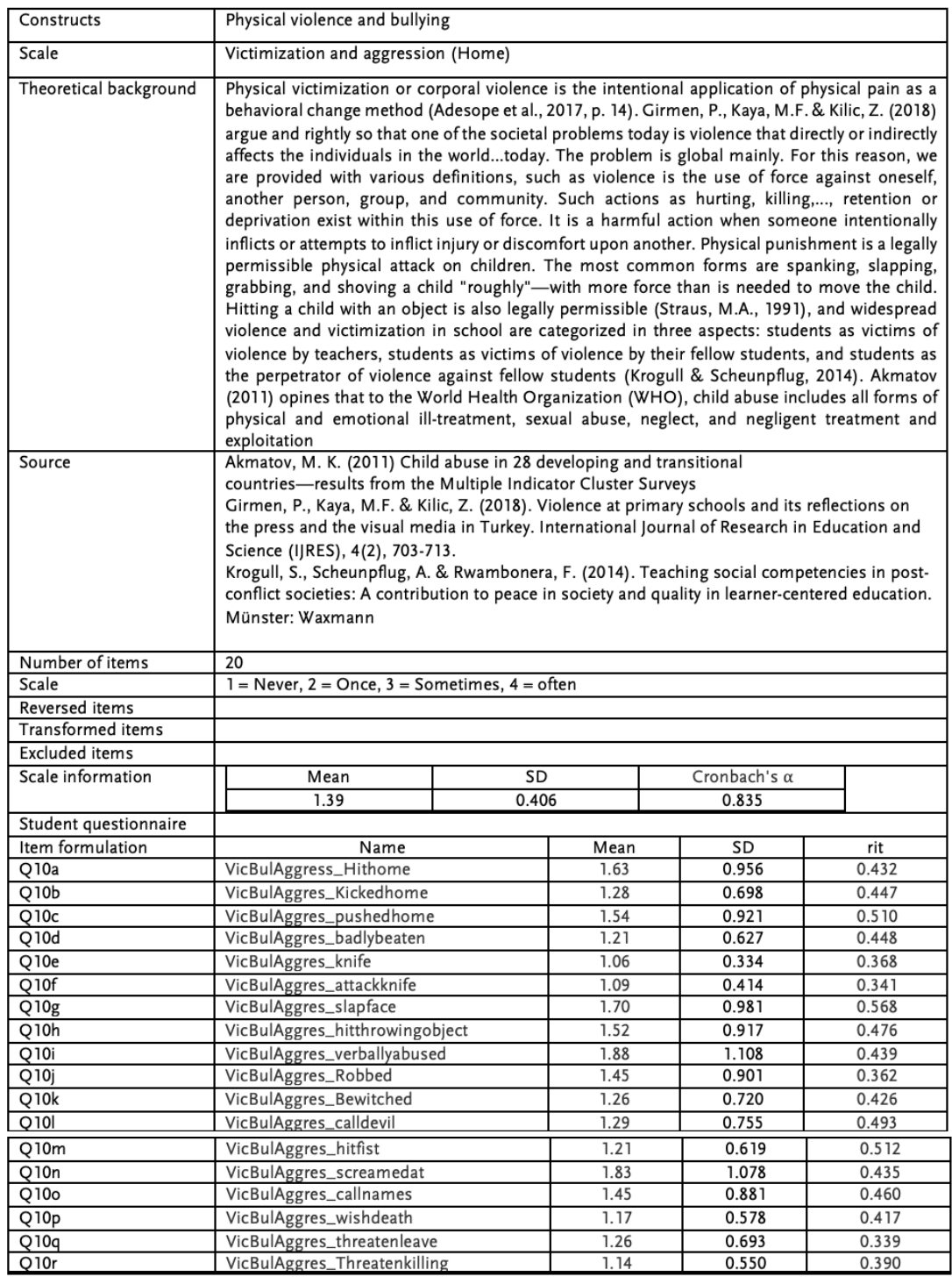




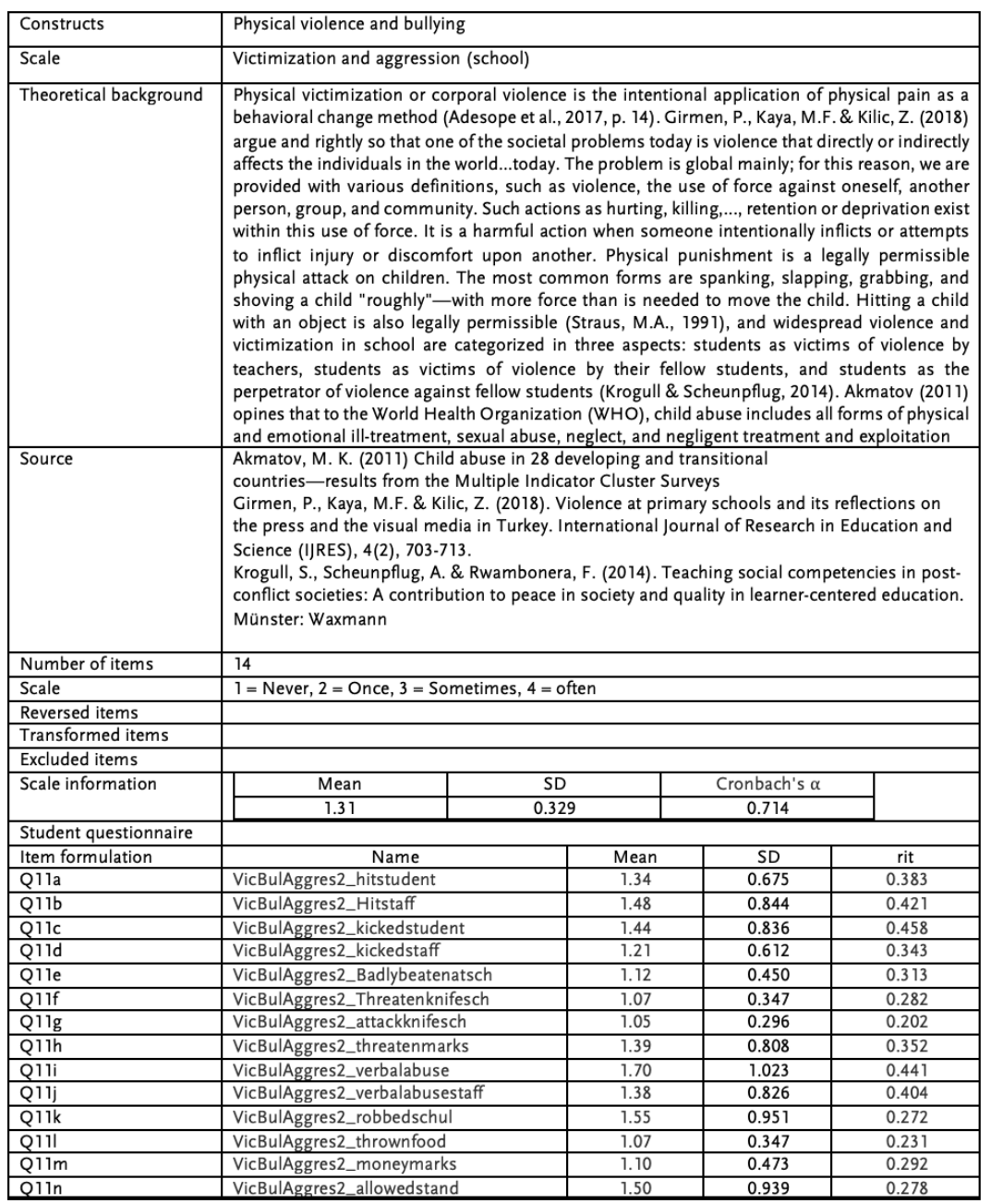




\begin{tabular}{|c|c|c|c|c|}
\hline Constructs & \multicolumn{4}{|l|}{ Madiator of Learning } \\
\hline Scale & \multicolumn{4}{|l|}{ Self-esteem } \\
\hline Theoretical background & \multicolumn{4}{|c|}{$\begin{array}{l}\text { Self-esteem is the degree to which people perceive themselves to be significant, } \\
\text { capable, and worthy, can be equated to general feelings of self-worth or self-value, } \\
\text { therefore motivates and shapes a person's belief in his or herself (Gardner \& Pierce, } \\
\text { 1998; Neil, 2005). Self-efficacy describes the experiences of one's competencies as } \\
\text { students view themselves as self-dependent, and this emotionally positive experience } \\
\text { enhances their motivation with students believing that such high efficacious acts are } \\
\text { likely to make them succeed in most or all of their duties and responsibilities (Krogull, } \\
\text { Scheunpflug \& Rwambonera, 2014; Gardner \& Pierce, 1998). Bandura (1977, 1978) } \\
\text { summarizes this by stating that it reflects an individual's belief in their capability to } \\
\text { perform a specific task at a particular performance level. }\end{array}$} \\
\hline Source & \multicolumn{4}{|c|}{$\begin{array}{l}\text { Gardner, D. G. \& Pierce, J. L. (1998). Self-Esteem and Self-Efficacy within the } \\
\text { Organizational Context. An Empirical Examination. Group and Organization } \\
\text { Management, 23(1), 48-70 } \\
\text { Krogull, Scheunpflug \& Rwambonera (2014) Teaching Social Competencies in Post- } \\
\text { Colonial Societies. A contribution to Peace in Society and Quality in Learner-Centered } \\
\text { Education. }\end{array}$} \\
\hline Number of items & \multicolumn{4}{|c|}{20} \\
\hline Scale & \multicolumn{4}{|c|}{$\begin{array}{l}5=\text { Not at all, } 4=\text { A little bit, } 3=\text { Somewhat, } 2=\text { Very much, } 1=\text { Extremely was the } \\
\text { format to answer and this means after reversing (1) indicated little self-esteem and } 5 \\
\text { (high self-esteem }\end{array}$} \\
\hline Reversed items & \multicolumn{4}{|c|}{07} \\
\hline \multicolumn{5}{|l|}{ Transformed items } \\
\hline \multicolumn{5}{|l|}{ Excluded items } \\
\hline \multirow[t]{2}{*}{ Scale information } & Mean & S.D & \multicolumn{2}{|c|}{ Cronbach's $\alpha$} \\
\hline & 2.31 & 0.564 & \multicolumn{2}{|c|}{0.770} \\
\hline \multicolumn{5}{|l|}{ Student questionnaire } \\
\hline Item formulation & Name & Mean & SD & rit \\
\hline Q12a & Selfesteem_feelconfident ${ }^{\mathrm{a}}$ & 2.26 & 1.23 & 0.369 \\
\hline Q12b & Selfesteem_worriedsuccess & 2.43 & 1.32 & 0.242 \\
\hline Q12c & Selfesteem_bodylooks ${ }^{\text {a }}$ & 2.47 & 1.47 & 0.303 \\
\hline Q12d & Selfesteem_frustrated & 2.26 & 1.34 & 0.412 \\
\hline Q12e & Selfesteem_Trouble & 2.40 & 1.17 & 0.324 \\
\hline Q12f & Selfesteem_respectme a & 2.99 & 1.31 & 0.304 \\
\hline Q12g & Selfesteem_myweight & 1.81 & 1.26 & 0.208 \\
\hline Q12h & Selfesteem_selfconscious & 2.02 & 1.35 & 0.211 \\
\hline Q12i & Selfesteem_smartothers ${ }^{a}$ & 3.17 & 1.40 & 0.355 \\
\hline Q12j & Selfesteem_displeased & 1.84 & 1.21 & 0.390 \\
\hline Q12k & Selfesteem_feelgood ${ }^{a}$ & 2.36 & 1.45 & 0.419 \\
\hline Q121 & Selfesteem_appearance a & 2.49 & 1.46 & 0.344 \\
\hline Q12m & Selfesteem_worried & 2.25 & 1.42 & 0.370 \\
\hline Q12n & Selfesteem_confident a & 3.23 & 1.28 & 0.265 \\
\hline Q120 & Selfesteem_inferior & 1.78 & 1.10 & 0.356 \\
\hline Q12p & Selfesteem_unattractive & 1.71 & 1.02 & 0.305 \\
\hline Q12q & Selfesteem_concerned & 2.29 & 1.34 & 0.282 \\
\hline Q12r & Selfesteem_lessscholastic & 2.28 & 1.28 & 0.373 \\
\hline Q12s & Selfesteem_foolish & 2.02 & 1.35 & 0.333 \\
\hline Q12t & Selfesteem_notdoing & 2.09 & 1.28 & 0.476 \\
\hline
\end{tabular}




\begin{tabular}{|c|c|c|c|c|}
\hline Constructs & \multicolumn{4}{|l|}{ Mediator of Learning } \\
\hline Scale & \multicolumn{4}{|l|}{ Motivation } \\
\hline Theoretical background & \multicolumn{4}{|c|}{$\begin{array}{l}\text { Self-determination theory (Deci et al., 1991: } 325 \text { ), when applied to the realm of } \\
\text { education, is concerned primarily with promoting in students an interest in learning, a } \\
\text { valuing of education, and confidence in their capacities and attributes. These outcomes } \\
\text { are manifestations of being intrinsically motivated and internalizing values and } \\
\text { regulatory processes. Research suggests that these processes result in high-quality } \\
\text { learning and conceptual understanding and enhanced personal growth and adjustment. } \\
\text { It is this interest and volition we offer that lead student to display greater flexibility in } \\
\text { problem-solving, more efficient knowledge acquisition, and a strong sense of personal } \\
\text { worth and social responsibility (Deci et al., 1991: 326). }\end{array}$} \\
\hline Source & \multicolumn{4}{|c|}{$\begin{array}{l}\text { Deci, et al. (1991:pp.325-326) Motivation and Education: The Self Determination } \\
\text { Perspective }\end{array}$} \\
\hline Number of items & \multicolumn{4}{|c|}{ 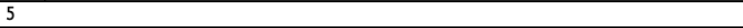 } \\
\hline Scale & \multicolumn{4}{|c|}{$1=$ Not at all true, $3=$ Somewhat true, $5=$ Very true } \\
\hline \multicolumn{5}{|l|}{ Reversed items } \\
\hline \multicolumn{5}{|l|}{ Transformed items } \\
\hline \multicolumn{5}{|l|}{ Excluded items } \\
\hline \multirow[t]{2}{*}{ Scale information } & Mean & SD & Cronb & \\
\hline & 2.87 & 0.267 & & \\
\hline \multicolumn{5}{|l|}{ Student questionnaire } \\
\hline Item formulation & Name & Mean & SD & rit \\
\hline Q13a & Motivation_newconcepts & 2.87 & 0.440 & 0.340 \\
\hline Q13b & Motivation_learnasmuch & 2.88 & 0.378 & 0.466 \\
\hline Q13c & Motivation_masterskills & 2.89 & 0.360 & 0.480 \\
\hline Q13d & Motivation_understandclasswork & 2.88 & 0.383 & 0.425 \\
\hline Q13e & Motivation_improveskills & 2.83 & 0.511 & 0.308 \\
\hline
\end{tabular}

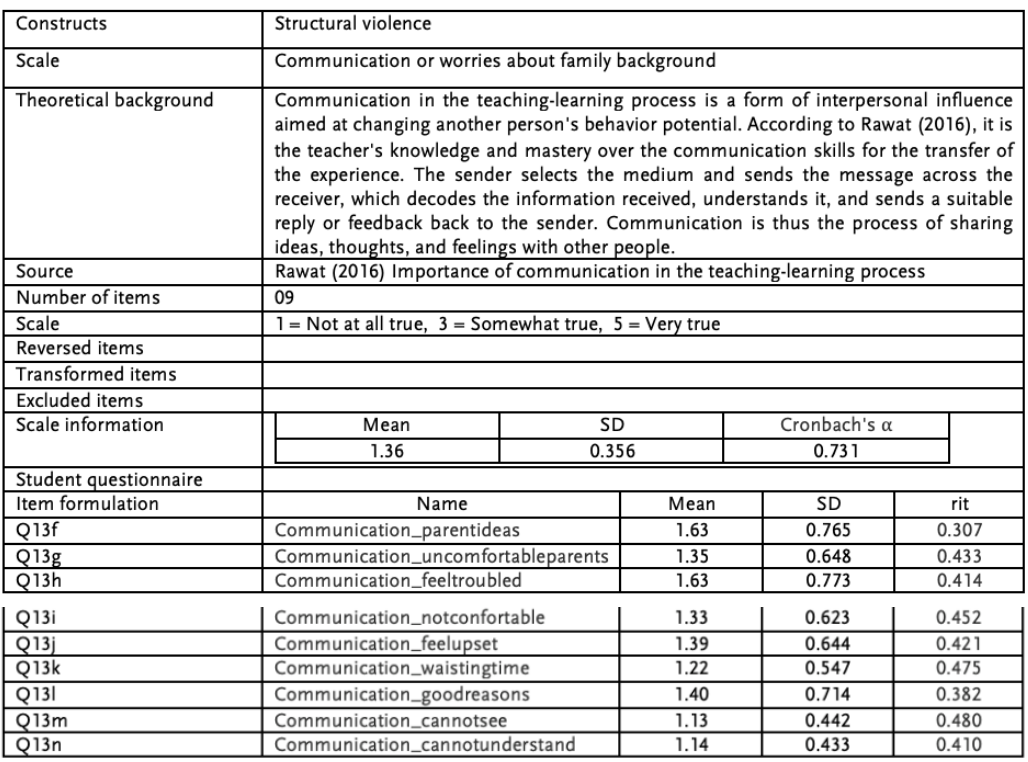




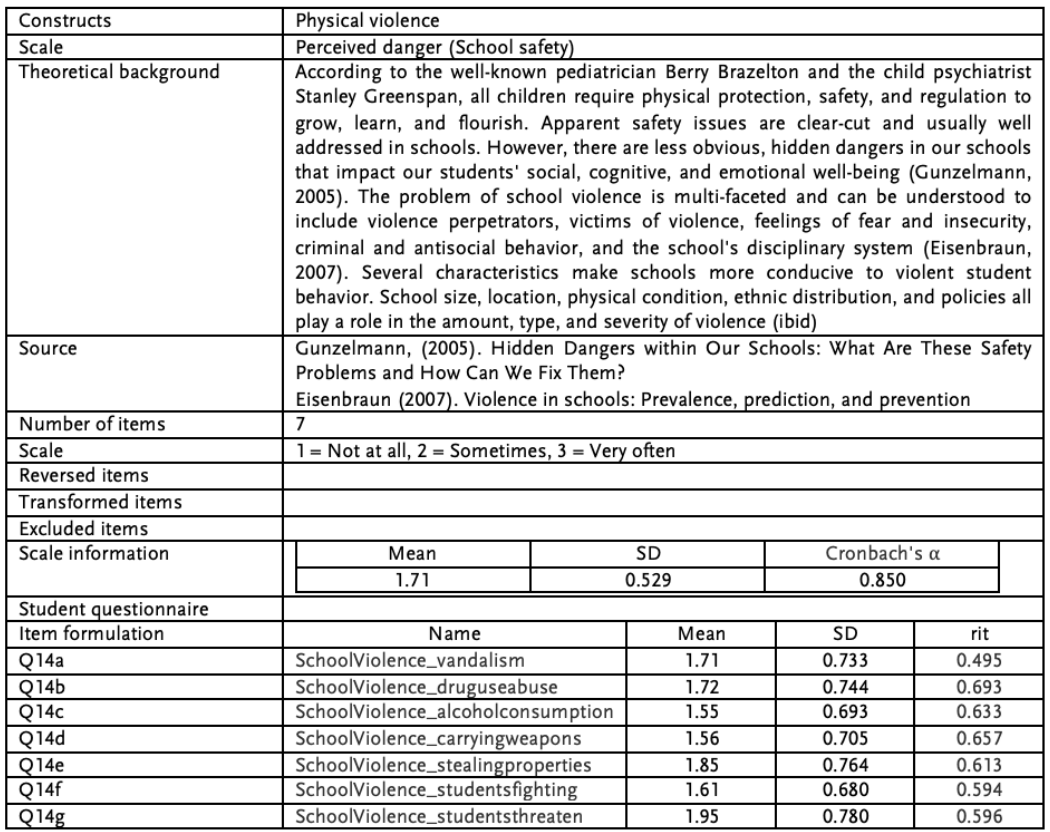




\begin{tabular}{|c|c|c|c|c|}
\hline Constructs & \multicolumn{4}{|l|}{ Structural violence } \\
\hline Scale & \multicolumn{4}{|l|}{ Physical health } \\
\hline Theoretical background & \multicolumn{4}{|c|}{$\begin{array}{l}\text { Former American President J.F. Kennedy said this about physical health "intelligence } \\
\text { and skill can only function at the peak of their capacity when the body is healthy and } \\
\text { strong." This has been corroborated by the Colorado education initiative (2015:3), } \\
\text { which states inter-alia that "educationally relevant health disparities, such as vision, } \\
\text { asthma, teen pregnancy, aggression and violence, physical activity, breakfast, and } \\
\text { inattention/hyperactivity, impede motivation and ability to learn through at least five } \\
\text { causal pathways: sensory perceptions, cognition, connectedness and engagement } \\
\text { with school, absenteeism, and dropping out." Simply put, physical health also appears } \\
\text { to promote other aspects that are important in terms of learning, such as classroom } \\
\text { behavior, concentration on assignments, and participation in classwork - and, } \\
\text { subsequently, learning itself. Physically active pupils also have higher goals for further } \\
\text { studies after comprehensive school. Moreover, physically fit pupils are absent from } \\
\text { school less frequently than their less-fit peers (Vitikka, Salminen \& Annevirta, 2012:6). }\end{array}$} \\
\hline Source & \multicolumn{4}{|c|}{$\begin{array}{l}\text { Colorado Education Initiative (2014). Colorado's Student Perception Survey. } \\
\text { Retrieved from http://www.coloradoedinitiative.org/our-work/educator- } \\
\text { effectiveness/studentsurvey/sps-administration/ } \\
\text { Vitikka, Salminen \& Annevirta (2012) Physical activity and learning }\end{array}$} \\
\hline Number of items & \multicolumn{4}{|c|}{8} \\
\hline Scale & \multicolumn{4}{|c|}{$\begin{array}{l}1=\text { Limited for more than three months, } 2=\text { Limited for three months or less, } \\
3=\text { Not limited at all }\end{array}$} \\
\hline \multicolumn{5}{|l|}{ Reversed items } \\
\hline \multicolumn{5}{|l|}{ Transformed items } \\
\hline \multicolumn{5}{|l|}{ Excluded items } \\
\hline \multirow[t]{2}{*}{ Scale information } & Mean & SD & \multicolumn{2}{|c|}{ Cronbach's $\alpha$} \\
\hline & 2.60 & 0.473 & \multicolumn{2}{|c|}{0.832} \\
\hline \multicolumn{5}{|l|}{ Student questionnaire } \\
\hline Item formulation & Name & Mean & SD & rit \\
\hline Q15a & Physicalhealth_heavyobjects & 2.50 & 0.771 & 0.635 \\
\hline Q15b & Physicalhealth_carryingtable & 2.54 & 0.748 & 0.659 \\
\hline Q15c & Physicalhealth_walkinguphill & 2.58 & 0.706 & 0.646 \\
\hline Q15d & Physicalhealth_bendingdown & 2.53 & 0.748 & 0.687 \\
\hline Q15e & Physicalhealth_walkingblock & 2.59 & 0.710 & 0.638 \\
\hline Q15f & Physicalhealth_eatingdressing & 2.71 & 0.652 & 0.539 \\
\hline Q15g & Physicalhealth_preventwork & 2.71 & 0.603 & 0.303 \\
\hline Q15h & Physicalhealth_unabletodowork & 2.66 & 0.627 & 0.335 \\
\hline
\end{tabular}




\begin{tabular}{|c|c|c|c|c|}
\hline Constructs & \multicolumn{4}{|l|}{ Structural violence } \\
\hline Scale & \multicolumn{4}{|l|}{ Social/learning climate } \\
\hline Theoretical background & \multicolumn{4}{|c|}{$\begin{array}{l}\text { Multicultural education represents a set of principles, values, and practices that are } \\
\text { directly linked to social justice where social justice refers not only to a critical interrogation } \\
\text { of power, privilege, and discrimination but also to acts that intentionally disrupt or } \\
\text { respond to systemic oppression ( Baker, 2018: } 49 \text { ). It is based on a central belief that all } \\
\text { students...should have an equal opportunity to learn. Thus, multicultural education seeks } \\
\text { to ensure such opportunities for all students, from micro-level classroom practices to } \\
\text { macro-level national and international education policy (Baker, 2018). Learning is } \\
\text { studying in the school and having confidence in the school's climate, institutions, and } \\
\text { social network. This is simply to determine students' feelings of school attachment }\end{array}$} \\
\hline Source & \multicolumn{4}{|c|}{$\begin{array}{l}\text { Baker (2018) A Multicultural Education Praxis: Integrating Past and Present, Living } \\
\text { Theories, and Practice }\end{array}$} \\
\hline Number of items & \multicolumn{4}{|l|}{12} \\
\hline Scale & \multicolumn{4}{|c|}{$1=$ Strongly disagree, $2=$ disagree, $3=$ Agree, $4=$ Strongly agree } \\
\hline \multicolumn{5}{|l|}{ Reversed items } \\
\hline \multicolumn{5}{|l|}{ Transformed items } \\
\hline \multicolumn{5}{|l|}{ Excluded items } \\
\hline \multirow[t]{2}{*}{ Scale information } & Mean & S.D & \multicolumn{2}{|c|}{ Cronbach's $\alpha$} \\
\hline & 3.09 & 0.528 & \multicolumn{2}{|c|}{0.841} \\
\hline \multicolumn{5}{|l|}{ Student questionnaire } \\
\hline Item formulation & Name & Mean & SD & rit \\
\hline Q16a & Social_learning_specialperson & 3.15 & 0.854 & 0.481 \\
\hline Q16b & Social_learning_sharejoys & 3.22 & 0.872 & 0.503 \\
\hline Q16c & Social_learning_familyhelp & 3.46 & 0.786 & 0.508 \\
\hline Q16d & Social_learning_emotionalhelp & 3.33 & 0.842 & 0.521 \\
\hline Q16e & Social_learning_sourceofcomfort & 3.20 & 0.870 & 0.526 \\
\hline Q16f & Social_learning_friendshelpme & 2.88 & 0.870 & 0.540 \\
\hline Q16g & Social_learning_thingsgowrong & 2.78 & 0.890 & 0.518 \\
\hline Q16h & Social_learning_havefriends & 3.02 & 0.845 & 0.566 \\
\hline Q16i & Social_learning_carefeelings & 3.11 & 0.931 & 0.463 \\
\hline Q16j & Social_learning_talkproblems & 3.08 & 0.922 & 0.488 \\
\hline Q16k & Social_learning_familywilling & 3.14 & 0.872 & 0.529 \\
\hline Q161 & Social_learning_problemfriends & 2.75 & 0.934 & 0.426 \\
\hline
\end{tabular}




\begin{tabular}{|c|c|c|c|c|}
\hline Constructs & \multicolumn{4}{|l|}{ Sexual violence } \\
\hline Scale & \multicolumn{4}{|l|}{ Sexual violence } \\
\hline Theoretical background & \multicolumn{4}{|c|}{$\begin{array}{l}\text { USAID (2016) views sexual violence as direct physical contact, such as unwanted } \\
\text { touching or any kind of rape, known as "defilement" for young people under the } \\
\text { legal age of consent. According to Meyer, (2006:555), sexual harassment is defined } \\
\text { as any behavior, verbal, physical, or psychological, that polices the boundaries of } \\
\text { traditional heterosexual gender norms and includes (hetero) sexual harassment, } \\
\text { homophobic harassment, and harassment for gender non-conformity. Common } \\
\text { examples of such behaviors include name-calling, jokes, gestures, physical and } \\
\text { sexual assaults that are sexist, homophobic, or transphobic. The literature on sexual } \\
\text { abuse and harassment and sexual violence is all rooted in the power differential } \\
\text { between the perpetrator and the victim and is heavily affected by gender. The } \\
\text { majority of sexual violence described in the literature focuses primarily on girls as } \\
\text { the target (USAID, 2016: 11). Therefore, sexual violence comprises physical or } \\
\text { psychological abuse or harassment of a child by an adult or another child through } \\
\text { any form of verbal acts of violence or forced or unwanted sexual activity where there } \\
\text { is no consent, consent is not possible, or power or intimidation is used to coerce a } \\
\text { sexual act (USAID, 2016: 12) }\end{array}$} \\
\hline Source & \multicolumn{4}{|c|}{$\begin{array}{l}\text { Meyer, E. J (2008) Gendered harassment in secondary schools: understanding } \\
\text { teachers' (non) interventions } \\
\text { USAID (2016) Literature review on school-related gender-based violence: How it is } \\
\text { defined and studied. }\end{array}$} \\
\hline Number of items & \multicolumn{4}{|l|}{7} \\
\hline Scale & \multicolumn{4}{|c|}{$\begin{array}{l}1=\text { Never, } 2=\text { Not in the past year but this has happened, } 3=\text { Sometimes, } 4=\text { Many } \\
\text { times }\end{array}$} \\
\hline \multicolumn{5}{|l|}{ Reversed items } \\
\hline \multicolumn{5}{|l|}{ Transformed items } \\
\hline \multicolumn{5}{|l|}{ Excluded items } \\
\hline \multirow[t]{2}{*}{ Scale information } & $\mathrm{M}$ & SD & \multicolumn{2}{|c|}{ Cronbach's $\alpha$} \\
\hline & 1.43 & 0.536 & & \\
\hline \multicolumn{5}{|l|}{ Student questionnaire } \\
\hline Item formulation & Name & Mean & SD & rit \\
\hline Q17a & Social_emotional_anyonekissing & 1.47 & 0.860 & 0.574 \\
\hline Q17b & Social_emotional_touchingprivate & 1.40 & 0.833 & 0.576 \\
\hline Q17c & Social_emotional_upsetyou & 1.46 & 0.860 & 0.512 \\
\hline Q17d & Social_emotional_lookprivate & 1.33 & 0.755 & 0.550 \\
\hline Q17e & Social_emotional_triedsex & 1.50 & 0.895 & 0.595 \\
\hline Q17f & Social_emotional_touchingway & 1.73 & 0.985 & 0.359 \\
\hline Q17g & Social_emotional_teachersex & 1.12 & 0.481 & 0.346 \\
\hline
\end{tabular}

Note: The original scale items have not been provided their Mean, SD and RIF and that explains the absence of such items from the original scales. 
This study was initiated to examine violence and its relation to learning outcomes of secondary school students in Cameroon. The study interconnected with educational quality values, and responsible behavior. Violence at school is still observable on a daily basis, not respecting the human rights of children and young learners and hindering them from learning despite the attempts of the government in Cameroon to institute quality service delivery policies, more equitable distribution of learning opportunities, and a strong incentive for greater efficiency in school through legislations. The study was guided by the social interaction theory and the research question focused on the extent of violence in education. The specific objective of this study was to understand the effects of violence on motivation and self-esteem, and its influence on learning outcomes. A model was operationalized measuring the different forms of violence, mediated by self-esteem, motivation and health to the learning outcome, quantified by class repetition, grades and reading enjoyment. The socio-economic context was statistically controlled. The study was designed using a quantitative approach with cross-sectional survey for students. Data had been collected from a sample population of 924 students in grades four to seven in Cameroon. The collected information was analyzed using descriptive statistics, and inferential statistics. The results indicate an acute prevalence of school the various forms violence, and the huge ratio of violence in the life of students in Cameroon becomes visible. The study shows that these experiences of violence affect the self-esteem and the motivation to learn. In addition, the poor school quality and a very discouraging socioeconomic background of students can be shown. Schools are neither an environment of the protection of students nor open spaces for real-world transmission of values. Violence remains a challenge.

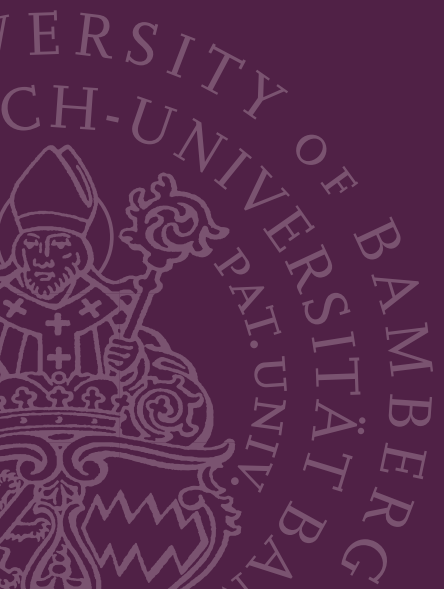

